\title{
CASTOR-1C Spent Fuel Storage Cask Decay Heat, Heat Transfer, and Shielding Analyses
}

December 1986

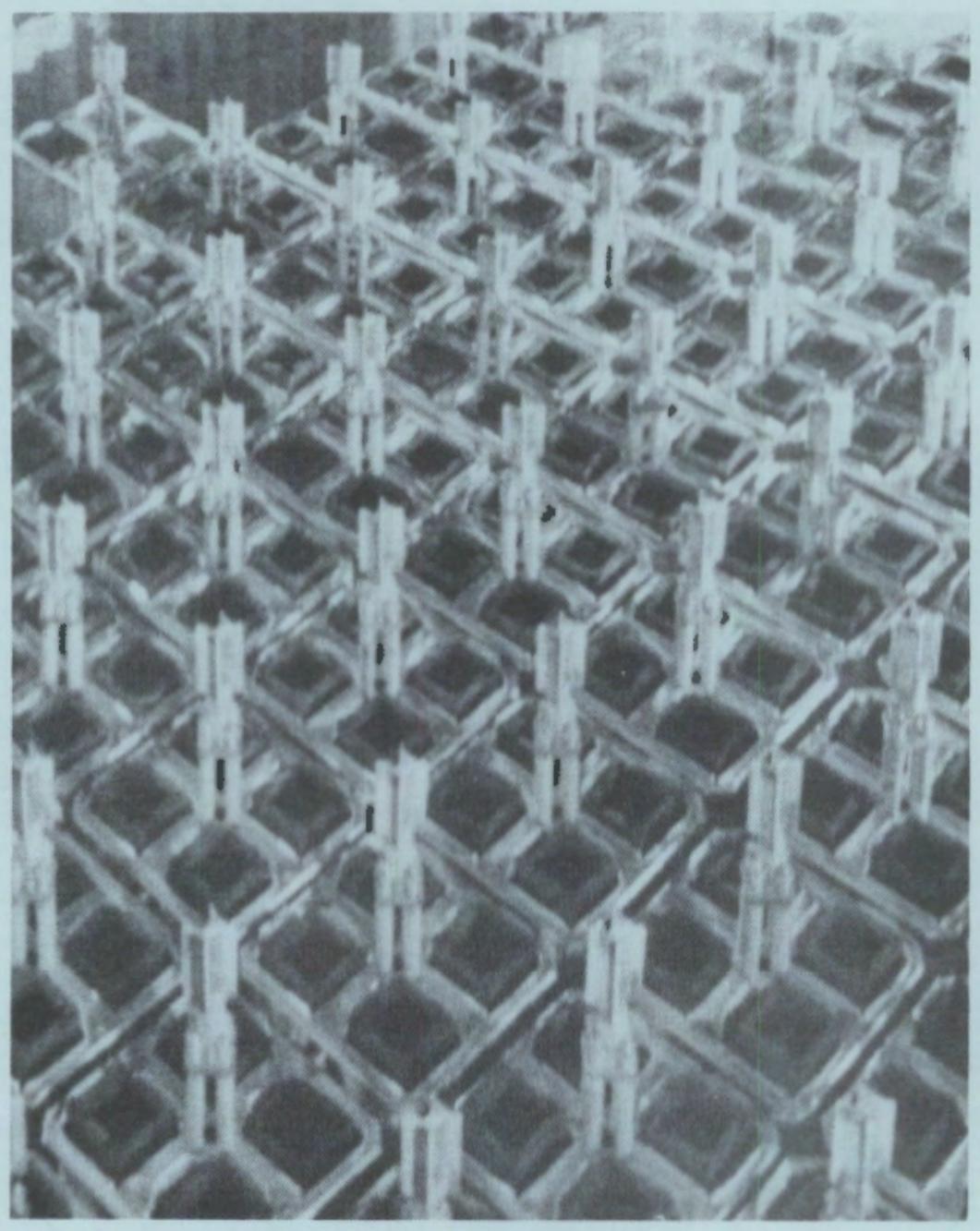

Prepared for the U.S. Department of Energy under Contract DE-AC06-76RLO 1830

Pacific Northwest Laboratory Operated for the U.S. Department of Energy by Battelle Memorial Institute 


\title{
DISCLAIMER
}

This report was prepared as an account of work sponsored by an agency of the United States Government. Neither the United States Government nor any agency thereof, nor Battelle Memorial institute, nor any of their employees, makes any warranty, expressed or implied, or assumes any legal liability or responsibility for the accuracy, completeness, or usefulness of any information, apparatus, product, or process disclosed, or represents that its use would not infringe privately owned rights. Reference herein to any specific commercial product, process, or service by trade name, trademark, manufacturer, or othenwise, does not necessarily constitute or imply its endorsement, recommendation, or favoring by the United States Government of any agency thereof, or Battelle Memorial Institute. The views and opinions of authors expressed herein do not necessarly state or reflect those of the United States Government or any agency thereof, or Battelle Memorial Institute.

\author{
PACIFIC NORTHWEST LABORATORY \\ operated by \\ BATTELLE \\ for the \\ UNITED STATES DEPARTMENT OF ENERGY \\ under Contract DE-ACO6-76RLO 1830
}

\begin{tabular}{|c|c|}
\hline \multicolumn{2}{|c|}{$\begin{array}{l}\text { Printed in the United States of America } \\
\text { Available from } \\
\text { National Technical Information Service } \\
\text { United States Depariment of Commerce } \\
5285 \text { Port Royal Road } \\
\text { Springfield, Virginia } 22161\end{array}$} \\
\hline \multicolumn{2}{|c|}{$\begin{array}{l}\text { NTIS Price Codes } \\
\text { Microfiche A01 }\end{array}$} \\
\hline \multicolumn{2}{|c|}{ Printed Copy } \\
\hline Pages & $\begin{array}{l}\text { Price } \\
\text { Codes }\end{array}$ \\
\hline $001-025$ & $\mathrm{~A} 02$ \\
\hline $026-050$ & $\mathrm{~A} 03$ \\
\hline $051-075$ & $\mathrm{~A} 04$ \\
\hline $076-100$ & A05 \\
\hline $101-125$ & A06 \\
\hline $126-150$ & $\mathrm{~A} 07$ \\
\hline $151-175$ & $\mathrm{~A} 08$ \\
\hline $176-200$ & A09 \\
\hline $201-225$ & A010 \\
\hline $226-250$ & A011 \\
\hline $251-275$ & A012 \\
\hline $276-300$ & A013 \\
\hline
\end{tabular}


CASTOR-1C SPENT FUEL STORAGE CASK DECAY HEAT, HEAT TRANSFER, AND SHIELDING ANALYSES

D. R. Rector

R. A. Mccann

U. P. Jenquin

C. M. Heeb

J. M. Creer

C. L. Wheeler

December 1986

Prepared for the U.S. Department of Energy under Contract DE-AC06-76RLO 1830 

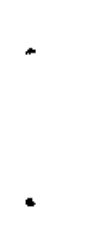
Appreciation is extended to the U.S. Department of Energy for sponsoring this work. D. R. Oden, D. F. Newman, and G. H. Beeman of the Commercial Spent Fuel Management Program Office managed by the Pacific Northwest Laboratory are acknowledged for their support and guidance during the study.

Special thanks are extended to J. Fleisch and K. Einfeld of the German Association for the Reprocessing of Nuclear Fuels (DWK) for test data and coordination of information transfer; K. Ramke of Preussen Elektra for spent fuel information; H. Baatz, D. Ritscher, H. Geiser, and D. Meitling of Gesellschaft fur Nuklear Services (GNS) for cask design details; and V. Barnhart of General Nuclear Services, Inc., for coordinating the information transfer from GNS. 


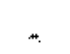

. 


\section{EXECUTIVE SUMMARY}

This report documents the decay heat, heat transfer, and shielding analyses of the Gesellschaft fur Nuklear Services (GNS) CASTOR-1C cask used in a spent fuel storage demonstration performed at Preussen Elektra's Wurgassen nuclear power plant. The demonstration was performed between March 1982 and January 1984, and resulted in cask and fuel temperature data and cask exterior surface gamma-ray and neutron radiation dose rate measurements.

The purpose of the analyses reported herein was to evaluate decay heat, heat transfer, and shielding computer codes. The analyses consisted of 1) performing pre-look predictions (predictions performed before the analysts were provided the test data), 2) comparing ORIGEN2 (decay heat), COBRA-SFS and HYDRA (heat transfer), and QAD and DOT (shielding) results to data, and 3) performing post-test analyses if appropriate. Even though two heat transfer codes were used to predict CASTOR-1C cask test data, no attempt was made to compare the two codes. The codes are being evaluated with other test data (single-assembly data and other cask data), and to compare the codes based on one set of data may be premature and lead to erroneous conclusions.

The CASTOR-1C cask is shown in Figures 5.1 and S.2. It consists of a nodular cast-iron body that provides gamma-ray and neutron shielding. Additional neutron shielding is provided in the wall of the cask with two concentric rows of axial holes containing polyethylene rods (moderator material). The maximum surface design dose rate (gamma-ray and neutron) is $200 \mathrm{mrem} / \mathrm{hr}$ or less, and the average is $20 \mathrm{mrem} / \mathrm{hr}$. Longitudinal fins on the cask surface enhance heat transfer from the cask wall.

The cask inner cavity contains a borated stainless steel basket designed to contain 16 boiling water reactor (BWR) spent fuel assemblies. The borated material reduces the possibility of criticality when loading fuel under water in a spent fuel storage pool. During normal operation, the cask inner cavity is filled with an inert gas at a pressure of 0.8 bar (22.76 psia).

The CASTOR-1C cask is sealed with a multiple-lid system consisting of a primary lid, a secondary lid, and a protection plate. The stainless steel primary and secondary lids contain elastomer and metallic 0-ring seals, which 


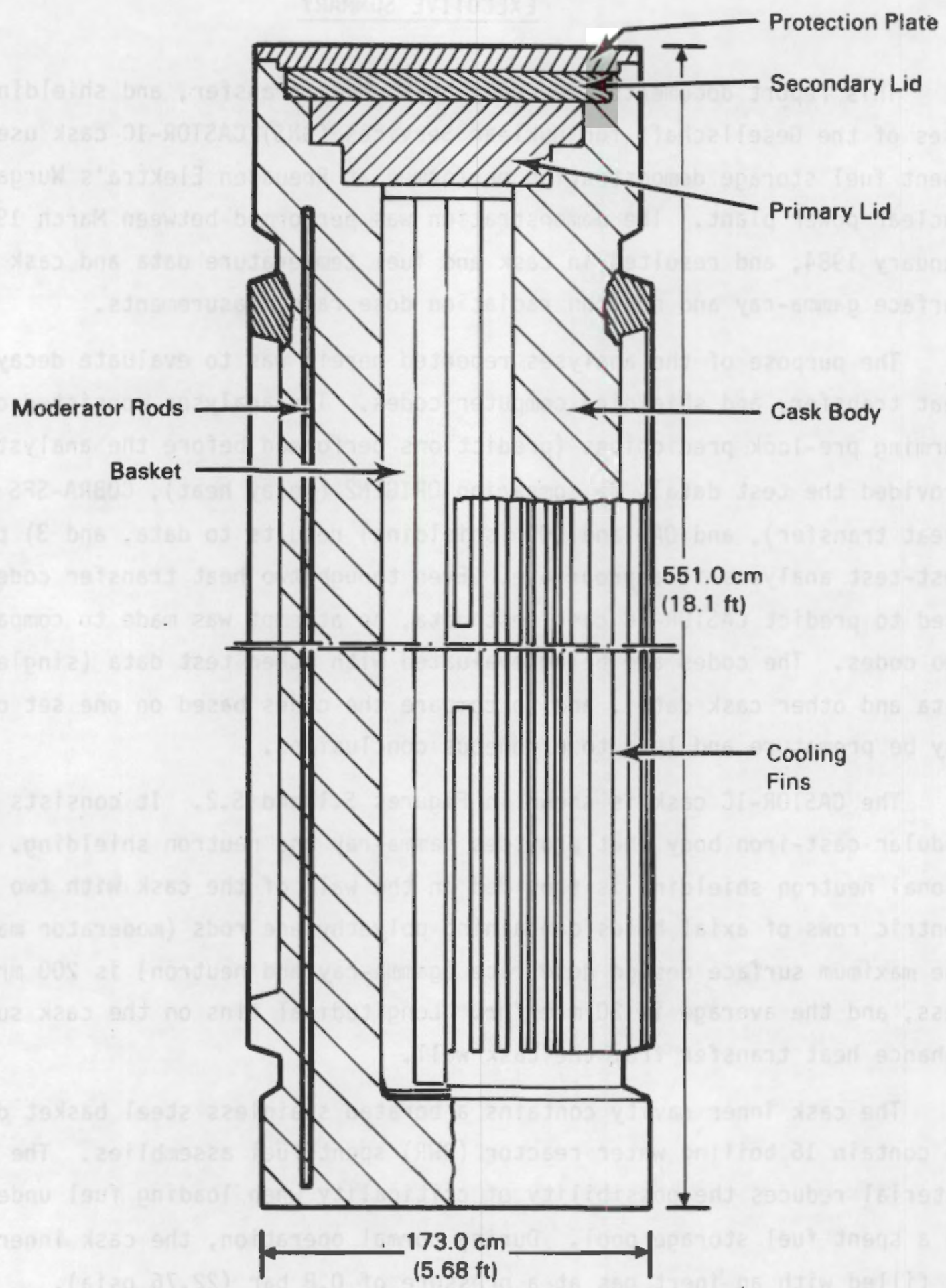

FIGURE S.1. Elevation View of the CASTOR-1C Cask 


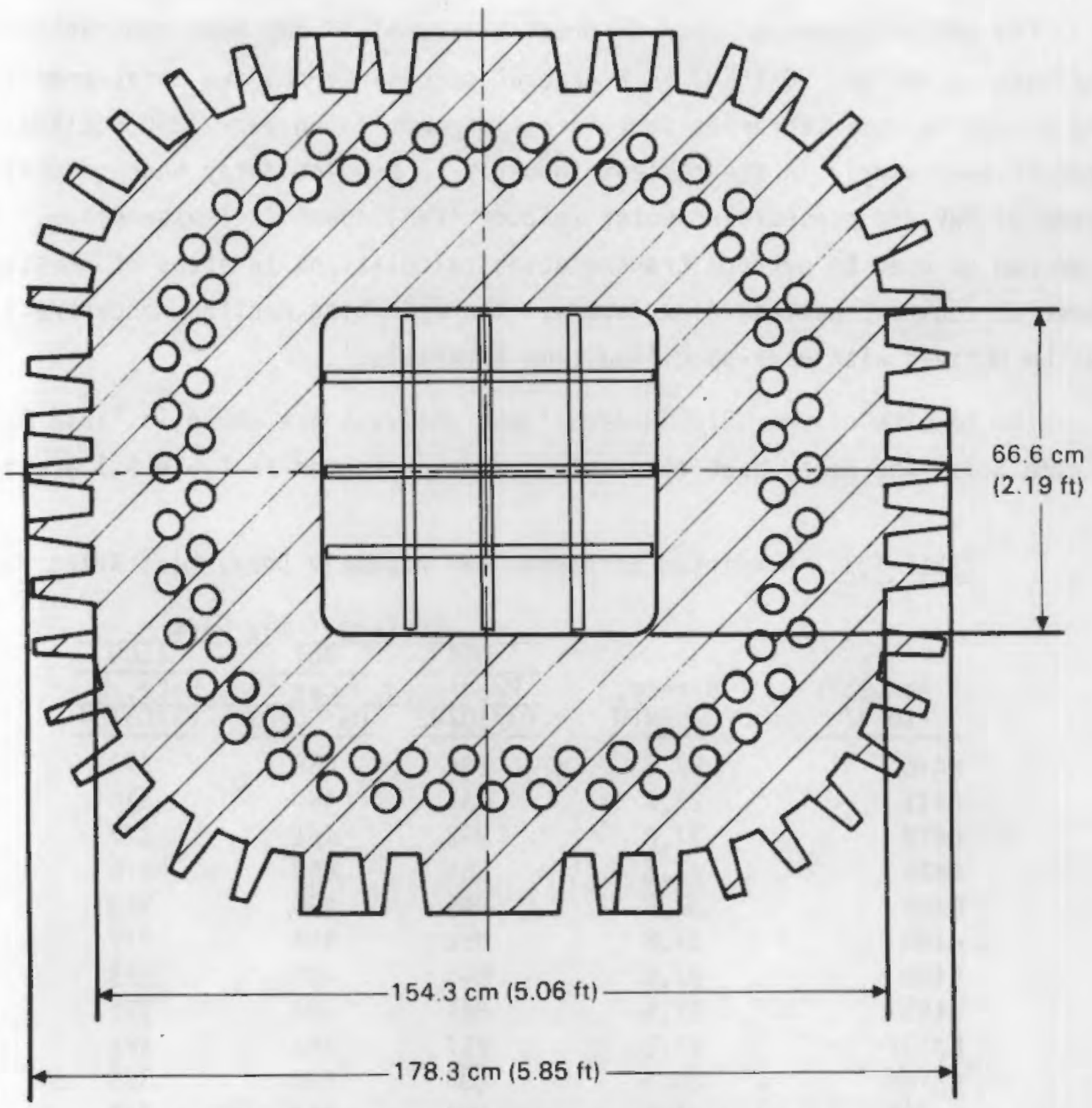

FIGURE S.2. Cross Section of the CASTOR-1C Cask

guarantee a high level of leak tightness. The protection plate is made of carbon steel and serves as mechanical protection as well as a dust and humidity seal.

The CASTOR-1C cask was loaded with 16 Wurgassen BWR spent fuel assemblies. Both $7 \times 7$ rod and $8 \times 8$ rod assemblies were loaded in each half of the cask basket. The assemblies are essentially identical to General Electric $7 \times 7$ and $8 \times 8$ rod BWR assemblies. 
The ORIGEN2 code was used to predict assembly decay heat generation rates and axial profiles. ORIGEN2 is a general purpose burnup and decay code featuring extensive data libraries containing information on over 1200 nuclides. The code is used widely in the nuclear industry to predict decay heat generation rates of BWR and pressurized water reactor (PWR) spent fuel assemblies. The code can be used to perform transmutation calculations in steps of constant power or constant neutron flux levels. The resulting nuclide concentrations can be decayed with user-specified time intervals.

The results of the ORIGEN2 decay heat analysis are shown in Table S.1 and Figure S.3. The decay heat generation rates presented in Table S.1 are for

TABLE S.1. Predicted Wurgassen BWR Assembly Decay Heat Rates

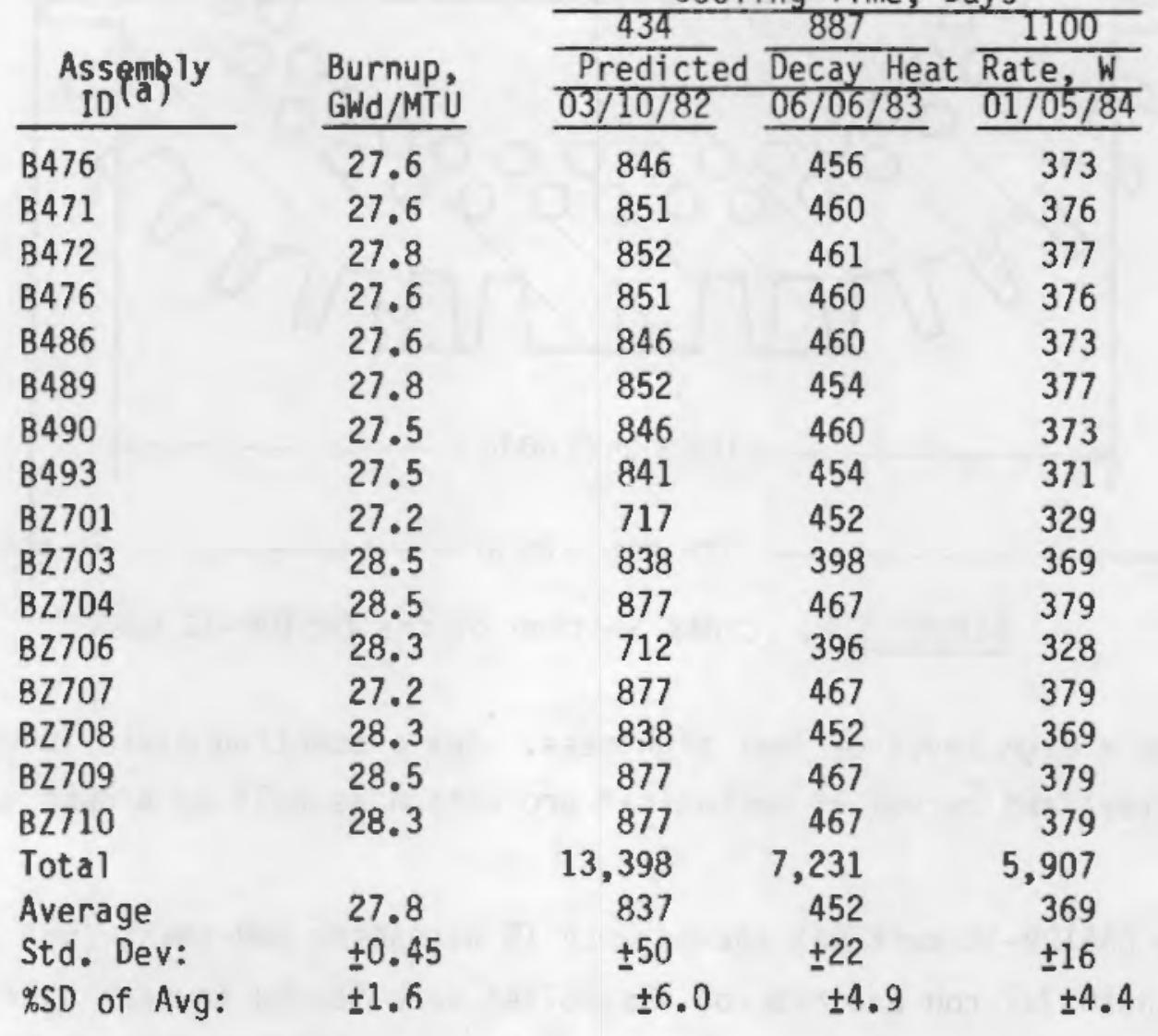

(a) Identification numbers starting with $B$ denote $7 \times 7$ rod assemblies; numbers starting with $B Z$ denote $8 \times 8$ rod assemblies. 


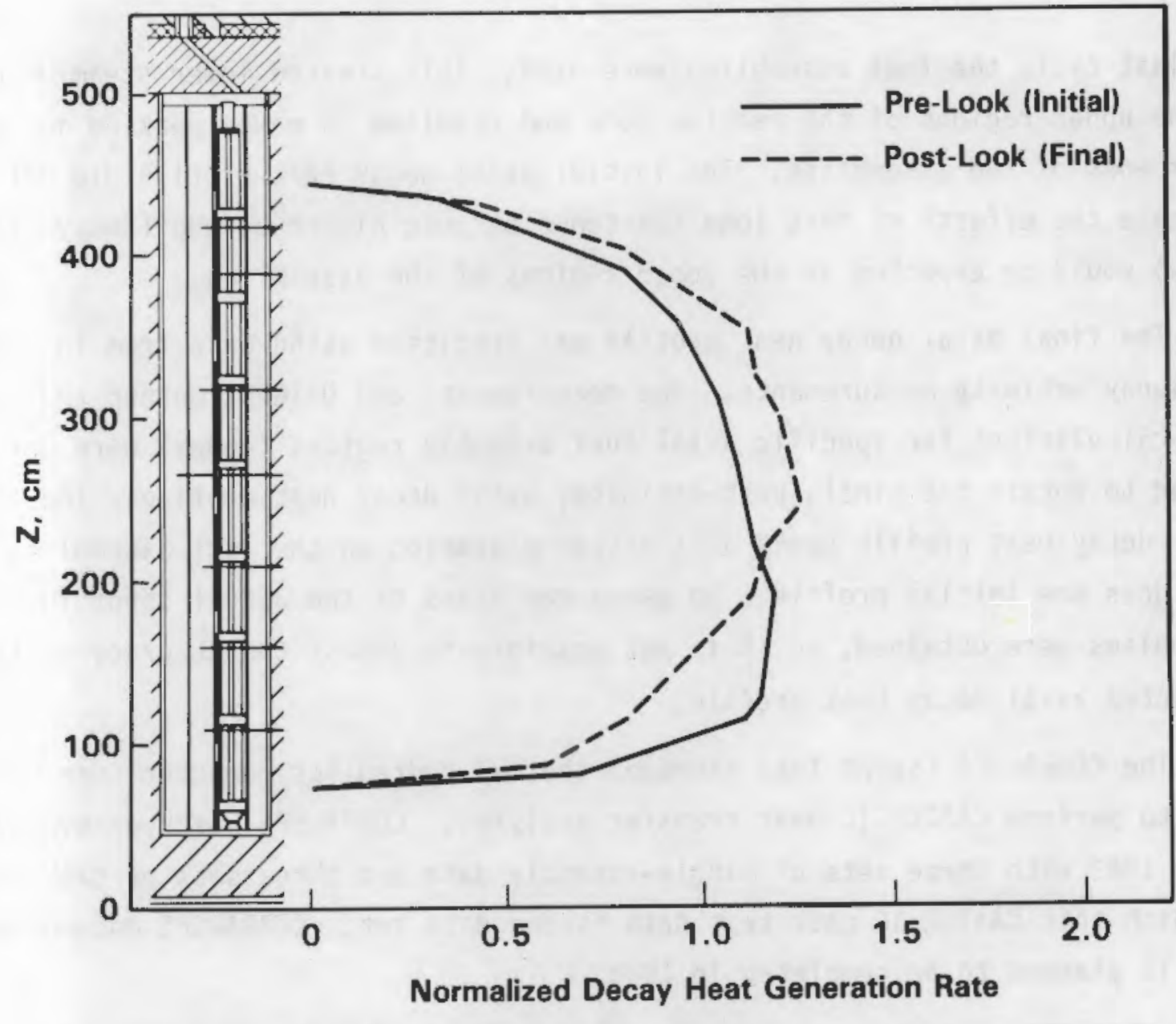

FIGURE S.3. Initial and Final Axial Decay Heat Profiles

three different times during the demonstration. As indicated, the average predicted fuel assembly decay heat rate at the beginning of the demonstration was $837 \mathrm{~W}$ for a total of $13.4 \mathrm{~kW}$. At the end of the demonstration, the assembly decay heat rates had decayed of to an average of $369 \mathrm{~W}$ for a total of $5.9 \mathrm{~kW}$. No calorimetry of the spent fuel assemblies was performed, so it is not possible to assess the accuracy of the ORIGEN2 decay heat predictions.

The three-dimensional COBRA-SFS and HYDRA heat transfer analyses are sensitive to axial decay heat profiles. The initial (pre-look heat transfer predictions) and final (post-test heat transfer predictions) axial decay heat profiles used for the Wurgassen spent fuel assemblies are shown in Figure S.3. The profile initially used peaks in the lower half of the assemblies, which was questionable. The Wurgassen reactor went through a 100-day coastdown during 
the last cycle the fuel assemblies were used. This created lower steam voids in the upper regions of the reactor core and resulted in power peaking in the upper ends of the assemblies. The initial axial decay heat profile did not indicate the effects of this long coastdown because higher burnup (decay heat rates) would be expected in the upper regions of the assemblies.

The final axial decay heat profile was predicted using data from in-reactor gamma-ray activity measurements. The measurements and ORIGEN2 burnup and decay heat calculations for specific axial fuel assembly regions (nodes) were performed to obtain the final, best-estimate, axial decay heat profile. The final axial decay heat profile peaks at a higher elevation on the fuel assemblies than does the initial profile. No gamma-ray scans of the actual spent fuel assemblies were obtained, so it is not possible to assess the accuracy of the predicted axial decay heat profile.

The COBRA-SFS (spent fuel storage) thermal hydraulics computer code was used to perform CASTOR-1C heat transfer analyses. COBRA-SFS has been evaluated since 1982 with three sets of single-assembly data and three sets of cask data, of which this CASTOR-1C cask test data is one data set. COBRA-SFS documentation is planned to be completed in 1986.

COBRA-SFS predicts steady-state three-dimensional velocity, pressure, and temperature distributions within spent fuel storage systems. The code uses an iterative procedure to solve finite-difference equations for mass, momentum, and energy conservation for an interconnected array of channels and structural members. It uses subchannel representations with arbitrary flow and thermal connections; therefore, the user has a great deal of flexibility in modeling complex geometries. Although COBRA-SFS assumes that the fill medium is incompressible, it uses a thermally expandable model to produce buoyancy-driven circulating flows within the system. Heat is transported throughout the system by conduction (fluid-to-fluid and solid-to-solid), natural convection, and planar radiation (rod-to-rod, rod-to-surface, and surface-to-surface).

COBRA-SFS predictions of peak cladding temperatures and total temperature differences between the peak cladding temperature and the ambient are the most obvious indicators of how well COBRA-SFS predicts the thermal performance of 
the CASTOR-1C cask. Table S.2 presents pre-look peak cladding temperature predictions compared to data. COBRA-SFS predictions are in excellent agreement with the data at each total decay heat rate value. However, predicted temperatures at various axial locations do not agree as well as predicted peak cladding temperatures.

COBRA-SFS pre-look and post-test axial temperature profile predictions at the high $(13.4 \mathrm{~kW})$ and low $(5.9 \mathrm{~kW})$ total decay heat generation rates are presented and compared to test data in Figure S.4. Pre-look predictions compared well with test data in the upper half of one of the centermost assemblies, but substantial disagreement $\left(50^{\circ} \mathrm{C}\right)$ exists in the lower half of the assembly. An erroneous initial axial decay heat profile (Figure S.3) is hypothesized to be the cause of the disagreement.

Post-test predictions of the same axial temperature profiles resulted in much better agreement $\left( \pm 10^{\circ} \mathrm{C}\right)$ with test data. The peak cladding temperature for the high decay heat rate is slightly overpredicted $\left( \pm 13^{\circ} \mathrm{C}\right)$, but the axial locations were accurately predicted. The improved accuracy of the predicted axial profile was due to the corrected final axial decay heat profile presented in Figure S.3.

Pre-look and post-test radial temperature profile predictions are presented and compared to data in Figure S.5. The radial profiles are for an axial location of $266 \mathrm{~cm}$. Both the pre-look and post-test predictions agree well with test data. The corrected axial decay heat generation rate profile of Figure S.3 did not significantly affect temperature predictions at this axial location. However, predicted temperatures in the lower half of the assemblies were significantly affected, as indicated in Figure \$.4.

TABLE S.2. COBRA-SFS Pre-Look Peak Cladding Temperature Predictions Compared to Test Data

\begin{tabular}{|c|c|c|c|c|c|c|}
\hline \multirow{2}{*}{$\begin{array}{l}\text { Case } \\
\text { No. }\end{array}$} & \multirow{2}{*}{$\begin{array}{c}\text { Total Decay } \\
\text { Heat, } \mathrm{kW} \\
\end{array}$} & \multicolumn{2}{|c|}{$\begin{array}{l}\text { Peak Cladding } \\
\text { Temperature, }{ }^{\circ} \mathrm{C}\end{array}$} & \multicolumn{3}{|c|}{ Total Temperature Difference } \\
\hline & & Measured & Predicted & Measured, & ${ }^{\circ} \mathrm{C}$ Predicted & ${ }^{\circ} \mathrm{C} \%$ Diff. \\
\hline 1 & 13.4 & 374 & 381 & 348 & 354 & 1.7 \\
\hline 2 & 7.2 & 255 & 252 & 226 & 225 & $(0.4)$ \\
\hline 3 & 5.9 & 221 & 219 & 189 & 192 & 1.6 \\
\hline
\end{tabular}




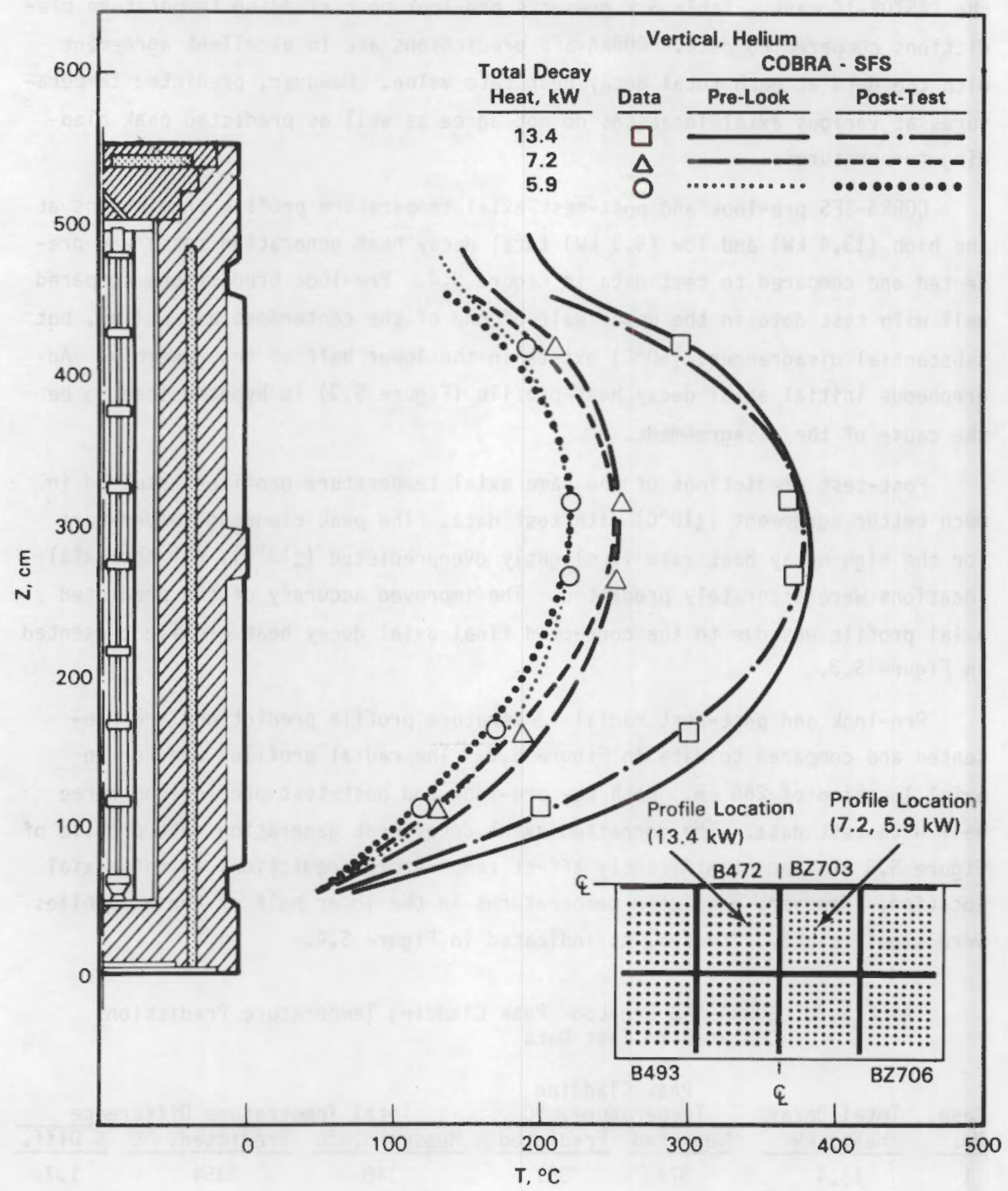

FIGURE S.4. COBRA-SFS Pre-Look and Post-Test Axial Temperature Profile Predictions Compared to Vertical, Helium Test Data 


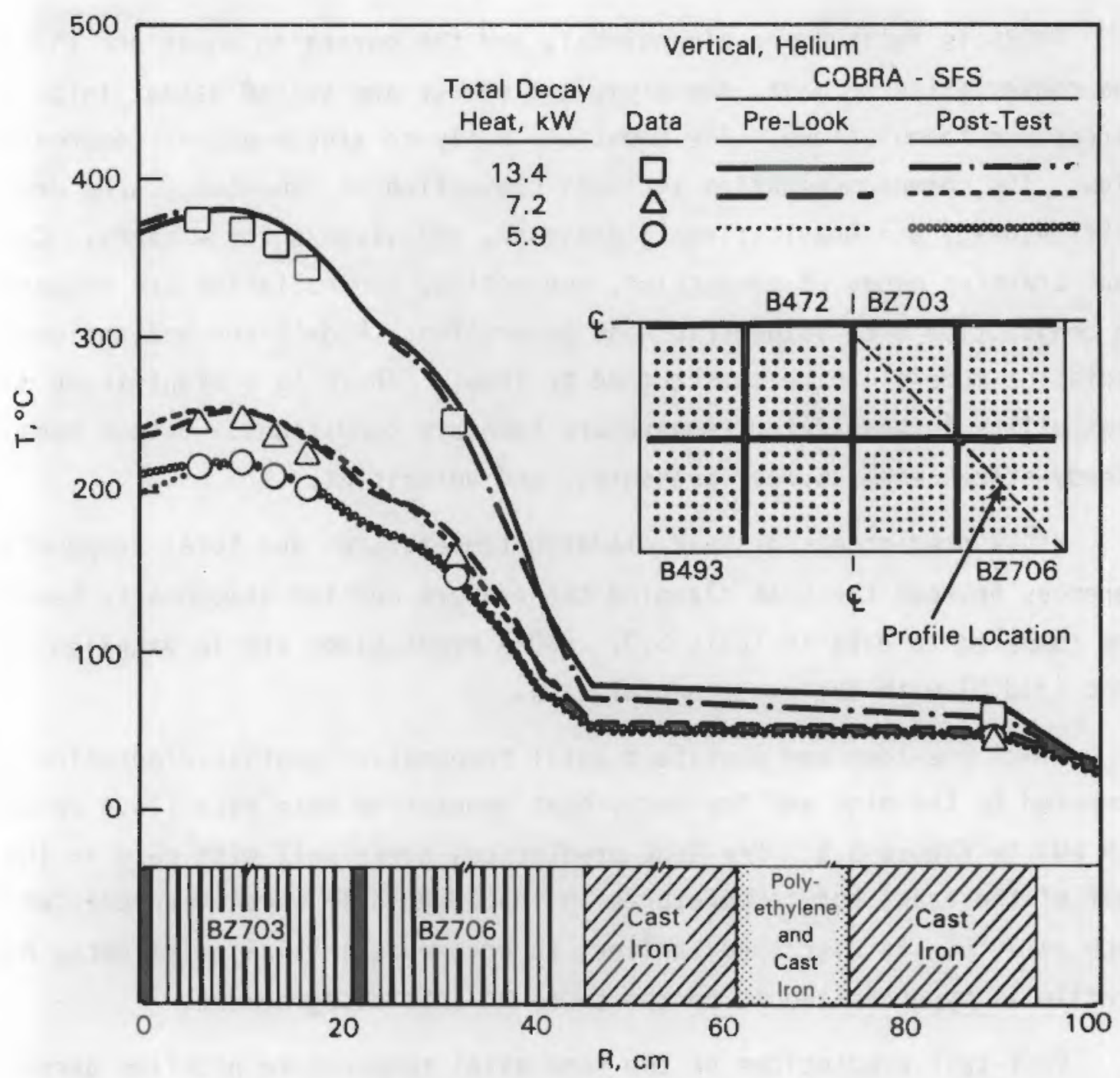

FIGURE S.5. COBRA-SFS Pre-look and Post-Test Radial Temperature Profile Predictions Compared to Vertical, Helium Test Data at $266-\mathrm{cm}$ Axial Location

The HYDRA steady-state thermal hydraulics computer code was also used to perform heat transfer analyses. The HYDRA code has been evaluated since 1982 using two single-assembly sets of experimental data and three sets of cask data, of which this CASTOR-1C cask test data is one data set. HYDRA documentation is planned during 1987. 
HYDRA is fully three-dimensional, and the governing equations that define the conservation of mass, momentum, and energy are solved using finitedifference formulations. The equations apply to single-phase, compressible flow. The momentum equation includes convection of momentum, Darcy drag, and orifice drag, and gravitational, pressure, and viscous force terms. Coupled heat transfer modes of conduction, convection, and radiation are accounted for in conjunction with volumetric heat generation. Rod-to-rod and enclosure radiation models can be constructed by input. There is a significant degree of flexihility in specifying temperature boundary conditions. Output consists of steady-state temperatures, pressures, and velocities.

HYORA predictions of peak cladding temperatures and total temperature differences between the peak cladding temperature and the atmospheric temperature are compared to data in Table S.3. HYDRA predictions are in excellent agreement $\left( \pm 10^{\circ} \mathrm{C}\right)$ with the experimental data.

HYDRA pre-look and post-test axial temperature profile predictions are compared to the high and low decay heat generation rate data $(13.4 \mathrm{~kW}$ and $5.9 \mathrm{~kW}$ ) in Figure S.6. Pre-look predictions agree well with data in the upper half of the cask, but temperatures in the lower half were overpredicted by as much as $70^{\circ} \mathrm{C}$. As discussed earlier, an erroneous initial axial decay heat profile is hypothesized to be the cause of this disagreement.

Post-test predictions of the same axial temperature profiles agree much better $\left( \pm 12^{\circ} \mathrm{C}\right)$ with data at all axial locations. The peak temperature for the high decay heat case is slightly overpredicted $\left(12^{\circ} \mathrm{C}\right)$, but the axial location

TABLE S.3. HYDRA Pre-Look Peak Cladding Temperature Predictions Compared to Test Data

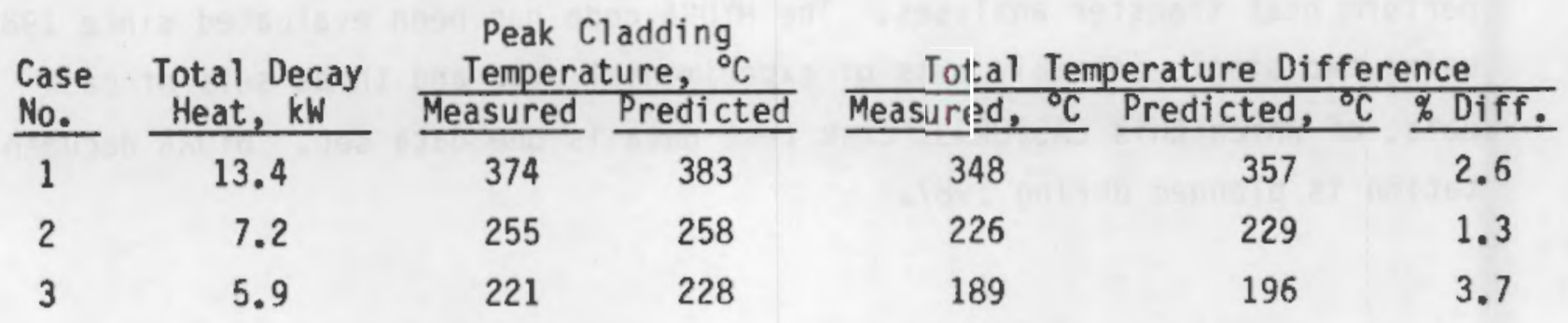




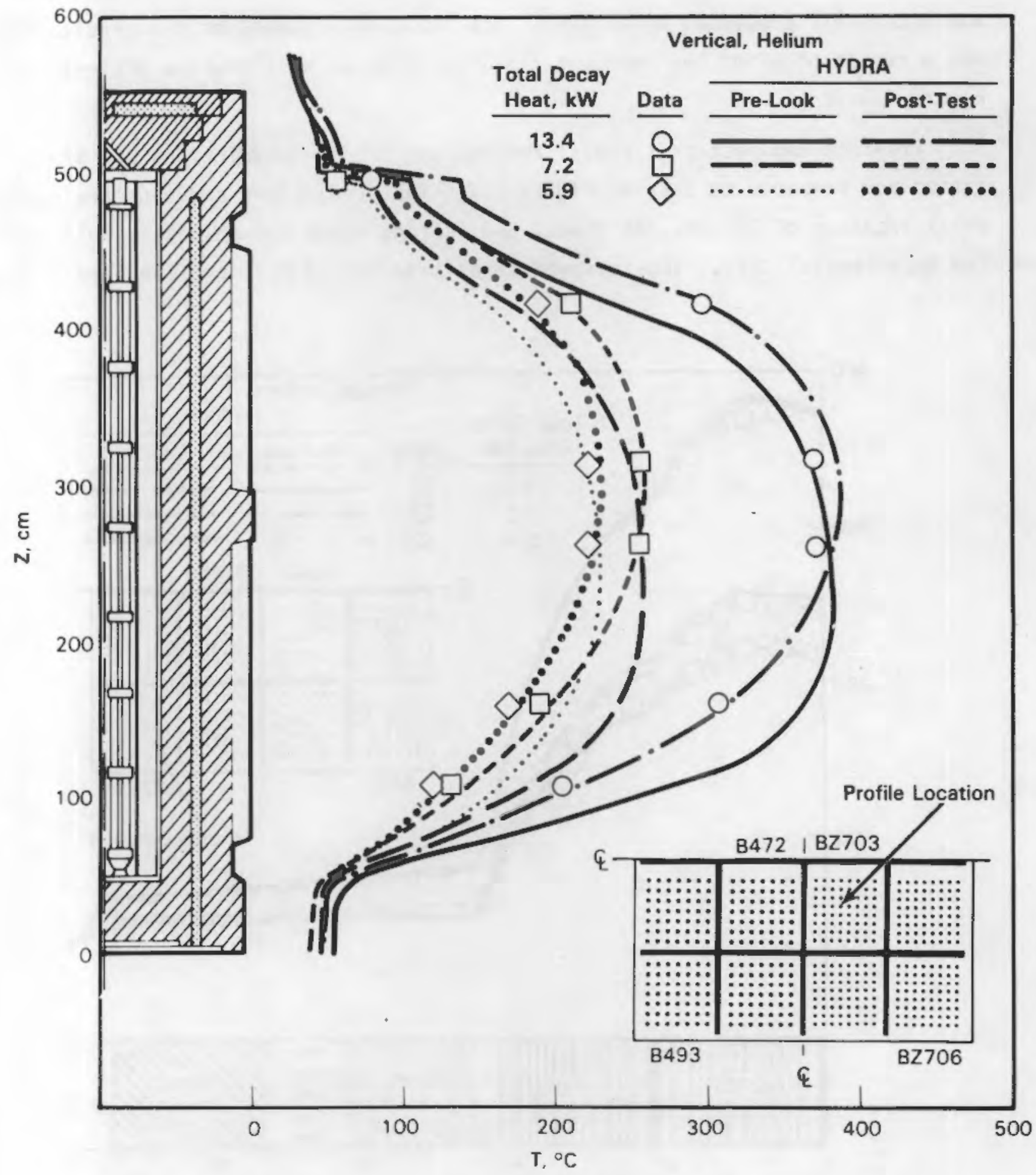

FIGURE S.6. HYDRA Pre-Look and Post-Test Axial Temperature Profile Predictions Compared to Vertical, Helium Test Data 
was accurately predicted with HYDRA. The improved accuracy of the predictions was a result of using the improved final axial decay heat profile presented in Figure S.3.

Pre-look and post-test radial temperature profile predictions are presented and compared to data in Figure S.7. The predictions and data are for an axial location of $266 \mathrm{~cm}$. As shown, predictions agree exceptionally well with the experimental data. The improved final axial decay heat profile used in the

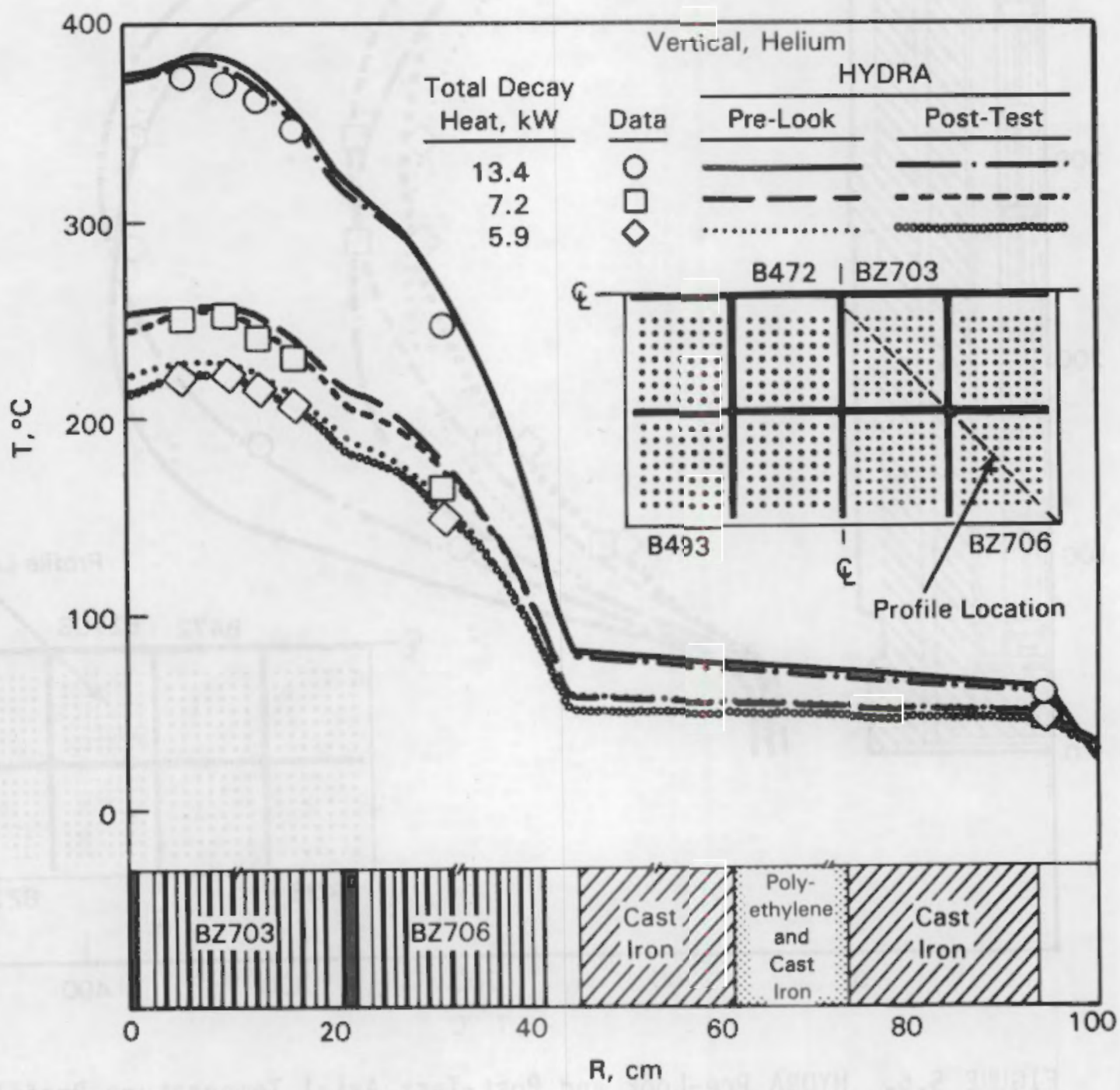

FIGURE S.7. HYDRA Pre-Look and Post-Test Radial Temperature Profile Predictions Compared to Vertical, Helium Test Data at 266-cm Axial Location 
post-test analysis did not significantly affect the temperature predictions at this axial location, but did affect the predictions at other axial locations, as indicated in Figure S.6.

The QAD computer code was used to predict gamma-ray radiation dose rates on the surface of the cask. It calculates fast-neutron and gamma-ray penetrations through shielding systems using the point-kernel method. The pointkernel method involves representing the source volume by a number of point isotropic sources and computing line-of-sight distances from each source point to points of interest on the exterior cask surface. Geometric and material attenuations are determined from distances through the shielding regions and attenuating characteristics of the shielding materials.

Predicted and measured gamma-ray dose rates are presented in Figure S.8. Dose rates were overpredicted by as much as a factor of two over most of the cask surface with the exception of the lower region. Dose rates in the lower region were underpredicted but, because the measured dose rates were extremely low ( $3 \mathrm{mrem} / \mathrm{hr})$, no significance is associated with this disagreement.

The DOT computer code was used to predict neutron dose rates on the cask surface. It calculates neutron and photon particle fluxes in two dimensions using the method of discrete ordinates to solve the Boltzmann transport equation. Balance equations are solved for the flow of particles moving in a set of discrete directions in each cell of a space mesh and in each group of a multi-group energy structure. Mesh spacing and discrete directions are selected by the user, and anisotropic cross sections can be expressed in a Legendre expansion of arbitrary order.

Predicted and measured neutron dose rates are shown in Figure S.9. Dose rates were overpredicted by as much as a factor of four over most of the cask surface. The overpredictions were probably due to high calculated neutron source strengths.

Overall, the predictions of both the gamma-ray and neutron dose rates are considered to be satisfactory. When consideration is given to the fact that the cask must attenuate a radiation source several orders of magnitude (three 


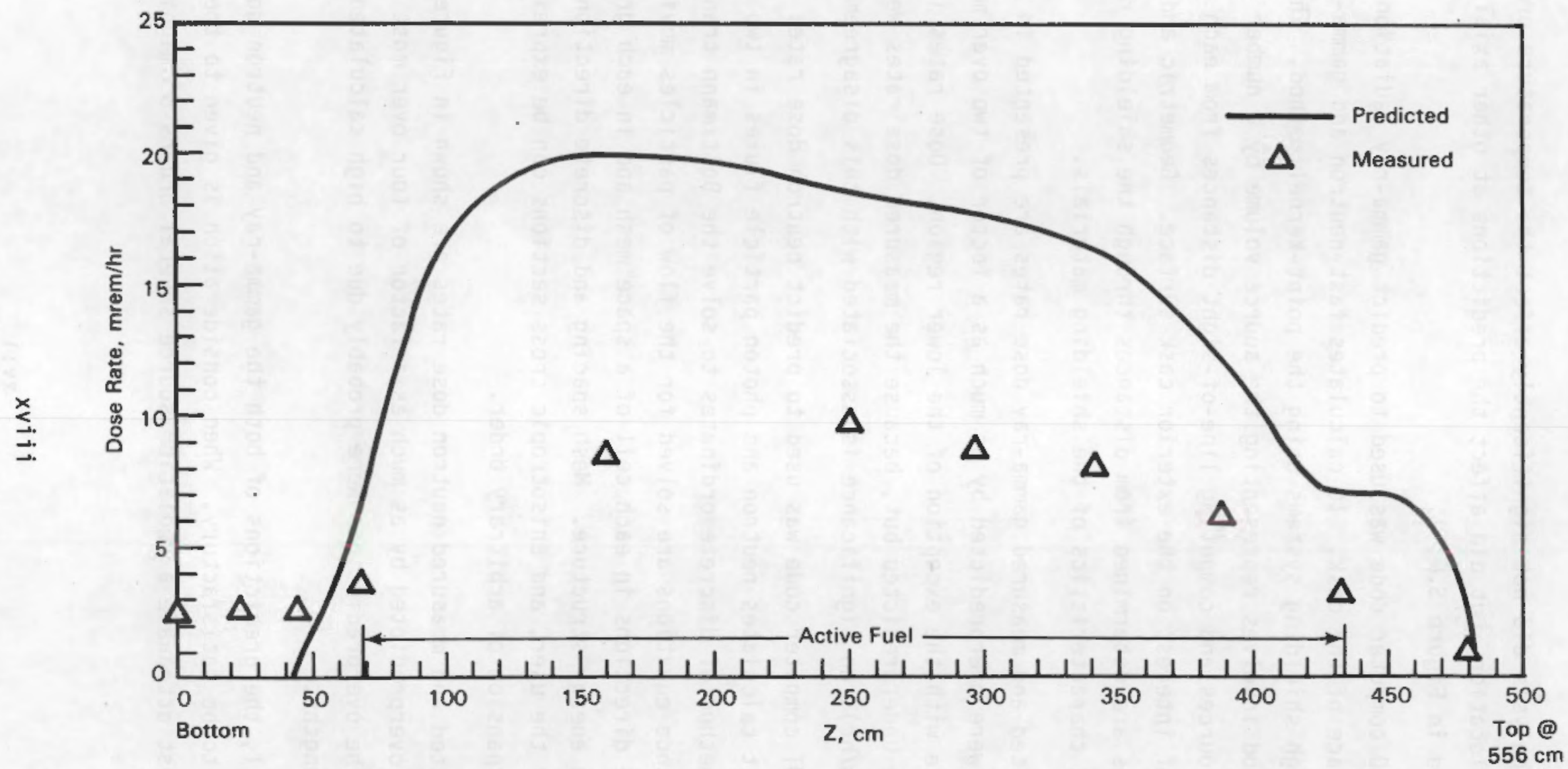

FIGURE S.8. QAD Axial Gamma-Ray Dose Rate Profile Predictions Compared to Test Data on Cask Side 


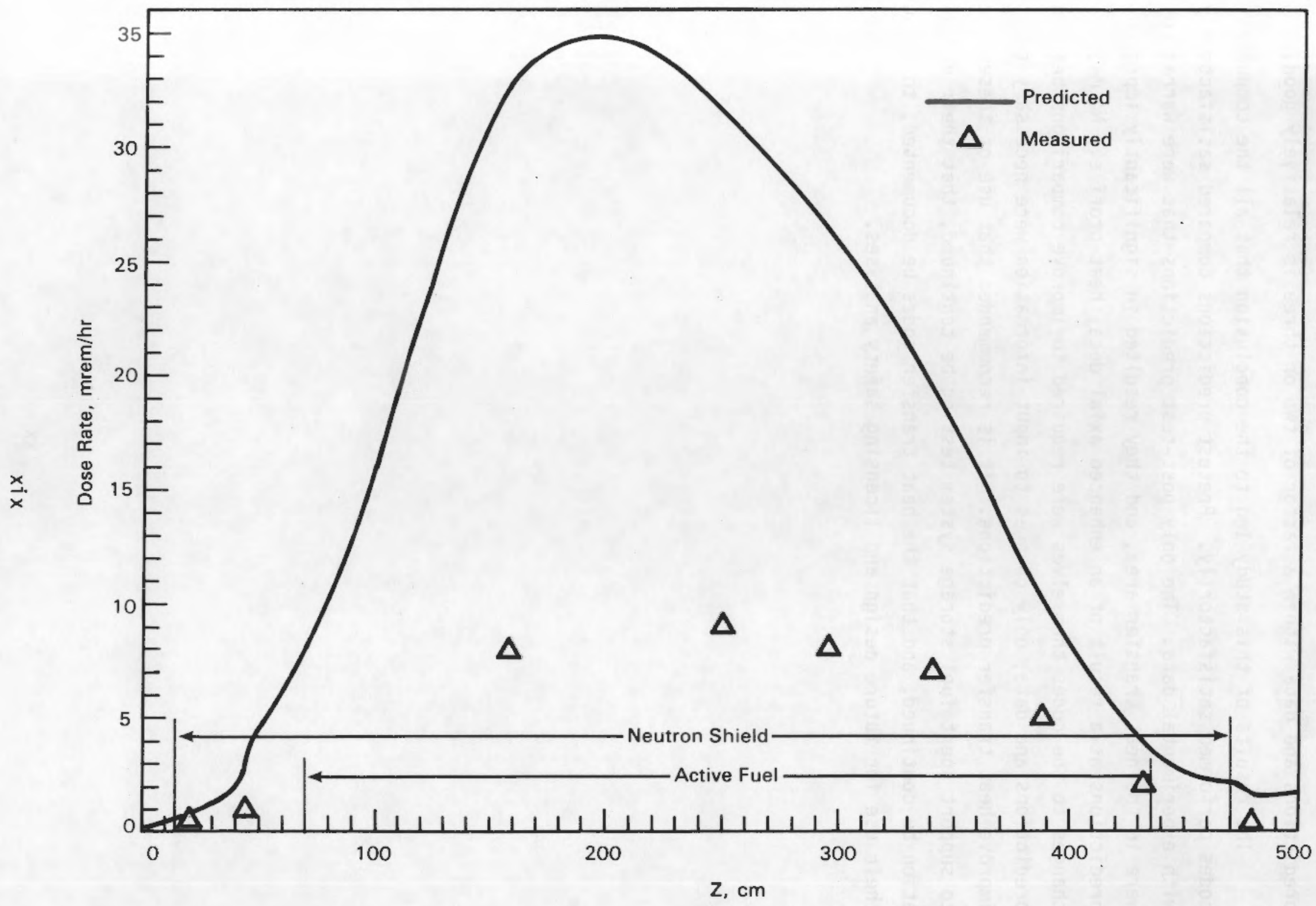

FIGURE S.9. DOT Axial Neutron Dose Rate Predictions Compared to Test Data on Cask Side 
or more) and reduce the level to a relatively low value, agreement between predictions and data within a factor of two or three is relatively good.

The results of this study led to the conclusion that all the computer codes performed satisfactorily. Pretest predictions compared satisfactorily with experimental data. The only post-test predictions that were warranted were in the heat transfer area, and they resulted in significantly improved predictions as a result of an enhanced axial decay heat profile. No major changes to the codes themselves were required to improve comparisons between predictions and data; only changes to input information were necessary to improve heat transfer predictions. It is recommended that use of these codes to support spent fuel storage system testing be continued, that their evaluation be continued, and that the heat transfer codes be documented, to allow their use for future design and licensing safety analyses. 


\section{CONTENTS}

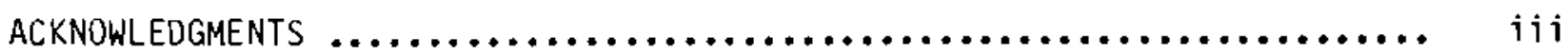

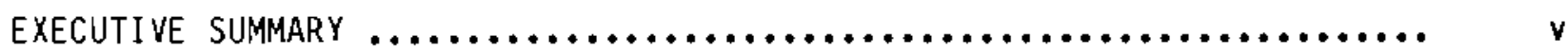

NOMENCLATURE

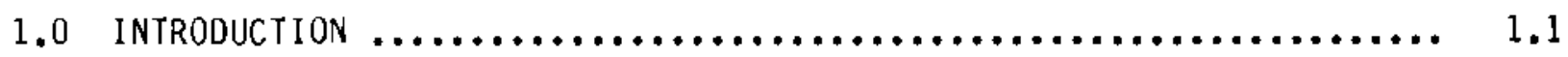

2.0 CONCLUSIONS AND RECOMMENDATIONS $\ldots \ldots \ldots \ldots \ldots \ldots \ldots \ldots \ldots \ldots \ldots . . .1$

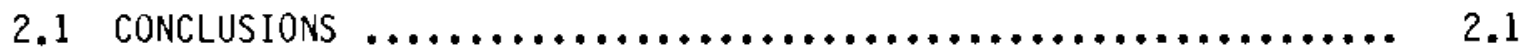

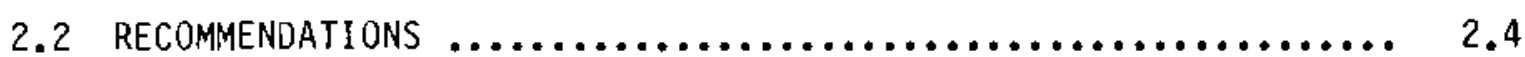

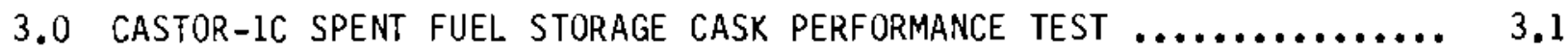

3.1 CASTOR $-1 \mathrm{C}$ CASK $\ldots \ldots \ldots \ldots \ldots \ldots \ldots \ldots \ldots \ldots \ldots \ldots \ldots \ldots \ldots \ldots \ldots \ldots, 3.1$

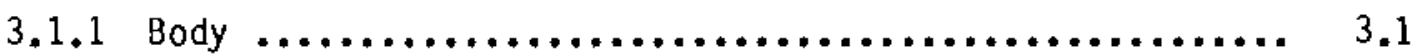

3.1.2 Cavity and Basket $\ldots \ldots \ldots \ldots \ldots \ldots \ldots \ldots \ldots \ldots \ldots, 3.5$

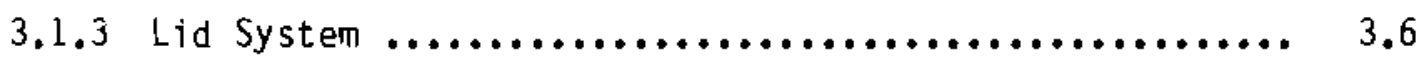

3.? WUKGASSEN BWR SPENT FUEL ASSEMBLIES $\ldots \ldots \ldots \ldots \ldots \ldots \ldots \ldots . \ldots . \ldots$

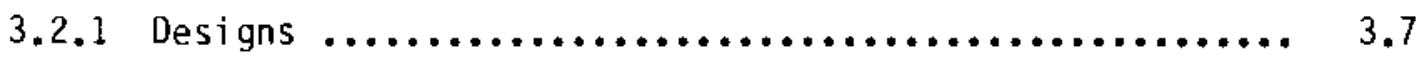

3.2.2 Predicted Decay Heat Generation Rates .............. 3.9

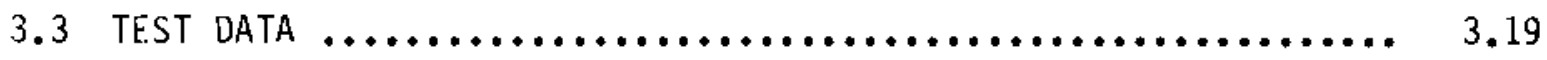

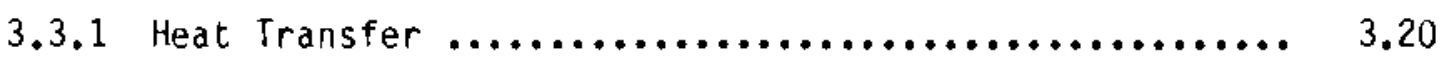

3.3 .2 Shielding $. \ldots \ldots \ldots \ldots \ldots \ldots \ldots \ldots \ldots \ldots \ldots \ldots \ldots, \quad 3.24$

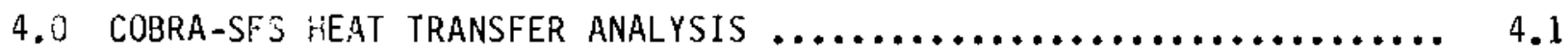

4.1 COBRA-SFS COMPUTER CJUE $\ldots \ldots \ldots \ldots \ldots \ldots \ldots \ldots \ldots \ldots \ldots \ldots, 4.1$

4.1.1 Modeling Capabilities .......................... 4.2

4.1 .2 Conservation Equations $\ldots \ldots \ldots \ldots \ldots \ldots \ldots \ldots \ldots \ldots, 4.2$

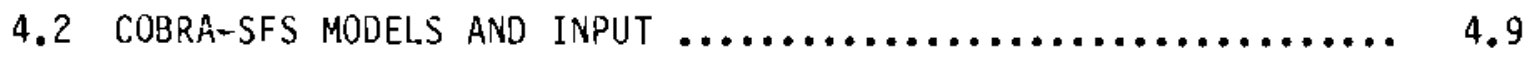

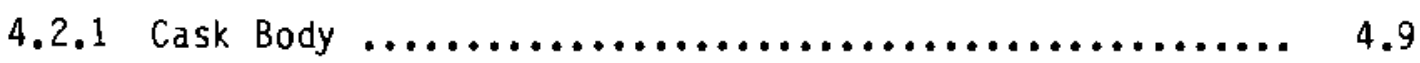


4.2 .2 Cask Basket and Fuel Assemblies ................... 4.9

4.2.3 Boundary Specifications ............................. 4.13

4.2.4 Material Properties .............................. 4.14

4.2 .5 Modeling Uncertainties ......................... 4.15

4.3 COBRA-SFS \$IMULATIONS COMPARED TO OATA ................... 4.16

4.3.1 Pre-Look Simulations ............................. 4.16

4.3 .2 Post-Test simulations ........................... 4.26

4.4 ADDITIONAL COBRA-SFS SIMULATIONS ....................... 4.31

5.0 HYORA HEAT TRANSFER ANALYSIS $\ldots \ldots \ldots \ldots \ldots \ldots \ldots \ldots \ldots \ldots \ldots \ldots, 5.1$

5.1 HYDRA COMPUTER CODE $\ldots \ldots \ldots \ldots \ldots \ldots \ldots \ldots \ldots \ldots \ldots \ldots \ldots, 5.1$

5.2 HYORA MODELS AND INPUT $\ldots \ldots \ldots \ldots \ldots \ldots \ldots \ldots, \ldots \ldots \ldots \ldots \ldots \ldots, 5.4$

5.2 .1 Computational Mesh ................................. 5.4

5.2 .2 Material Properties and Correlations ................ 5.4

5.2 .3 Modeling Uncertainties ............................ 5.8

5.3 HYORA PREDICTIONS COMPARED TO DATA $\ldots \ldots \ldots \ldots \ldots \ldots \ldots \ldots \ldots \ldots . \ldots \ldots$

5.3.1 HYORA Pre-Look Predictions .......................... 5.11

5.3 .2 HYRA Post-Test Predictions ....................... 5.11

5.4 ADDIT TONAL MYDRA SIMULATIONS ...................... 5.17

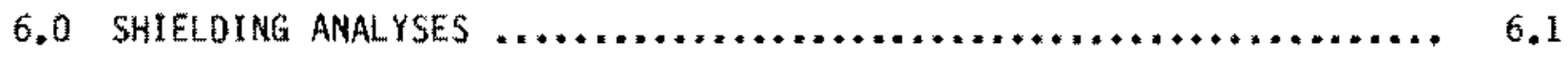

6.1 QAD COMPUTER CODE $\ldots \ldots \ldots \ldots \ldots \ldots \ldots \ldots \ldots \ldots \ldots \ldots \ldots \ldots, 6.1$

6.1 .1 QAD Description ............................... 6.1

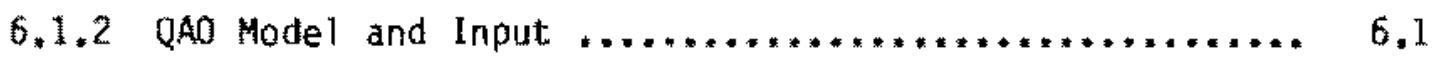

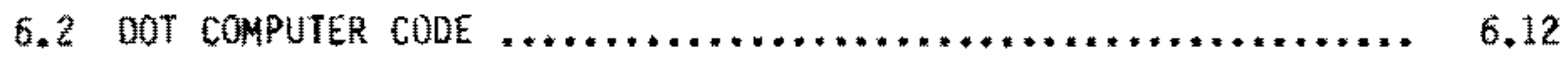

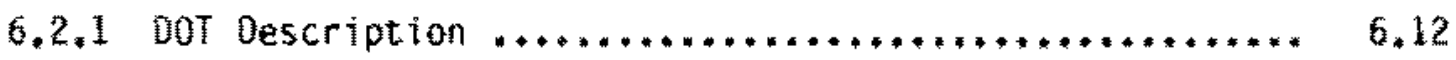

6.2 .2 Dot Models and Input ........................... 6.12 
6.3 SHIELUING PREDICTIONS COMPAREI TO DATA $\ldots \ldots \ldots \ldots \ldots \ldots \ldots \ldots \ldots \ldots, 6 . \ldots$

6.3 .1 Gamma-Ray Dose Rates $\ldots \ldots \ldots * \ldots \ldots \ldots \ldots \ldots \ldots \ldots \ldots \ldots \ldots \ldots * 6.16$

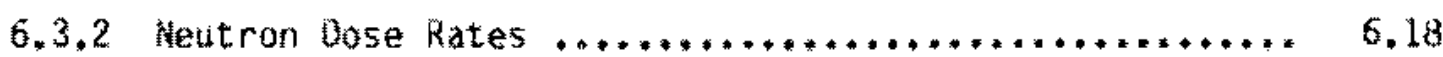

REFERENCES $\ldots \ldots \ldots \ldots \ldots \ldots \ldots \ldots \ldots \ldots \ldots \ldots \ldots \ldots \ldots \ldots \ldots \ldots \ldots \ldots \ldots \ldots \ldots \ldots \ldots \ldots \ldots \ldots \ldots n$ Ref, 1

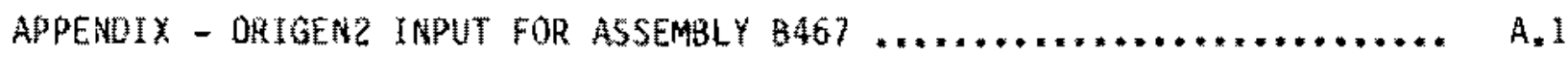


• 


\section{FIGURES}

S.1 Elevation View of the CASTOR-1C Cask ..................... vi

S.2 Cross Section of the CASTOR-1C Cask ...................... vij

S.3 Initial and Final Axial Decay Heat Profiles .................. ix

S.4 COBRA-SFS Pre-Look and Post-Test Axial Temperature Profile Predictions Compared to Vertical, Helium Test Data............ xi

S.5 COBRA-SFS Pre-Look and Post-Test Radial Temperature Profile Predictions Compared to Vertical, Helium Test Data at 266-cm Axial Location ......................................

S.6 HYDRA Pre-Look and Post-Test Axial Temperature Profile Predictions Compared to Vertical, Helium Test Data .............. xv

S.7 HYDRA Pre-Look and Post-Test Radial Temperature Profile Predictions Compared to Vertical, Helium Test Data at

266-cm Axial Location

S.8 QAD Axial Gamma-Ray Dose Rate Profile Predictions

Compared to Test Data on Cask Side

S.9 DOT Axial Neutron Dose Rate Predictions Compared to Test

Data on Cask Side

3.1 Elevation View of the CASTOR-1C Cask

3.2 Cross Section of the CASTOR-1C Cask

3.3 Cooling Fin Geometry $\ldots \ldots \ldots \ldots \ldots \ldots \ldots \ldots \ldots \ldots \ldots \ldots \ldots \ldots \ldots \ldots \ldots \ldots$

3.4 Typical General Electric $8 \times 8$ Fuel Assembly .................. 3.8

3.5 Wurgassen Operating History ............................. 3.14

3.6 Assembly B467 Specific Decay Heat History ................... 3.15

3.7 Initial Decay Heat Profile ........................... 3.17

3.8 Final Axial Decay Heat Profiles ......................... 3.18

3.9 Comparison of Initial and Final Axial Decay Heat Profiles ....... 3.19

3.10 CASTOR-1C Cask and Spent Fuel Thermocouple Locations ........... 3.21

3.11 Measured Peak Cladding Axial Temperature Profiles .............. 3.23 
3.12 Measured Peak Cladding Radial Temperature Profiles ............. 3.24

3.13 Measured Gamma and Neutron Dose Rates on CASTOR - $1 \mathrm{C}$

Cask Side ...........................................

4.1 Subchannel Definition $\ldots \ldots \ldots \ldots \ldots \ldots \ldots \ldots \ldots \ldots \ldots \ldots \ldots \ldots \ldots \ldots \ldots$

4.2 Transverse Momentum Control Volume ....................... 4.6

4.3 COBRA-SFS One-Half Symmetry Model of CASTOR-1C Cask Body ....... 4.10

4.4 COBRA-SFS One-Half Symmetry Model of the CASTOR-1C Cask

Basket and Spent Fuel Assemblies ........................ 4.11

4.5 Comparisons of COBRA-SFS Pre-Look Peak Cladding Axial

Temperature Profile Predictions with Test Data ................ 4.18

4.6 Comparisons of COBRA-SFS Pre-Look Radial Temperature Profile

Predictions With Test Data ............................... 4.20

4.7 Comparisons of COBRA-SFS Post-Test Peak Cladding Axial

Temperature Profile Predictions with Test Data ............... 4.28

4.8 Comparisons of COBRA-SFS Post-Test Radial Temperature

Profile Predictions with Test Data ......................... 4.29

4.9 COBRA-SFS Peak Cladding Axial Temperature Profile Predictions

for Helium, Nitrogen and Vacuum in the Vertical Drientation ...... 4.33

4.10 COBRA-SFS Peak Cladding Axial Temperature Profile Predictions

for Helium and Nitrogen in the Horizontal Orientation and

Vacuum in the Vertical Orientation ..........................

4.11 COBRA-SFS Peak Cladding Axial Temperature Profile Predictions

for $14.0 \mathrm{~kW}$ Total Uniform Decay Heat Compared to $13.4 \mathrm{~kW}$

Total Decay Heat in Helium

4.12 COBRA-SFS Peak Cladding Axial Temperature Profile Predictions

for $12.4 \mathrm{~kW}$ Total Uniform Decay Heat Compared to $13.4 \mathrm{~kW}$

Total Decay Heat in Nitrogen

5.1 Transverse Computational Mesh and Alignment of Mesh with

Physical Cask Features

5.2 Axial Computational Mesh and Alignment with Physical

Cask Features ....................................... 5.6

5.3 HYDRA Pre-Look Axial Temperature Profile Predictions

Compared to Vertical, Helium Test Data 
5.4 HYDRA Pre-Look Radial Temperature Profile Predictions

Compared to Vertical, Helium Test Data at $266-\mathrm{cm}$

Axial Location ..................................... 5.13

5.5 HYDRA Post-Test Axial Temperature Profile Predictions

Compared to Vertical, Helium Test Data ..................... 5.15

5.6 HYDRA Post-Test Radial Temperature Profile Predictions

Compared to Vertical, Helium Test Data at $266-\mathrm{cm}$

Axial Location .........................................

5.7 HYDRA Axial Temperature Profile Predictions for $13.5 \mathrm{~kW}$

Total Uniform Assembly Decay Heat Compared to Vertical,

Helium Predictions and Data for $13.4 \mathrm{~kW}$ Total Decay Heat

5.8 HYDRA Axial Temperature Profile Predictions for $11.7 \mathrm{~kW}$

Total Uniform Assembly Decay Heat in Nitrogen and for

$13.4 \mathrm{~kW}$ Total Decay Heat in Nitrogen and Vacuum in a

Vertical Orientation

5.9 HYDRA Axial Temperature Profile Predictions for a Horizontal

Orientation with Helium and Nitrogen Backfills Compared to

Vertical Helium Predictions and Test Data

6.1 QAD Model of CASTOR-1C Cask

6.2

6.2 CASTOR-1C Cask Cross Section

6.4

6.3 Radial Locations of Polyethylene Moderator Rods ............... 6.5

6.4 Top View of Cask $\ldots \ldots \ldots \ldots \ldots \ldots \ldots \ldots \ldots \ldots \ldots \ldots \ldots \ldots \ldots \ldots \ldots \ldots . \ldots \ldots . \ldots \ldots$

6.5 Bottom View of Cask $\ldots \ldots \ldots \ldots \ldots \ldots \ldots \ldots \ldots \ldots \ldots \ldots \ldots \ldots \ldots \ldots \ldots \ldots . \ldots . \ldots \ldots$

6.6 Cask Basket and Fuel Assemblies $\ldots \ldots \ldots \ldots \ldots \ldots \ldots \ldots \ldots \ldots \ldots \ldots . \ldots . \ldots . \ldots$

6.7 Axial Burnup Shape for Wurgassen Fuel Assemblies .............. 6.10

6.8 DOT Model of CASTOR-1C Cask $\ldots \ldots \ldots \ldots \ldots \ldots \ldots \ldots \ldots \ldots \ldots \ldots \ldots \ldots \ldots \ldots \ldots \ldots$

6.9 Neutron Source Strength as a Function of Exposure ............. 6.15

6.10 Fuel Assembly Relative Axial Neutron Profile ................. 6.17

6.11 Comparisons of Predicted to Measured Gamma-Ray Dose Rates on Cask Side

6.12 Predicted Neutron Dose Rate Profile on Cask Top ............... 6.20 


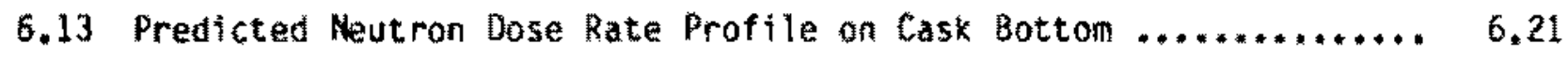

6.14 Comparisons of Predicted and Measured Neutron Dose Rates on Cask Side

6.23 
TABLES

\$.1 Predicted Wurgassen BWR Assembly Decay Heat Rates ............. viji

S.2 CoBen-SFS Pre-Look Peak Cladding Temperature Predictions

Compared to Test Data ......................................

xi

5. 3 HYDRA Pre-Look Peak Cladding Temperatume Predictions Compared

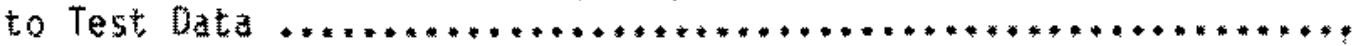

3.1 CASTOR-1C Cask pimensions and bestgn Specifications ........... 3.3

3.2 Characteristics of Typical General Electric BWR Fuel

Assentiles

3.3 Wurgassen Fuel Assembly Design Data

3.4 Wurgassen BWR Assenbly Burnup Histories

3.5 Predicted Hurgassen BuR Assembly Decay Heat Rates .............

3.6 CASTOR-16 Cask Test Temperature Data, ${ }^{\circ} \mathrm{C}$

4.1 COBRA-SFS Capabilities and Limitations ....................

4.2 Boundary Heat Transfer Correlations

4.3 Material Properties and Surface Emissivitites

4.4 COBRA-SFS Premlook Peak Cladding Temperature Predictions

4.5 CoBha-SFS Pre-Look Predictions Compared to Measured Cask

Surface-tomAmbient Temperature Differences

4.6 COBRA-SFS Pre-Look Predictions Compared to Measured Corner

Assembly-to-Cask Outer Surface Temperature Differentes

4.7 COBRA-SFS Pre-Look Predictions Compared to Measured Peak

Rod-to-Gask Duter Surface Temperature bifferences

4.8 COBRA-SFS Post-Test Predictions Compared to Measured Peak

Cladding Temperatures and Total Temperature Dlfferences

4.9 COBRA-5FS Post-Test Predictions Compared to Cask

Surface-to-Ambient Temperature Differences

4.10 COBRA-SFS Post-Test Predictions Compared to Corner

As sembly-to-Surface Temperature Differences 
4.11 COBRA-SFS Post-Test Predictions Compared to

Peak-Rod-to-Surface Temperature Differences

4.12 Additional COBRA-SFS Simulation Descriptions $\ldots \ldots \ldots \ldots \ldots \ldots \ldots \ldots . \ldots 42$

4.13 COBRA-SFS Predictions of Peak Cladding Temperatures ........... 4.32

4.14 COBRA-SFS Predictions of Maximum Allowable Total

Decay Heat Rate ..................................... 4.35

5.1 Material Properties ................................. 5.7

5.2 Convective Heat Transfer Correlations ...................... 5.8

5.3 HYDRA Peak Cladding Temperature Predictions for Uniform Assembly Decay Heat Generation Rates ......................... 5.18

6.1 Material Densities for $Q A D$ Input $\ldots \ldots \ldots \ldots \ldots \ldots \ldots \ldots \ldots \ldots \ldots \ldots \ldots . \ldots . \ldots . \ldots . \ldots \ldots$

6.2 Photon Source Strengths for $Q A D$ Input $\ldots \ldots \ldots \ldots \ldots \ldots \ldots \ldots \ldots \ldots \ldots .6 . \ldots$

6.3 Axial Gamma-Ray Source Shape for QAD Input .................. 6.11

$6.4{ }^{60}$ Co Source Strengths for $Q A D$ Input for Sixteen Assemblies ....... 6.11

6.5 Axial ${ }^{60}$ Co Source Shapes for $Q A D$ Input ...................... 6.12

6.6 DOT Material Atom Densities or Volume Fractions ................ 6.14

6.7 Axial Neutron Source Shape for DOT Input .................. 6.18 
NOMENCLAT URE

ACRONYMS AND INITIALISMS

$\begin{array}{ll}\text { BWR } & \text { boiling water reactor } \\ \text { DOE } & \text { U.S. Department of Energy } \\ \text { DWK } & \text { German Association for the Reprocessing of Nuclear Fuels } \\ \text { EOC } & \text { end-of-cycle } \\ \text { GE } & \text { General Electric } \\ \text { GNS } & \text { Gesellschaft fur Nuklear Services } \\ \text { GNSI } & \text { General Nuclear Services, Inc. } \\ \text { GWd } & \text { gigawatt-day(s) } \\ \text { H/U } & \text { hydrogen-to-uranium (ratio) } \\ \text { MWd } & \text { megawatt-day(s) } \\ \text { MTU } & \text { metric ton(s) of uranium } \\ \text { NWPA } & \text { Nuclear Waste Policy Act of } 1982 \\ \text { ORNL } & \text { Oak Ridge National Laboratory } \\ \text { PNL } & \text { Pacific Northwest Laboratory } \\ \text { R\&D } & \text { research and development } \\ \text { SS } & \text { stainless steel }\end{array}$

SYMBOLS AND NOTATIONS

$\alpha_{m} \begin{aligned} & \text { set of wall numbers with a thermal conduction connection to } \\ & \text { wall node } m\end{aligned}$
$\beta_{n} \begin{aligned} & \text { set of wall numbers with a thermal radiation connection to } \\ & \text { rod } n\end{aligned}$
$Y_{j}$
set of subchannel numbers with a thermal connection to rod $i$
time step


SYMBOLS ANO MUTAIIONS (contd)

$\mathbf{\Delta x}$

E

$\xi_{11}$

6

$\kappa_{n}$

$\lambda$

$\lambda_{1}$

H

$\xi_{\text {III }}$

p

o

$\boldsymbol{o}_{\mathrm{m}}$

1

$\phi$

$\$$

$\psi_{i}$

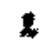

A

B

c

0

o axial step

surface emittance or a member of a set

set of rod numbers wth a thermal radiation connection to rod $n$

prohlem orientation, angle from vertical

set of rod numbers with a thermal radiation connection to wall $n$

thermal conductivity

set of rod numbers with a thermal connection to subchannel $i$

viscosity

set of subchannel numbers with themal connection to wall (1)

density

Stephan-Boltzmann constant

set of wall numbers with a thermal radiation connection to wall $\mathrm{n}$

set of wall numbers for wl1s that connect to subchannel 1

area fraction

rod to subchannel i heat fraction

set of transverse gap connections to suhchannel $\mathfrak{i}$

length of transverse momentum control volume

area

empirical coefficient

drag. axial loss coefficient, empirical coefficlent, or specific heat

Darcy and orifice drag

hydraulic diameter 
5YHBOLS AND MOTATIONS (contd)

\begin{tabular}{|c|c|}
\hline$e_{k}$ & $\begin{array}{l}\text { altiplier ( }+1) \text { that gives the correct stgn to the } \\
\text { transverse connection terms }\end{array}$ \\
\hline$f$ & friction factor \\
\hline$F_{i j}$ & radiatorit exchange factor, surface ito to \\
\hline $\mathrm{g}$ & acceleration due to gravity \\
\hline$g$ & gravitational vector \\
\hline Gr & Grashoff number \\
\hline$h, H$ & $\begin{array}{l}\text { Huid enthalpy, average fllm coefficient, or heat transfer } \\
\text { coeffictent. }\end{array}$ \\
\hline$H_{g}$ & fuel-claditing gap conductance \\
\hline$H_{i j}$ & radiation exchange factor based on geometry and emittances \\
\hline$k, K, \lambda$ & thermal conductivity \\
\hline$L$ & length \\
\hline $\overrightarrow{\mathrm{in}}$ & mass flux \\
\hline Nu & Musselt number \\
\hline$p, p$ & pressure \\
\hline $\operatorname{Pr}$ & Prandt number \\
\hline$\dot{q}$ & heat generation rate \\
\hline arad & thermat radiation transport \\
\hline$q^{3}$ & volumetric heat generation in wall \\
\hline $\mathrm{R}$ & radial thermal resistance or radius \\
\hline$r$ & radius \\
\hline $\mathrm{Ra}$ & Rayleigh number \\
\hline$R_{\mathrm{C}}$ & outer radius of the cladding \\
\hline Re & Reynolds number \\
\hline
\end{tabular}


SYMBOLS ARO MOTATIONS (cont)

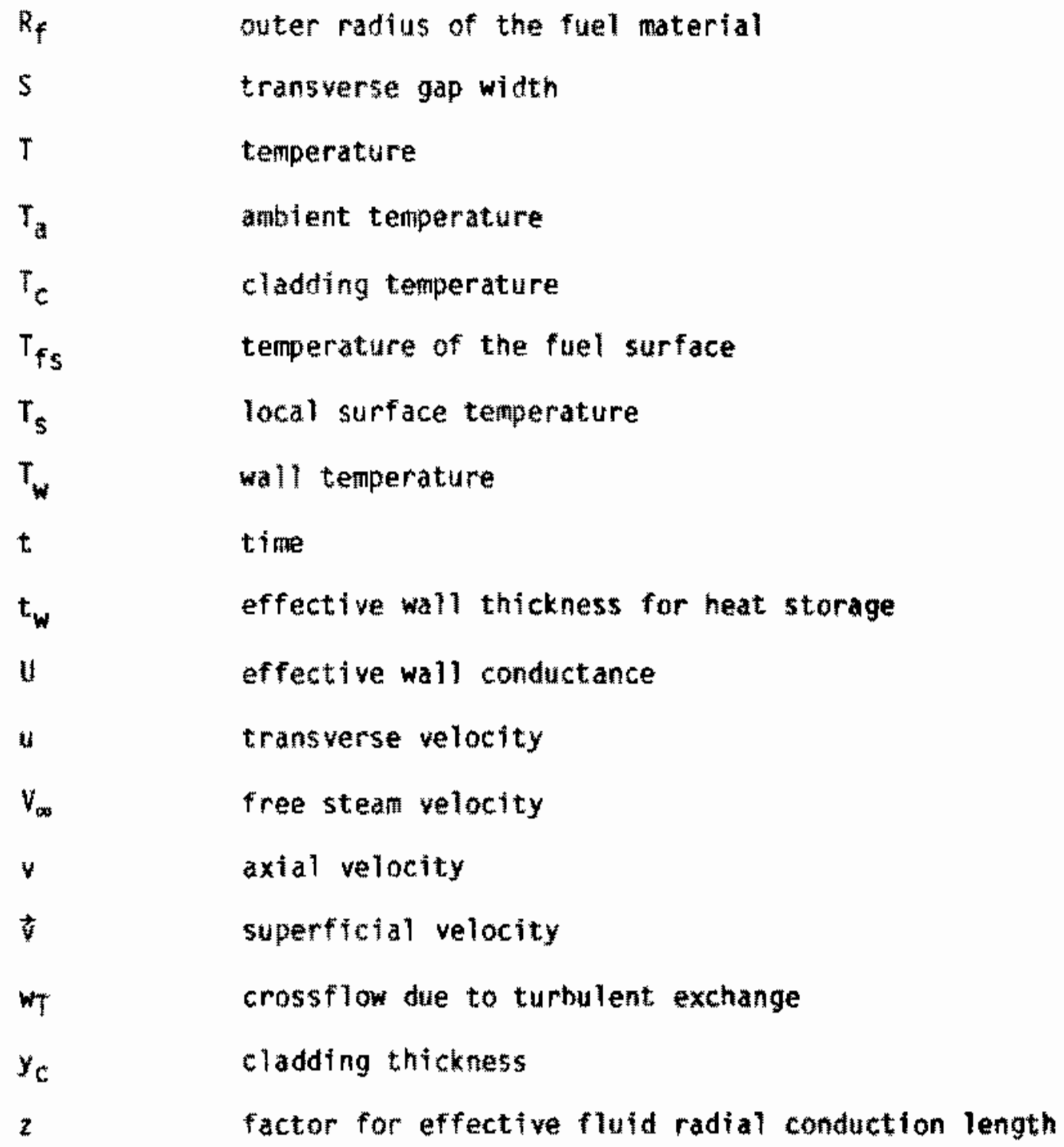

SUPERSCRIPTS

n

N

*

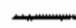

time step level or Musselt number exponent

empirical coefficient

donor cell quantity

average value 
SUBSCRIPTS

$a$

$c$

0

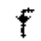

i

HTR

HTW

j

II

j)

$k$

L.

n

n

0

p

$r$

R

s

$T$

$w$

$x$ antient

cladding or convection

di ameter

friction or fuel

subchannel number of generalized subscript for matrix notation

hedt transfer from a rod

heat transfer fron wall

axial level or generalized subscript for matrix notation

refer to channel numbers on either side of transverse gap

transverse gap number

length

mixed convection or wall number

rod number

outside

pressure

radiation

rod

surface

transverse

พa11

local parameter 
,

, 


\section{CASTOR-1C SPENT FUEL STORAGE CASK DECAY HEAT, HEAT TRANSFER, ANO SHIELDING ANALYSES}

\subsection{INTROOUCTION}

Implementation of spent fuel dry storage systems may be required in the late 1980 s because several at-reactor storage pools will attain maximum capacity (Dot 1985). Under the Nuclear Waste Policy Act of 1982 (NWPA), the U.S. Department of Energy (DOE) is asstgned the responsibility for assisting utilities with their spent fuel storage problens. An additional provision of the Nuph is that DoE shall provide generic research and development (RoD) of alternative spent fuel storage systems to enhance utility-provided at-reactor storage capability* As a result of these NwPA provisions, and because DoE and utilities are planning to conduct tests and demonstrations of dry storage systens, analysis tools (computer codes) needed to be identified and evaluated during the first few tests and demonstrations. The computer codes are also needed to effectively select test conditions, identify spent fuel assemblies, select assembly loading patterns, and determine instrumentation placenents, and to minimize the number of future expensive, time-consuming tests and demonstrations.

The Pacific Northwest Laboratory (PNL) (a) selected five computer codes to support the dry storage system testing and demonstration activities. The codes were ORIGEN2 (decay heat), COBRA-SFS and HYDRA (heat transfer), and OAO and DOT (shielding).

QRIGEN2 (Croff $1980 a, b$ ) was selected to predict spent fuel assembly decay heat generation rates and radiation source rates. The code has been widely used throughout the nuclear industry to perform design and licensing safety anulyses.

The COBRA-SFS and WYORA heat transfer codes were chosen based on their treatment of the equations for mass, momentum, and energy. The codes have been

(a) The Pacific Northwest Laboratory is operated by Battelle Memorial Institute for the U.S. Department of Energy. 
evaluated since 1982 using both singlemassembly data and multiassembly cask data. Documentation is planned in 1996 and 1987.

The QAD (Malenfant 1967; ORNL 1977) and DOT (Rhoades and Childs 1982) computer codes were selected to predict gamamay and neutron dose rates, respectively. Both codes have been used extensively to perforn storage system shielding analyses.

Among the spent fuel dry storage systens being examined is the CASTOR-1C boiling water reactor (BWR) cask designed and manufactured by Gesellschaft fur Nuklear Services (GNS) of the Federal Republite of Germany. The CASTOR-1C gUR cask demonstration is reported by Fleisch, Finfeld, and Luhmann (1982). The objectlves of this activity were to 1) predict decay heat rates of spent fuel used during the cask demonstration; z) predict cask temperatures and dose rates prior to having access to test data, i.e.s pre-look; 3) compare pre-look heat transfer and shielding code predictions with test data to evaluate the codes; and 4) perform post-test analyses to improve predictions, if appropriate. Comparisons of code predictions with CASTOR-1C cask experimental data reported herein will be used, along with additional comparisons, to qualify the heat transfer codes for later use in design and licensing safety analyses of candidate dry storage systems. No attempt was made to compare the two heat transfer codes because results of the other evaluations have not been completed, and a comparison based on one data set may be prenature and lead to erroneous conclusions.

Section 2.0 of this report presents the major conclusions drawn from this work, along with the important recommendations permitted by the results and conclusions. A brief summary of the CASTOR-1C BWR spent fuel storage cask demonstration is provided in Section 3.0. Decay heat, heat transfer, and shielding andlyses, as well as the overall results, are discussed in detall in Sections 3.0 through 6.0 . 


\subsection{CONCLUSIONS AND RECONAENOATIONS}

The major conclusions and important recomendations resulting from these analyses are presented in this section. In general, all the codes performed very well. Pre-test temperature and dose rate predictions compared satisfactorily with experimental data. Selected post-test heat transfer analyses, performed with an improved axial decay heat grofile, resulted in significantly better predictions. In all cases, no major changes to the codes themselves were required to improve comparisons between predictions and data. Changes to onty the input information were necessary to imprave heat transfer predictions. The documented ORIGEN2 decay heat and DAD and DOT shielding codes should be used for design and licensing analyses of dry storage systems. Once the COBRASFS and HYORA heat transfer codes are successfully evaluated, they should be documented and used for these andyses aiso.

\section{I CONCLUSIONS}

The following specific conclusions resulted from these analyses: ORIGEN2 Decay Heat Analysis

- The initial total decay heat generation rate in the CASTOR-1C cask shortly after loating with Wurgassen BwR spent fuel assemblies was predicted to be $-13.5 \mathrm{~kW}(840 \mathrm{~W} / \mathrm{assembly})$, less than the $16-\mathrm{kW}$ (1-kW/astembly) cask design linit.

- The shape of the predicted axial decay heat proflle was significantly changed (the peak occurred at a higher axial location) when data from an in-reactor radiation scan was used in conjunction with ORIfEN2 to determine the profile shape.

COSRA-SFS Heat Iransfer Analys is

- Pre-look temperature predictions compared very closely with data, falling within \pm 2 of the total peak-to-ambient temperature drop at all three decay heat leyels. However, despite the excellent 
agreement in peak temperature, there were significant differences between predicted and measured temperature differences at specific axial locations.

- Pre-look axial temperature profiles for the peak temperature rods do not compare favorably with measured proflles. For example, temperatures near the lower ends of the axial proflles were overpredlcted by as much as $50^{\circ} \mathrm{C}$. Temperatures in the upper regtons were underpredicted by as mch as $10^{\circ} \mathrm{C}$. It was determined that these differences were due primarily to an incorrectly specified axial decay heat profile.

- Existing natural convection heat transfer coefficients significantly underpredict heat transfer from the cask surface, resulting in a prelock predicted cask surface-to-anbient temperature difference that was 30 to $40 \%$ greater than measured values for all three decay heat levels.

- Both the corner assembly-to-cask surface and the peak rod-to-cask surface temperature differences were within $10^{\circ} \mathrm{C}$ of measured values in all three pre-look simulations. The peak rod-to-cask surface tenperature differences were consistenty underpredicted in all three cases.

- The values used for rod-to-fluid convection heat transfer coefficlents in the pre-look andysis were based on constant heat flux from the rods. The shape of the axial temperature proflle suggests that the coefficlents be changed to those based on constant temperature conditions.

- The post-test peak temperature predictions compared very closely with data, falling within $\pm 2 \%$ of the total peak-to-ambient temperature drop in all three cases. In addition, there were improvements in comparisons of predicted to measured temperature differences throughatt the cask.

- The use of an axial decay heat profile that reflects the operating history tha reactor resulted in much improved agreenent between 
the post-test axial temperature proftle predictions and measured profiles. Near the lower end of the profiles, differences between predicted and measured temperatures were less than $5^{\circ} \mathrm{C}$ in all three cases. Near the top end of the profile, the temperatures were under* predicted by as much as 10 to $15^{\circ} \mathrm{C}$.

- Both the corner assembly-to-cask surface and peak rod-to-cask surface temperature differences were still within $10^{\text {th }} \mathrm{C}$ of measured values in all three post-test simulations. The decrease in rod-to-fluid heat transter coefficients resulted in slight increases in these temperature differences for all cases.

HYDRA Heat Transfer Analysis

- Pre-look temperature predictions agreed well with test data, being within $\pm 4 \%$ of the total peak rod-to-ambient temperature difference. However, predictions of temperatures at sone axial locations were in significant disagreement with data.

- Pre-look predictions of axial temperature profiles were as much as $70^{\circ} \mathrm{C}$ higher than test data in the lower regions of the fuel assemblies. An erroneous initial axial decay heat profile appears to have been the cause of the majority of the disagreement.

- Standard natural convection heat transfer correlations for the exterior surface of the cask resulted in slight $\left(<10^{\circ} \mathrm{C}\right)$ overpredictions of cask surface temperatures. This and other similar analyses (Wiles et a1. 1986, Wheeler et al. 1986) have led to the conclusion that existing correlations may not be accurate models for very large casks.

- Post-test predictions of peak cladding temperatures were not noticeably affected by the use of a nore reasonable axtal decay heat profile. However, agreement between predictions and data at other axial locations was sugnificantly improved $\left(12^{\circ}\right)$. 
QAD and DOT Shlelding Analyses

- QAD code predictions resulted in conservatively high gatma-ray dose rates for CASTOR-1C. Predictions were as much as twice as high as test data,

- Secondary gamma-ray contributions to total dose rates were much less than prinary gamma-ray contributions.

- Dot code predictions of neutron dose rates were conservatively high for CASTOR-1C. Predicted values were as much as a factor of four higher than measured values. Neutron source strengths may have been the cause of the high dose rate predictions.

\subsection{RECOMMENDATIONS}

As a result of comparisons of code predictions with test data, the following recommendations are made:

OR1GEN2 Decay Heat Predictions

- ORIGEN2 should be used to predict decay heat generation rates of spent fuel assemblies for interin storage system design and licensing safety analyses. This recommendation is based on the results of this study and of the Wiles et al. (1986) and McKinnon et a1. (1986a,b) studies for BWR assemblies, as well as on schmittroth's (1984) study for PWR assemblies.

- When ORIGENz is used to predict decay heat generation rates of BWR spent fuel assenblies, cycle-by-cycle burnup values must be used to ensure good accuractes $( \pm 10 \%)$.

COBRA-SFS and HYDRA Heat Transfer Analyses

- The two codes should continue to be used to predict temperatures in spent fuel ary storage systens and, once successfully evaluated and documented, should be used for design and licensing safety analyses.

- Predictions of dry storage system temperatures within 25 or $30^{\circ} \mathrm{C}$ can be obtained. Further, if it is desirable to improve this agreenent, the following, in order of importance, should be pursued: 
- System geometries, especially gap widths and characteristics of contacting surfaces, must be better known to significantly improve temperature predictions.

- Detailed in reactor radiation scans or assembly gamma scans should be considered in the development of axial decay heat profiles to be used as input in future cask analyses, to permit better predictions of axial temperature profiles.

- The effects of free-stream turbulence and mixed convection (free and forced) adjacent to the exterior surface of the cask shouid be modeled, to improve heat transfer correlations.

- In COBRA-SFS, the two-dimensional momentum and heat transfer in the regions above and helow the basket should be modeled. Suggestions for refinements include radially varying inlet conditions, multidimensional heat transfer hetween solid structures, and a computed velocity field.

- Velocity fields should be measured in simulated casks, and COBRASFS and HYDRA predictions should be evaluated with the measured distributions to enhance convection heat transfer results.

- The heat transfer data contained in this report should be used to evaluate other heat transfer codes.

QAD and DOT Shielding Analyses

- The QAD and DOT codes should continue to be used to predict dose rates in spent fuel dry storage systems.

- Magnitudes of radiation source terms should he determined more accurately if better prediction accuracies are desired. Space- and energy-dependent neutron and gamma-ray source strength measurements are desirable.

- Shielding analyses of one or two casks should he performed with a Monte Carlo code to provide an independent check on methodology and determine if more accurate predictions are practical. 
. 


\subsection{CASTOR-1C SPENT FUEL STORAGE CASK PERFORMANCE TEST}

To add to the current body of knowledge and to gain operational experience in dry spent fuel storage, a program for handling and monitoring spent fuel containers was initiated by the Federal Republic of Germany, using a cask of the CASTOR-1C type. This program was carried out at the Wurgassen Nuclear Power Plant by the German Association for the Reprocessing of Nuclear Fuels (DWK) in conjunction with the Preussen Elektra utility. The CASTOR-1C spent fuel storage cask and cask performance test conducted at the Wurgassen plant are briefly described in this section.

\subsection{CASTOR-1C CASK}

The Gesellschaft fur Nuklear Services (GNS) CASTOR-1C cask (GNS 1983, 1985) is designed to safely store and remove the decay heat from 16 BWR spent fuel assemblies for extended time periods. A cutaway drawing of the CASTOR-1C cask is shown in Figure 3.1. The cask consists of a thick-walled nodular cast-iron body, which is cast in one piece. The body physically protects the fuel assemblies and provides radiation shielding. The central cavity of the cask contains a stainless steel basket that separates and supports the spent fuel assemblies. The top of the cask is sealed using a multiple-lid system. The overall cask dimensions and design specifications are summarized in Table 3.1. Each major component of the cask is described in more detail below.

\subsubsection{Body}

A cross section of the CASTOR-1C cask is shown in Figure 3.2. The nodular cast-iron body has an overall length of $5510 \mathrm{~mm}(18 \mathrm{ft}$ ) and a maximum outside diameter of $1730 \mathrm{~mm}(5.7 \mathrm{ft})$. The side wall thickness (without fins) is approximately $440 \mathrm{~mm}$ (17.3 in.). Gamma-ray and neutron radiation are shielded by the cast-iron wall of the cask. For improved neutron shielding through the side, two concentric rows of axial holes in the cask body wall are filled with poly-ethylene rods (moderator material). The rods are $60 \mathrm{~mm}(2.4 \mathrm{in.}$ ) in diameter and extend axially from the bottom of the cask to above the top elevation of the fuel assemblies. The maximum dose rate (gamma-ray and neutron) on the 


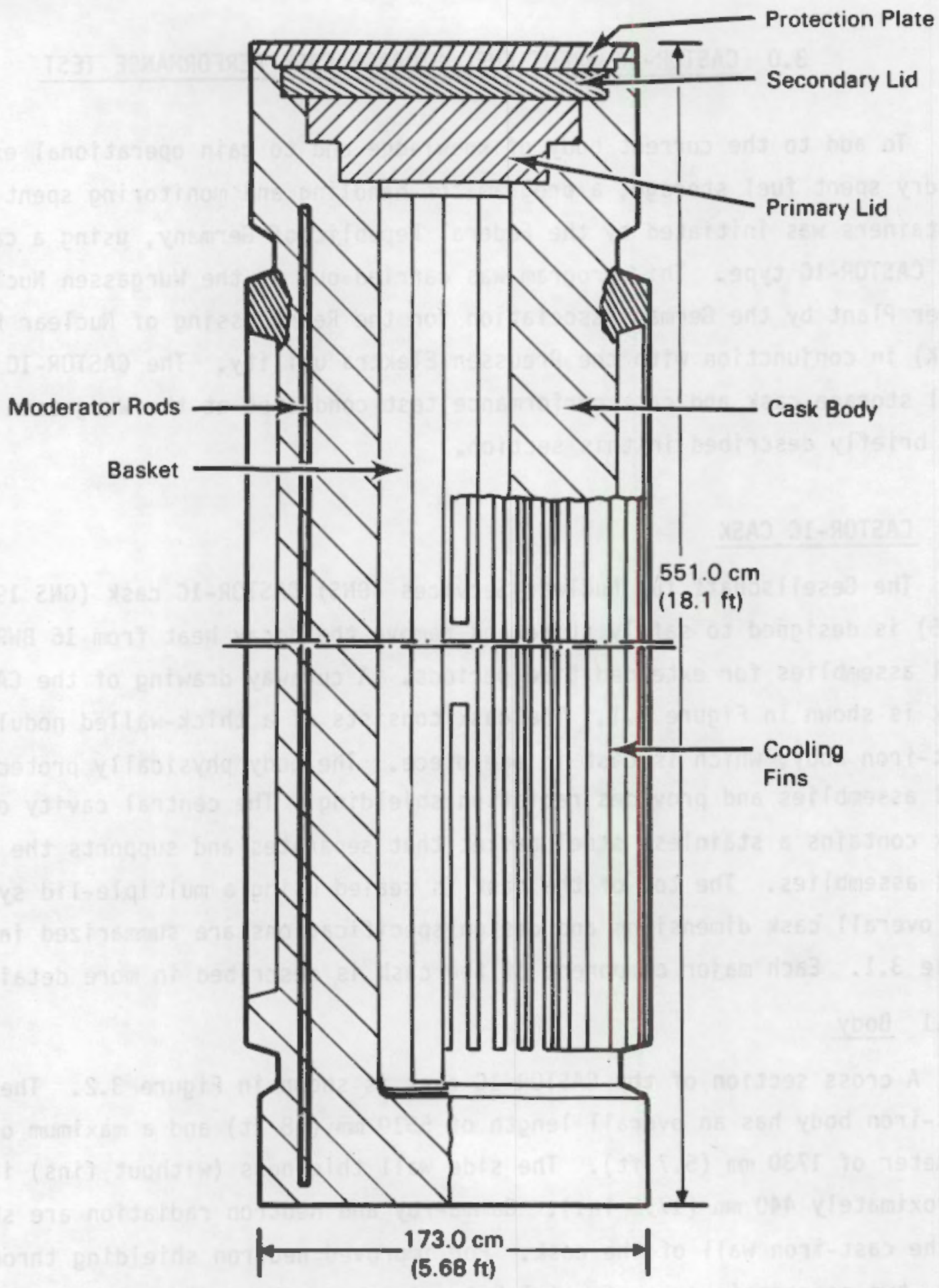

FIGURE 3.1. Elevation View of the CASTOR-1C Cask 
TABLE 3.1. CASTOR-1C Cask Dimensions and Design Specifications

Cask overall length:

Cross section:

Cask cavity width:

Cavity length:

Side wall thickness without fins:

Lid thicknesses:

- primary lid

- secondary lid (including moderator)

- protection plate

Bottom thickness:

Moderator dimensions:

- number of polyethylene moderator rods

- rod diameter

- thickness, secondary lid

- thickness, bottom

Number of cooling fins:

Cask fuel assembly capacity:

Cask atmosphere:

Cavity pressure:

Weight:

- empty cask

- loaded cask
$551 \mathrm{~cm}(18 \mathrm{ft})$

$173 \mathrm{~cm}(5.7 \mathrm{ft})$

$66.6 \mathrm{~cm}(2.2 \mathrm{ft})$

$456 \mathrm{~cm}(15 \mathrm{ft})$

$44 \mathrm{~cm}(17 \mathrm{ft})$

$34 \mathrm{~cm}$ (13 in.)

$13 \mathrm{~cm}$ ( 5 in.)

$8 \mathrm{~cm}$ (3 in.)

$44.7 \mathrm{~cm}(18 \mathrm{in.})$

80

$6 \mathrm{~cm}$ ( 2.4 in.)

$6 \mathrm{~cm}$ (2.4 in.)

$4.2 \mathrm{~cm}(1.7 \mathrm{in.})$

48

16

helium

0.8 bar (11.76 psia)

76.6 ton

81.1 ton

cask surface is designed to be $200 \mathrm{mrem} / \mathrm{hr}$ or less. The maximum design value for the average surface dose rate is $20 \mathrm{mrem} / \mathrm{hr}$.

The outside surface of the cask varies as a function of axial level. Near the top and bottom of the cask, the surface is a cylinder $81905 \mathrm{~mm}(6.25 \mathrm{ft})$ in diameter: with four flat surfaces machined so the minimum flat-to-flat distance is $1730 \mathrm{~mm}(5.7 \mathrm{ft})$. In the axial region of the fuel assemblies, a set of 48 axial cooling fins is provided to enhance the removal of heat by natural convection. A cross section of the CASTOR-IC cask illustrating the cooling fin 


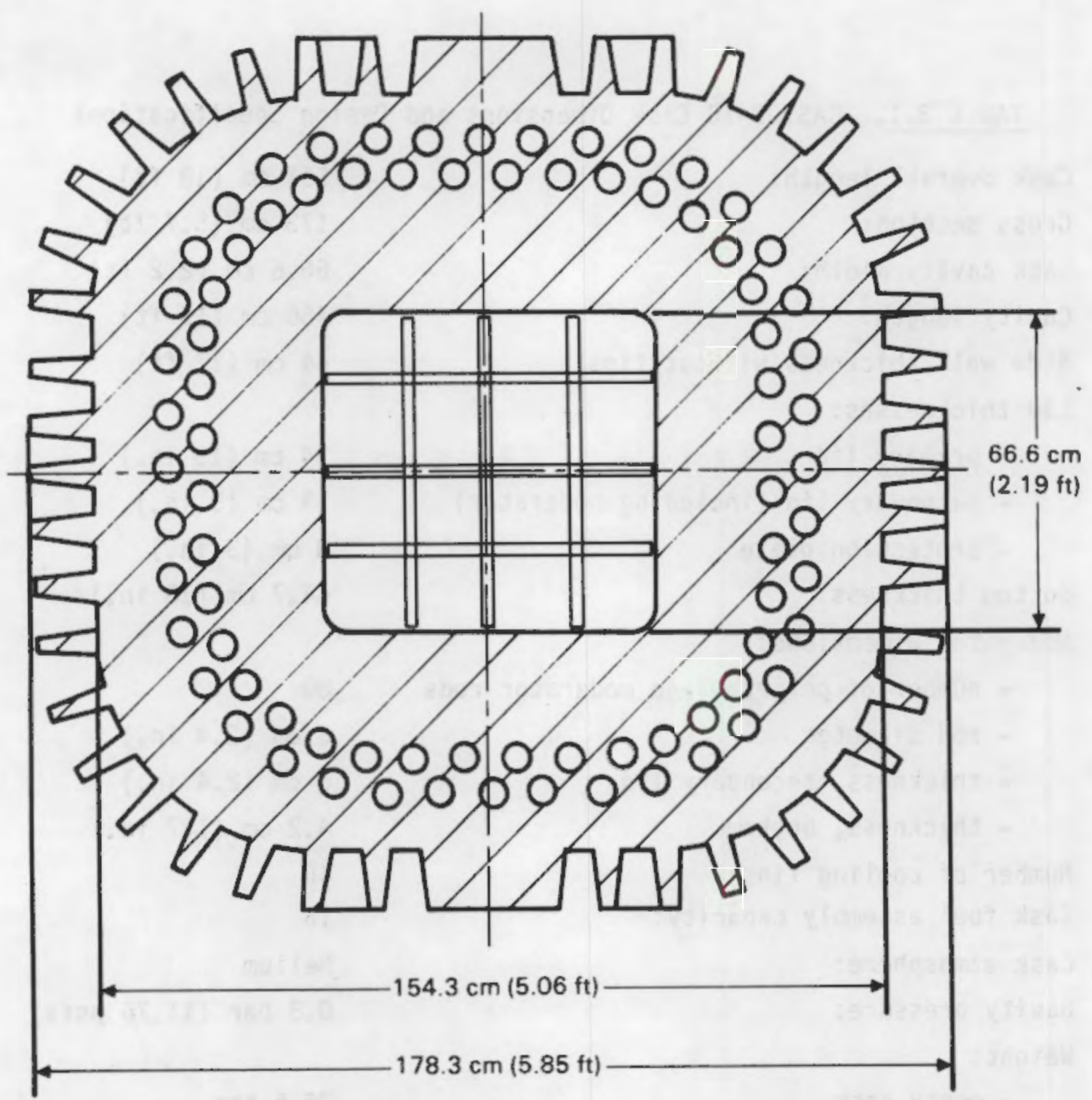

FIGURE 3.2. Cross Section of the CASTOR-1C Cask

geometry is shown in Figure 3.3. The fins are $120 \mathrm{~mm}$ (4.7 in.) long, $50 \mathrm{~mm}$ (1.97 in.) wide at the base, and are spaced approximately $112 \mathrm{~mm}(4.4 \mathrm{in.})$ apart. The outside of the cask is protected by an epoxy resin coating in the fin area. The fins are also covered with a high-emissivity paint to aid in transferring heat from the cask surface. The remainder of the cask surface is covered with a corrosion-resistant nickel coating.

The thickness of material from the bottom of the inner cavity to the exterior bottom of the cask is approximately $450 \mathrm{~mm}(17.7 \mathrm{in.}$ ). The major portion of this is cast iron. However, some of the cast iron is machined from the 


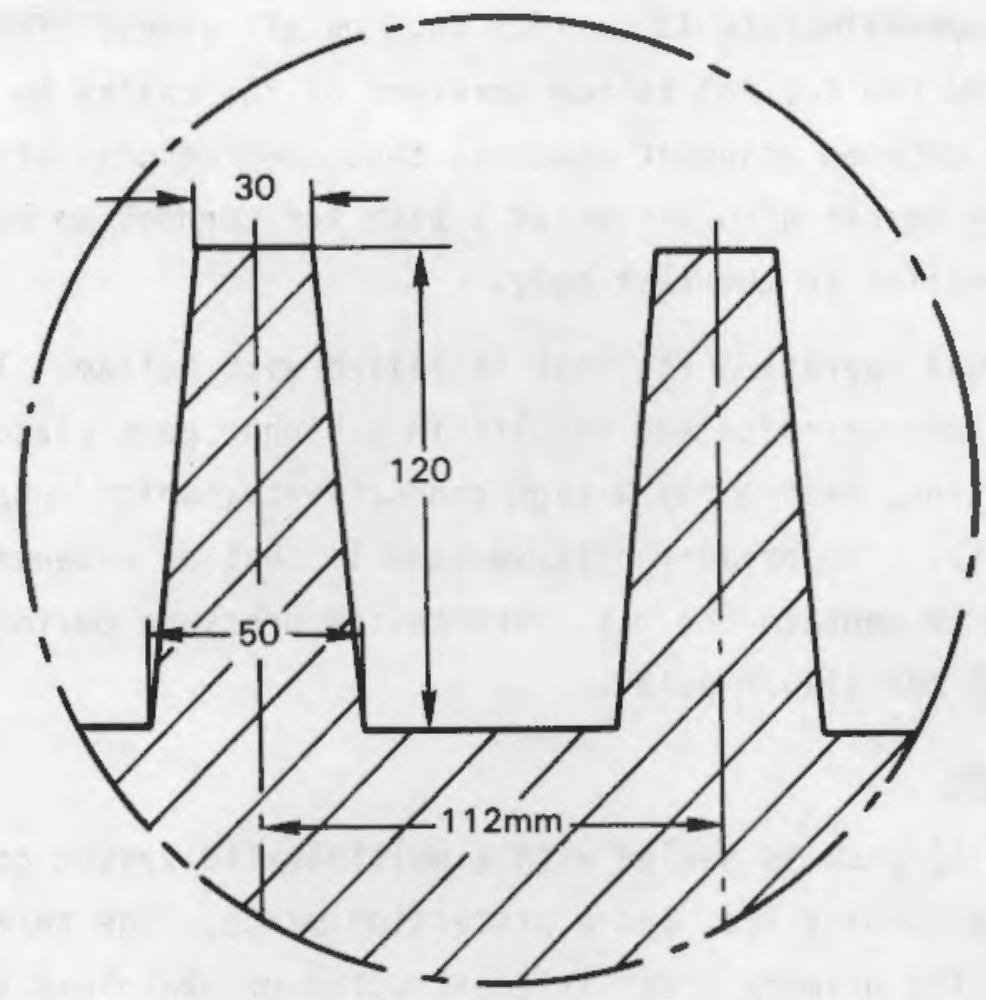

FIGURE 3.3. Cooling Fin feometry

bottom of the cask and is replaced by concentric rings of polyethylene that serve as neutron shields. A semi-permanent steel cover plate is secured over the rings to hold them in place.

\subsubsection{Cavity and Basket}

The cask inner cavity is square, $666 \mathrm{~mm}(26.2 \mathrm{in.})$ wide, and $4560 \mathrm{~mm}$ (15 ft) long. The bottom of the cavity is sloped slightly to enhance draining of fluid. The inside of the cask, including the sealing surfaces, has a nickel coating for corrosion protection. A support plate is placed on the bottom of the cavity to provide a level support for the basket and fuel assemblies.

The basket is of welded construction and is made of borated stainless steel to reduce the possibility of criticality. The basket divides the cavity into 16 regions, each designed to contain a single BWR spent fuel assembly. A cross section of the fuel basket is visible in Figure 3.2. The stainless steel plates used to construct the basket are $10 \mathrm{~mm}(0.4 \mathrm{in.})$ thick, and the overall basket width is $640 \mathrm{~mm}(25 \mathrm{in}$.). This leaves a gap between the basket and 
cavity wall of approximately $13 \mathrm{~mm}(0.5 \mathrm{in.})$ on all sides. The basket is designed to allow the top and bottom portions of the cavity to be open. This allows gas flow between adjacent assembly tubes and natural circulation inside the cavity. The basket also serves as a path for conduction heat transfer from the center assemblies to the cask body.

During normal operation the cask is filled with helium. The use of this inert gas inhibits corrosion and results in a higher peak cladding temperature limit. In addition, helium has a high conductivity, which enhances heat transfer in the cavity. The primary disadvantage is that an extensive sealing system is required to contain the gas. The cavity pressure during normal cask operation is 0.8 bar ( 11.76 psia).

\subsubsection{Lid System}

The CASTOR-1C cask is sealed with a multiple-lid system consisting of a primary lid, a secondary lid, and a protection plate. The three lids are shown in Figure 3.1. The primary cover is constructed of stainless steel and has an outside diameter of $1200 \mathrm{~mm}(3.9 \mathrm{ft})$ and an overall thickness of about $340 \mathrm{~mm}$ (13.4 in.). The secondary cover is made primarily of stainless steel and has a 1415-mm (4.6-ft) diameter and a 130-rim (5.1-i . .) thickness. Some of the stainless steel in the secondary cover is replaced with concentric polyethylene rings that act as neutron shields. The protective plate is made of carbon steel and serves as a general mechanical protection against outside forces as well as dust and humidity. Each lid is bolted directly to the cask body. A combination of multiple elastomeric and metallic seals for each cover guarantees a high level of leak-tightness. The maximum leak rate is designed to be $10^{-7} \ell / \mathrm{s}$.

\subsection{WURGASSEN BWR SPENT FUEL ASSEMBLIES}

Sixteen BWR spent fuel assemblies from the Wurgassen reactor operated by Preussen Elektra were loaded in the CASTOR-1C cask during testing. The fuel assembly designs and decay heat predictions required as input for the heat transfer and shielding analyses are described in this section. 


\subsubsection{Designs}

Four different basic types of BWR assemblies are generally acceptable for storage in a CASTOR-1C cask:

- assembly type $7 \times 7$ General Electric (GE), Exxon

- assembly type $7 \times 7$ (revised GE)

- assembly type $8 \times 8$ (GE, Exxon)

- assembly type $8 \times 8$ retrofit (GE).

The spent fuel assemblies used in the Wurgassen CASTOR-1C cask test were the GE $7 \times 7$ and $8 \times 8$ assembly types. The design characteristics of these two assembly types are listed in Table 3.2. The Exxon BWR fuel assemblies of the

TABLE 3.2. Characteristics of Typical General Electric BWR Fuel Assemblies

Assembly length

Fuel rods

Number

Length

Active length

Outside diameter

Wall thickness

Pitch

Material

Tie rods - fueled

Number

Outside dianleter

Wall thickness

Material

Spacer capture rods

Number

Outside diameter

Material

Spacers

Number

Material

Springs

Tie plate material
$7 \times 7$ Assembly

$4354 \mathrm{~mm}$ (171.40 in.)

49

$3964 \mathrm{~mm}$ (156 in.)

$3683 \mathrm{~mm}$ (145 in.)

$14.3 \mathrm{~mm}(0.563 \mathrm{in.})$

$0.89 \mathrm{~mm}(0.035 \mathrm{in.})$

$18.7 \mathrm{~mm}$ (0.738 in.)

$2 r-2$

8

$14.3 \mathrm{~mm}(0.563 \mathrm{in.})$

0.89 mाm (0.035 in.)

$\mathrm{Zr}-2$

1

$14.3 \mathrm{~mm}(0.563$ in.)

$\mathrm{Zr}-2$

7

$\mathrm{Zr}-4$

Incone $1-X$

304 SS 8x8 Assembly

$4354 \mathrm{~mm}$ (171.40 in.)

63

$3964 \mathrm{~mm}$ (156 in.)

$3733 \mathrm{~mm}$ (147 in.)

$12.5 \mathrm{~mm}$ (0.493 in.)

$0.86 \mathrm{~mm}(0.034 \mathrm{in.})$

$16.3 \mathrm{~mm}(0.640 \mathrm{in.})$

$\mathrm{Zr}-2$

8

$12.5 \mathrm{~mm}(0.493$ in.)

0.86 mाता (0.034 in.)

$\mathrm{Zr}-2$

1

$12.5 \mathrm{~mm}(0.493 \mathrm{in.})$

$\mathrm{Zr}-2$

7

$2 r-4$

Incone $1-X$

304 SS 
$7 \times 7$ and $8 \times 8$ type are also acceptable for storage. Their dimensions and specifications are quite similar to those of the GE fuel assemblies.

General Electric fuel assemblies contain fuel rods (and one center water rod in the $8 \times 8$ bundle only) spaced and supported in a square array by the lower and upper tie plates. A typical GE $8 \times 8$ fuel assembly is shown in Figure 3.4. The upper and lower tie plates are 304 stainless steel (SS) castings. The lower tie plate has a nose-piece that supports the fuel assembly in the reactor. The upper tie plate has a handle for transferring the fuel assembly from one location to another. An Inconel- expansion spring on the upper end plug shank of each fuel rod keeps the rods seated in the lower tie plate.

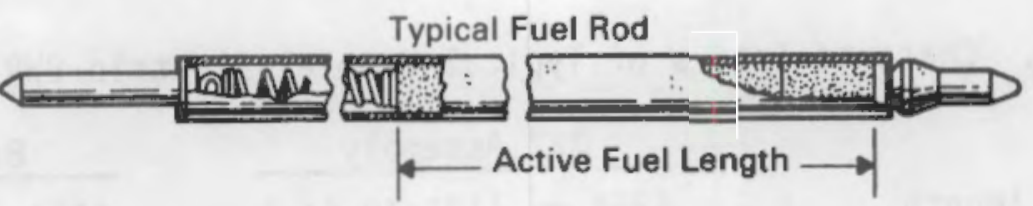

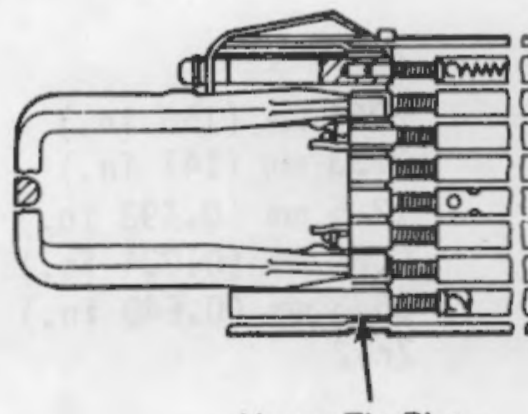

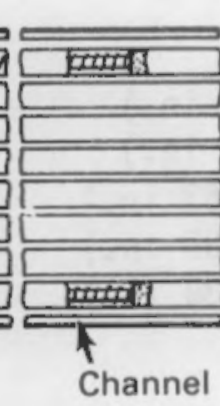

Upper Tie Plate

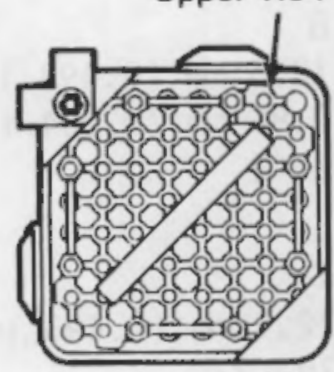

FIGURE 3.4. Typical General Electric 8x8 Fuel Assembly

Registered trade name of Huntington Alloys, Inc., Huntington, West Virginia. 
Besides the standard fuel rods, two other rod types are used in the fuel assembly: tie rods and a nonfuel water rod. The eight tie rods in each assembly have lower end plugs that thread into the lower tie plate casting and upper end plugs that extend through the upper tie plate casting. These tie rods support the weight of the assembly only during fuel handling when the assembly hangs by the handle; during operation, the fuel rods are supported by the lower tie plate.

\subsubsection{Predicted Decay Heat Generation Rates}

The ORIGEN2 code (Croff 1980a,b) was used to predict decay heat generation rates of the Wurgassen BWR spent fuel assemblies used in the CASTOR-1C cask performance test. A brief description of ORIGEN2, a summary of the input, and predictions of the decay heat rates of each assembly are provided.

\subsubsection{ORIGEN2 Computer Code}

The ORIGEN2 code (Croff $1980 \mathrm{a}, \mathrm{b}$ ) is widely used in the nuclear industry to predict decay heat rates of spent fuel assemblies. This general purpose burnup and decay code features extensive data libraries containing information on over 1200 nuclides. The code can be used to perform transmutation calculations in steps of constant power level or constant neutron flux level. The resulting nuclide concentrations can be decayed with user-specified time intervals. Output options are available for decay heat rate as well as spent fuel compositions and radioactivity.

A standard version of the ORIGEN2 code was used to predict the decay heat rates of 16 Wurgassen BWR spent fuel assemblies used during CASTOR-1C BWR cask performance testing. The code was benchmarked with a standard problem to ensure that the predictions are what would be expected from the code as it would be received from the Oak Ridge National Laboratory (ORNL) Radiation Shielding Information Center.

ORIGEN2 results are based on a large library of one energy group cross sections of the nuclides. These cross sections are the result of extensive calculations starting with a numerical description of the cross section of each isotope as a function of neutron energy. The basic cross sections are averaged 
over the energy range of $17 \mathrm{MeV}$ to $0 \mathrm{eV}$ using a computed neutron energy spectrum. Neutron spectrum caiculations are performed with a composition appropriate to a specific reactor core design and operating condition. The user is provided with various data libraries, each representing a reactor type, core loading, and operating condition. There is one BWR cross section library for a $235 \mathrm{U}$ enriched core; this actinide library has the numerical designation 252. Associated with it are activation product 1ibrary 251 and fission product library 253, which were generated using the same neutron spectrum used to generate library 252.

A special concern in making decay heat rate predictions with ORIGEN2 for BWR fuel, as opposed to PWR fuel, is the effect of appreciable steam voids on the neutron spectrum. The ratio of plutonium to uranium fissions and the actinide composition at a given burnup are influenced by differences in the neutron spectrum. Assembly decay heat rates are determined by different fission product yields for uranium and plutonium and by the mix of actinide isotopes in the spent fuel. A series of calculations was performed to evaluate the sensitivity of decay heat rates to variations of core steam void fractions. A version of the LEOPARD code (Barry 1963) was used to calculate the effect of unit cell steam voiding on the one group spectrum-averaged cross sections of the isotopes responsible for most of the decay heat. The change in the spectrum-averaged cross section at a given void fraction relative to the ORIGEN2 library default void fraction of $31.6 \%$ was determined for a range of void fractions. These relative change factors were used to alter the cross section of ORIGEN2 library 252 via code input for a series of ORIGEN2 cases, each representing a particular core steam void fraction in the range of $0 \%$ to $90 \%$. As a result of these sensitivity calculations, it was found that core void variations of $0 \%$ to $90 \%$ can cause the decay heat rate to vary by $11 \%$ to $30 \%$, depending on the time out of reactor.

The spectrum used in computing libraries 251, 252, and 253 was calculated assuming a GE BWR- 6 assembly ( $8 \times 8$ rod array) at $31.6 \%$ core average steam void fraction (Croff et al. 1978). The Wurgassen fuel assemblies used in this study were of a different $7 \times 7$ and $B \times 8$ rod design. The void fraction that has the same hydrogen-to-uranium $(H / U)$ ratio as the $31.6 \%$ used in calculating the 
ORIGEN2 1ibrary is $38 \%$ for the Wurgassen $7 \times 7$ rod design and $37 \%$ for the $8 \times 8$ rod design. The $H / U$ ratio is a reasonable basis from which to determine the equivalent void fraction because it is a measure of the relative moderation and absorption rates that determine the form of the neutron spectrum. The Wurgassen BWR assemblies had an average operating void fraction of approximately $40 \%$, which is close to the $36 \%$ and $37 \%$ equivalent void fractions of the library. Therefore, no corrections for void fraction were made.

\subsubsection{ORIGEN2 Input Specifications}

Wurgassen fuel assembly data are summarized in Table 3.3. Decay heat from neutron activation of assembly structural materials is usually less than $5 \%$ of the total decay heat, and over $95 \%$ of this amount comes from cobalt. Generic values of other elements such as gadolinium, which contribute activation heating, were used and obtained from Croff et al. (1978). The Zirconium-2 cladding was assumed to contain $10 \mathrm{ppm}$ of cobalt.

Before the decay heat analysis was performed, it was anticipated that individual cycle burnup values would be required for accurate ORIGEN2 predictions. End-of-cycle (EOC) burnup values for each Wurgassen spent fuel assembly

\section{TABLE 3.3. Wurgassen Fuel Assembly Design Data}

\begin{tabular}{llll} 
& \multicolumn{1}{c}{$7 \times 7$ Assembly } & & $8 \times 8$ Assembly \\
\cline { 2 - 3 } Fuel rod outside diameter & $14.29 \mathrm{~mm}(0.563 \mathrm{in.})$ & & $12.5 \mathrm{~mm}(0.492 \mathrm{in.})$ \\
Cladding thickness & $0.8 \mathrm{~mm}(0.032 \mathrm{in.})$ & & $0.85 \mathrm{~mm}(0.034 \mathrm{in.})$ \\
Fuel rod pitch & $18.75 \mathrm{~mm}(0.74 \mathrm{in.})$ & & $16.25 \mathrm{~mm}(0.64 \mathrm{in.})$ \\
Shroud internal flat-to-flat & $134 \mathrm{~mm}(5.28 \mathrm{in.})$ & & $134 \mathrm{~mm}(5.28 \mathrm{in.})$ \\
Shroud thickness & $2.1 \mathrm{~mm}(0.083 \mathrm{in.})$ & & $2.54 \mathrm{~mm}(0.10 \mathrm{in.})$ \\
Assembly pitch & $152.5 \mathrm{~mm}(6.0 \mathrm{in.})$ & & $152.5 \mathrm{~mm}(6.0 \mathrm{in.})$ \\
Zr-2 weight & $46 \mathrm{~kg}(101 \mathrm{lb})$ & & $50 \mathrm{~kg}(110 \mathrm{lb})$ \\
Total stainless steel weight & $8.7 \mathrm{~kg}(19 \mathrm{lb})$ & & $3.2 \mathrm{~kg}(7 \mathrm{lb})$ \\
Steel with $2000 \mathrm{ppm}$ cobalt & $3.98 \mathrm{~kg}(8.8 \mathrm{lb})$ & & $3.2 \mathrm{~kg}(7 \mathrm{lb})$ \\
Steel with $200 \mathrm{ppm}$ cobalt & $4.72 \mathrm{~kg}(10.4 \mathrm{lb})$ & & $0.0 \mathrm{~kg}(0 \mathrm{lb})$
\end{tabular}


are presented in Table 3.4 in terms of gigawatt-days (GWd) per metric ton of uranium (MTU). Burnup values shown in Table 3.4 are very uniform from assembly to assembly.

All assemblies were initially enriched to $2.5 \mathrm{wt} \% 235 \mathrm{U}$ averaged over all rods in each assembly. Sensitivity studies were conducted using ORIGEN2 with different enrichments to ensure that calculated decay heat rates based on a single average assembly enrichment closely approximated average decay heat rates from ORIGEN2 based on individual rod enrichments in the assemblies.

TABLE 3.4. Wurgassen BWR Assembly Burnup Histories

\begin{tabular}{|c|c|c|c|c|}
\hline \multirow[b]{2}{*}{ Assembly (a) } & \multicolumn{4}{|c|}{ Burnup, GWd/MTU } \\
\hline & EOC2 & $\mathrm{EOC3}$ & EOC4 & EOC5 \\
\hline B467 & 8.8 & 15.2 & 21.0 & 27.6 \\
\hline B471 & 8.1 & 13.3 & 21.2 & 27.6 \\
\hline B472 & 8.0 & 14.0 & 21.4 & 27.8 \\
\hline B476 & 8.1 & 13.3 & 21.2 & 27.6 \\
\hline B486 & 8.8 & 15.2 & 21.0 & 27.6 \\
\hline B489 & 8.0 & 14.0 & 21.4 & 27.8 \\
\hline B490 & 8.6 & 14.7 & 20.9 & 27.5 \\
\hline B493 & 8.6 & 14.7 & 21.0 & 27.5 \\
\hline B2701 & 9.0 & 15.4 & 22.1 & 27.2 \\
\hline BZ703 & 8.9 & 14.8 & 21.8 & 28.5 \\
\hline BZ704 & 7.5 & 13.3 & 20.9 & 28.3 \\
\hline BZ706 & 9.0 & 15.4 & 22.1 & 27.2 \\
\hline B2707 & 7.5 & 13.3 & 20.9 & 28.3 \\
\hline BZ708 & 8.9 & 14.8 & 21.8 & 28.5 \\
\hline B2709 & 7.5 & 13.3 & 20.9 & 28.3 \\
\hline B2710 & 7.5 & 13.3 & 20.9 & 28.3 \\
\hline
\end{tabular}

(a) Identification numbers starting with B denote $7 \times 7$ rod assemblies with $195 \mathrm{~kg} \mathrm{U}$ content, while numbers prefaced with BZ indicate $8 \times 8$ rod assemblies with $185 \mathrm{~kg} \mathrm{U}$ content. 
Power histories for the assemblies were determined from EOC burnup values shown in Table 3.4, and from the reactor operating history shown in Figure 3.5 . The specific powers indicated in Figure 3.5 are based on a design core power of $18 \mathrm{MW} / \mathrm{MTU}$. Assembly power histories within a reactor operating cycle were calculated by multiplying ratios of incremental burnup for the cycle to the core average incremental burnup for that cycle by the core average specific power history. The resulting specific power history used as input to ORIGEN2 is shown in Figure 3.6 for assembly B467. The input file for the ORIGEN2 prediction of the decay heat from $B 467$ is presented in the Appendix.

\subsubsection{ORIGEN2 Predictions}

ORIGEN2 predictions of decay heat generation rates of each Wurgassen spent fuel assembly are presented in this section. Also included are calculated fuel assembly axial decay heat generation profiles. Both predicted decay heat generation rate magnitudes and axial profiles are needed as input to heat transfer computer codes as discussed in Sections 4.0 and 5.0.

3.2.2.3.1 Predicted Decay Heat Generation Rate Magnitudes. Predicted assembly decay heat generation rate magnitudes on the three test dates are shown in Table 3.5 for each of the 16 Wurgassen assemblies. The predicted decay heat rates are remarkably similar because of the similarity of burnup values. The standard deviation of burnup is only $\pm 1.6 \%$ about the average burnup for all 16 assemblies. At 434 days cooling time, the standard deviation of the predicted decay heat rate is $\pm 6.0 \%$, which reduces to $\pm 4.4 \%$ for the longest cooling period.

3.2.2.3.2 Predicted Axial Decay Heat Profiles. The three-dimensional COBRA and HYDRA thermal analyses (Sections 4.0 and 5.0 ) are sensitive to axial decay heat profiles. The initial axial decay heat curve (burnup curve) provided for the Wurgassen spent fuel is shown in Figure 3.7. As shown, the curve peaked in the lower half of the assemblies. The pre-look heat transfer analyses showed that the initial axial decay heat profile may not represent that from the actual fuel assemblies used in the CASTOR-1C cask performance test. The final conclusion that the initial axial profile may not be applicable was 


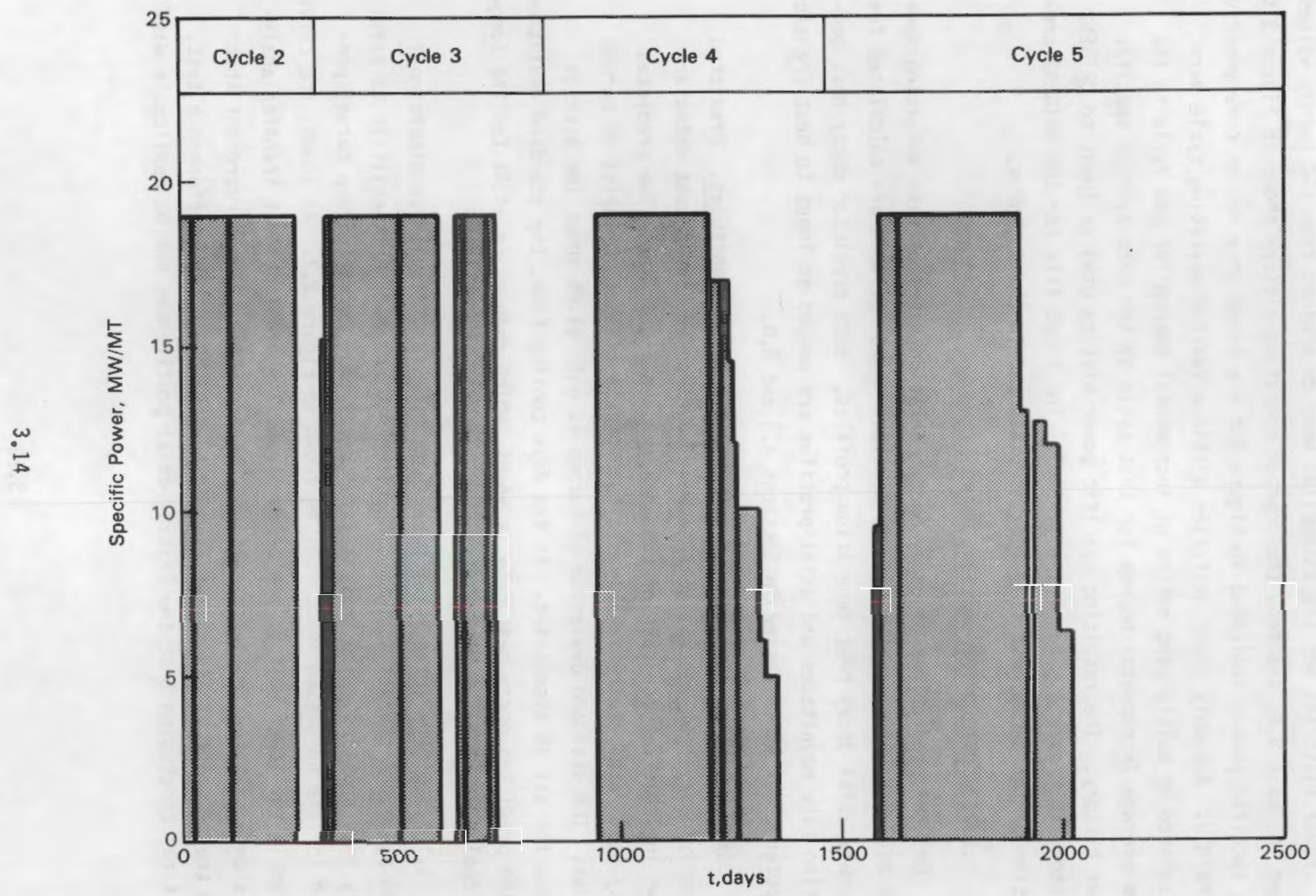

FIGURE 3.5. Hurgassen Operating History (Cycles 2 Through 5) 


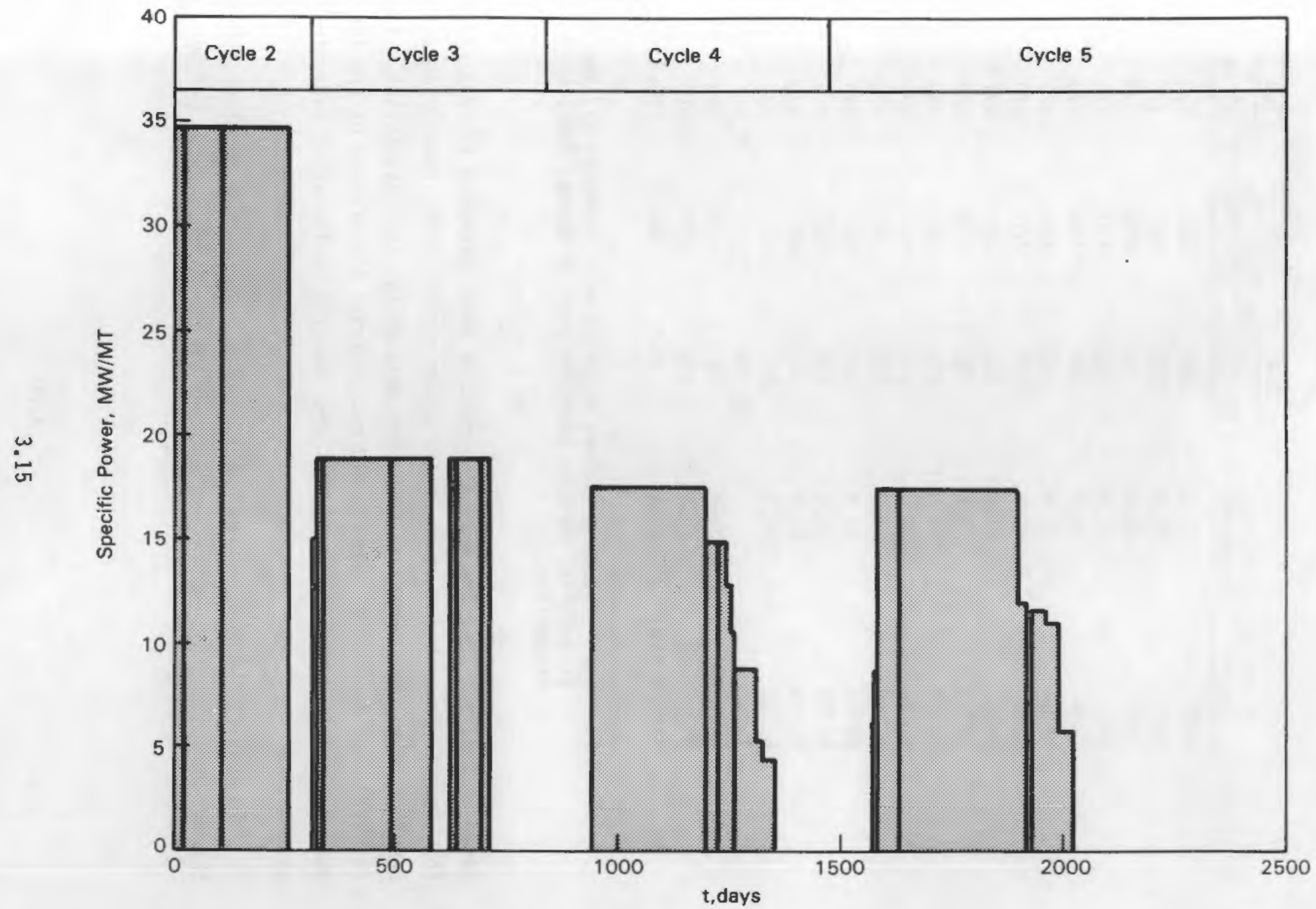

FIGURE 3.6. Assembly B467 Specific Decay Heat History 
TABLE 3.5. Predicted Wurgassen BWR Assembly Decay Heat Rates

\begin{tabular}{|c|c|c|c|c|}
\hline \multirow[b]{2}{*}{$\begin{array}{l}\text { Assembly } \\
\text { ID }\end{array}$} & \multirow[b]{2}{*}{$\begin{array}{l}\text { Burnup, } \\
\text { GWd/MTU }\end{array}$} & \multicolumn{3}{|c|}{ Cooling Time, Days } \\
\hline & & $\begin{array}{l}\frac{434}{1} \\
\text { Predicted } \\
03 / 10 / 82\end{array}$ & $\begin{array}{l}\frac{887}{\text { Decay Heat }} \\
06 / 06 / 83 \\
\end{array}$ & $\begin{array}{c}\frac{1100}{\text { Rate, }_{2} W} \\
01 / 05 / 84 \\
\end{array}$ \\
\hline B476 & 27.6 & 846 & 456 & 373 \\
\hline B471 & 27.6 & 851 & 460 & 376 \\
\hline B472 & 27.8 & 852 & 461 & 337 \\
\hline $\begin{array}{l}\text { B476 } \\
\text { B486 }\end{array}$ & $\begin{array}{l}27.6 \\
27.6\end{array}$ & $\begin{array}{l}851 \\
846\end{array}$ & $\begin{array}{l}460 \\
460\end{array}$ & $\begin{array}{l}376 \\
373\end{array}$ \\
\hline B489 & 27.8 & 852 & 454 & 377 \\
\hline$B 490$ & 27.5 & 846 & 460 & 373 \\
\hline B493 & 27.5 & 841 & 454 & 371 \\
\hline BZ701 & 27.2 & 717 & 452 & 329 \\
\hline BZ7D3 & 28.5 & 838 & 398 & 369 \\
\hline BZ704 & 28.3 & 877 & 467 & 379 \\
\hline BZ706 & 27.2 & 712 & 396 & 328 \\
\hline BZ707 & 28.3 & 877 & 467 & 379 \\
\hline B2708. & 28.5 & 838 & 452 & 369 \\
\hline BZ709 & 28.3 & 877 & 467 & 379 \\
\hline BZ710 & 28.3 & 877 & 467 & 379 \\
\hline Total & & 13,398 & 7,231 & 5,907 \\
\hline Average & 27.8 & 837 & 452 & 369 \\
\hline Std. Dev: & \pm 0.45 & \pm 50 & \pm 22 & \pm 15 \\
\hline \%SD of Avg: & \pm 1.6 & \pm 6.0 & \pm 4.9 & \pm 4.4 \\
\hline $\begin{array}{l}\text { (a) Ident } \\
\text { assem } \\
\text { assem }\end{array}$ & $\begin{array}{l}\text { ion num } \\
\text { number: }\end{array}$ & $\begin{array}{l}\text { startin } \\
\text { rting w }\end{array}$ & $\begin{array}{l}\text { th } B \text { denot } \\
B Z \text { denote }\end{array}$ & $\begin{array}{l}\text { te } 7 \times 7 \text { rod } \\
8 \times 8 \text { rod }\end{array}$ \\
\hline
\end{tabular}

based on the fact that the Wurgassen reactor went through a 100-day coastdown. This created lower steam voids in the upper region of the reactor core and resulted in higher burnups in the upper ends of the fuel assemblies. The initial axial decay heat profile did not indicate the effects of the long coastdown because higher burnup would be expected in the upper regions of the assemblies.

To provide the best-estimate axial decay heat profile required for the thermal analyses, information was obtained on the average axial burnup values 


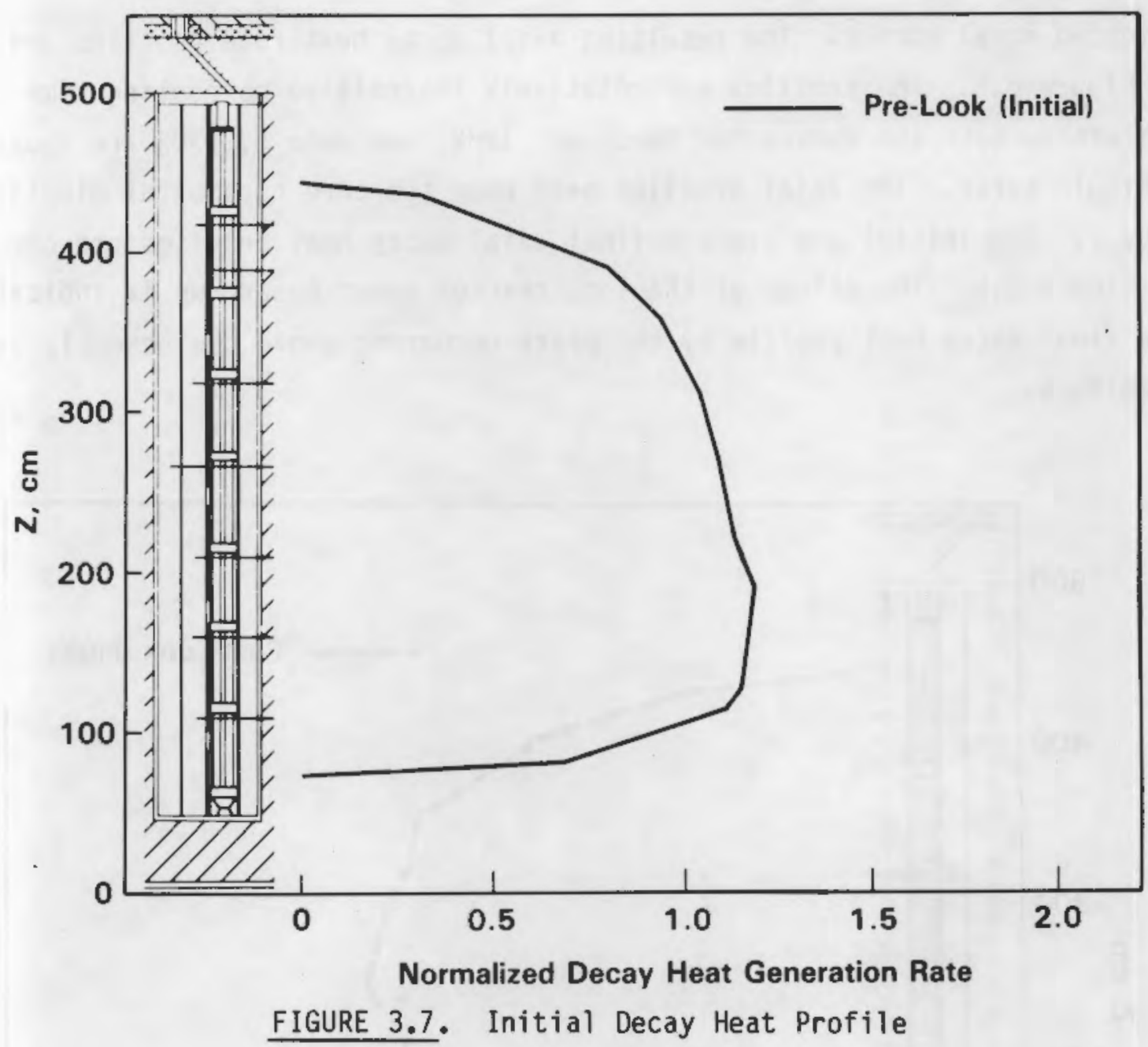

for 14 axial assembly regions (nodes) at the end of cycle 5 (EOC5). In addition, data from in-reactor gamma-ray activity measurements, which were averaged in the radial direction, were made available for the final 3 months of cycle 5.

A weighting scheme was devised, which preserved the nodal decay heat rate and satisfied the condition that the average axial burnup calculated for cycle 5 matched the profile supplied. Next, an ORIGEN2 burnup calculation using the Wurgassen power history for cycles 2 through 5 was performed over a range of specific powers bracketing the axial node burnup range. The ORIGEN2 burnup results were then decayed out to the measurement dates of March 10 , 1982, and June 6, 1983. This provided an ORIGEN2 decay heat rate for each 
weighted nodal burnup. The resulting axial decay heat rate profiles are shown in Figure 3.8. The profiles are relatively insensitive to cooling time. Therefore, both the curves for March 10, 1982, and June 5, 1983 are shown as a single curve. The axial profiles peak near the core horizontal midplane at node 7. The initial and average final axial decay heat profiles are compared in Figure 3.9. The effect of the long reactor power coastdown is indicated in the final decay heat profile by the peaks occurring above the assembly axial midplanes. ..

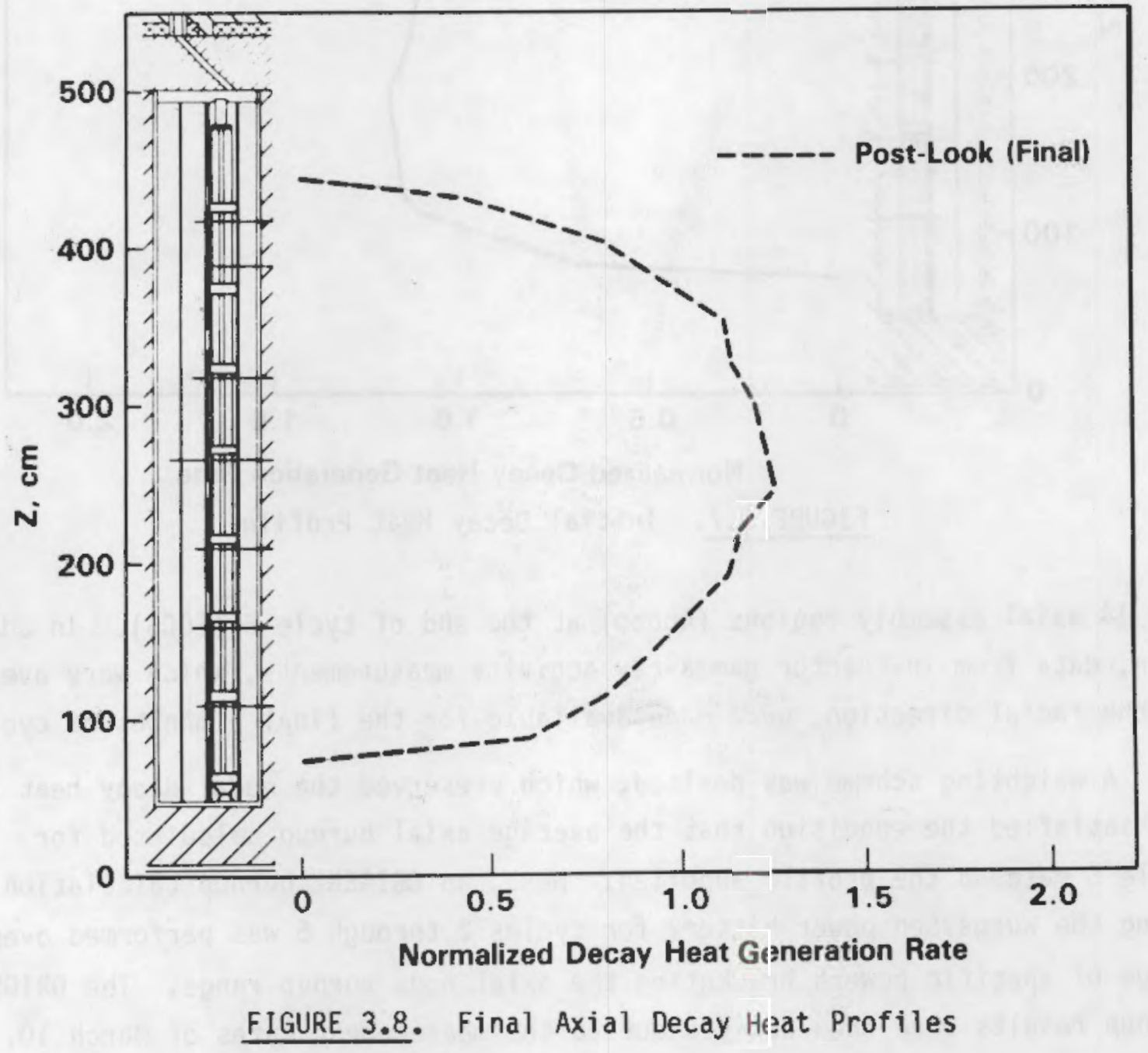




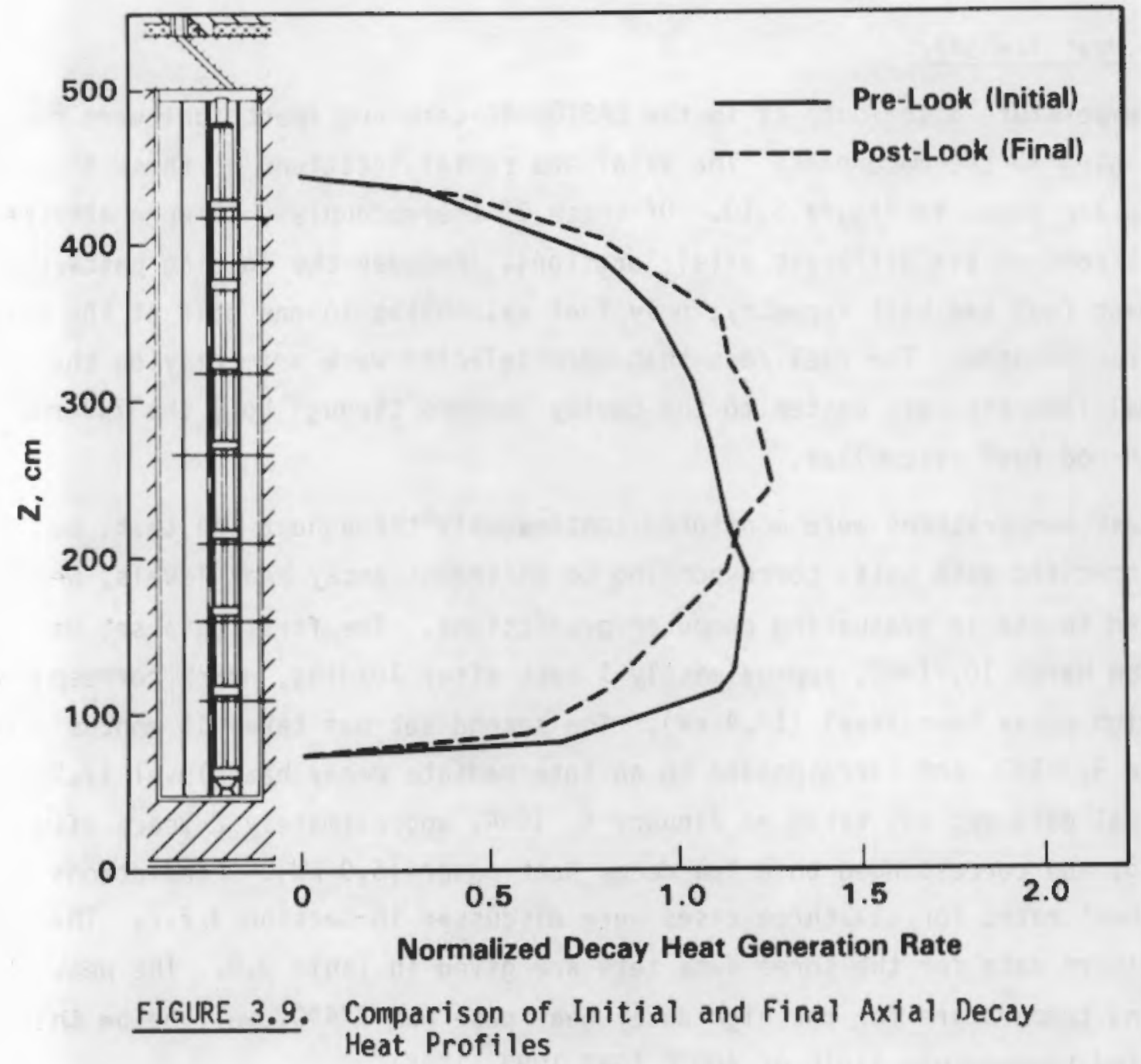

\subsection{TEST DATA}

On March 1, 1982, the CASTOR-1C cask was loaded with 16 spent fuel assemblies from the bolling water reactor of the Wurgassen power plant. Fuel assemblies chosen for the test program were typical of those with cooling times of approximately 1 year; they represented a typical loading for the CASTOR-1C cask. During the next 2-year period, measurements were taken of both the temperature distribution inside the cask and radiation dose rates on the cask surface at different spent fuel decay heat levels. The results of these measurements are described in the following paragraphs. 


\subsubsection{Heat Transfer}

Temperature distributions in the CASTOR-1C cask and spent fuel were measured using 25 thermocouples. The axial and radial locations of these thermocouples are shown in Figure 3.10. Of these 25 thermocouples, 17 were attached to fuel rods at six different axial locations. Because the loading pattern of the spent fuel had half symmetry, only fuel assemblies in one half of the cask were instrumented. The fuel rods that were selected were primarily on the diagonal from the cask center to the cavity corners through both the $7 \times 7$ rod and $8 \times 8$ rod fuel assemblies.

Cask temperatures were monitored continuously throughout the test, but three specific data sets, corresponding to different decay heat levels, were selected to use in evaluating computer predictions. The first data set was taken on March 10,1982, approximately 1 week after loading, which corresponded to a high decay heat level $(13.4 \mathrm{~kW})$. The second set was taken 15 months later on June 9, 1983, and corresponded to an intermediate decay heat level (7.2 kW). The final data set was taken on January 5, 1984, approximately 2 years after loading, and corresponded to a low decay heat power $(5.9 \mathrm{~kW})$. Predictions of decay heat rates for all three cases were discussed in Section 3.2.2. The temperature data for the three data sets are given in Table 3.6. The peak cladding temperature for the high decay heat case was $374^{\circ} \mathrm{C}$, well below the specified temperature limit of $400^{\circ} \mathrm{C}$ (GNS 1983, 1985).

To examine the trends represented by the data, axial and radial plots of the data are given in Figures 3.11 and 3.12, respectively. Figure 3.11 shows axial temperature profiles for the fuel rod having the peak measured temperature for all three decay heat levels. The fuel rod with the peak temperature for the high decay heat case $(13.4 \mathrm{~kW})$ was located in the centermost $7 \times 7$ fuel assembly, near the center of the assembly, and was instrumented with thermocouples 3 through 7 , as shown in Figure 3.10. The fuel rod with the peak temperature for the medium $(7.2 \mathrm{~kW})$ and $10 \mathrm{w}(5.9 \mathrm{~kW})$ decay heat cases was located in the centermost $8 \times 8$ fuel assembly, near the center of the assembly, and was instrumented with thermocouples 10 through 14 . Note that the peak temperatures at all three decay heat levels occurred in the elevation range of 2700 to $3100 \mathrm{~mm}$ (106 to $122 \mathrm{in.)}$. 


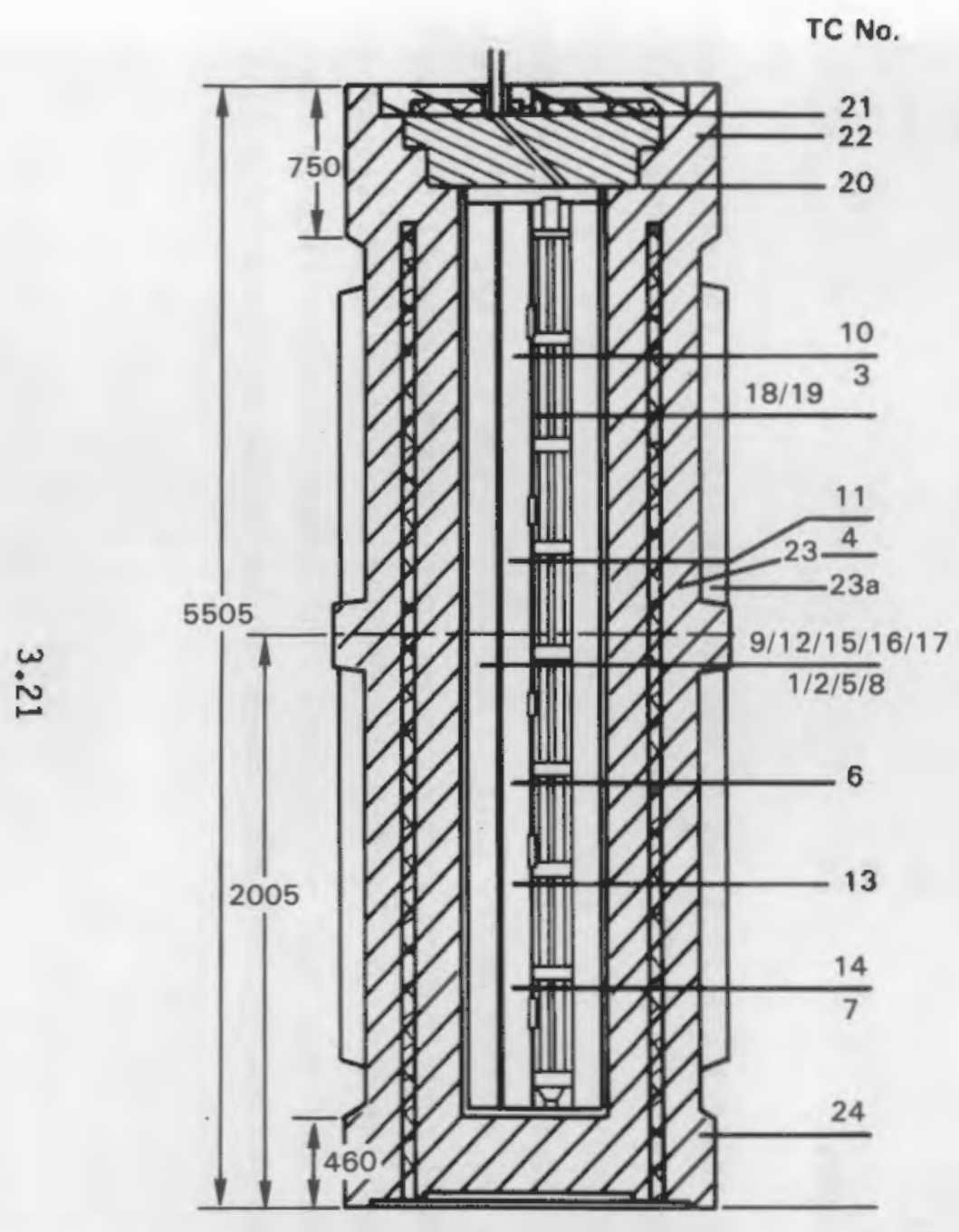

Elevation
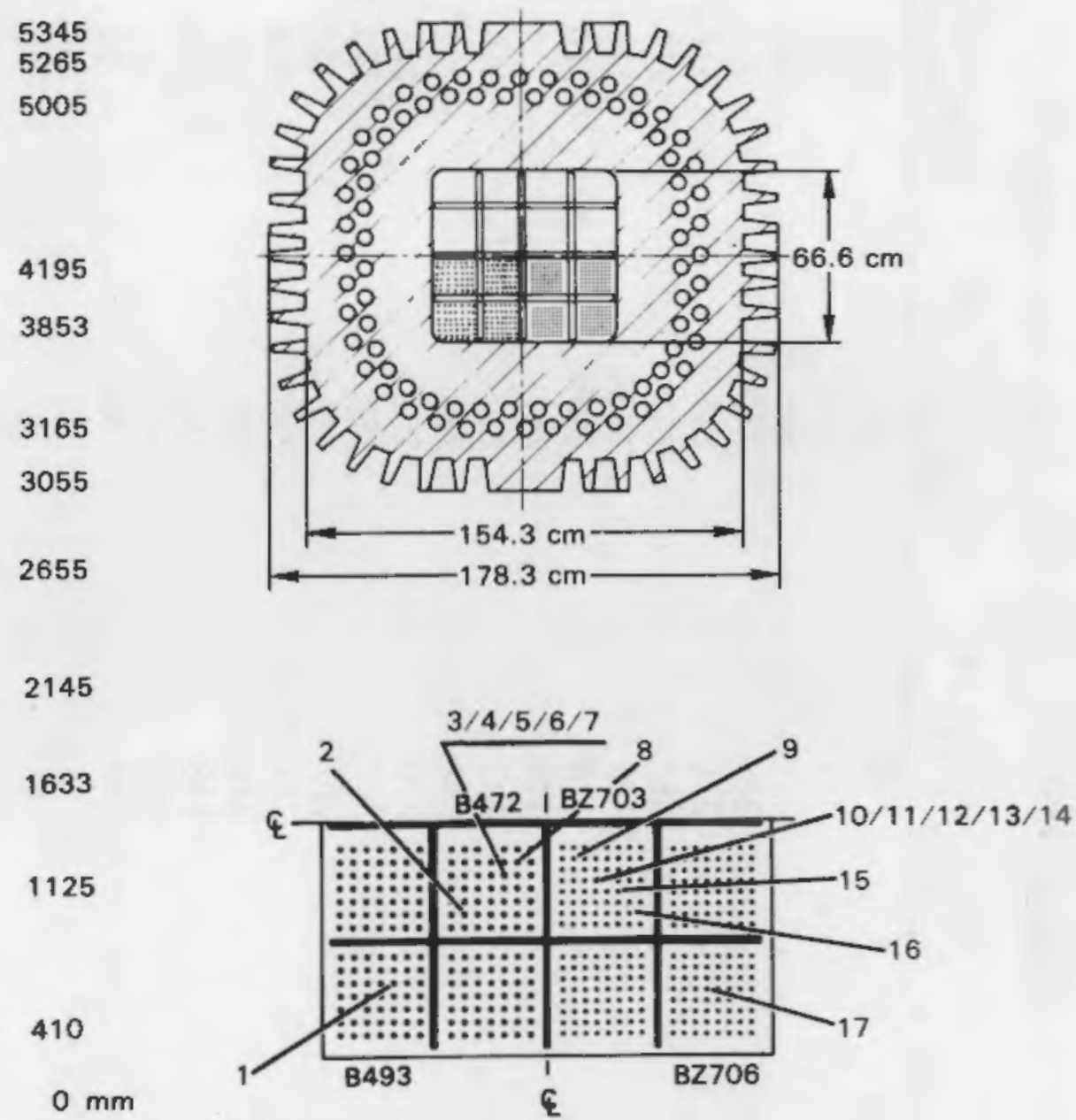

FIGURE 3.10. CASTOR-1C Cask and Spent Fuel Thermocouple Locations 
TABLE 3.6. CASTOR-1C Cask Test Temperature Data, ${ }^{\circ} \mathrm{C}$

\begin{tabular}{|c|c|c|c|}
\hline Thermocouple & $\begin{array}{c}Q_{\text {total }}=13.4 \mathrm{~kW} \\
-(03 / 10 / 82) \\
\end{array}$ & $\begin{array}{l}a_{\text {total }}=7.2 \mathrm{~kW} \\
(06 / 09 / 83)\end{array}$ & $\begin{array}{l}a_{\text {tgtal }}=5.9 \mathrm{~kW} \\
(01 / 05 / 84)\end{array}$ \\
\hline 1 & 275 & 185 & 168 \\
\hline 2 & 351 & 235 & 210 \\
\hline 3 & 325 & 235 & 210 \\
\hline 4 & 366 & 245 & 218 \\
\hline 5 & 374 & 245 & 218 \\
\hline 6 & 357 & 240 & 211 \\
\hline 7 & 186 & 125 & 116 \\
\hline 8 & 374 & 250 & 220 \\
\hline 9 & 373 & 250 & 220 \\
\hline 10 & 295 & 210 & 190 \\
\hline 11 & 368 & 255 & 221 \\
\hline 12 & 370 & 252 & 221 \\
\hline 13 & 302 & 190 & 170 \\
\hline 14 & 202 & 130 & 120 \\
\hline 15 & 361 & 240 & 214 \\
\hline 16 & 346 & 230 & 205 \\
\hline 17 & 248 & 165 & 149 \\
\hline 18 & 267 & 185 & 165 \\
\hline 19 & 72 & 55 & 55 \\
\hline 20 & 78 & 60 & 60 \\
\hline 21 & 50 & 47 & 48 \\
\hline 22 & 50 & 45 & 47 \\
\hline 23 & 59 & 48 & 48 \\
\hline $23 a$ & 56 & n.a. & n.a. \\
\hline 24 & 45 & 39 & 42 \\
\hline Room Temp. & 26 & 29 & 32 \\
\hline
\end{tabular}

Radial temperature profiles at the $2655-\mathrm{mm}$ elevation for all three decay heat levels are shown in Figure 3.12. The profiles were measured along the diagonal through the $8 \times 8$ fuel assemblies, and are represented by thermocouples $9,12,15,16,17,23$, and 23a shown in Figure 3.10. Note that temperature drops from the surface of the cask to the ambient are less than $35^{\circ} \mathrm{C}$ in all cases, a small contribution when compared to the maximum overall temperature drops through the cask of $\sim 348^{\circ} \mathrm{C}$. The primary temperature drops appear to occur in the outermost fuel assemblies. The temperature profiles in the interior assemblies, by contrast, appear to be smooth and relatively flat. 


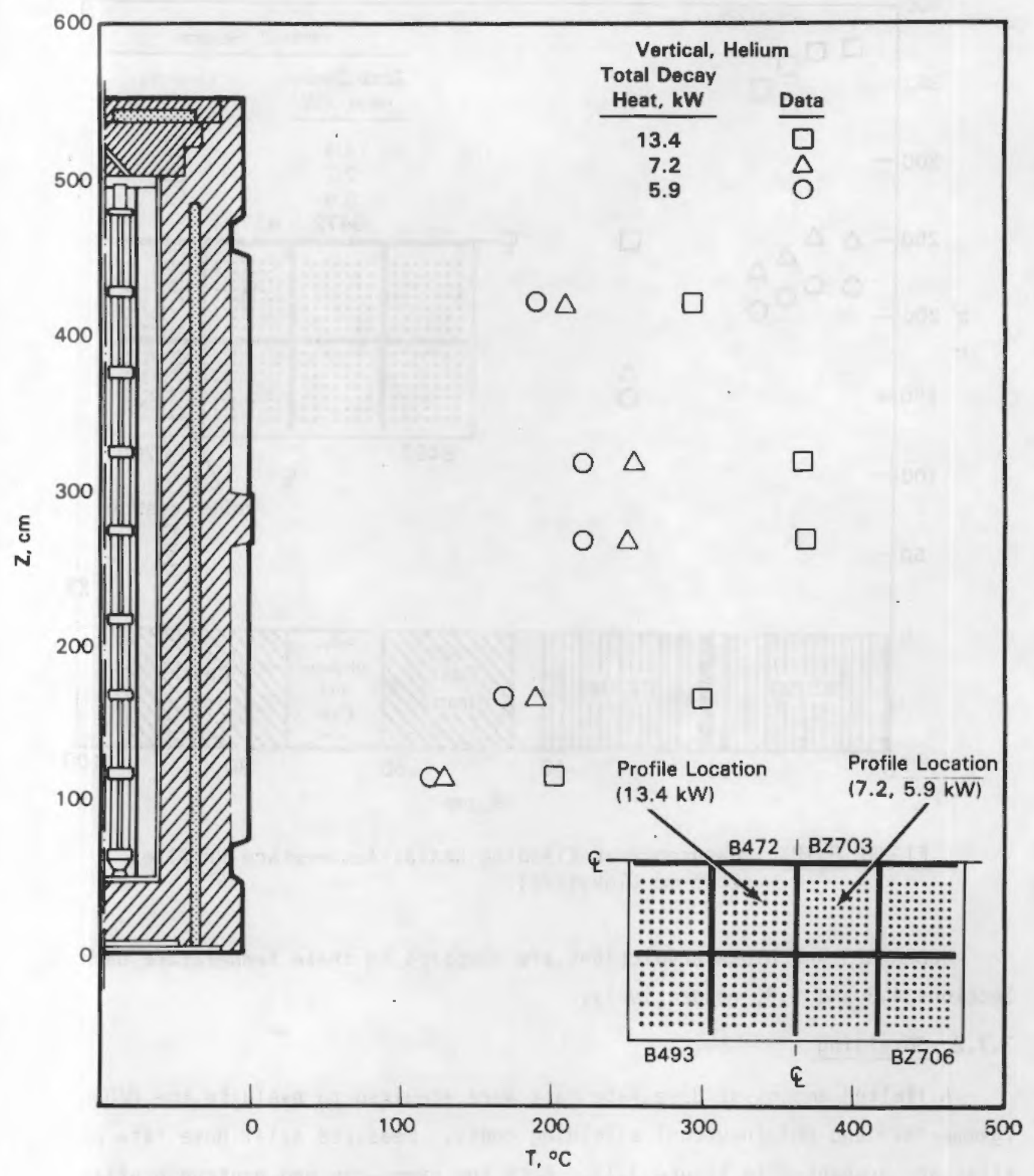

FIGURE 3.11. Measured Peak Cladding Axial Temperature Profiles 


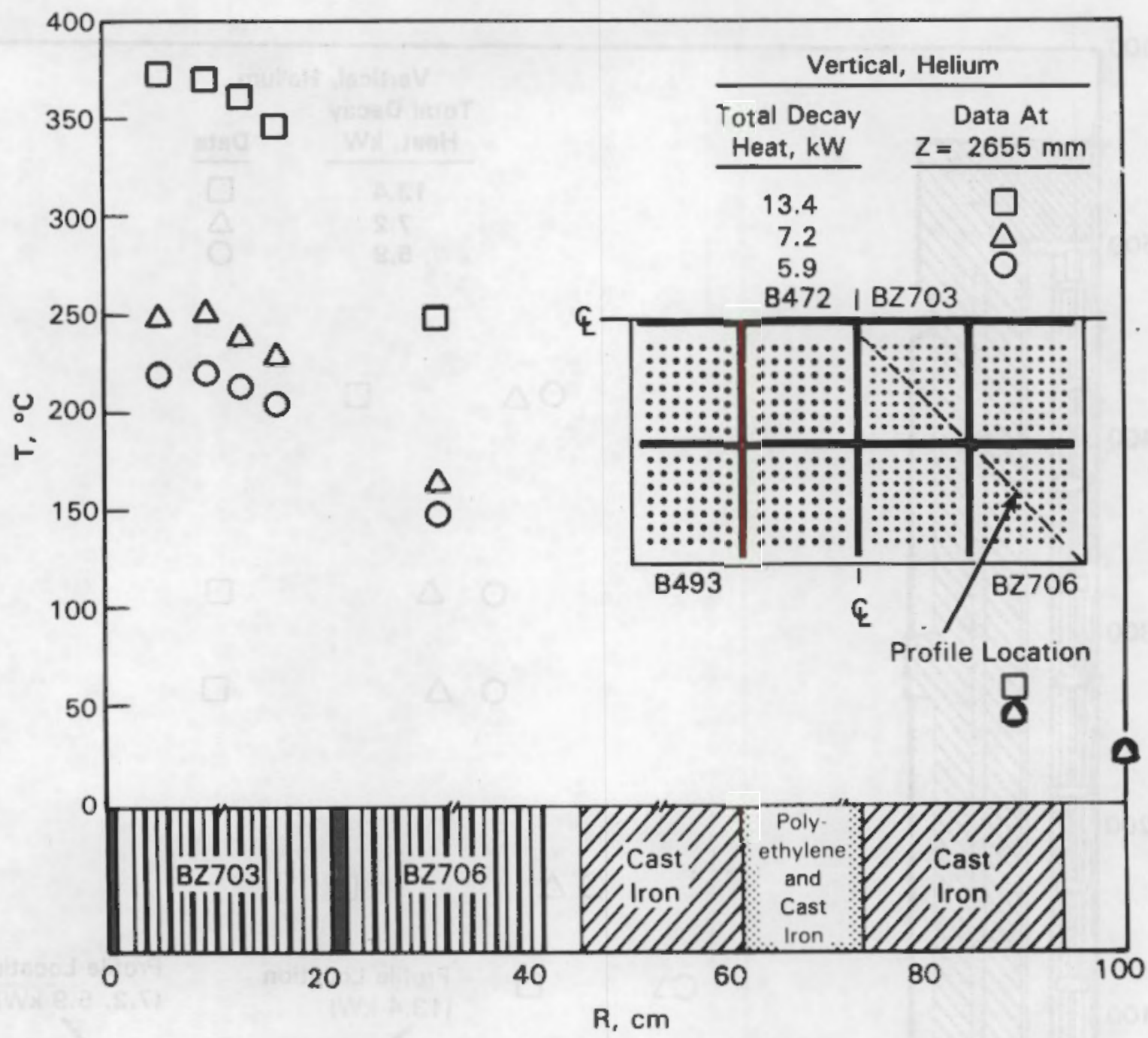

FIGURE 3.12. Measured Peak Cladding Radial Temperature Profiles (2655-nm Elevation)

COBRA-SFS and HYDRA predictions are compared to these temperature data in Sections 4.3 and 5.3 , respectively.

\subsubsection{Shielding}

A limited amount of dose rate data were acquired to evaluate the QAD (gamma-ray) and DOT (neutron) shielding codes. Measured axial dose rate profiles are presented in Figure 3.13. Both the gamma-ray and neutron profiles peak near the axial midplane of the cask $(250 \mathrm{~mm}, 98 \mathrm{in.})$. The peak dose rates are relatively low: $\sim 10 \mathrm{mrem} / \mathrm{hr}$. 


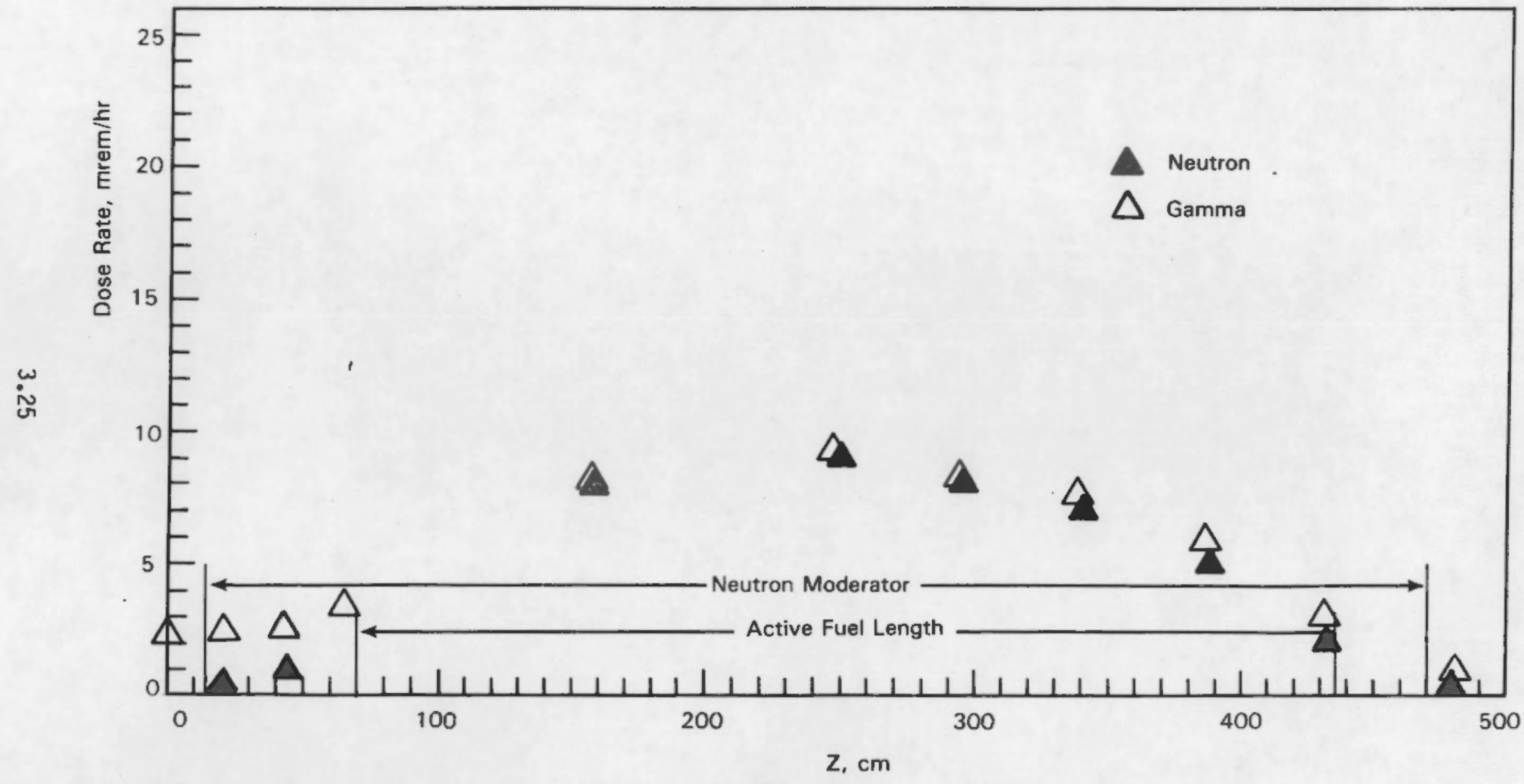

FIGURE 3.13. Measured Gamma-Ray and Neutron Dose Rates on CASTOR-1C Cask Side 


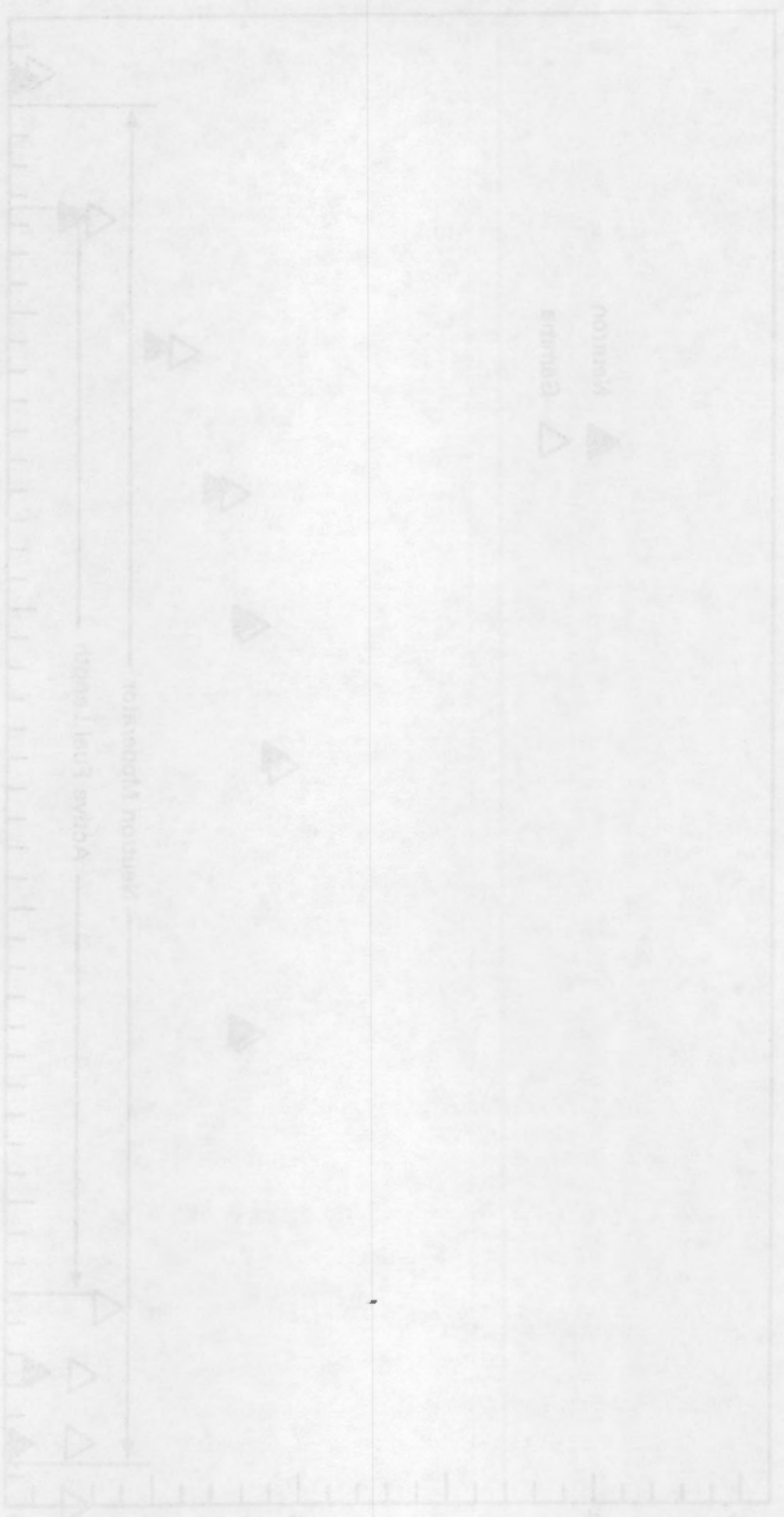

$\checkmark$
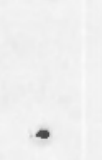


\subsection{COBRA-SFS HEAT TRANSFER ANALYSIS}

The COBRA-SFS (Spent Fuel Storage) computer code was used to predict temperature and velocity distributions in the CASTOR-1C spent fuel storage cask. Results were obtained for three different decay heat levels. In this section, a description of the COBRA-SFS code, the conservation equations, and modeling capabilities are presented, along with a comparison of COBRA-SFS predictions with test data.

\subsection{COBRA-SFS COMPUTER CODE}

The COBRA-SFS code is a steady-state, lumped finite-volume computer code that predicts flow and temperature distributions in spent fuel storage systems and fuel assemblies under mixed and/or natural convection conditions. Derived from the COBRA family of codes (Rowe 1973; Stewart et a1. 1977; George et al. 1980; Khan et al. 1981), which have been extensively evaluated against in-pile and out-of-pile data, COBRA-SFS retains all the important features of the COBRA codes and extends the range of application to problems with two-dimensional radiation and conduction heat transfer. This capability permits analyses of single- and multiassembly spent fuel storage systems with unconsolidated or consolidated fuel, with a variety of fill media (Creer 1984; Cuta, Rector, and Creer 1984; Wiles et al. 1986; Wheeler et al. 1986; Rector, Cuta, and Creer 1986).

COBRA-SFS provides finite-difference solutions to the equations governing mass, momentum, and energy conservation for incompressible flows. Analyses are conducted using a subchannel approach in which the flow areas of assemblies or storage systems are divided axially into discrete control volumes for which the conservation equations of mass, momentum, and energy are written. These equations are then solved using an iterative implicit method. The energy equations for the coolant, rod cladding, fuel, and structural members (walls) are solved simultaneously in a plane. Axial conduction in the structural members is modeled. A nonparticipating, gray body radiation heat transfer model also 
allows two-dimensional radiant heat exchange among all solid members in an enclosure and is iteratively coupled to the rod and wall energy equations.

The flow field may be either user-prescribed or internally calculated as a function of the gravitational and dynamic pressure losses. Specifications of heat losses from the boundary may vary circumferentially and axially, and can include both radiation and convection heat transfer. Axial heat transfer from the subchannel model to plenum regions (regions above and below the fuel assemblies) also can be modeled.

In the following sections, the COBRA-SFS modeling capabilities are outlined, and a brief description of the conservation equations is given.

\subsubsection{Modeling Capabilities}

COBRA-SFS allows simulations of a wide range of dry storage systems via input instructions. In addition to the multiassembly cask analysis described in this report, applications have included analyses of single-assembly spent fuel storage systems under multiple orientations and fill media (Lombardo et al. 1986) and analyses of both single- and multiassembly consolidated fuel storage systems (Creer 1984; Cuta, Rector, and Creer 1984; Wiles et al. 1986; Wheeler et al. 1986; Rector, Cuta, and Creer 1986). The code contains thermalhydraulic models for pressure drop, turbulent mixing, diversion crossflow, buoyancy-induced flow recirculation, and conduction and radiation heat transfer. A versatile fuel rod model allows simulation of consolidated fuel assemblies. The code's capabilities and limitations are outlined in Table 4.1.

\subsubsection{Conservation Equations}

The COBRA-SFS code solves the conservation equations of mass, momentum, and energy in a fuel assembly or fuel storage system using finite difference equations derived by performing suitable balances on finite control volumes. Empirical relationships are used where needed to close the set of equations.

The fluid control volume for continuity, axial momentum, and energy is characterized by a flow cross-sectional area, $A$; an axial length, $\Delta x$; and a gap width, $S$, for the connection between itself and adjacent control volumes. 


\section{TABLE 4.1. COBRA-SFS Capabilities and Limitations}

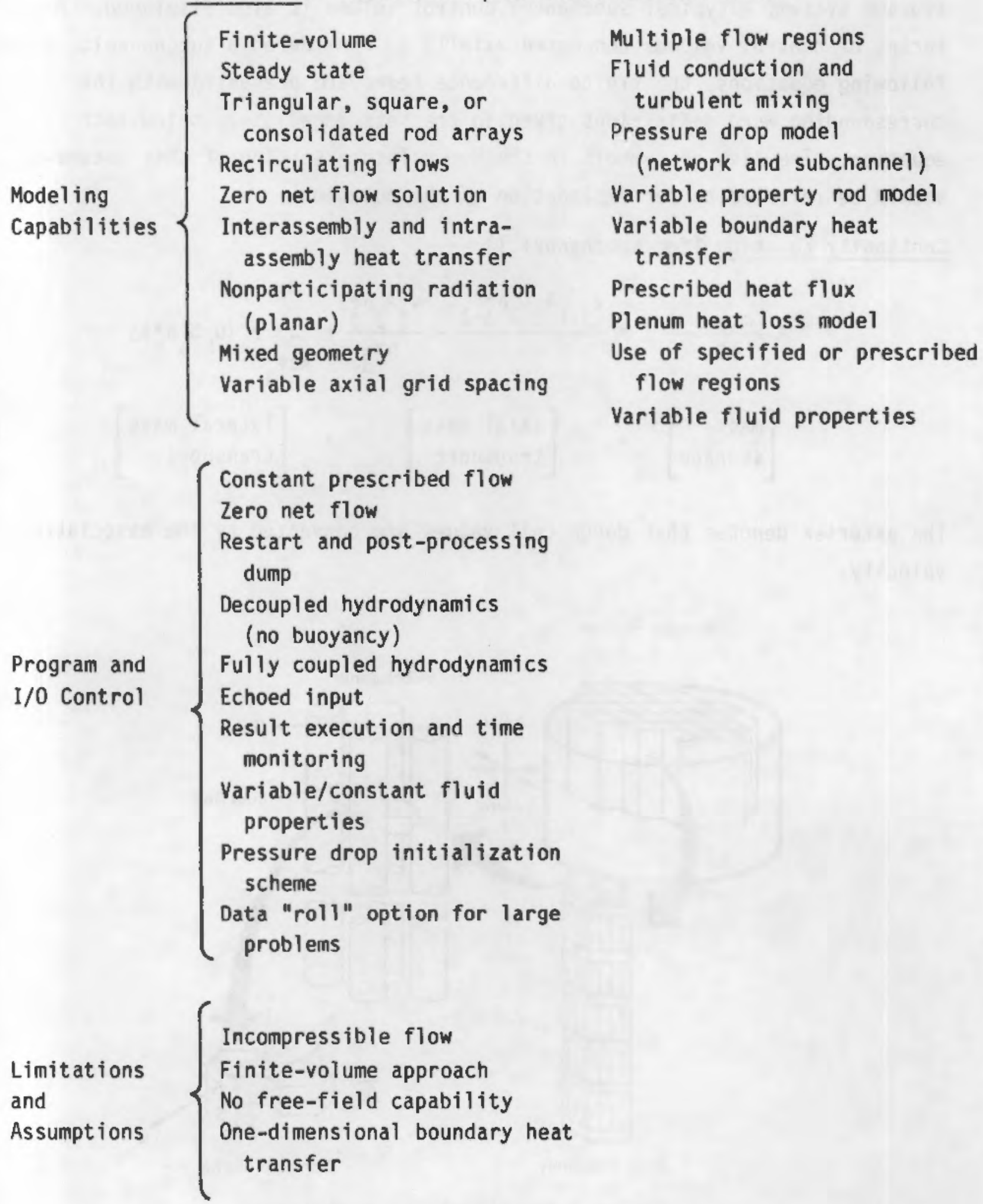


Figure 4.1 shows the relationship of a subchannel control volume to a fuel storage system; a typical subchannel control volume is also displayed. Any series of control volumes connected axially is considered a subchannel. In the following equations, the finite-difference terms are presented with the corresponding word definitions given in brackets immediately below each equation. The list of symbols in the Nomenclature section of this document should be referred to for explanation of the notation.

Continuity Equation (for subchannel i)

$$
\begin{aligned}
\bar{A} \frac{(\rho-\rho)}{\Delta t} j & =\frac{v_{j-1} A_{j-1} \rho_{j}^{*}-1}{\Delta x_{j}}-\frac{v_{j} A_{j} \rho_{j}^{*}}{\Delta x_{j}}+\sum_{k \varepsilon_{Y}{ }_{i}} e_{k}\left(u_{k} S_{k} \rho_{k}^{*}\right) j \\
{\left[\begin{array}{l}
\text { mass } \\
\text { storage }
\end{array}\right] } & =\left[\begin{array}{l}
\text { axial mass } \\
\text { transport }
\end{array}\right]+\left[\begin{array}{l}
\text { lateral mass } \\
\text { transport }
\end{array}\right]
\end{aligned}
$$

The asterisk denotes that donor cell values are convected by the associated velocity.

Storage System

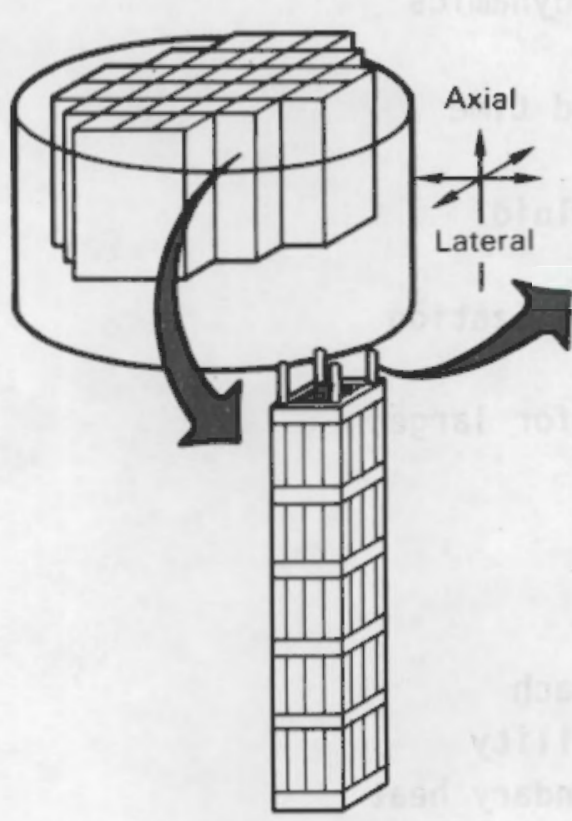

Fuel Assembly
Subchannel

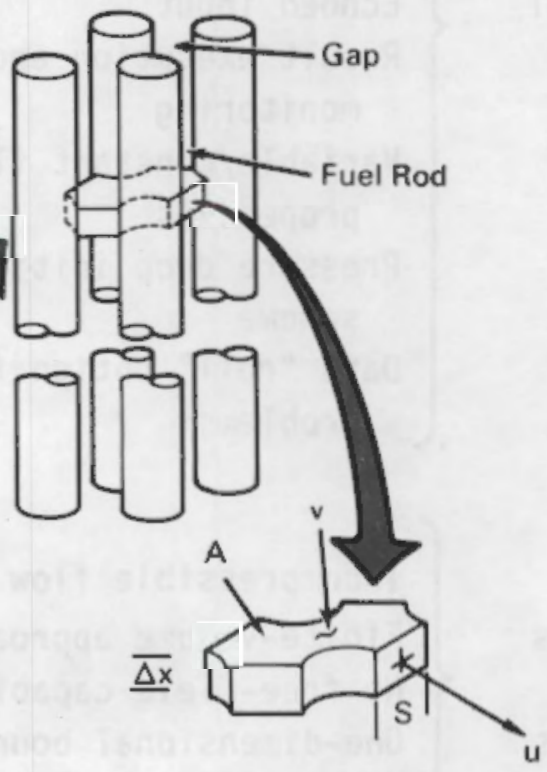

Control Volume

FIGURE 4.1. Subchannel Definition 
Fluid Energy Equation (for channel i)

$$
\begin{aligned}
& \bar{A} \frac{\left(\rho h-(\rho h)^{n}\right)}{\Delta t} j=\frac{v_{j-1} A_{j-1} \rho_{j-1}^{*} h_{j-1}^{*}}{\Delta x_{j}}-\frac{v_{j} A_{j} \rho_{j}^{*} h_{j}^{*}}{\Delta x_{j}}+\sum_{k \in \Psi} e_{j}\left(u_{k} S_{k} \rho_{k}^{*} h_{k}^{*}\right)_{j} \\
& {\left[\begin{array}{l}
\text { energy } \\
\text { storage }
\end{array}\right]=\left[\begin{array}{l}
\text { axial energy } \\
\text { transport }
\end{array}\right]+\left[\begin{array}{l}
\text { lateral energy } \\
\text { transport }
\end{array}\right]} \\
& +\sum_{n \in \lambda} \frac{A_{H T R}{ }^{H} R}{\Delta x}\left(T_{c_{n}}-T\right)+\sum_{m \varepsilon \tau_{j}} \frac{A_{H T W}{ }^{H} W}{\Delta x_{j}}\left(T_{w_{m}}-T\right) \\
& +[\text { rod heat flux }]+[\text { wall heat flux }] \\
& +\sum_{k E \psi_{i}}^{\Sigma_{j}} e_{k} S_{k} k_{k} \frac{\left(T_{I I}-T_{J J}\right)}{l_{k} Z_{k}}+\sum_{k \in \Psi_{i}} \frac{e_{k} w_{T}}{\Delta x_{j}}\left(h_{I I}-h_{J J}\right) \\
& +\left[\begin{array}{l}
\text { lateral conduction } \\
\text { heat transfer }
\end{array}\right]+\left[\begin{array}{l}
\text { turbulent energy } \\
\text { exchange }
\end{array}\right]
\end{aligned}
$$

All other forms of energy transport that are not explicitly represented in Equation (4.2) (e.g., potential and kinetic energy) have been neglected. Axial Momentum Equation (for channel i)

$$
\begin{aligned}
& \bar{A} \frac{\left(\rho v-(\rho v)^{n}\right)}{\Delta t} j=\frac{A_{j-1} v_{j-1} v_{j-1}^{*} \rho_{j-1}^{*}}{\Delta x_{j}}-\frac{A_{j} v_{j} v_{j}^{*} \rho_{j}^{*}}{\Delta x_{j}}+\sum_{k \in \psi_{j}} e_{k}\left(u_{k} S_{k} v_{k}^{*} \rho_{k}^{*}\right)_{j} \\
& {\left[\begin{array}{l}
\text { axial } \\
\text { momentum } \\
\text { storage }
\end{array}\right]=\left[\begin{array}{l}
\text { axial momenum } \\
\text { transported } \\
\text { axially }
\end{array}\right]+\left[\begin{array}{l}
\text { axial momentum } \\
\text { transported } \\
\text { laterally }
\end{array}\right]} \\
& +\bar{A}_{j} \frac{\left({ }_{j-1}-P_{j}\right)}{\Delta x_{j}} \\
& +\left[\begin{array}{l}
\text { pressure } \\
\text { gradient }
\end{array}\right]+\left[\begin{array}{l}
\text { turbulent momentum } \\
\text { exchange }
\end{array}\right] \\
& +\sum_{k \in \Psi} \frac{e_{k} w_{T}}{\Delta x}\left(v_{I I}-v_{J J}\right)
\end{aligned}
$$




$$
\begin{aligned}
& -\frac{1}{2}\left(\frac{f}{D_{h}}+\frac{C}{\Delta x_{j}}\right) \rho{ }_{j}^{*} v_{j}\left|v_{j}\right| A_{j}-\bar{A}_{j} \rho g \cos \theta \\
& -\left[\begin{array}{l}
\text { irreversible friction } \\
\text { and form losses }
\end{array}\right]-\left[\begin{array}{l}
\text { gravitational } \\
\text { head }
\end{array}\right]
\end{aligned}
$$

In the derivation of the axial momentum equation, it is assumed that all irreversible losses can be obtained by use of suitable friction factors and loss coefficients applied to the bulk velocity. Also, it is assumed that pressure changes linearly along the control volume, and the shear stress terms due to flow in the adjacent subchannels can be neglected.

\section{Transverse Momentum Equation}

The momentum control volume length, $\ell$, and gap width, $S$, define a transverse momentum control volume as shown in Figure 4.2. Inside this control volume, the transverse velocity is normal to the transverse gap; the flow is assumed to have no transverse component outside the transverse momentum control volume.

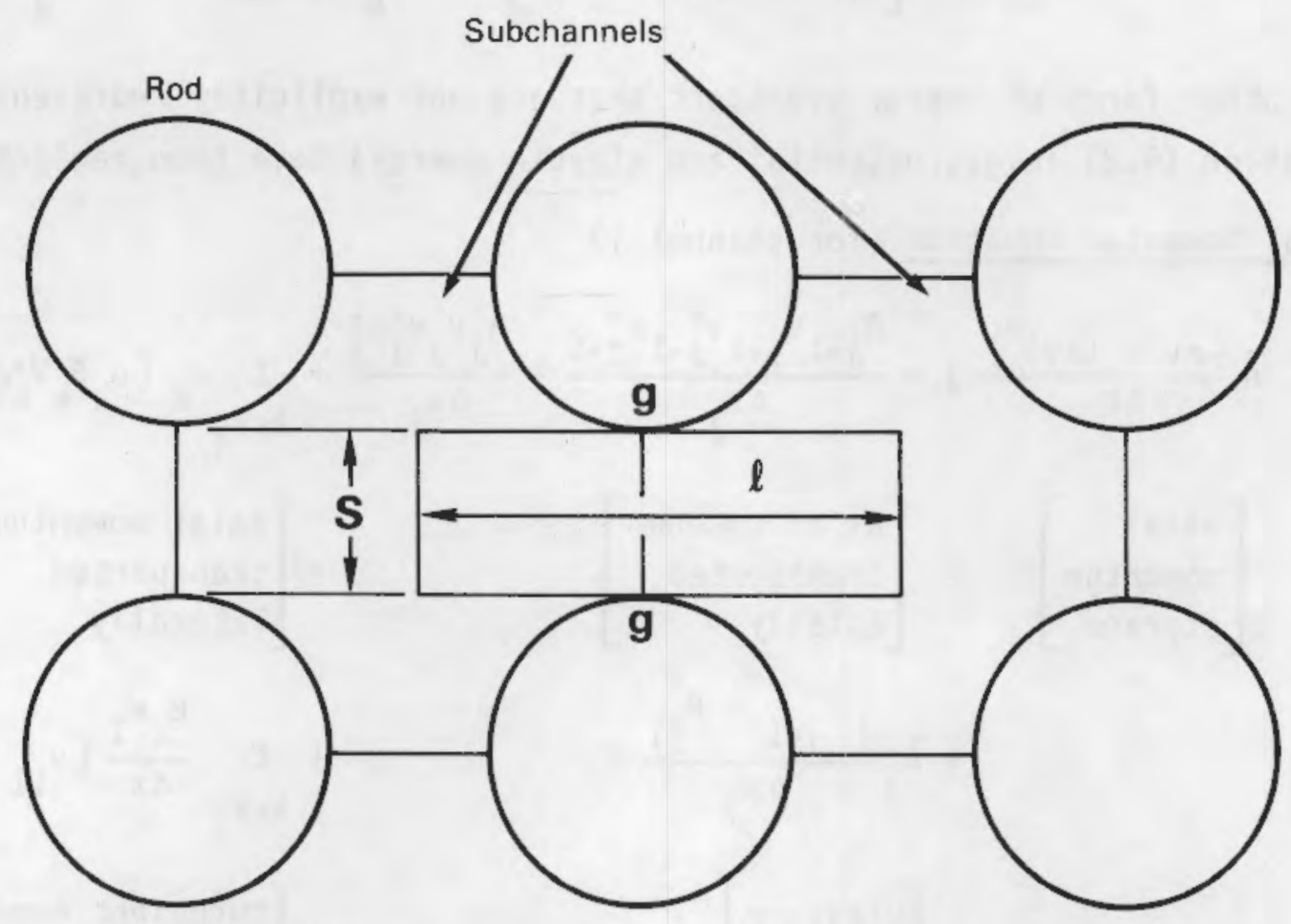

FIGURE 4.2. Transverse Momentum Control Volume 


$$
\begin{aligned}
\Delta \Delta x_{j} \frac{\left(\rho^{*} u-\left(\rho^{*} u\right)^{n}\right)}{\Delta t} j & =S_{k} v_{j-1}(\rho u)_{k, j-1}^{*}-S_{k} v_{j}(\rho u)_{k, j}^{*} \\
& =\left[\begin{array}{l}
\text { lateral } \\
\text { momentum } \\
\text { storage }
\end{array}\right] \\
& +\frac{S_{k} \Delta x_{j}}{t_{k}}\left(p_{I I}-P_{j J}\right)_{j-1}-C_{T} u_{k} u_{k} \frac{\rho S \Delta x_{j}}{\mathbf{u}_{k}} \\
& +[\text { pressure gradient }]-\left[\begin{array}{l}
\text { irreversible formentum } \\
\text { and friction loss }
\end{array}\right]
\end{aligned}
$$

A further assumption in the transverse momentum equation is that there are no applied body forces in the transverse direction.

Fuel Rod and Cladding Energy Equations

By assuming that 1) there is no heat transfer axially, 2) the heat is generated uniformly throughout the fuel at a given axial location, and 3) the fuel properties do not vary with the radial variation in temperature, the cladding temperature is obtained by performing a lumped energy balance on the cladding material at each axial level. The finite-difference form of the equation used is presented in Equation (4.5).

$$
\begin{aligned}
& y_{c}{ }^{p} c^{c} c \frac{T_{c}-T_{c}{ }^{n}}{\Delta t}=H_{R} \sum_{i \in \gamma_{i}} \phi_{i}\left(T_{c}-T\right)+H_{g} \frac{R_{f}}{R_{c}}\left(T_{f s}-T_{c}\right) \\
& {\left[\begin{array}{l}
\text { energy } \\
\text { storage }
\end{array}\right]=\left[\begin{array}{l}
\text { convection } \\
\text { transfer } \\
\text { to fluid }
\end{array}\right]+\left[\begin{array}{l}
\text { heat transfer } \\
\text { from fuel }
\end{array}\right]} \\
& +\sigma \sum_{n \in \zeta_{n}} F_{i n}\left(T_{c}^{4}-T_{c_{n}}{ }^{4}\right)+\sigma \sum_{m \in B} F_{m}\left(T_{c}{ }^{4}-T_{W_{n}}{ }^{4}\right) \\
& +\left[\begin{array}{l}
\text { radiation } \\
\text { heat transfer } \\
\text { from rods }
\end{array}\right]+\left[\begin{array}{l}
\text { radiation } \\
\text { heat transfer } \\
\text { from walls }
\end{array}\right]
\end{aligned}
$$


In Equation (4.5), it is assumed that the temperature is uniform around the circumference of the cladding. The film coefficient, $H_{R}$, is given by userspecified correlations, and the gap conductance between fuel pellet and cladding, $H_{g}$, is assumed constant. $F_{i n}$ and $F_{i m}$ are gray body radiation exchange factors that account for multiple reflections within an enclosure. $F_{\text {in }}$ is a coefficient for rod-to-rod heat transfer, while $F_{i m}$ is a coefficient for rodto-wall heat transfer. Both are derived by assuming constant surface emissivity. The gray body exchange factors can be user-prescribed or calculated. internally by specifying black body view factors and surface emissivity values. Energy Equations

$$
\begin{aligned}
& \rho_{w} c_{w}^{t} \frac{\left({ }_{w}-T_{w}^{n}\right)}{\Delta t}=\sum_{i \in \xi_{i}} U\left(T-T_{w}\right)+\sigma \sum_{m \in \sigma_{m}} F_{i m}\left(T_{w}^{4}-T_{w}{ }^{4}\right) \\
& {\left[\begin{array}{l}
\text { energy } \\
\text { storage }
\end{array}\right]=\left[\begin{array}{l}
\text { heat transfer } \\
\text { from adjacent } \\
\text { chanels }
\end{array}\right]+\left[\begin{array}{l}
\text { radiation heat transfer } \\
\text { from walls }
\end{array}\right]} \\
& +\sigma \sum_{n \in K_{n}} F_{i n}\left(T_{w}^{4}-T_{c_{n}}^{4}\right)+q^{\prime \prime} \\
& {\left[\begin{array}{l}
\text { radiation heat transfer } \\
\text { from rods }
\end{array}\right]+\left[\begin{array}{l}
\text { heat } \\
\text { generation }
\end{array}\right]} \\
& +U_{j-1}\left(T_{w}-T_{w j-1}\right)-U_{j}\left(T_{w}-T_{w_{j+1}}\right)+\sum_{m \varepsilon \alpha_{m}} U\left(T_{w}-T_{w_{m}}\right) \\
& +\left[\begin{array}{l}
\text { axial conduction } \\
\text { heat transfer }
\end{array}\right] \quad+\left[\begin{array}{l}
\text { heat transfer from } \\
\text { adjacent walls }
\end{array}\right]
\end{aligned}
$$

As before, $F_{i m}$ and $F_{i n}$ are the gray body exchange factors from wall node $i$ to wall node $m$ and rod node $n$, respectively. Axial heat transfer from the walls to a plenum region can be included at the end axial levels. 


\subsection{COBRA-SFS MOOELS AND INPUT}

A three-dimensional, half-symmetry model of the CASTOR-1C cask was used for the COBRA-SFS analysis. A half-symmetry model was dictated by the arrangement of $7 \times 7$ and $B \times 8$ rod BWR fuel assemblies and by the radial decay heat distribution. This model, the boundary specifications, and properties used, are described in detail below.

\subsubsection{Cask Body}

A radial cross section of the computational cell arrangement used to represent the cask body is presented in Figure 4.3. A total of 136 wall nodes at each axial level are used to model the heat transfer through the cask body. Of these, 40 are zero-thickness nodes that represent the temperatures on the outside and inside surfaces of the cask body. These surface nodes are necessary to accurately calculate the radiation heat transfer at the cask surfaces. Surface fin models are described in Section 4.2 .3 , which is devoted to boundary specifications.

Wall conduction heat transfer in the radial, circumferential, and axial directions is modeled by specifying the appropriate thermal resistance terms between adjacent nodes. The input thermal resistance values may reflect a composite of materials and parallel and/or series heat transfer paths. For example, wall nodes containing both polyethylene neutron absorber rods and cast iron are modeled using a composite conductivity.

\subsubsection{Cask Basket and Fuel Assemblies}

A radial cross section of the computational cell arrangement used to represent the cask basket and fuel assemblies is presented in Figure 4.4. The stainless steel basket is represented by 34 wall nodes at each axial level. The BWR fuel assemblies are modeled using a detailed rod and subchannel nodalization. A typical $7 \times 7$ rod assembly is modeled using 49 rods and 60 fluid subchannels. A typical $8 \times 8$ rod assembly is modeled using 64 rods and 77 fluid subchannels. The resulting half-symmetry cask model consists of a total of 170 wall, 452 rod, and 548 subchannel nodes at each axial level. The basket and fuel assembly region of the cask is modeled using 18 uniform axial nodes. 


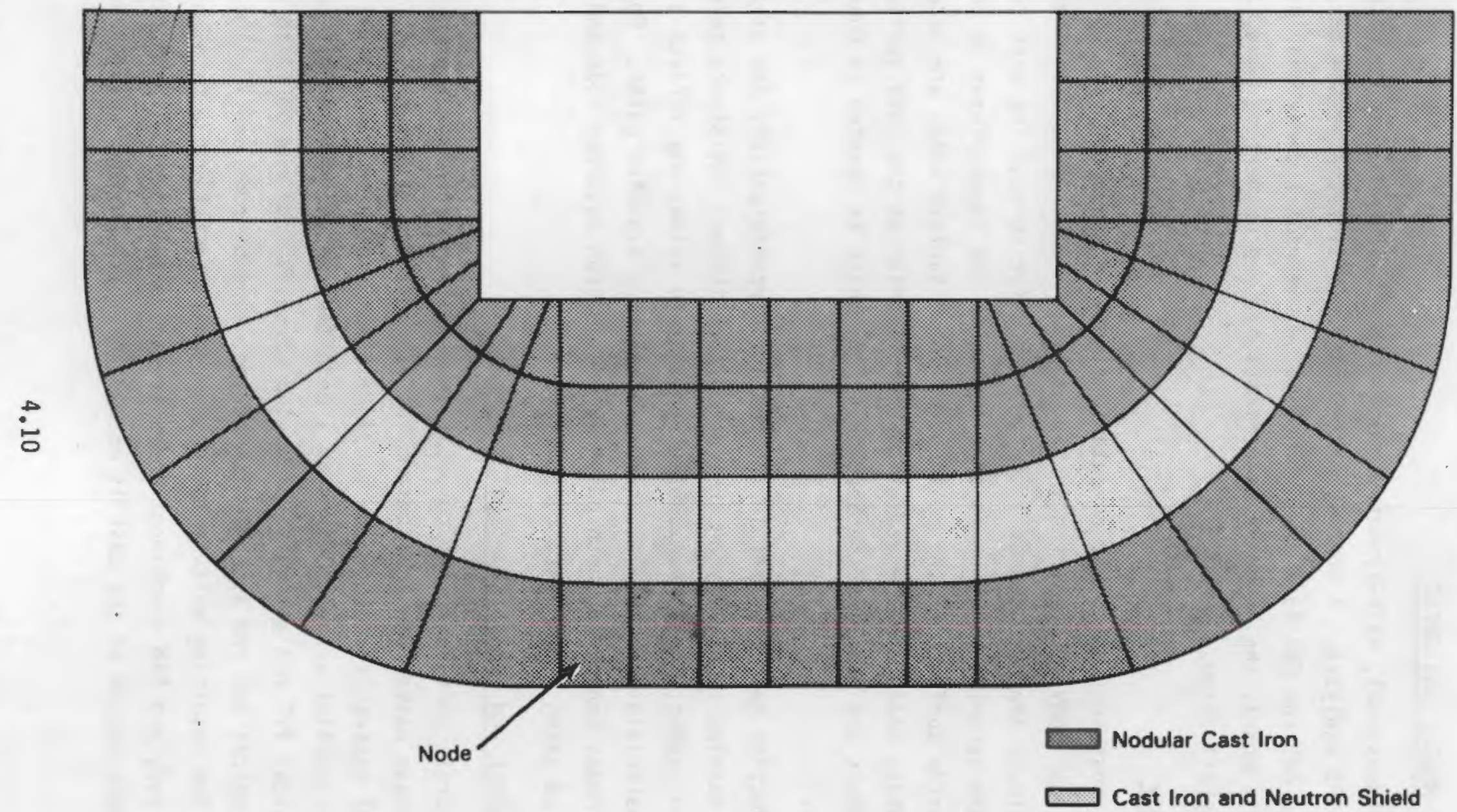

FIGURE 4.3. COBRA-SFS One-Half Symmetry Model of CASTOR-1C Cask Body 


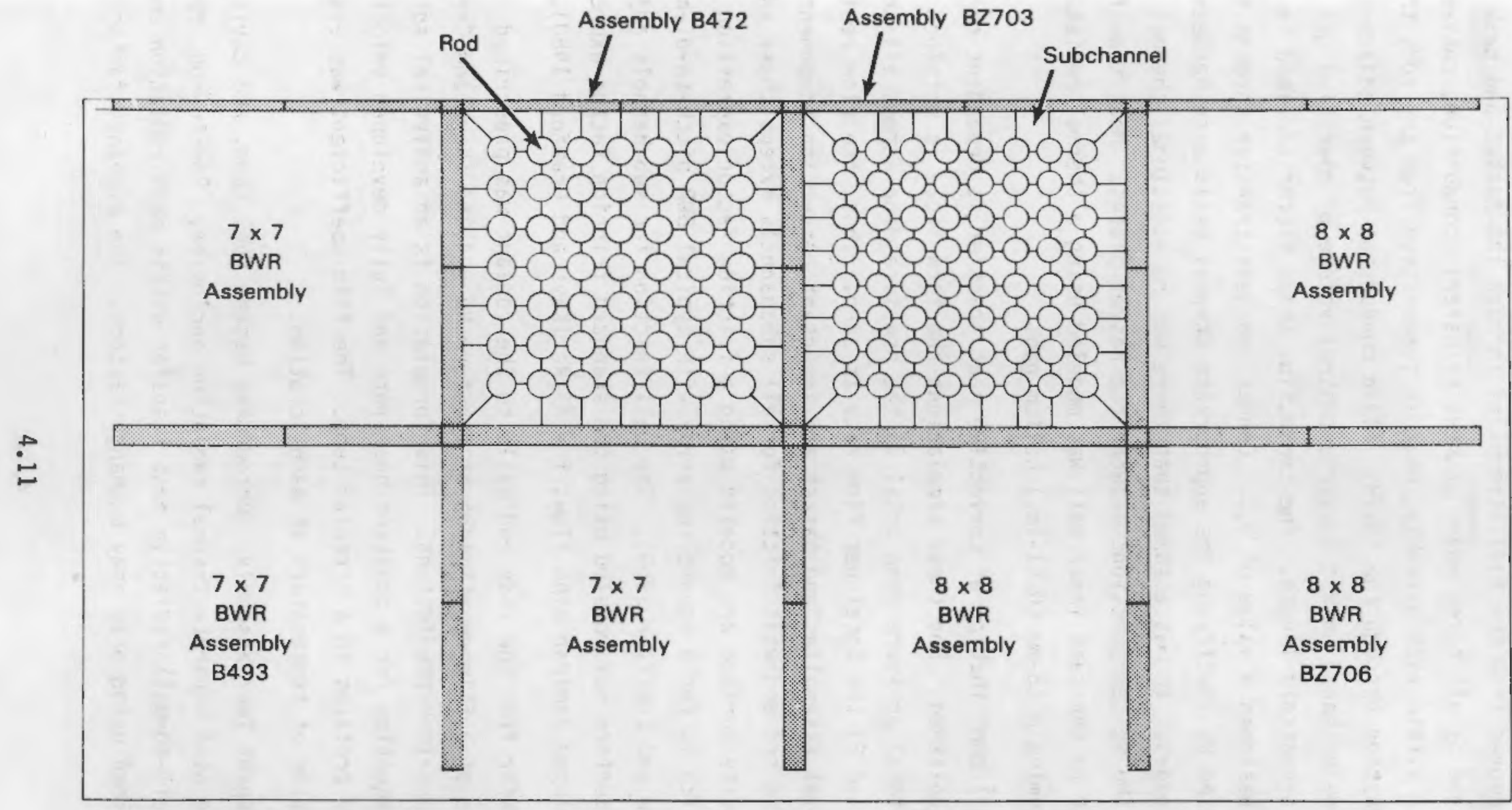

Borated Stainless Steel

FIGURE 4.4. COBRA-SFS One-Half Symmetry Model of the CASTOR-IC Cask Basket and Spent Fuel Assemblies 
Heat is removed from the fuel assemblies through the basket and cask body to the atmosphere by all three modes of heat transfer: conduction, convection, and radiation. Within each assembly, heat is transmitted from the rods to the basket by conduction through the fluid. Fluid conduction between adjacent subchannels is modeled hased on a transverse control volume of specified gap width and centroid-to-centroid length. The conduction shape factor (defined in Section 4.1) was assigned a value of 1.0. Conduction heat transfer through the basket is modeled by specifying the appropriate thermal resistance between adjacent wall nodes. It was assumed that there was no additional thermal resistance at the welded junctions between the basket plates. Heat transfer from the basket to the cask inner wall was modeled using a thermal resistance derived by assuming a 13-mm (0.51-in.) helium gap.

The overall contribution of convective heat transfer is dependent on the flow field established. For these simulations the flow field is obtained by adjusting the total pressure drop until 1) the pressure drop across all channels is equal and 2) the total net flow rate is zero. Thus, the flow resistance of the fuel assemblies and basket are important convection component parameters. The rod and wall friction for all subchannels except those adjacent to the cavity surface are modeled using a friction factor expression of $f=100 / R e$, which is for a square rod array with typical BWR pitch-to-diameter ratios (Sparrow and Loeffler 1959). The wall friction for subchannels adjacent to the cavity surface was modeled using the standard friction factor expression for fully developed laminar pipe flow; $f=64 / \operatorname{Re}$ (Kays and Crawford 1980).

Heat transfer from the rods and walls to the coolant was prescribed through the use of a film coefficient of the form $\mathrm{Nu}=4.364$ (Kays and Crawford 1980) for the pre-look predictions. This formulation is an analytical solution of the energy equation for a constant heat rate and fully developed velocity and temperature profiles in a circular tube. The film coefficient was evaluated as a function of temperature at each location.

Each BWR spent fuel assembly, surrounding basket fuel tube, and cavity wall is treated as a separate thermal radiation enclosure. Rod-to-rod, rodto-wall, and wall-to-wall radiative heat transfer within each radiation enclosure is prescribed using gray body exchange factors. The exchange factors for 
each BWR spent fuel assembly are derived using geometric view factors for onequarter pin surface segments. This subdivision of the fuel rod surface, when determining view factors, has previously been shown to he adequate in determining the proper radiative heat transfer from a rod bundle (Cox 1977).

\subsubsection{Roundary Specifications}

The computational noding model described earlier extends radially outward to the cask surface. Within this model the wall and fluid energy equations are solved simultaneously. Boundary conditions are provided to the model by specifying heat transfer coefficients that describe the heat transport from the cask surface to the ambient air. The two coefficients of interest are 1) heat transfer from the cask barrel to the ambient and 2) heat transfer from the cask ends to the ambient.

The outside surface geometry of the cask varies as a function of axial level. In the axial region of the fuel assemblies, a set of 48 axial cooling fins is provided to assist in removing heat by natural convection. The amount of heat being removed by natural convection from a finned surface is calculated using the Nusselt number expression (Chaddock 1970)

$$
N u=0.112(R a \cdot b / L)^{0.534}\left[1-e^{-129 /(R a \cdot b / L)}\right]^{0.284}
$$

where $\mathrm{Ra}$ is the Rayleigh number, $\mathrm{b}$ is the distance hetween vertical fins, and $\mathrm{L}$ is the total vertical length of the fin.

Heat is removed from the fins by thermal radiation also. The amount of heat removed is calculated using a composite gray body exchange factor. This factor is calculated using Hottel's method (Cox 1977) and is hased on the surface emissivities and the black body view factors between the cask and fin surfaces and ambient air. The ambient air was assumed to be a black body surface at a temperature of $26.7^{\circ} \mathrm{C}\left(80^{\circ} \mathrm{F}\right)$ in the pre-look analysis.

Near the top and bottom of the cask, the outer surface of the cask is essentially a smooth cylinder. The amount of heat removed by natural convection is calculated using the Nusselt number expression for vertical cylinders in air at $1 \mathrm{~atm}$ (Lindeburge 1981): 


$$
\mathrm{Nu}=0.13(\mathrm{GrPr})^{0.33}
$$

The top of the cask is represented by a horizontal flat plate. The Nusselt number expression for this geometry in air at 1 atm (Lindeburge 1981) is

$$
\mathrm{Nu}=0.14(\mathrm{GrPr})^{0.33}
$$

The radiation heat transfer from the top and smooth side surfaces is derived from the expression for heat transfer between parallel plates and the cask. As before, the ambient air is assumed to he a black body at a temperature of $26.7^{\circ} \mathrm{C}\left(80^{\circ} \mathrm{F}\right)$ for the pre-look analysis.

The hottom of the CASTOR-1C cask rested on a supporting surface. Because the surface temperature and contact resistance were unknown, the bottom surface of the cask was conservatively assumed to be an adiabatic boundary.

The heat transfer correlations used are summarized in Table 4.2.

\subsubsection{Material Properties}

The material properties used to develop the CASTOR-1C model are presented in Table 4.3. Most of these properties were obtained from GNS (GNS 1983). Constant thermal conductivities are specified for cast iron and the polyethylene neutron moderator. However, the thermal conductivity for the fuel basket is specified as a function of temperature. As stated earlier, the thermal conductivities are not used in the COBRA-SFS code directly, but are used to determine the resistance coefficient between adjacent wall nodes. A

\begin{tabular}{|c|c|c|}
\hline Type & Region & Natural Convective Component \\
\hline Radial & Fins & $N u=0.112\left(R a \cdot b / L^{0.534}\left[1-e^{-129 /(R a \cdot b / L)}\right]^{0.284}\right.$ \\
\hline Radial & Smooth & $\mathrm{Nu}=0.13(\mathrm{GrPr})^{0.33}$ \\
\hline Axial & Top & $\mathrm{Nu}=0.14(\mathrm{GrPr})^{0.33}$ \\
\hline Axial & Bottom & Adiabatic \\
\hline
\end{tabular}

\section{TABLE 4.2. Boundary Heat Transfer Correlations}


TABLE 4.3. Material Properties and Surface Emissivities

Thermal Conductivities

Nodular cast iron $=0.35 \mathrm{~W} / \mathrm{cmK}$

Neutron moderator $=0.15 \times 10^{-2} \mathrm{~W} / \mathrm{cmK}$

Fuel basket $=\left(9.503+1.445 \times 10^{-2} \mathrm{~T}-4.989 \times 10^{-2} \mathrm{~T}^{2}+3.33 \times 10^{-9} \mathrm{~T}^{3}\right) 10^{-2} \mathrm{~W} / \mathrm{cmK}$ where $\mathrm{T}$ is temperature in ${ }^{\circ} \mathrm{K}$

Surface Emissivities

Fuel rods $=0.8$

Fuel basket $=0.4$

Nickel-plated surfaces $=0.25$

Painted fins $=0.93$ (Measured)

preliminary CASTOR-1C simulation was performed using an average value for the thermal conductivity to estimate specific temperatures to evaluate the thermal conductivity for each connection.

A list of surface emissivities is provided in Table 4.3. The nickelplated surfaces correspond to both the inside surface of the cavity and the outside surface of the cask above and below the fin region.

\subsubsection{Modeling Uncertainties}

In the design information used to develop the CASTOR-1C cask model, a number of uncertainties exist, affecting the ability to accurately predict the cask thermal performance. The following parameters introduce uncertainties into the analysis:

- The basket-to-cask wall gap is assumed to be a nominal $13 \mathrm{~mm}$ $(0.51 \mathrm{in.})$. No effort has been made to account for thermal expansion or eccentric positioning of the basket within the cavity.

- The fuel assemblies are assumed to be perfectly vertical and positioned in the center of each basket fuel tube. In reality, the fuel assemblies will probably lean against the side of the fuel tube for support. The resulting eccentricity affects the heat transfer from the assembly to the basket.

- Natural convection heat transfer from the outside surface of the cask is difficult to predict accurately. The correlation selected is 
based on vertical rectangular fins extending from a flat surface in a static environment, which may not accurately model the physical system.

- The hottom surface of the cask is assumed to he adiabatic. In reality, there will be heat transfer to the supporting concrete surface, which depends on the contact resistance between the surfaces.

\subsection{COBRA-SFS SIMULATIONS COMPARED TO DATA}

The COBRA-SFS computer code was used to predict the temperature and velocity distributions in the CASTOR-1C cask using the three-dimensional model described in Section 4.2. Two sets of simulations were performed. A set of pre-look simulations, which were performed without any prior knowledge of the data, were compared to the measured data. Following the comparison, improvements in the computational model were recommended and a set of post-test simulations was made. An assessment of the COBRA-SFS predictive capabilities is given based on the comparison of pre-look and post-test results with measured test data. An outline of the evaluation procedure follows.

To properly evaluate code predictions, several comparisons of code predictions to data must be made. The most obvious comparison is of peak cladding temperatures. However, comparisons of temperature differences between components in the cask and comparisons of axial temperature profiles are needed to thoroughly evaluate the cask model. Pre-look comparisons of peak cladding temperatures may be used to assess the predictive capabilities of the code. However, the pre-look comparisons are directly affected by the accuracy, reliability, and completeness of the cask input description as well as test data.

\subsubsection{Pre-Look Simulations}

Three pre-look simulations were made, each corresponding to a different total decay heat level. To perform pre-look predictions, cask internal pressure, cask loading pattern, assembly decay heat generation rates, and ambient temperatures were supplied for each run. The axial power profile was the burnup curve shown in Figure 3.7 , because it was assumed that it was calculated 
from in-reactor activity scans. The ambient temperatures for the three cases were not known initially, so a temperature of $80^{\circ}\left(27^{\circ} \mathrm{C}\right)$ was assumed.

The most obvious indicator of how well the COBRA-SFS code predicts the thermal performance of the cask is the comparison of peak cladding temperatures. However, because ambient temperatures used in the simulations are not equal to the measured values, it is more appropriate to compare total, temperature drop from the peak cladding to the ambient. Both peak cladding temperature and total temperature drop comparisons for all three cases are presented in Table 4.4 .

Predicted total temperature differences compare very closely to test data, falling within $2 \%$ in all three cases. Despite the excellent agreement between total temperature differences, it will be shown later that there are differences between predicted and measured temperature drops in specific regions of the cask.

Comparisons of predicted axial temperature profiles to test data for all three decay heat loads are shown in Figure 4.5. As stated previously, predicted peak cladding temperatures compare favorably with measured test data. However, temperatures near the lower end of the axial profile are overpredicted. For example, the temperature of the lowest measured position on the peak rod is overpredicted by approximately $50^{\circ} \mathrm{C}$ in the high decay heat case. In addition, temperatures in the upper region appear to be slightly underpredicted. For example, the temperature at the highest measured position on the peak rod is underpredicted by approximately $10^{\circ} \mathrm{C}$ in the low decay heat case.

\section{TABLE 4.4. COBRA-SFS Pre-Look Peak Cladding Temperature Predictions Compared to Data}

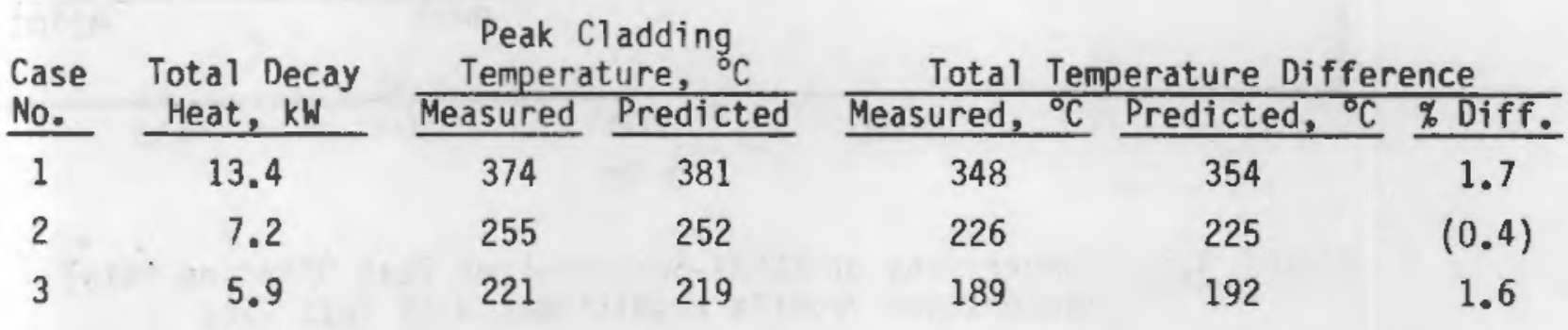




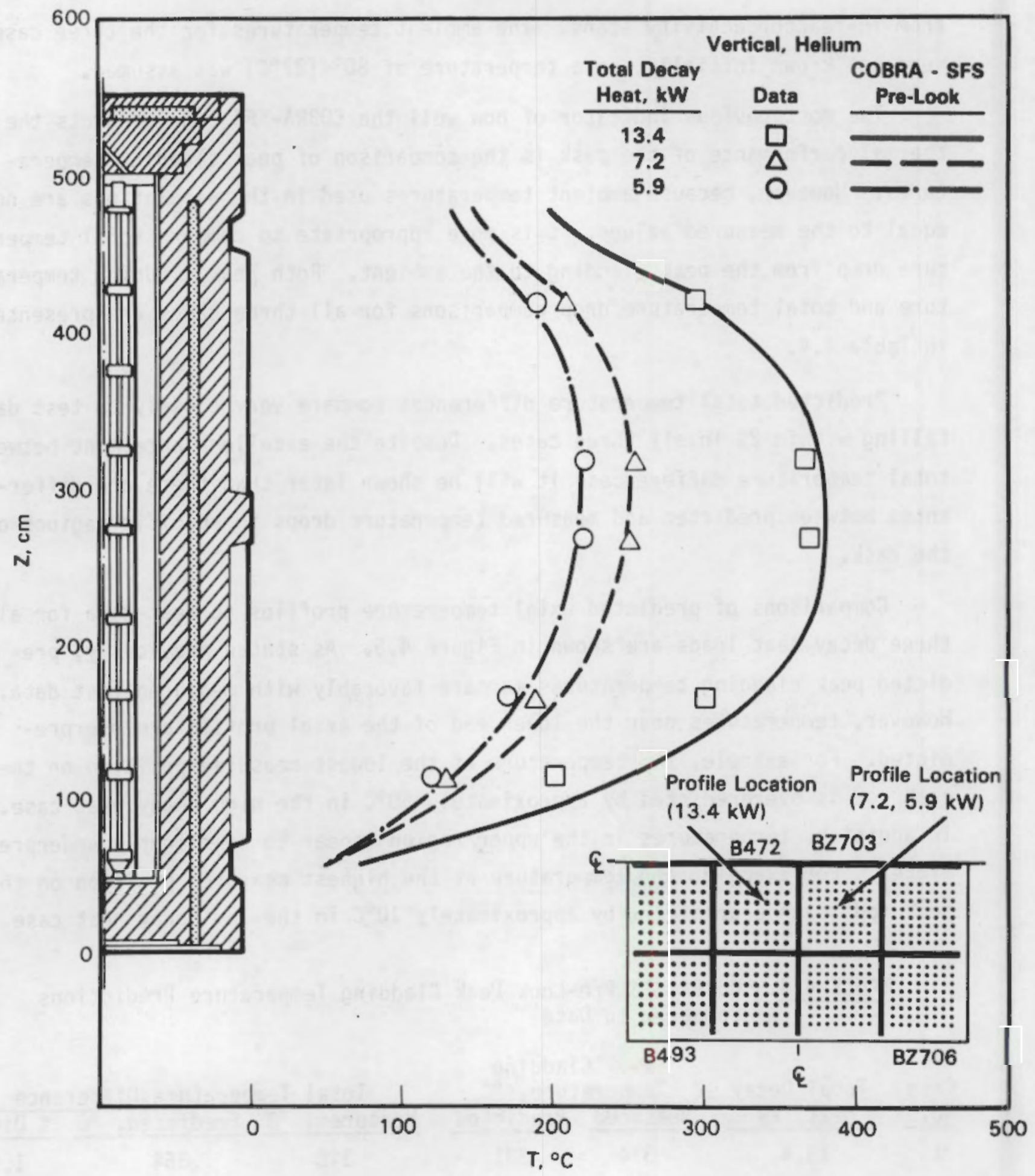

FIGURE 4.5. Comparisons of COBRA-SFS Pre-Look Peak $\mathrm{Cladding} \mathrm{Axial}$ Temperature Profile Predictions with Test Data 
Differences between predicted and measured axial temperature profiles could be the result of several contributing factors. One possible reason is that the amount of natural circulation occurring within the cask is not being accurately predicted. Under stagnant conditions, the axial temperature profile will mirror the axial decay heat profile except for axial conduction effects. When a significant amount of natural circulation occurs, the axial temperature profile is skewed upward, cooling the lower regions and heating the upper regions. The lack of data regarding the cask flow field makes any evaluation of the predicted convection difficult. However, experience with other test simulations give confidence in predicted flow velocities (Lombardo et al. 1986; Wiles et al. 1986; Wheeler et al. 1986).

Another possible reason for the difference between predicted and measured axial temperature profiles is an improperly specified axial decay heat profile. As stated earlier, the axial burnup curve in Figure 3.7 was selected because it was assumed that it was determined from in-reactor activity scans. As discussed in Section 3.2.2, it has been determined that the curve shown in Figure 3.8 more accurately reflects the actual axial decay heat distribution in the fuel assemblies. Note that the new decay heat curve is skewed upward when compared to the initial curve (Figure 3.9).

The ability to correctly pretict peak cladding temperatures suggests that important physical phenomena occurring within the cask are properly modeled with CORRA-SFS. However, the radial temperature profiles shown in Figure 4.6 illustrate greater local temperature differences between predicted and measured values and suggest where changes to the cask model can be made. For example, cask surface temperatures are overpredicted in all cases, which suggests a deficiency in cask surface convective or radiative heat transfer correlations. Comparisons of predicted and measured temperatures in the interior of the cask are complicated by differences in predicted and measured surface temperatures. More meaningful comparisons can be made when predictions and data are compared using temperature differences, rather than absolute values. 


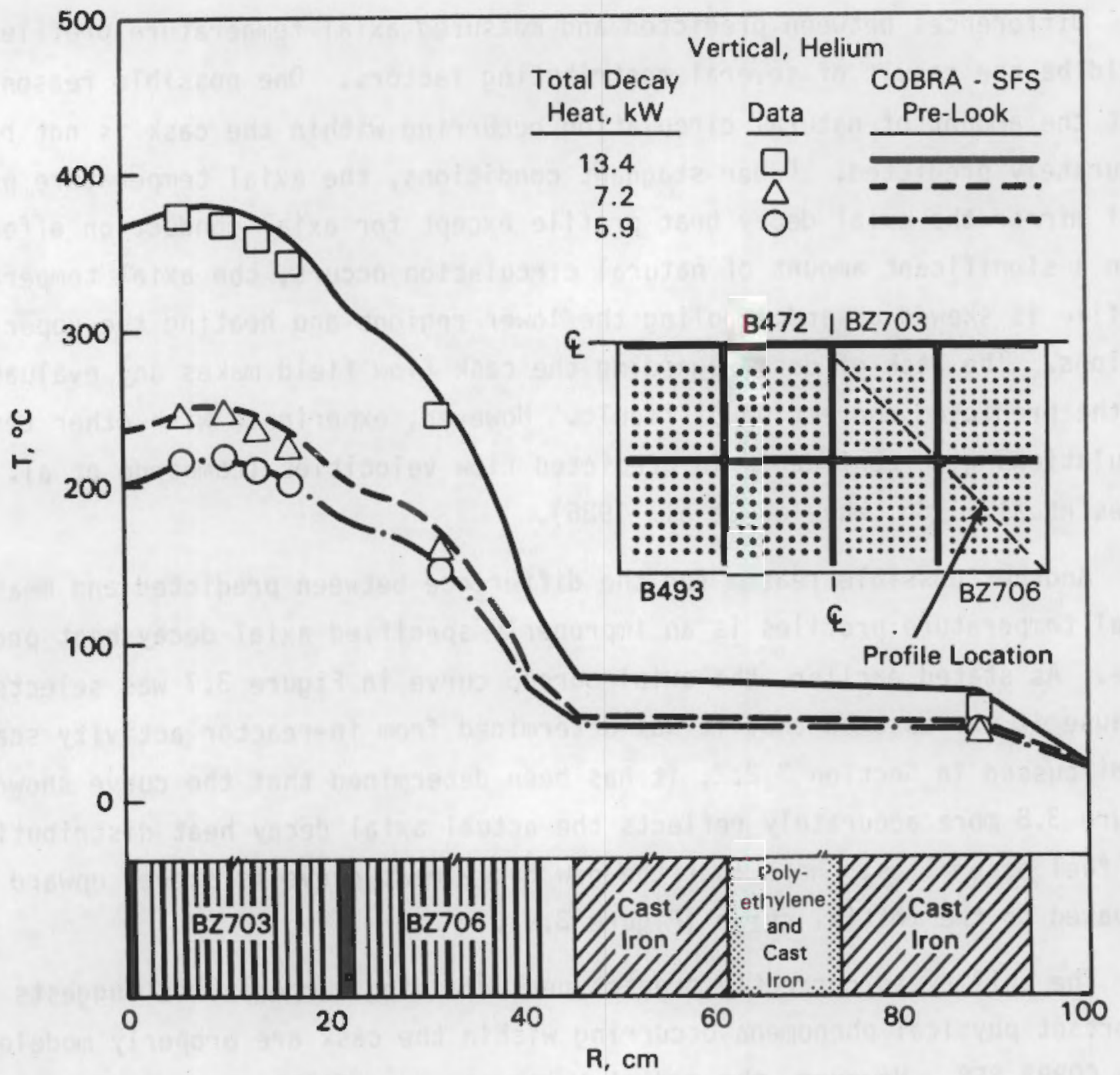

FIGURE 4.6. Comparisons of COBRA-SFS Pre-Look Radial Temperature Profile Predictions With Test Data (266-cm Elevation)

To determine the important temperature differences to be used for evaluation, it is important to understand the heat transfer phenomena occurring within the cask. The important heat transfer phenomena in each cask region are briefly described below:

- On the cask surface, heat is removed hy both natural convection and thermal radiation. Most of the heat generated leaves through the side of the cask; relatively little leaves through the top or bottom. The side temperature is characterized by two thermocouples at the 
3055-mm (120-in.) elevation (Figure 4.4). A comparison of sideto-ambient temperature differences will be used to evaluate this region.

- The only mode of heat transfer through the cask body is solid conduction. Because the cask body geometry and thermal properties are well known, there is little potential for differences. The cask inner surface can be characterized only by the single thermocouple at the 3853-mm (152-in.) elevation, which is adjacent to the upper end of the axial profile. Comparisons of this temperature with the lower cask surface and rod temperatures will yield biased radial temperature differences. Therefore, evaluation of the cask body model could not be performed separately, but was done as part of the cask cavity evaluation.

- The heat generated by the spent fuel assemblies in the cavity of the CASTOR-IC cask is removed by all three modes of heat transfer. Heat is transferred to the cask inner surface through the basket and through the outer ring of assemblies. The steep radial temperature gradient through the corner assemblies indicates a significant amount of conduction and radiation heat transfer through the outer ring of fuel assemblies. The heat transfer through this region is evaluated by comparing the temperature difference between one of the center rods of the corner $8 \times 8$ rod assembly and the cask outer surface.

- The total heat transfer through the cavity region, including heat transfer through the basket and outer fuel assemblies, is evaluated by comparing the temperature difference between the peak rod temperature in the centermost $8 \times 8$ rod assembly and the cask outer surface.

To summarize, the primary temperature differences used to evaluate the COBRASFS radial temperature profile predictions are the cask surface-to-ambient temperature difference, the corner assembly-to-cask outer surface temperature difference, and the peak rod-to-cask outer surface temperature difference. Each of these temperature differences is examined in more detail below. 


\subsubsection{Cask Surface}

Comparisons of predicted to measured cask surface-to-ambient temperature differences are presented in Table 4.5. Surface temperatures are from two thermocouples, one on the base surface and one on a nearby fin, at the $3055-\mathrm{mm}$ $\left(120-i n_{0}\right)$ elevation. Note that surface temperature difference are conservatively overpredicted by 30 to $40 \%$ in all cases. This indicates that the convective and/or radiative heat transfer components are underpredicted.

The radiation heat transfer component is defined by two parameters, the surface emissivity and surface area. The surface emissivity is a measured property of the paint used on the fins and will not deviate significantly from the specified value. The equivalent surface area is calculated using view factors based on the fin geometry and is a constant with respect to that geometry. Therefore, the radiative heat transfer component is well defined. However, the convective component is not so well defined.

The correlations used in determining the surface convection heat transfer were discussed in Section 4.2.3. These correlations were developed based on ideal geometries and test conditions. For example, the correlation for free convection heat transfer from vertical fins is derived from rectangular fins attached to a flat surface suspended in a perfectly stagnant environment. In reality, the cask geometry consists of trapezoidal fins on a cylindrical surface. Even more significant is the range of applicability of the correlation. The primary dimensionless parameter used in the correlation is the Rayleigh number ( $R a)$. The Rayleigh number determines the flow regime for most

TABLE 4.5. COBRA-SFS Pre-Look Predictions Compared to Measured Cask Surface-to-Ambient Temperature Differences

\begin{tabular}{|c|c|c|c|c|}
\hline Case & Total Decay & Tempera & re Differe & $={ }^{\circ}{ }^{\circ} \mathrm{C}$ \\
\hline No. & Heat, $k W$ & Measured & Predicted & \\
\hline 1 & 13.4 & 33 & 46 & 39.4 \\
\hline 2 & 7.2 & 19 & 25 & 31.6 \\
\hline 3 & 5.9 & 16 & 21 & 31.3 \\
\hline
\end{tabular}


vertical surface natural convection correlations. The flow is turbulent for Rayleigh numbers greater than $10^{10}$ with a transition region in between. The data set used to develop the correlation is taken from small fin arrays ( $<$ < $25 \mathrm{~cm}, 10 \mathrm{in.}$ ), and has Rayleigh numbers less than $10^{8}$, which indicates laminar flow. The CASTOR-1C cask, however, has a relatively large length scale $(\mathrm{L}>4 \mathrm{~m}, 14 \mathrm{ft})$, which results in Rayleigh numbers greater than $10^{11}$. No correlations for turbulent flow in vertical fin arrays similar to those on the CASTOR-1C cask were found in the literature. It was therefore concluded that the surface-to-ambient heat transfer is not accurately modeled by conventional natural convection correlations. It may be possible to develop an improved correlation from the test data, but the new correlation would be limited in application to the CASTOR-1C cask geometry and the site-specific test conditions. Therefore, because an appropriate convection correlation was not found, the cask surface heat transfer component in each post-test simulation was increased to obtain the measured cask surface temperature. This approach was employed only as a means of correcting the surface temperature difference so that the interior cask temperatures could be evaluated directly.

\subsubsection{Corner Assembly-to-Surface}

The second temperature difference used for evaluation is between one of the center rods (Rod 28) in the corner $8 \times 8$ rod assembly and the cask surface. Comparisons of predicted to measured temperature differences are presented in Table 4.6. Note that agreement is within $3 \%$ in all three cases. This is especially significant when considering that the steepest radial temperature gradient is located in the outer ring of fuel assemblies. This indicates that the cask body and the important modes of heat transfer in the corner assembly are accurately modeled.

\subsubsection{Center Assembly-to-Cask Outer Surface}

The final temperature difference used for evaluation is between one of the center rods in the center $8 \times 8$ rod assembly and the cask outer surface. Comparisons of predicted to measured temperature differences are presented in Table 4.7. In all cases the temperature differences are underpredicted. Although the difference in each case is less than $4 \%$, the absolute magnitude of the difference is comparable to that of the surface temperature difference. 
TABLE 4.6. COBRA-SFS Pre-Look Predictions Compared to Measured Corner Assembly-to-Cask Outer Surface Temperature Differences

\begin{tabular}{|c|c|c|c|c|}
\hline Case & Total Decay & \multicolumn{3}{|c|}{ Temperature Difference, ${ }^{\circ} \mathrm{C}$} \\
\hline & Heat, $\mathrm{kW}$ & Measured & Predicted & $\%$ Diff. \\
\hline 1 & 13.4 & 189 & 188 & $(0.5)$ \\
\hline 2 & 7.2 & 117 & 120 & 2.6 \\
\hline 3 & 5.9 & 101 & 102 & 1.0 \\
\hline
\end{tabular}

TABLE 4.7. COBRA-SFS Pre-Look Predictions Compared to Measured Peak Rod-to-Cask Outer Surface Temperature Differences

\begin{tabular}{|c|c|c|c|c|}
\hline Case & Total Decay & Tempera & ure Differ & $\mathrm{ee},{ }^{\circ} \mathrm{C}$ \\
\hline No. & Heat, kW & Measured & Predicted & \% Diff. \\
\hline 1 & 13.4 & 315 & 308 & $(2.2)$ \\
\hline 2 & 7.2 & 207 & 200 & $(3.4)$ \\
\hline 3 & 5.9 & 173 & 171 & $(1.2)$ \\
\hline
\end{tabular}

These differences, when added, offset each other and give excellent total temperature difference comparisons. When surface temperatures are corrected, a corresponding correction must be made to peak cladding temperatures. To determine the source of the differences in peak cladding-to-cask outer surface temperature differences, the parameters describing the primary modes of heat transfer must be examined.

One path for removing heat from central assemblies is through the stainless steel fuel basket. The resistance along this path is a function of the gap between fuel assemblies and the basket fuel tubes, the thermal properties of the basket material, the welded connections in the basket, and the gap between the basket and the cavity wall. It was assumed that the fuel assemblies were centered in the basket fuel tube, creating a uniform fuel assemblyto-fuel tube gap around the periphery of the assembly. Eccentrically located assemblies give lower peak cladding temperatures. The thermal properties of the stainless steel used in the basket are well known quantities with low uncertainties. The welded junctions between basket plates were assumed to have negligible thermal resistance. Considering the size of the welds and the degree of quality control, this is a good assumption. The value used for the 
gap between the basket and the cavity wall was based on the assumption of a perfectly centered basket. When the basket is eccentrically located, local temperatures near the larger gap are increased, but peak temperatures decrease due to a reduction in overall resistance. Thermal expansion of the basket relative to the cask results in a lower peak temperature. Assuming no expansion of the cask body and using a typical coefficient of expansion for stainless steel, the maximum reduction in the basket-to-cavity wall gap was determined to be less than $10 \%$. Therefore, no change in gap width was made for the post-test analysis.

Heat is removed from the fuel rods in the central assemblies by thermal radiation, conduction, and convection. Radiation heat transfer is defined by the geometry and the surface emissivities of the fuel rods, basket, and inner cask wall. The emissivities are a function of both the material type and surface condition. Unless the emissivities are measured directly, significant uncertainties are associated with their values. The fraction of total heat removed by radiation increases as the total heat load increases. Therefore, an incorrect radiation model would result in an error that changes as the heat load increases. No such trend appears in Table 4.7. Therefore, the same emissivities used in the pre-look analysis were used in the post-test analysis.

The amount of heat removed by natural circulation within the cask is defined by friction factor expressions and heat transfer coefficients. The magnitude of velocities in the flow field are moderate, with a maximum assembly average velocity of less than $12 \mathrm{~cm} / \mathrm{sec}(5 \mathrm{in} / \mathrm{sec})$. The lack of data regarding the cask flow field makes any evaluation of the predicted flow field difficult. However, experience with other test simulations give confidence in the flow parameters used (Lombardo et al. 1986, Wiles et al. 1986, Wheeler et al. 1986). In addition, because magnitudes of gas velocities are low and the fluid has a low thermal capacity, a large adjustment in the friction factor or other flow parameters would be required to affect the temperature distribution. Therefore, the same flow parameters were used in the post-test analysis as used in the pre-look analysis.

The convection heat transfer coefficients between rods and fluid, which are expressed in terms of Nusselt numbers, directly affect the temperature 
distribution within the cask. A Nusselt number of 4.364 was specified for the pre-look analysis. This value is derived from an analytical solution of the energy equation by assuming a constant heat rate and fully developed velocity and temperature profiles in a circular tube. It has been demonstrated in other validation studies (Lombardo et al. 1986) that a Nusselt number of 3.658 results in a better comparison between simulations and test data. This value will create a greater resistance to heat from the rods to the fluid, which will result in an increase in the peak cladding temperature.

\subsubsection{Post-Test Simulations}

The evaluation of pre-look simulations resulted in the identification of three primary improvements to be made to the CASTOR-1C computational cask model:

- specification of a new axial decay heat profile that more accurately reflects the power history of the Wurgassen spent fuel assemblies

- use of a Nusselt number of 3.658 , rather than 4.364 , to describe convection heat transfer from the fuel rods to the gas

- increasing the cask surface heat transfer coefficient to obtain the correct surface temperatures.

Following implementation of these improvements, a second set of three simulations was performed, each corresponding to a different decay heat level. The temperature results were then compared with data to evaluate the model. The comparisons demonstrate the improved ability to predict the peak cladding temperature and axial and radial temperature profiles.

The primary indicator of how well the COBRA-SFS code predicts the thermal performance of the cask is the comparison of peak cladding temperatures. Both the peak cladding temperature and total temperature drop comparisons for all three post-test analysis cases are presented in Table 4.8. As in the pre-look analysis, the results of the total temperature drop compare very closely to test data, falling within $2 \%$ in all three cases.

A major problem identified in the pre-look evaluation was that the shape of the axial temperature profile was incorrectly predicted. As stated earlier, 
TABLE 4.8. COBRA-SFS Post-Test Predictions Compared to Measured Peak Cladding Temperatures and Total Temperature Differences

\begin{tabular}{|c|c|c|c|c|c|c|}
\hline \multirow{2}{*}{$\begin{array}{l}\text { Case } \\
\text { No. }\end{array}$} & \multirow{2}{*}{$\begin{array}{l}\text { Total Decay } \\
\text { Heat, } \mathrm{kW} \\
\end{array}$} & \multicolumn{2}{|c|}{ Peak Cladding } & \multicolumn{3}{|c|}{ Total Temperature Difference } \\
\hline & & Measured & Predicted & Measured, & ${ }^{\circ} \mathrm{C}$ Predicted, ${ }^{\circ} \mathrm{C}$ & \% Diff. \\
\hline 1 & 13.4 & 374 & 376 & 348 & 350 & 0.6 \\
\hline 2 & 7.2 & 255 & 251 & 226 & 222 & $(1.8)$ \\
\hline 3 & 5.9 & 221 & 220 & 189 & 188 & $(0.5)$ \\
\hline
\end{tabular}

the temperatures near the lower end of the axial profile were severely overpredicted, in one case by approximately $50^{\circ} \mathrm{C}$, and the temperatures in the upper region were slightly underpredicted. The cause was determined to be an incorrectly specified axial decay heat profile. As a result, a new axial decay heat profile was calculated based on detailed in-reactor radiation scans (Section 3.2.2). This new axial profile was then used in performing the post-test cask simulations.

Comparisons of the predicted peak cladding axial temperature profiles with test data for all three decay heat cases are shown in Figure 4.7. The comparisons show a dramatically improved agreement between predictions and data. Near the lower end of the axial profile there is excellent agreement, with a maximum temperature difference of less than $5^{\circ} \mathrm{C}$ in all cases. Near the top of the profile there is still good agreement, with a maximum temperature underprediction of between $10^{\circ}$ to $15^{\circ} \mathrm{C}$. This improvement in the axial temperature profile prediction illustrates the importance of providing accurate input to the code.

The radial temperature profiles for all three post-test simulations are shown in Figure 4.8. Predictions are in excellent agreement with all test data.

The primary temperature differences from the pre-look analysis, which were used to evaluate the COBRA-SFS radial temperature profile predictions, are the cask surface-to-ambient temperature difference and the peak rod-to-cask surface temperature difference. The effect of the computational modeling changes resulting from the pre-look analysis on each of these temperature differences is examined in more detail below. 


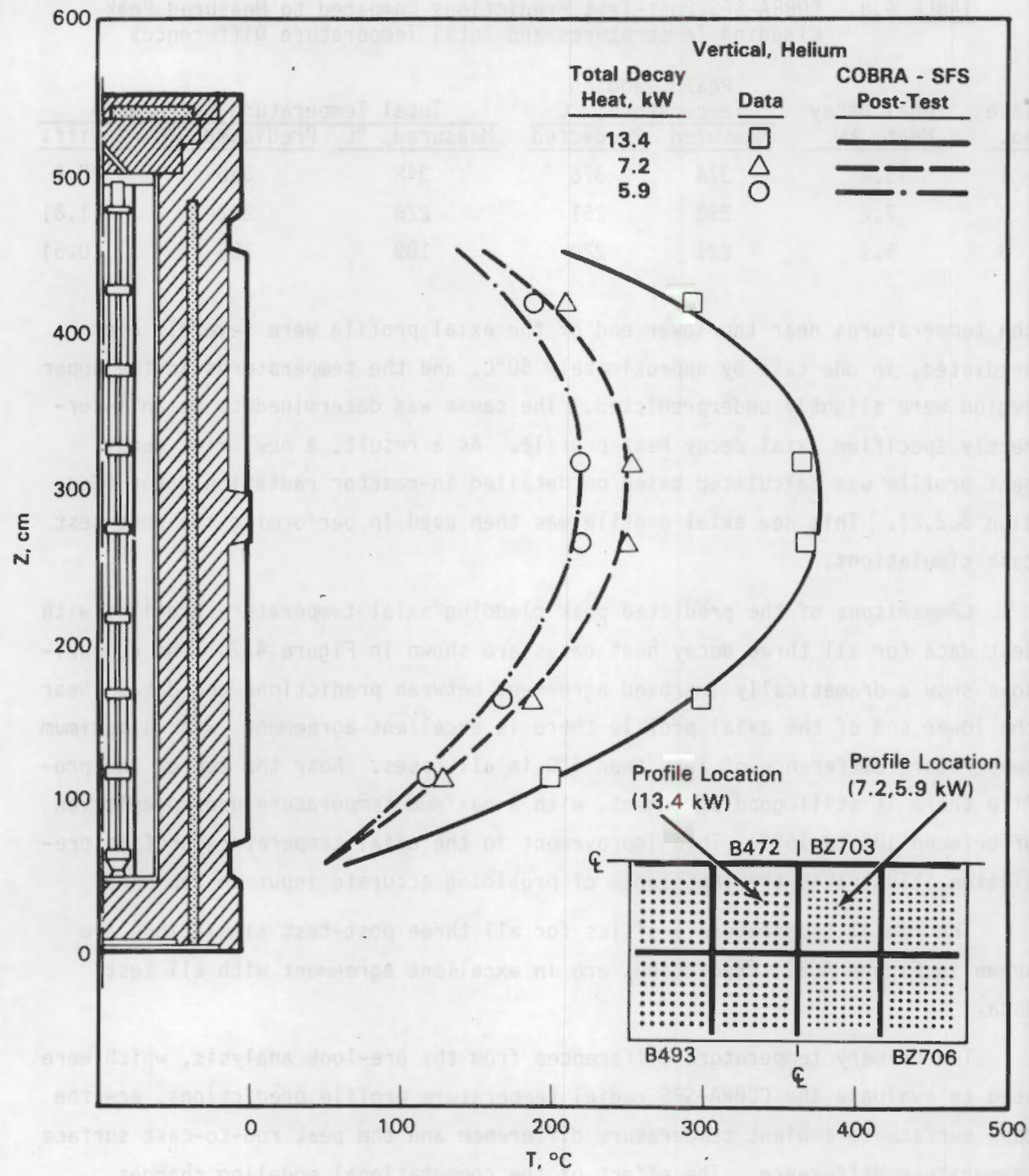

FIGURE 4.7. Comparisons of COBRA-SFS Post-Test Peak Cladding Axial Temperature Profile Predictions with Test Data 


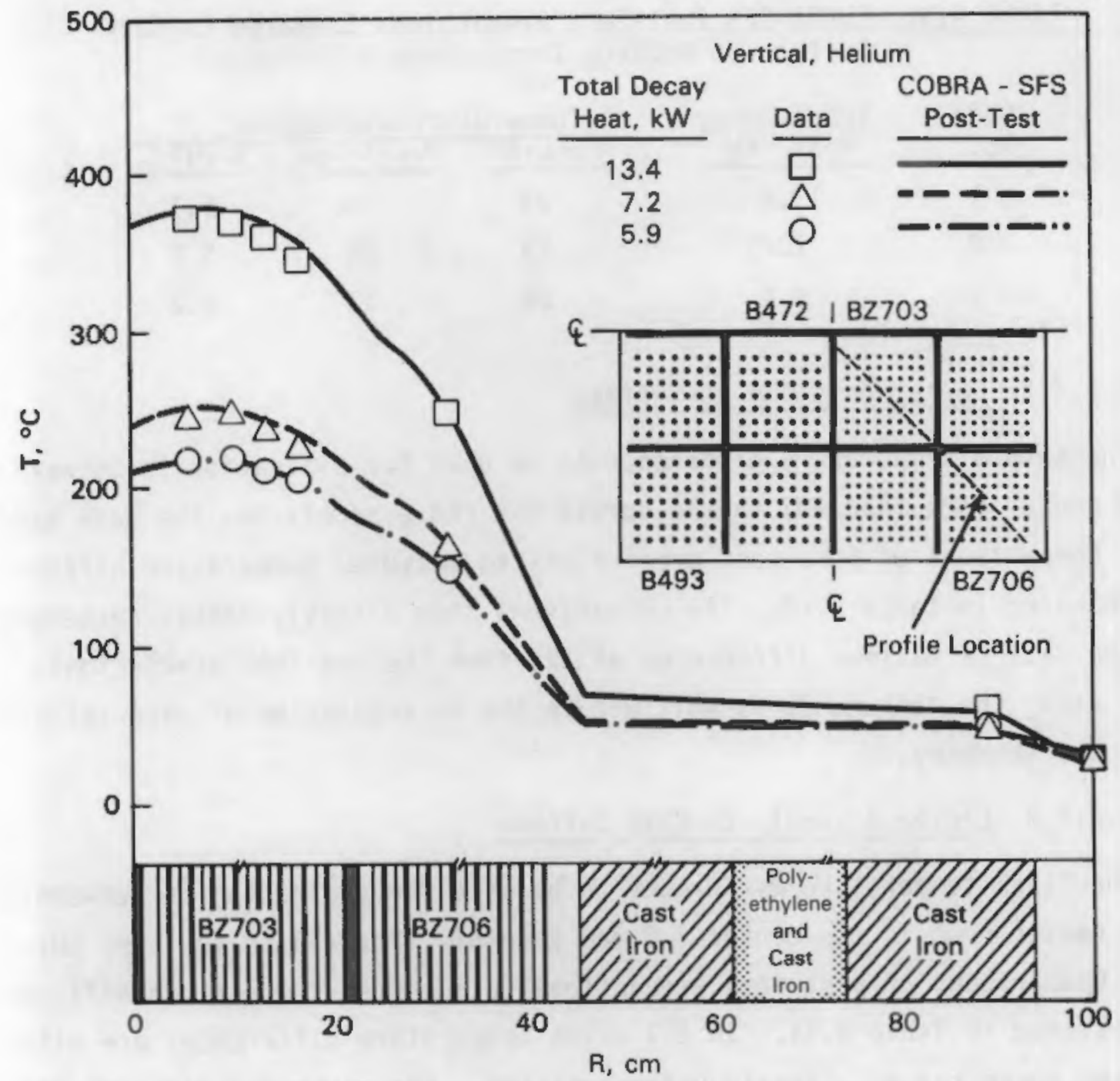

FIGURE 4.8. Comparisons of COBRA-SFS Post-Test Radial Temperature Profile Predictions with Test Data (266-cm Elevation)

\subsubsection{Cask Surface}

A comparison of predicted to measured cask surface-to-ambient temperature differences is presented in Table 4.9. Predicted temperature differences were obtained by adjusting the surface heat transfer coefficient until the predicted surface temperature was within 1 or $2^{\circ} \mathrm{C}$ of the measured temperature. As explained in the pre-look discussion, this approach was employed only as a means of correcting the surface temperature difference so that the interior cask temperatures might be evaluated directly. 
TABLE 4.9. COBRA-SFS Post-Test Predictions Compared to Cask

Surface-to-Ambient Temperature Differences

\begin{tabular}{|c|c|c|c|c|}
\hline Case & Total Decay & Tempera & Ire Differ & $c e,{ }^{\circ} \mathrm{C}$ \\
\hline No. & Heat, $\mathrm{kW}$ & Measured & Predicted & \\
\hline 1 & 13.4 & 33 & 35 & 6.1 \\
\hline 2 & 7.2 & 19 & 20 & 5.2 \\
\hline 3 & 5.9 & 16 & 17 & 6.3 \\
\hline
\end{tabular}

\subsubsection{Corner Assembly-to-Surface}

The second temperature difference to be used for evaluation is between one of the center rods (Rod 28) in the corner $8 \times 8$ rod assembly and the cask surface. Comparisons of post-test predictions to measured temperature differences are presented in Table 4.10. The comparisons show slightly better agreement with the data (a maximum differences of $2 \%$ ) than the pre-look predictions. In either case, the difference is well within the uncertainties of material properties and geometry.

\subsubsection{Center Assembly-to-Cask Surface}

The final temperature difference to be used for evaluation is between one of the center rods in the center $8 \times 8$ rod assembly (Rod 28) to the cask surface. Comparisons of post-test predictions to measured temperature differences are presented in Table 4.11. In all cases temperature differences are either predicted correctly or slightly underpredicted. The maximum difference was reduced from less than $4 \%$, in the pre-look analys is to less than $3 \%$ in all three cases. This slight improvement is attributed to the reduction of the value of the Nusselt number, which defines the convection heat transfer coefficients from rods to fluid, from 4.364 to 3.658 . This change resulted in a

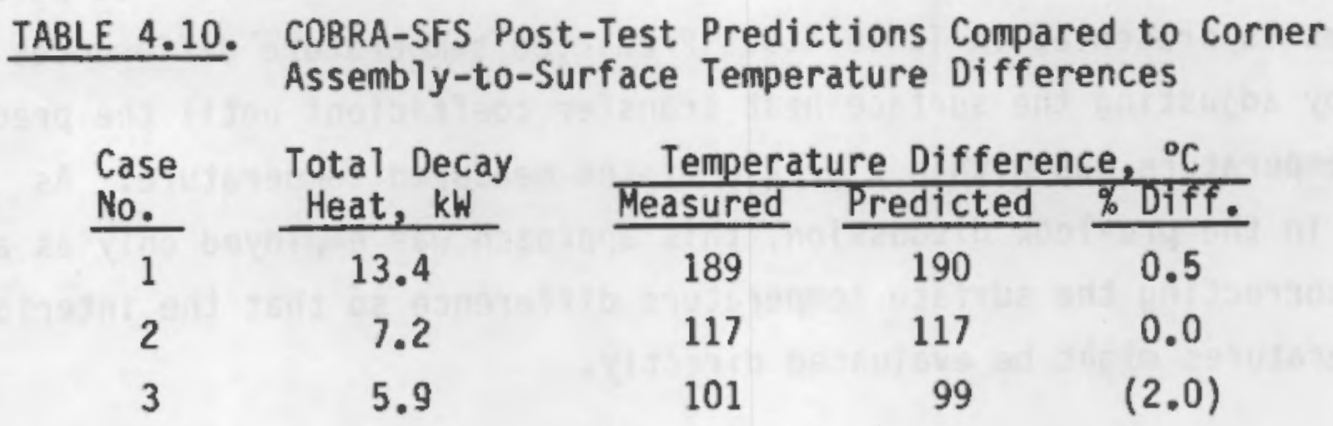




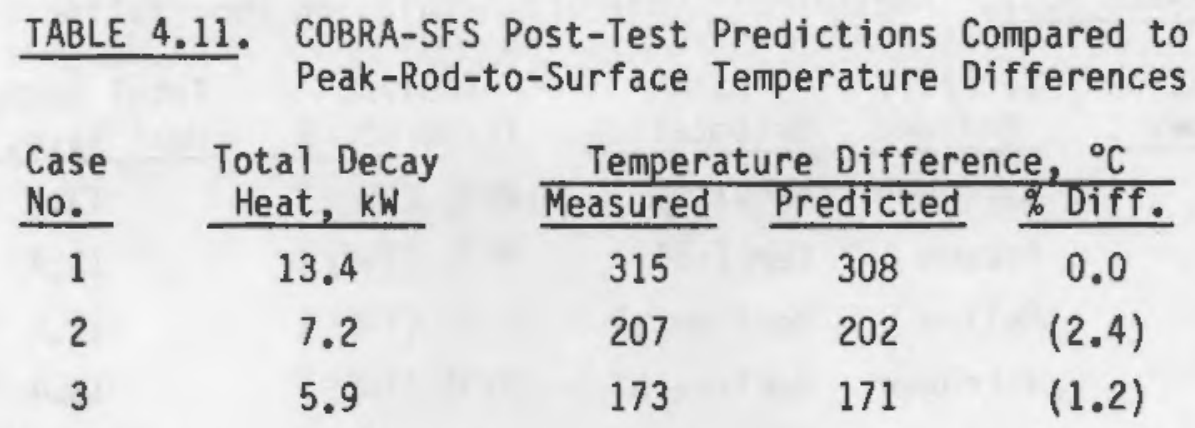

small increase in predicted temperature because conduction and radiation are the primary modes of heat transfer in the radial direction. In both the preand post-test predictions, the error is well within the uncertainty of the material properties and the geometry.

\subsection{AODITIONAL COBRA-SFS SIMULATIONS}

A set of six additional simulations were performed to more fully characterize the thermal performance of the CASTOR-1C cask. The results of these simulations are presented in this section. Four of the simulations are used to examine the effect of cask orientation and backfill medium on the temperature distribution within the cask. The remaining two simulations predict the maximum allowable total decay heat rates to reach a peak cladding temperature of $400^{\circ} \mathrm{C}$ for different backfill media. Descriptions of the six simulations are presented in Table 4.12. The ambient temperature of $26^{\circ} \mathrm{C}$ and total decay heat rate of $13.4 \mathrm{~kW}$ corresponds to the test conditions of the high power data set taken on March 10, 1982. The decay heat axial profile for all additional simulations is the same as the corrected profile used for all post-test simulations.

The peak cladding temperature results for the first four simulations are presented in Table 4.13. Only the horizontal, helium case was predicted to yield peak cladding temperatures of less than $400^{\circ} \mathrm{C}$. The vertical, nitrogen case was predicted to produce peak cladding temperatures of $417^{\circ} \mathrm{C}$, which is near the $400^{\circ} \mathrm{C}$ allowable. However, the horizontal, nitrogen and vertical, vacuum cases resulted in peak cladding temperatures signficantly above the $400^{\circ} \mathrm{C}$ allowable. Figures 4.9 and 4.10 show the peak cladding axial temperature 
TABLE 4.12. Additional COBRA-SFS Simulation Descriptions

\begin{tabular}{|c|c|c|c|c|}
\hline $\begin{array}{c}\text { Simulation } \\
\text { Number } \\
\end{array}$ & $\begin{array}{l}\text { Backfill } \\
\text { Medium }\end{array}$ & $\begin{array}{c}\text { Cask } \\
\text { Orientation } \\
\end{array}$ & $\begin{array}{c}\text { Ambient } \\
\text { Temperature } \\
\end{array}$ & $\begin{array}{l}\text { Total Decay } \\
\text { Heat Rate, kW }\end{array}$ \\
\hline 1 & Nitrogen & Vertical & $26^{\circ} \mathrm{C}\left(79^{\circ} \mathrm{F}\right)$ & 13.4 \\
\hline 2 & Vacuum & Vertical & $26^{\circ} \mathrm{C}\left(79^{\circ} \mathrm{F}\right)$ & 13.4 \\
\hline 3 & Helium & Horizontal & $26^{\circ} \mathrm{C}\left(79^{\circ} \mathrm{F}\right)$ & 13.4 \\
\hline 4 & Nitrogen & Horizontal & $26^{\circ} \mathrm{C}\left(79^{\circ} \mathrm{F}\right)$ & 13.4 \\
\hline 5 & Helium & Vertical & $38^{\circ} \mathrm{C}\left(100^{\circ} \mathrm{F}\right)$ & to reach $400^{\circ} \mathrm{C}$ \\
\hline 6 & Nitrogen & Vertical & $38^{\circ} \mathrm{C}\left(100^{\circ} \mathrm{F}\right)$ & to reach $400^{\circ} \mathrm{C}$ \\
\hline
\end{tabular}
TABLE 4.13. COBRA-SFS Predictions of Peak Cladding
Temperatures

\begin{tabular}{|c|c|c|}
\hline $\begin{array}{l}\text { Backfill } \\
\text { Medium }\end{array}$ & $\begin{array}{c}\text { Cask } \\
\text { Orientation }\end{array}$ & $\begin{array}{l}\text { Peak Cladding } \\
\text { Temperatures }\end{array}$ \\
\hline Nitrogen & Vertical & $417^{\circ} \mathrm{C}\left(782^{\circ} \mathrm{F}\right)$ \\
\hline Vacuum & Vertical & $499^{\circ} \mathrm{C}\left(930^{\circ} \mathrm{F}\right)$ \\
\hline Helium & Horizontal & $394^{\circ} \mathrm{C}\left(741^{\circ} \mathrm{F}\right)$ \\
\hline Nitrogen & Horizontal & $493^{\circ} \mathrm{C}\left(920^{\circ} \mathrm{F}\right)$ \\
\hline
\end{tabular}

profiles for different media with the cask in a vertical and horizontal orientation, respectively. The vacuum case is shown in both figures because it is insensitive to the cask orientation. For the cask in a vertical orientation, the axial temperature profile for the nitrogen case is skewed upward as compared to the helium and vacuum cases, indicating a significant amount of natural convection. In contrast, the helium temperature profile indicates relatively little convection. The vacuum axial temperature profile mirrors the decay heat axial profile, indicating that convection is not an important mode of heat transfer in the vacuum case.

When the cask is placed in a horizontal orientation, the effect of natural convection within the cask is virtually eliminated. The axial temperature profiles for both the nitrogen and helium cases are similar in shape to the vacuum 


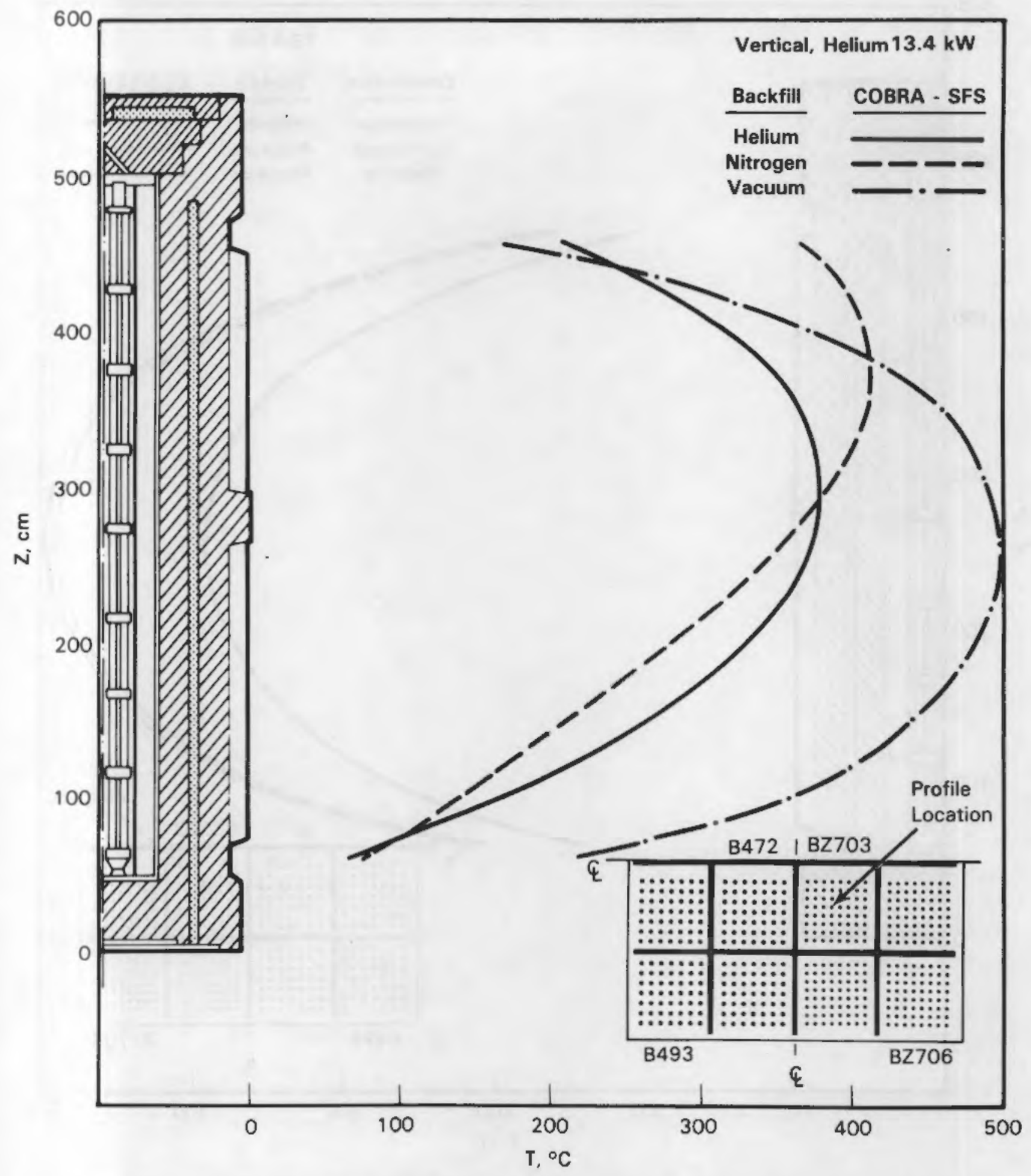

FIGURE 4.9. COBRA-SFS Peak Cladding Axial Temperature Profile Predictions for Helium, Nitrogen and Vacuum in the Vertical Orientation 


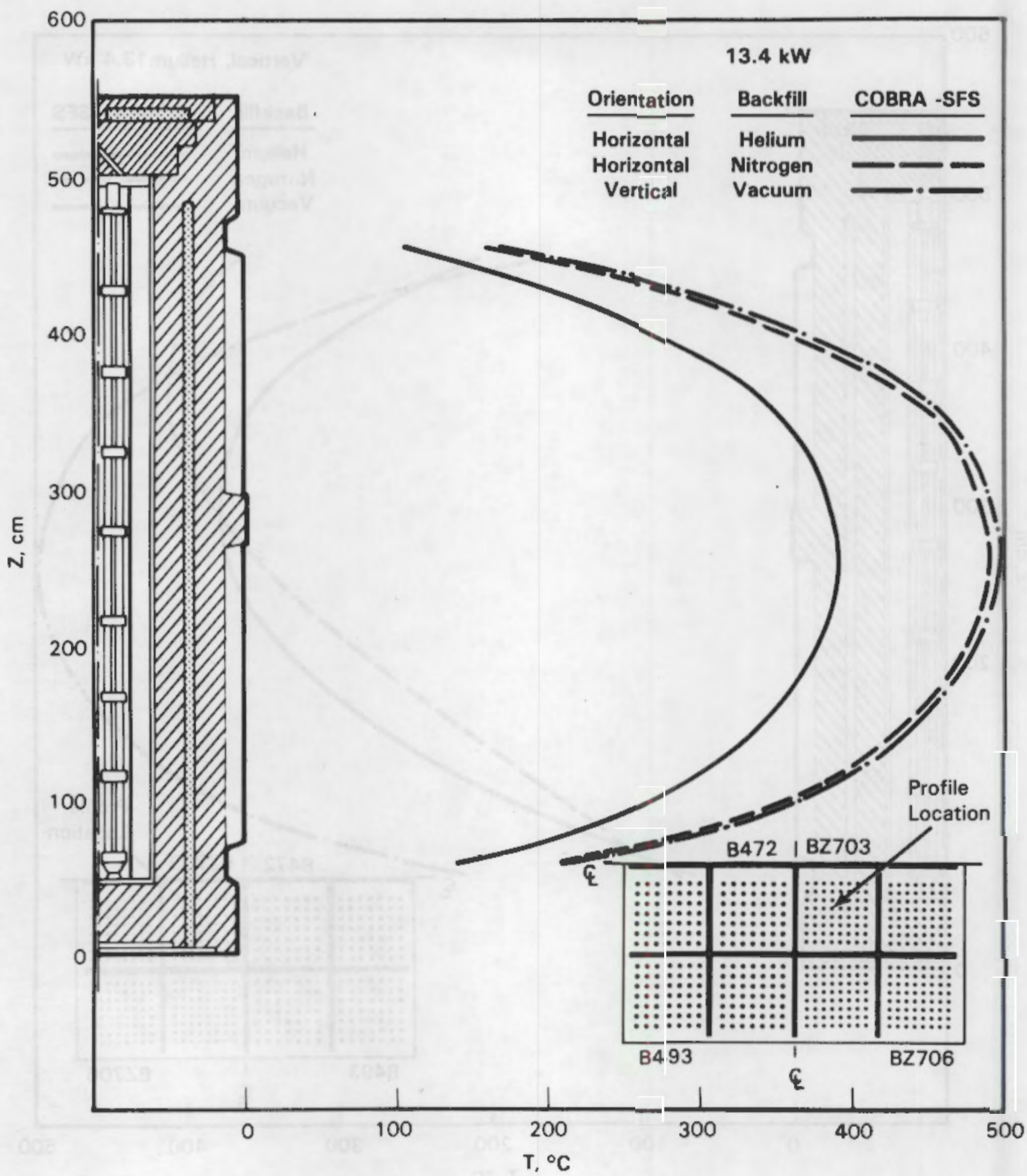

FIGURE 4.10. COBRA-SFS Peak Cladding Axial Temperature Profile Predictions for Helium and Nitrogen in the Horizontal Orientation and Vacuum in the Vertical Orientation 
case. The peak cladding temperature in the nitrogen case is $493^{\circ} \mathrm{C}\left(920^{\circ} \mathrm{F}\right)$, an increase of $77^{\circ} \mathrm{C}\left(138^{\circ} \mathrm{F}\right)$ over that for a vertical orientation. There is little difference between the nitrogen and vacuum cases, indicating that radiation is the dominant mode of heat transfer in the horizontal nitrogen case. In contrast, the peak cladding temperature in the helium case is $394^{\circ} \mathrm{C}\left(741^{\circ} \mathrm{F}\right)$, an increase of only $18^{\circ} \mathrm{C}\left(32^{\circ} \mathrm{F}\right)$ over that for a vertical orientation.

The results of the last two simulations, which predict the assembly decay heat rates required to achieve a peak cladding temperature of approximately $400^{\circ} \mathrm{C}$, are summarized in Table 4.14 . The cask is predicted to dissipate $13 \%$ more heat with a helium backfill gas than with a nitrogen backfill gas for approximately the same peak cladding temperature. Figures 4.11 and 4.12 compare the axial temperature profiles for these cases with those calculated using the high power $(13.4 \mathrm{~kW})$, March 10, 1982, test conditions for helium and nitrogen cases, respectively. It should be kept in mind when comparing these profiles that the ambient temperatures are different and that the March 10 , 1982, assembly heat generation rates are not uniformly identical. The decay heat in the high power test run was concentrated toward the center of the cask, resulting in higher temperatures than for a uniform heat generation case. Therefore, comparisons between the two axial temperature profiles must be made with care.

TABLE 4.14. COBRA-SFS Predictions of Maximum Allowable Total Decay Heat Rate

\begin{tabular}{|c|c|c|c|}
\hline $\begin{array}{l}\text { Backfill } \\
\text { Medium } \\
\end{array}$ & $\begin{array}{c}\text { Assembly Decay } \\
\text { Heat, } W\end{array}$ & $\begin{array}{l}\text { Total Decay } \\
\text { Heat Rate, kw } \\
\end{array}$ & $\begin{array}{c}\text { Predicted Peak } \mathrm{Cladding} \\
\text { Temperature, }{ }^{\circ} \mathrm{C}\end{array}$ \\
\hline Helium & 875 & 14.0 & 398 \\
\hline Nitrogen & 775 & 12.4 & 400 \\
\hline
\end{tabular}




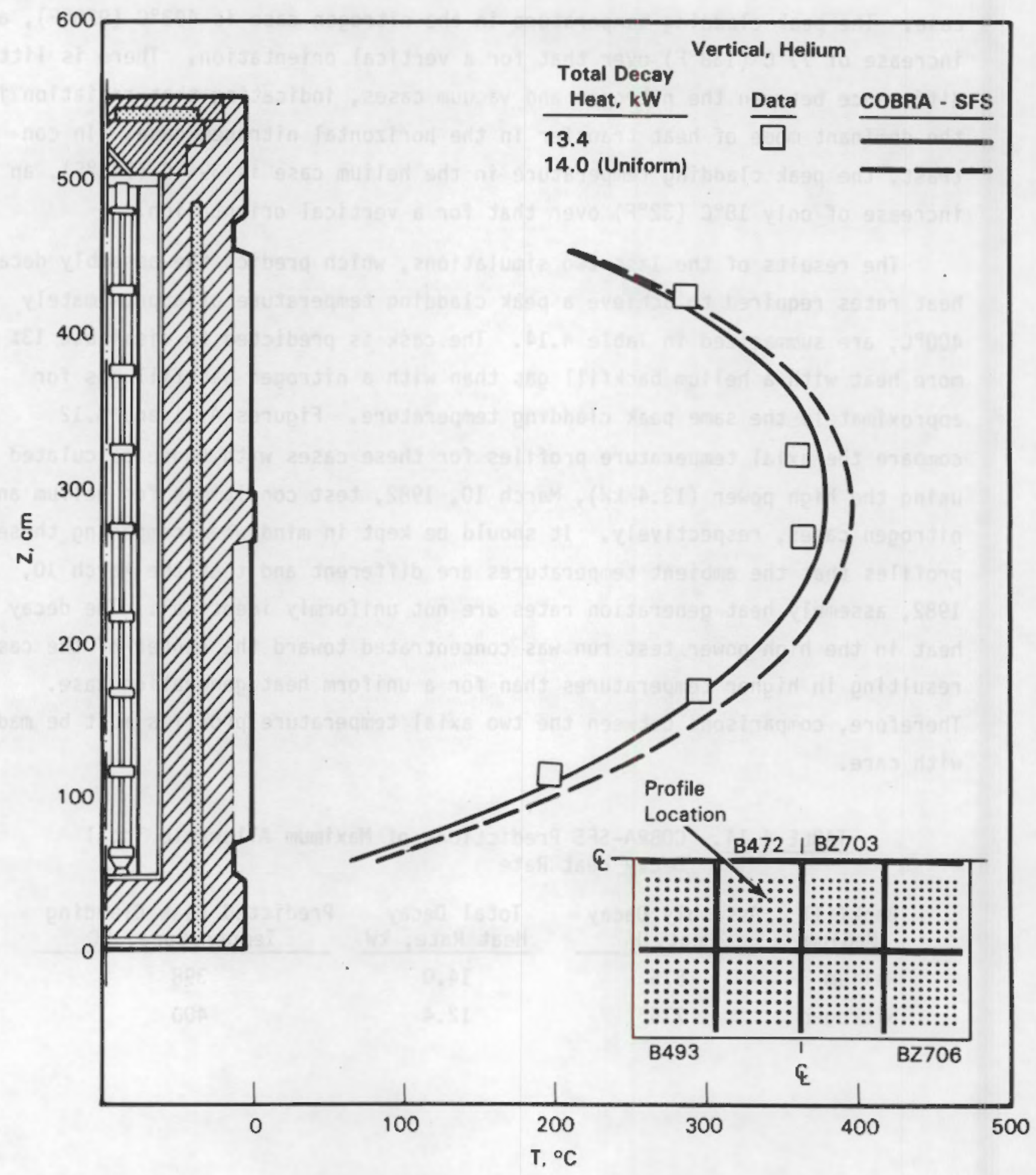

FIGURE 4.11. COBRA-SFS Peak Cladding Axial Temperature Profile Predictions for $14.0 \mathrm{~kW}$ Total Uniform Decay Heat Compared to $13.4 \mathrm{~kW}$ Total Decay Heat in Helium 


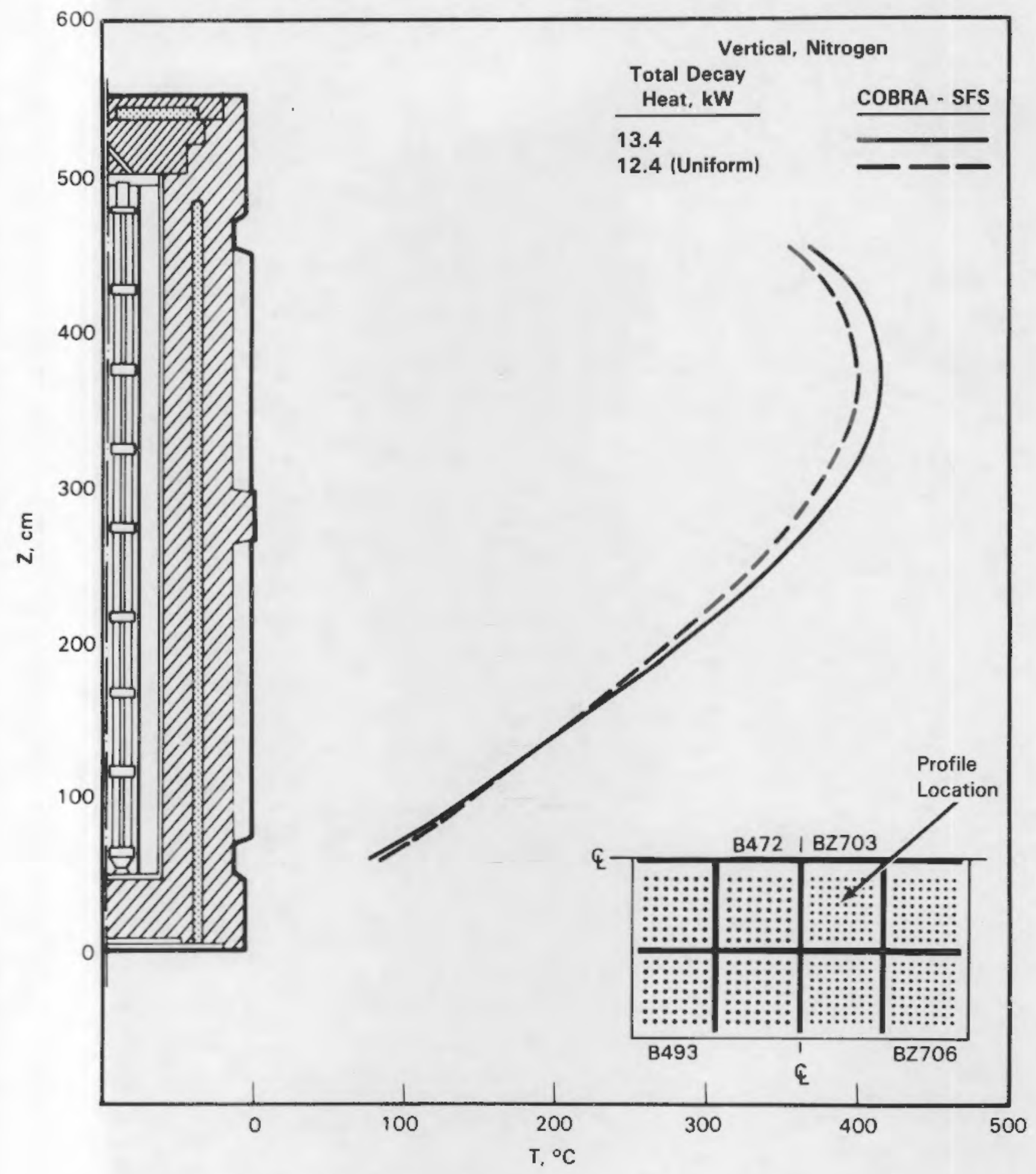

FIGURE 4.12. COBRA-SFS Peak Cladding Axial Temperature Profile Predictions for $12.4 \mathrm{~kW}$ Total Uniform Decay Heat Compared to $13.4 \mathrm{~kW}$ Total Decay Heat in Nitrogen 


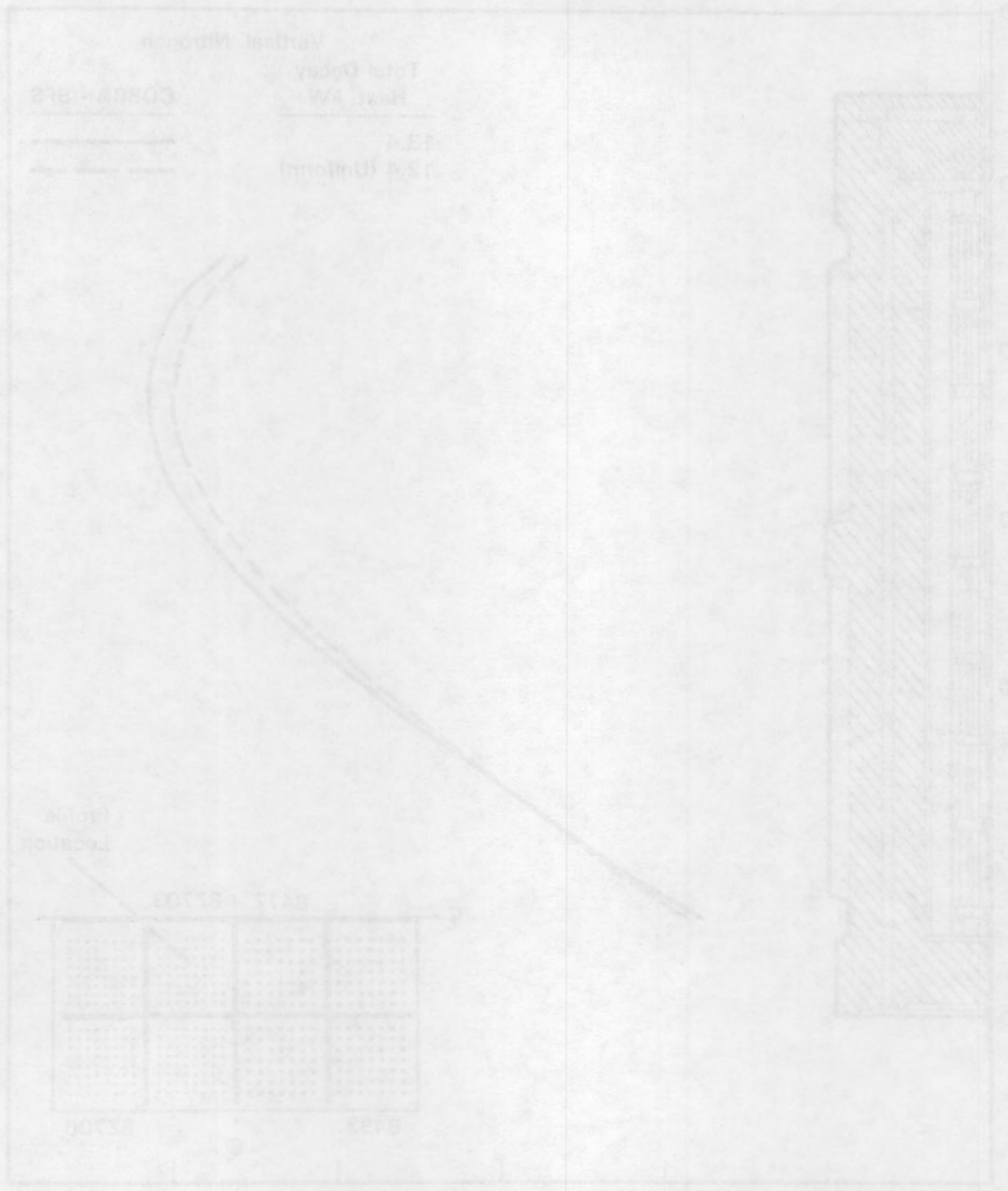

$-$

$+$

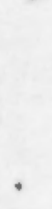




\subsection{HYDRA HEAT TRANSFER ANALYSIS}

In this section, the pre-look (before analyst was provided experimental data) and post-test heat transfer analysis using the HYDRA thermal hydraulics computer code are described. After the pre-look analysis was performed and predictions were compared to data, post-test predictions were completed. This approach provided an unbiased evaluation of HYDRA predictions and the identification of refinements that improved predictions.

The numerical basis and features of HYDRA are briefly discussed along with the geometry model, material properties, and important heat transfer and thermal hydraulic correlations. HYDRA predictions, both pre-look and post-test, are presented and compared to CASTOR-1C test data. Best-estimate predictions of the cask heat dissipation capability with uniform fuel assembly heat generation rates are presented for vertical and horizontal cask orientations with both nitrogen and helium hackfill gases.

\subsection{HYDRA COMPUTER CODE}

HYDRA is a fully three-dimensional thermal hydraulics computer code that solves equations of continuity, momentum, and energy by finite difference techniques. The code is currently under evaluation using applications ranging from simulations with known solutions to full-scale spent fuel storage system tests (Creer 1984; Wiles et al. 1986; Wheeler et al. 1986). The use of HYDRA for predicting the operating characteristics of the CASTOR-1C spent fuel storage cask is one in a series of simulations being performed to evaluate and qualify the program for design and safety analyses.

The time-dependent conservation equations of momentum and mass for compressible fluids are used as the basis for calculating single-phase flow fields. The time-dependent conservation equation of energy with convection and heat sources is the basis for calculating the temperature field. These conservation equations are as follows: 
Momentum

$$
\frac{\partial}{\partial t}(\vec{m})=\rho \vec{g}-\nabla p-D_{m}^{+}+\nabla \cdot(\mu \nabla \vec{v})-\nabla \cdot(\vec{v} \vec{m})
$$

where $t=$ time

而 = mass flux

$\phi=$ area fraction

$\rho=$ density

$す=$ gravitational vector

$p=$ pressure

D = Darcy and orifice drag

$\mu=$ viscosity

$\vec{v}$ = superficial velocity.

Mass

$$
\frac{\partial}{\partial t}(p)=-\nabla \cdot(\vec{m})
$$

Energy

$$
\frac{\partial}{\partial t}\left(\rho C_{p} T\right)=\nabla \cdot(\lambda \nabla T)-\nabla \cdot\left(C_{p} \dot{m} T\right)+\dot{q}
$$

where $C_{p}=$ specific neat

$T=$ temperature

$\lambda=$ thermal conductivity.

The source term, $\dot{q}$, in the energy equation represents heat generation and thermal radiation heat transfer. The latter is given by an expression of the form 


$$
\dot{q}_{\mathrm{rad}^{i+j}}=H_{i j}\left(T_{i}^{4}-T_{j}^{4}\right)
$$

where $\mathrm{H}_{i j}$ is an exchange factor based on geometry and emittances.

A thermodynamic state relationship of the form

$$
\rho=f(p, T)
$$

is required, as are other relationships needed for definition of temperaturedependent material properties.

The conservation equations are converted to finite-difference equations using the locally one-dimensional philosophy embodied in Spaulding's Hybrid scheme [see for example, Patankar (1980)]. Both the energy equation and the three linear momentum equations are solved using an alternating-direction algorithm described by Douglas and Gunn (1964). The linking of the momentum equations with the conservation of mass equation is accomplished in a manner consistent with the spirit of the CTS SIMPLE algorithm described by Raithby and Schneider $(1979,1980)$.

HYDRA uses a Cartesian coordinate system for the computational mesh in the inner cask cavity (fuel basket region). A cylindrical coordinate system is available for convenience in calculating temperatures in the surrounding cask body. When both coordinate systems are invoked to model a cask, the code will automatically align the two systems and enforce conservation of energy at their interface.

HYDRA has been designed to provide a user-oriented input interface, eliminating the need for internal code changes. Any application for which the code is an appropriate choice can be completely described through the construction of an input file. The user may optionally request a formatted echo of the input file to confirm that the intended parameters are actually those used by the code. A selectable commentary monitoring the progress of the code toward a steady-state solution is available, as is a summary of energy balances. 
Finally, results may be written to a tape at the conclusion of a run in the event that the user may wish to restart the solution from its most recent point.

\subsection{HYORA MODELS AND INPUT}

The complete description of a given simulation is contained on an input file. The input file is read by HYDRA, and the information contained is stored and used to guide subsequent execution of the code. This section describes some of the information on the input file: the computational mesh, material properties, and correlations. Modeling uncertainties associated with the CASTOR-1C cask are also discussed.

\subsubsection{Computational Mesh}

A transverse cross section of the cask was illustrated previously in Figure 3.2. This cross section shows a square cavity inside the cask whose outside surface is approximately cylindrical. Figure 5.1 shows the corresponding computational mesh employed and indicates the alignment of the computational mesh with various physical features of the cask. Cartesian coordinates are used in the cask cavity, and a cylindrical coordinate system is used to represent the cask body.

An elevation view section of the cask is seen in Figure 3.1. A corresponding axial cross section of the computational mesh is shown in Figure 5.2 and indicates the location of physical cask features relative to the computational mesh.

The code computes a temperature and three mass fluxes (if a fluid is present) corresponding to each computational cell. The shape and location of each cell is selected, insofar as practical, to coincide with physical structures or boundaries of the cask and its contents. The accuracy of predicted temperatures and mass fluxes is influenced significantly by how well the computational mesh is aligned with the physical structure.

\subsubsection{Material Properties and Correlations}

Material properties were obtained from the cask topical safety analysis report (GNS 1983, 1985) and from Touloukian and Ho (1970). The material 


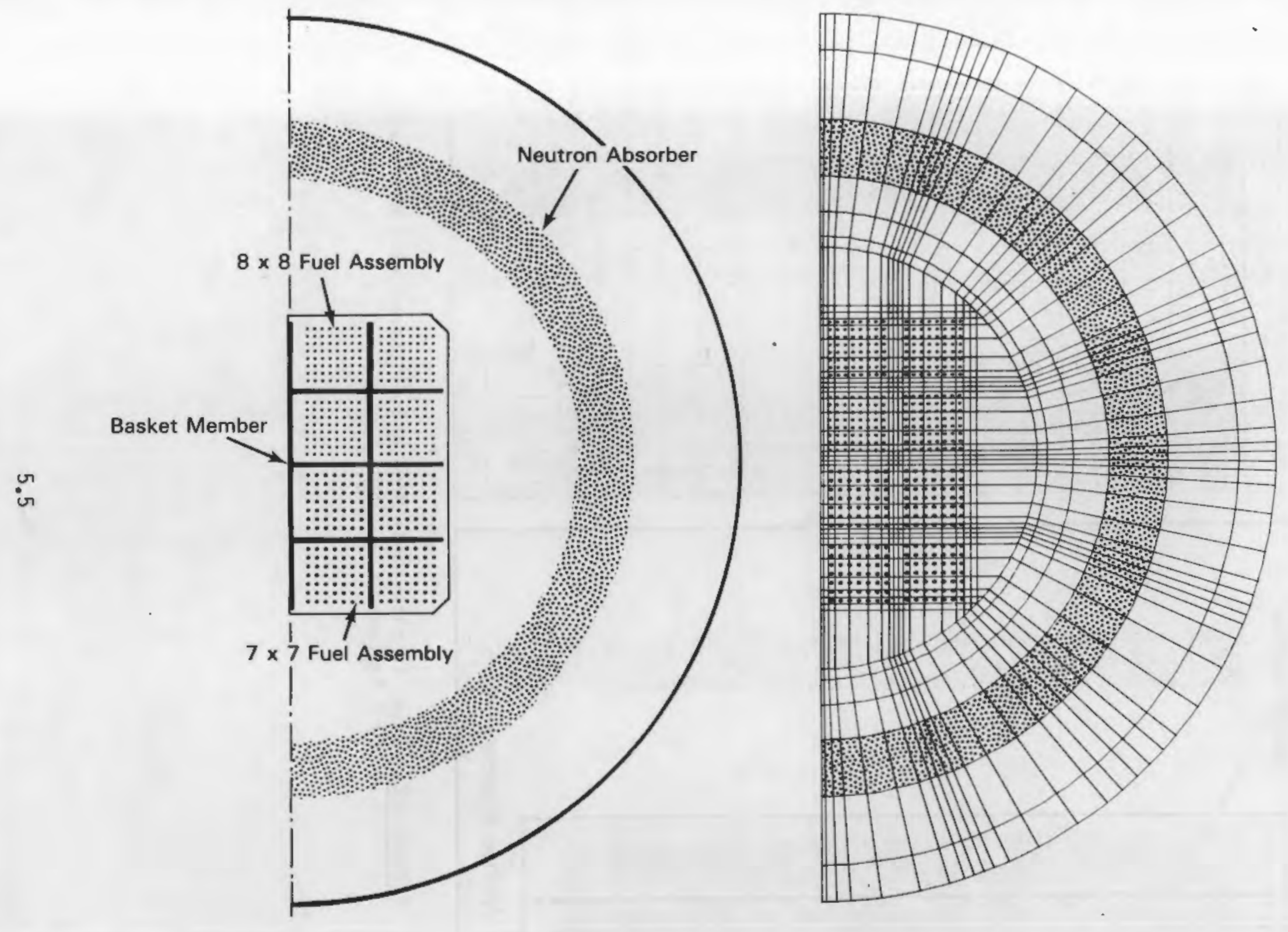

FIGURE 5.1. Transverse Computational Mesh and Alignment of Mesh with Physical Cask Features 

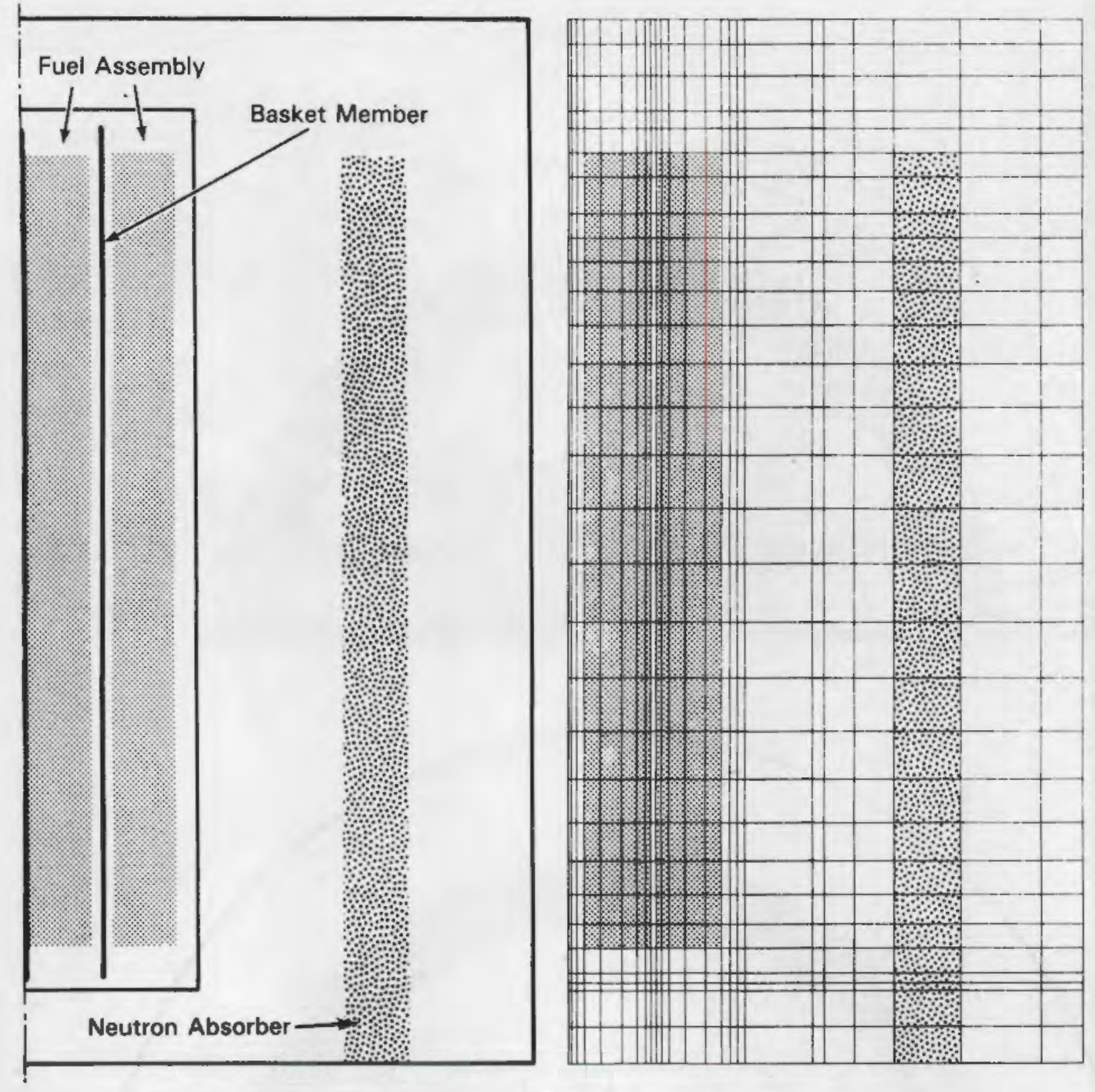

FIGURE 5.2. Axial Computational Mesh and Alignment with Physical Cask Features 
properties used for all simulations are listed in Table 5.1. Effective thermal conductivities were estimated for those computational cells containing more than one material. For those simulations where the backfill is denoted as vacuum, it is to be understood that the actual backfill is nitrogen gas at low pressure. The pressure is high enough, however, so that the mean free path of the gas is less than any significant lengths (gaps). The properties used for the vacuum simulations are, therefore, those of nitrogen.

The total heat transfer from the external surface of the cask to ambient was computed by HYDRA for both convection and radiation modes acting in parallel. Heat transfer correlations were used to predict convection heat

\section{IABLE 5.1. Material Properties}

$\begin{array}{ll}\text { Thermal Conductivity }\left(\mathrm{W} / \mathrm{cm}^{\left.2{ }^{\circ} \mathrm{K}\right)}\right. & \\ \text { Stainless steel } & 0.09215+(0.1465 \mathrm{E}-3) \mathrm{T} \\ \text { Boron steel (Radionox) } & 0.079+(0.21 \mathrm{E}-3) \mathrm{T} \\ \text { Nodular cast iron } & 0.5162-(0.3205 \mathrm{E}-3) \mathrm{T} \\ \text { Epoxy } & 0.15 \mathrm{E}-2 \\ \text { Concrete } & 0.017 \\ \text { Air } & 0.688 \mathrm{E}-4+(0.634 \mathrm{E}-6) \mathrm{T} \\ \text { Helium } & 0.52 \mathrm{E}-3+(0.32 \mathrm{E}-5) \mathrm{T} \\ \text { Nitrogen }(a) & 0.75 \mathrm{E}-4+(0.6167 \mathrm{E}-6) \mathrm{T} \\ \left.\text { Specific Heat (W sec } / \mathrm{g}^{\circ} \mathrm{K}\right) & \\ \text { Helium } & 5.234 \\ \text { Nitrogen } & 1.053 \\ \text { Viscosity (g/cm sec) } & \\ \text { Helium } & 0.700 \mathrm{E}-4+(0.400 \mathrm{E}-6) \mathrm{T} \\ \text { Nitrogen } & 0.794 \mathrm{E}-4+(0.355 \mathrm{E}-6) \mathrm{T} \\ \text { Emittance } & \\ \text { Fuel cladding } & 0.8 \\ \text { Fuel basket } & 0.4 \\ \text { Cast iron (nickel-plated) } & 0.25 \\ \text { Cast iron (smooth) } & 0.3 \\ \text { Cast iron (painted fins) } & 0.92 \text { (Measured) } \\ \text { Stainless steel } & 0.2\end{array}$

(a) Vacuum properties were the same as those for nitrogen because the vacuum was actually low-pressure nitrogen. 
transfer from the external surface of the cask to ambient. The correlations used for all external surfaces relate the Nusselt number, Nu, to the Rayleigh number, Ra, and are of the form

$$
\mathrm{Nu}=\mathrm{C}[\mathrm{Ra}(\mathrm{L})]^{\mathrm{n}}
$$

The values of $C, n$, and the significant length, $L$ are listed in Table 5.2. Correlations for smooth surfaces were taken from Sissom and Pitts (1972) and the correlations for finned surfaces were estimated from Chaddock (1970).

\subsubsection{Modeling Uncertainties}

Typical spent fuel storage casks are large and complex thermal hydraulic systems; hence, some uncertainty about how best to construct an accurate overall model will always be present. These uncertainties lead inevitably to approximations, some of which may be difficult to quantify. Most uncertainties may be placed within one of three broad categories:

1. basic information that is application-specific and measurable (e.g., cask dimensions, heat generation rates, ambient conditions)

2. information generic to most applications (e.g., property values, correlations)

3. decisions about how to achieve the best match between a particular code and the application (e.g., computational mesh, internal algorithms).

\section{TABLE 5.2. Convective Heat Transfer Correlations}

\begin{tabular}{|c|c|c|c|}
\hline Surface & $C$ & $\mathrm{n}$ & L, $\mathrm{Cm}$ \\
\hline Vertical & 0.13 & $1 / 3$ & 172.0 \\
\hline $\begin{array}{l}\text { Horizontal-heated surface } \\
\text { facing up }\end{array}$ & 0.14 & $1 / 3$ & 172.0 \\
\hline Vertical fins & 0.75 & $1 / 4$ & 8.0 \\
\hline Horizontal fins & 0.5 & $1 / 4$ & 8. \\
\hline
\end{tabular}


Some of the more important factors falling within the above categories include:

- The information shown on cask drawings may not entirely reflect the as-built cask geometry. Design information and not as-built information was normally used as HYDRA input.

- Dimensional tolerances may be particularly significant when they influence small gaps with important thermal resistances. The input to HYDRA specified nominal dimensions.

- Potential eccentricities, such as the actual location of the basket within the cask cavity, are a source of uncertainty. Other eccentricities, such as the location of a fuel assembly within a basket fuel tube, are certain to occur and can substantially alter some thermal and flow resistances. The input to HYDRA specified no eccentricities.

- Assembly decay heat generation rates and corresponding axial profiles have a direct impact on predicting cladding temperatures. Both heat generation rates and axial profiles are amenable to experimental determination, and that is the preferred approach. Predicted values were used as input to HYDRA.

- All material property values possess a range of uncertainties, although the range for most well-characterized materials is usually not significant. Exceptions include the emittance of some material surfaces, especially if the surface has been altered by some process (e.g., corrosion, crud, oxidation, or sandblasting). The HYDRA input file specified values believed to be typical. The potential consequences of a range of emittances values on predicted temperatures have not been investigated.

- Convection heat transfer coefficients, as employed on the outside surface of the cask, are known to result in approximate local heat transfer rates. The HYDRA input file specified heat transfer coefficients based on information obtained in the open literature for conditions similar, but not identical, to cask surfaces. 
- Some boundary conditions may be difficult to determine. An example is the heat loss from the cask bottom to the concrete floor upon which it rested. The HYDRA input file specified a relatively small rate of heat loss.

- Some uncertainties are inherent in the use of discrete solution methods. An example is the trade-off between mesh coarseness and accuracy. The conservation equations have been formulated within HYDRA in an entirely consistent fashion. This means that any desired numerical accuracy may be achieved by using a sufficiently large number of computational cells. The practical trade-off is between accuracy and computer time and costs. The optimum is difficult to determine a priori.

- Another source of uncertainty results from limitations of models constructed internal to the code. Thermal radiation models are a good example. All radiation enclosures within the cask are threedimensional. Two-dimensional radiation models are used extensively within HYDRA for practicality. The errors associated with this approximation can be reduced, but not eliminated, by careful selection of a computational mesh.

Finally, there is a fourth category of uncertainty not mentioned previously-muman error. The internal coding or input specifications intended may not be what is actually present. This situation is at its worst when the offending mistake results in an error that is both significant and unobtrusive.

\subsection{HYDRA PREDICTIONS COMPARED TO DATA}

Pre-look and post-test predictions of temperatures are compared to experimentally measured test data in this section. All pre-look predictions were conducted without the modeler having access to the experimental results (except cask internal gas pressure and the ambient temperature) and having not previously modeled the CASTOR-1C cask. The post-test prediction results, which conclude this section, are much improved over pre-look predictions and are in substantial agreement with test data. 
The post-test predictions benefitted from comparisons between predictions and measured temperature data. These comparisons resulted in one modification to the code input files. Post-test predictions used an assembly axial decay heat generation rate profile believed to be more representative than that used in pre-look predictions. This modification is briefly mentioned now as an aid in interpreting the pre-look predictions.

\subsubsection{HYORA Pre-Look Predictions}

This subsection includes selected temperature profiles showing the comparison between pre-look predictions and measured data. Comparisons are made for each of the three test runs that occurred on three separate dates. A11 test runs were conducted with the cask oriented vertically and backfilled with nelium gas. Most of the discussion of code predictions and comparisons to data is deferred until post-test results are presented.

Predicted and measured axial temperature profiles presented in Figure 5.3 show that temperatures are overpredicted $\left(70^{\circ} \mathrm{C}\right)$ in the lower half of the cask shile temperatures in the upper half are underpredicted $\left(70^{\circ} \mathrm{C}\right)$. Comparisons between predicted and measured peak cladding temperatures are satisfactory $\left(10^{\circ} \mathrm{C}\right)$. However, axial positions at which peak temperatures occur are not satisfactorily predicted.

Figure 5.4 shows three radial temperature profiles at an axial elevation of $266 \mathrm{~cm}$. The agreement between predictions and data $\left(15^{\circ} \mathrm{C}\right)$ is acceptable over the radius from cask center to external surface. Agreement is satisfactory because of the fortuitous axial location of the thermocouples; agreement at other axial locations would not be as good, as indicated in Figure 5.3.

Clearly, one or more phenomena are not properly accounted for in the mathematical description of the cask if it is tacitly assumed that no serious experimental data problems exist. This matter will be pursued in the following subsection on post-test simulations.

\subsubsection{HYORA Post-Test Predictions}

This subsection begins with a statement and explanation of the single input file modification that was applied to all three runs. Next, post-test comparisons are illustrated graphically as counterparts to those presented 


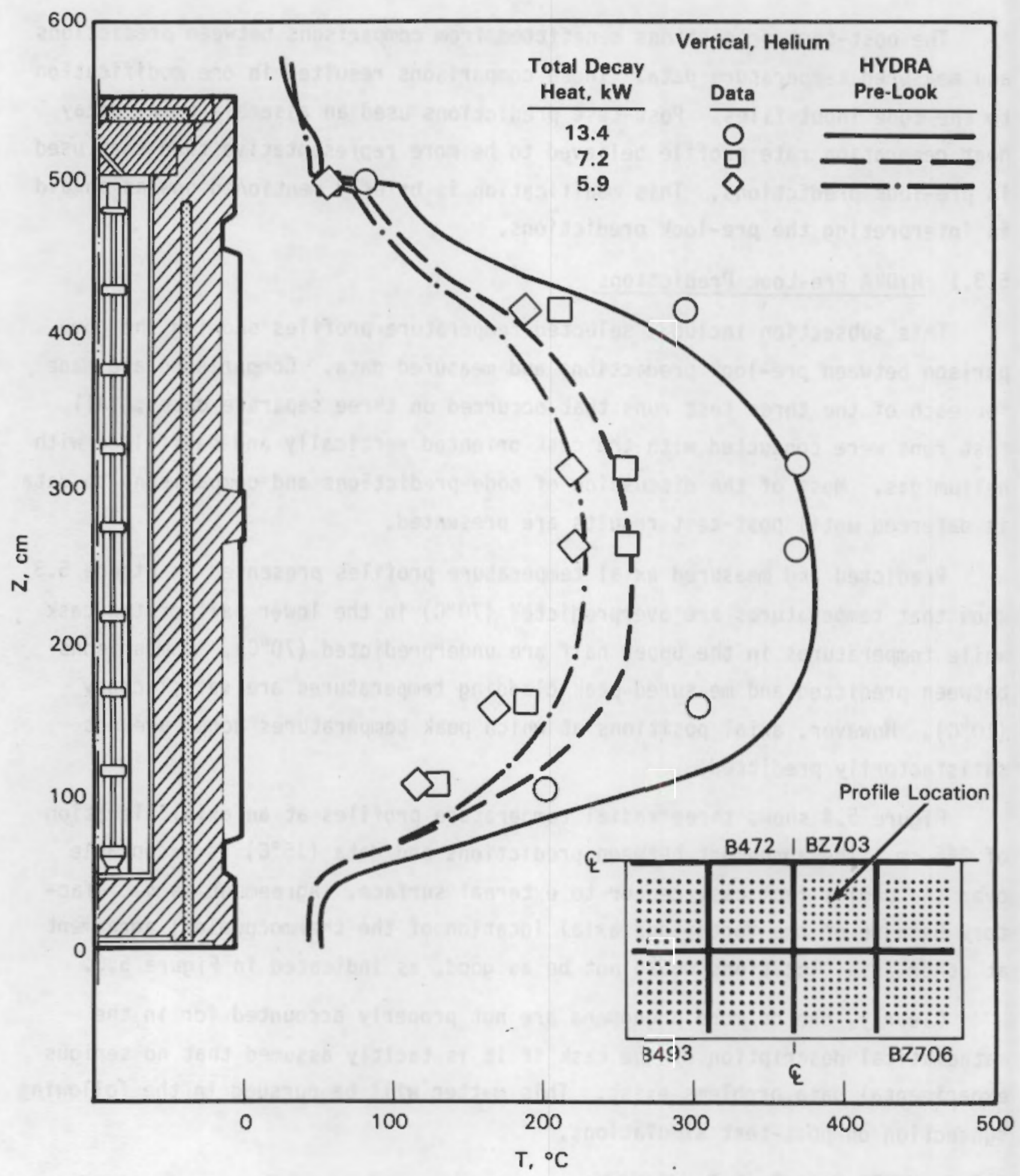

FIGURE 5.3. HYDRA Pre-Look Axial Temperature Profile Predictions Compared to Vertical, Helium Test Data 


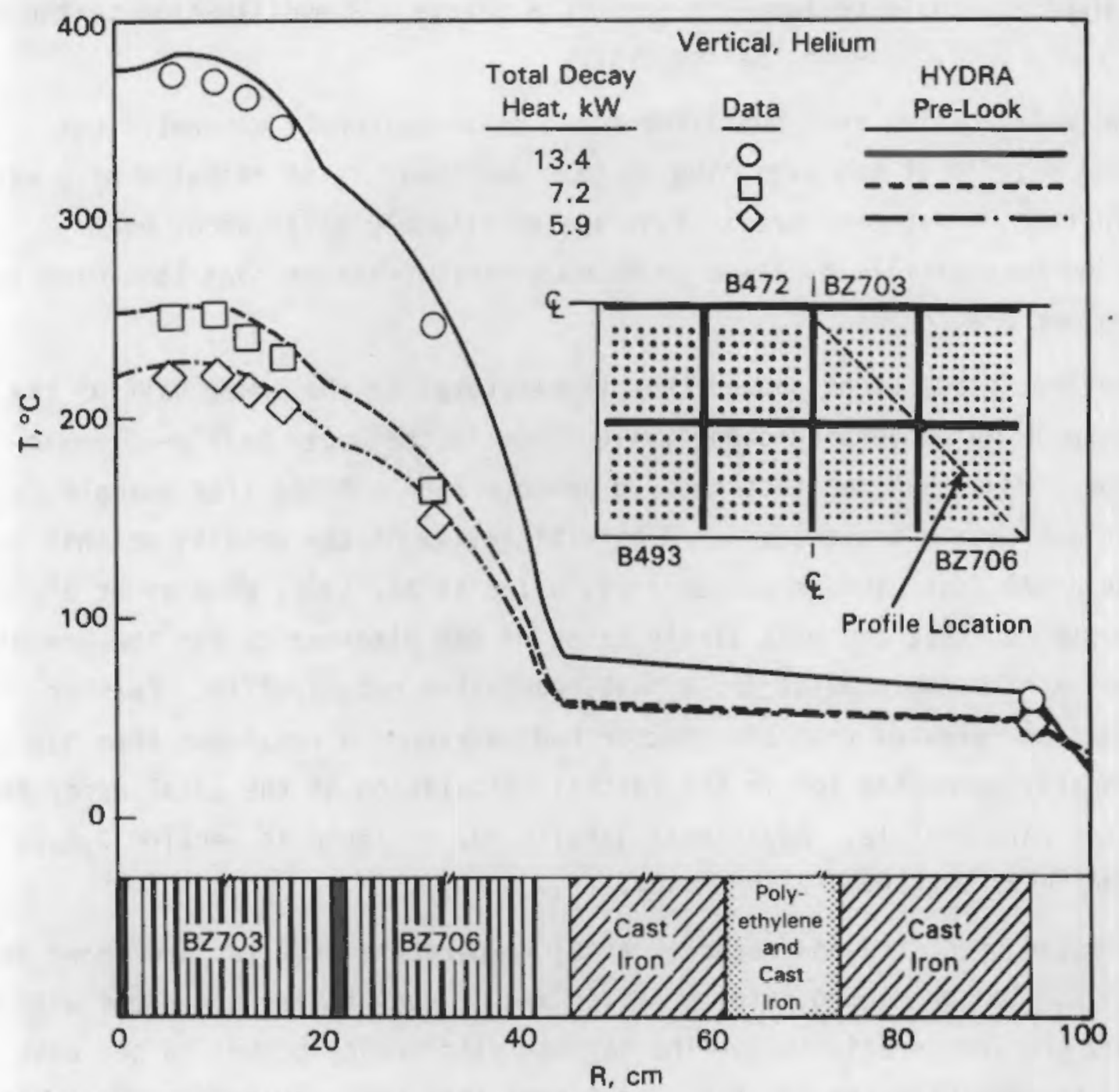

\section{FIGURE 5.4. HYDRA Pre-Look Radial Temperature Profile Predictions Compared to Vertical, Helium Test Data at $266-\mathrm{cm}$ Axial Location}

previously for pre-look comparisons. This subsection concludes with a discussion of the results of the simulations, to provide additional insight into CASTOR-1C cask performance.

After the experimental data were made available and compared to pre-look predictions, the HYDRA code and its input files were reviewed carefully. The experimental data were accepted as provided, and the experimental procedures were not examined for deficiencies that could result in errors in the reported temperature, or backfill pressure or composition. The code itself was reviewed, 
and no evidence could be found to support a change. A modification to the code input files could, however, be supported.

The modification to input files found to be uniformly warranted was mentioned briefly at the beginning of this section. It is restated here with amplification. Post-test predictions use an assembly axial decay heat generation rate profile believed to be more representative than that used in the pre-look predictions.

Pre-look predictions showed that temperatures in the lower half of the fuel assembly were overpredicted, while those in the upper half were underpredicted. More than one factor could promote such a trend (for example, insufficient upward convection). A careful review of the results of this and previous HYDRA applications (Creer 1984, Wiles et al. 1986, Wheeler et al. 1986) suggested that the most likely cause of the discrepancy was the use of an inappropriate assembly axial decay heat generation rate profile. Further investigation revealed that the reactor had undergone a coastdown that had not been properly accounted for in the initial calculation of the axial decay heat generation rate profile. Additional details may be found in Section 3.2.2, Predicted Decay Heat Generation Rates.

Selected predicted and measured axial temperature profiles are shown in Figure 5.5. The predicted axial profiles are in much better agreement with the data than pre-look predictions. The largest discrepancy occurs in the peak cladding temperatures for the high decay heat test run. This discrepancy is $12^{\circ} \mathrm{C}$, which could be reduced to $6^{\circ} \mathrm{C}$ if adjustments were made for surface temperature overpredictions.

Figure 5.6 shows predicted and measured radial temperature profiles at an axial elevation of $266 \mathrm{~cm}$. These profiles are virtually identical to those shown previously in Figure 5.4 for the pre-look results, a change of axial heat generation rate profile did not affect temperatures at this axial elevation by any substantial amount. 


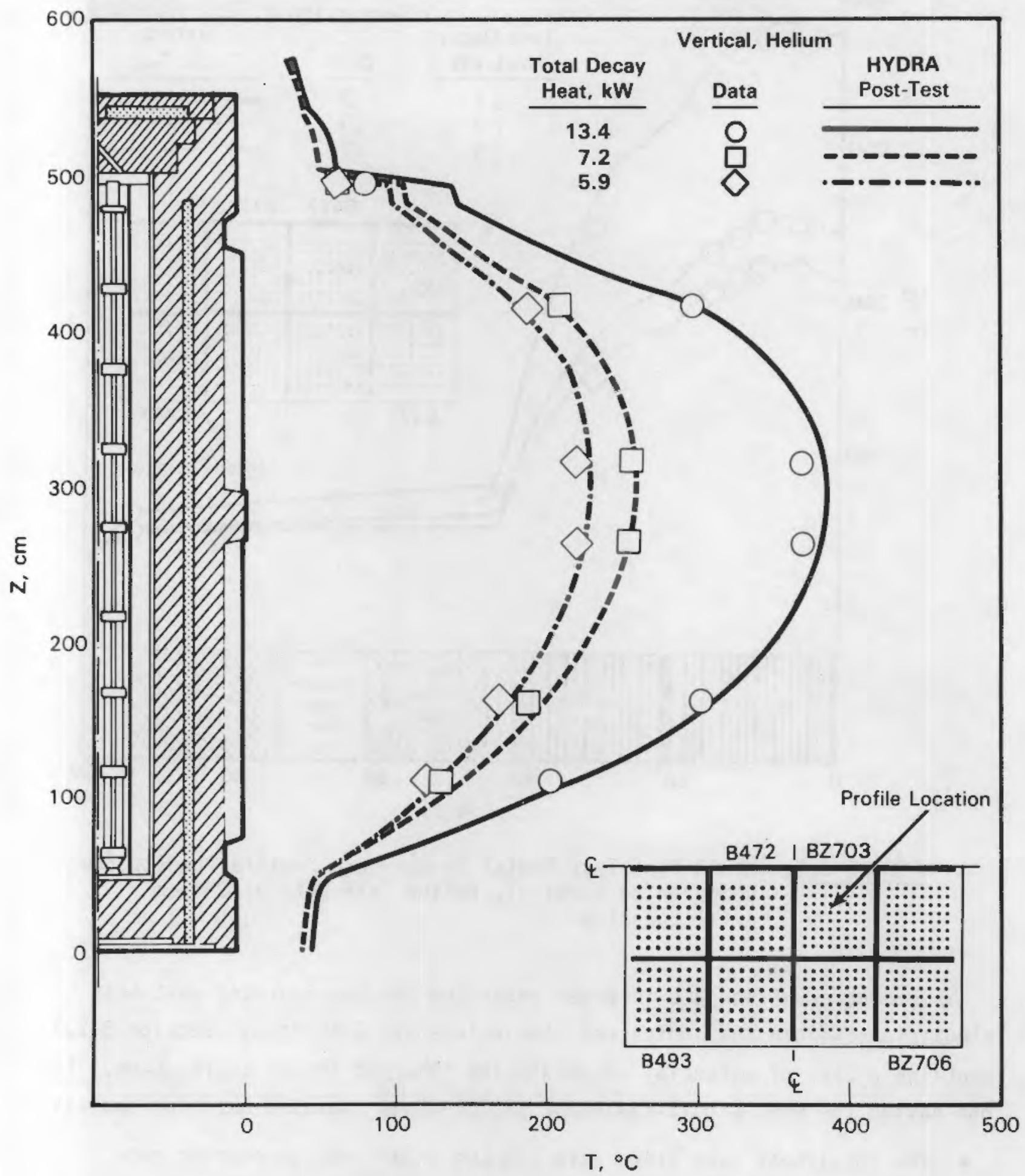

FIGURE 5.5. HYDRA Post-Test Axial Temperature Profile Predictions Compared to Vertical, Helium Test Data 


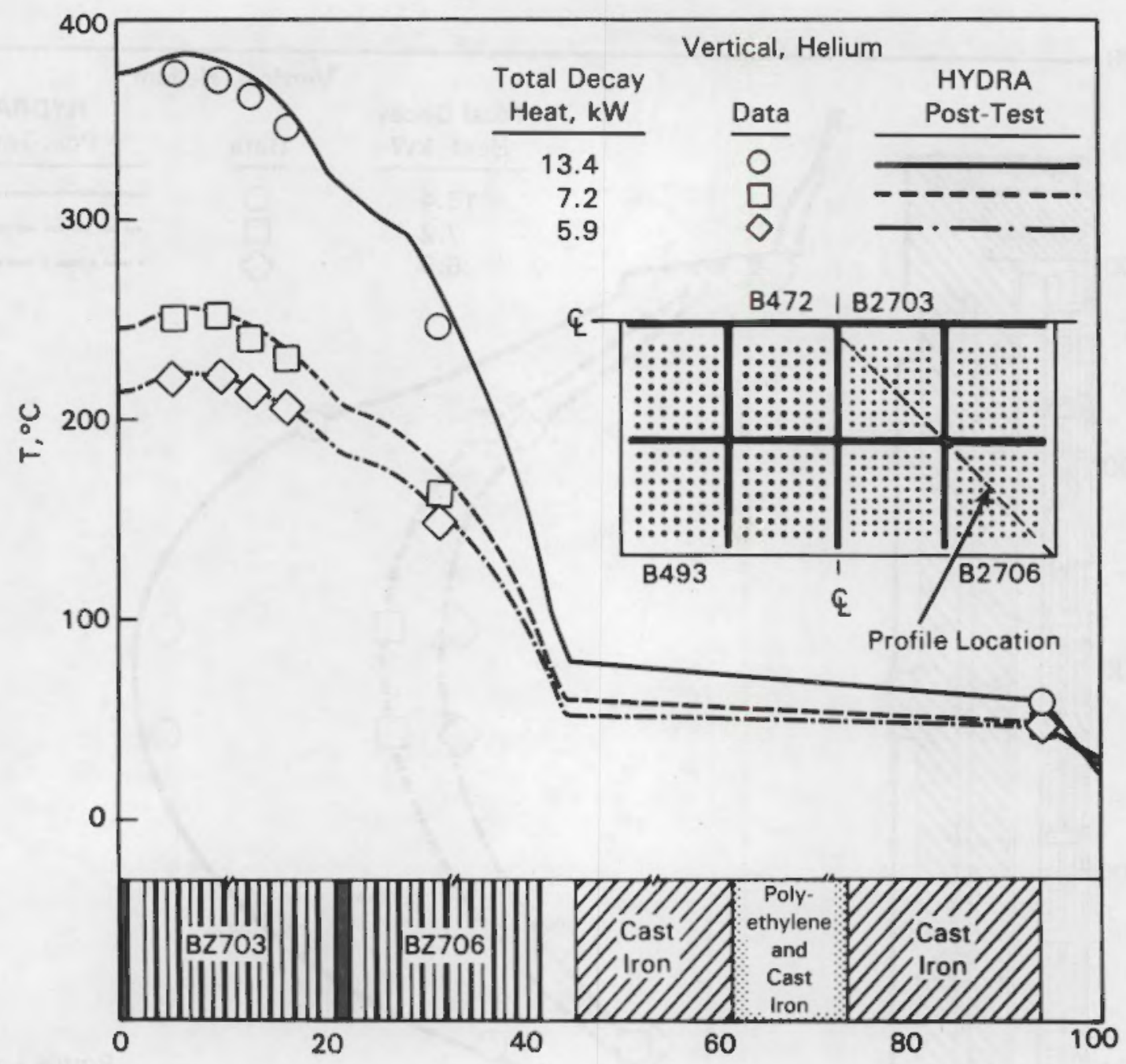

$\mathrm{R}, \mathrm{cm}$

FIGURE 5.6. HYDRA Post-Test Radial Temperature Profile Predictions Compared to Vertical, Helium Test Data at 266-cm Axial Location

Some observations are in order regarding the pre-look and post-test simulations before the additional simulations are described. Section 5.2.3 contains a list of potential uncertainties inherent in any application. The one having the most significance for CASTOR-1C is repeated here for emphasis:

- The total heat generation rate and the axial heat generation rate profile have a direct impact on predicted cladding temperature. Both the total generation rate and the axial profile are amenable to experimental determination, and that is the preferred approach. 
An estimate of the effect that the heat generation rate axial profile may have on temperature can be obtained by comparing Figures 5.3 and 5.5. The predicted temperatures at an axial elevation of $163 \mathrm{~cm}$ for the high decay heat profiles are $365^{\circ} \mathrm{C}$ and $301^{\circ} \mathrm{C}$, and the respective normalized local generation rates are 1.19 and 1.03 . The percentage difference in local temperatures is $24 \%$, and the percentage difference in local heat generation rates is $16 \%$ (the total heat generation rate is the same in both cases). The differences at other axial elevations may be more or less, and other heat generation rate profiles may also be expected to yield different results.

The above concern regarding the heat generation rate profile also applies to assembly heat generation rates. It is estimated that the percentage uncertainty in the predicted total decay heat generation rate described in Section 3.2 is $\pm 5 \%$ (one sigma confidence level). The percentage uncertainty in the profile is similarly estimated at $\pm 10 \%$. Considering these uncertainties, the agreement between predicted temperatures and measured data is perhaps better than what might be expected.

\subsection{ADDITIONAL HYDRA SIMULATIONS}

Six additional HYDRA simulations are described in this section. These simulations were performed to provide additional insight into the expected thermal performance of the CASTOR-1C cask under conditions where no data currently exist. Two of the simulations predict the maximum allowable cask decay heat dissipation; the remaining four examine various combinations of cask orientations and backfill gases.

The six simulations are:

1. uniform assembly decay heat rates to reach $400^{\circ} \mathrm{C}$, vertical orientation, helium backfill, $38^{\circ} \mathrm{C}$ ambient temperature

2. uniform assembly decay heat rates to reach $400^{\circ} \mathrm{C}$, vertical orientation, nitrogen backfill, $38^{\circ} \mathrm{C}$ ambient temperature

3. vertical orientation, nitrogen backfill, March 10, 1982, test conditions 
4. vertical orientation, vacuum backfill, March 10, 1982, test conditions

5. horizontal orientation, helium backfill, March 10, 1982, test conditions

6. horizontal orientation, nitrogen backfill, March 10, 1982, test conditions.

The relevant test conditions of March 10, 1982, are:

- $13.4 \mathrm{~kW}$ total power with each assembly generating its unique amount

- $26^{\circ} \mathrm{C}$ ambient temperature.

The axial decay heat generation rate profile employed is the same as the corrected profile used for all post-test simulations. The backfill pressure for all simulations is 0.75 bar, except for the vacuum (low-pressure nitrogen) backfill simulation, which uses 1 mbar.

The results of the first two simulations establishing the decay heat required to reach approximately $400^{\circ} \mathrm{C}$ are summarized in Table 5.3. The assembly and total decay heat predicted to be dissipated by the CASTOR-1C cask while maintaining peak cladding temperatures near $400^{\circ} \mathrm{C}$ were $844 \mathrm{~W}$ and $13.5 \mathrm{~kW}$, respectively, using helium, and $731 \mathrm{~W}$ and $11.7 \mathrm{~kW}$, respectively, using nitrogen. Therefore, the cask is predicted to dissipate $15 \%$ more heat with a helium backfill gas than with a nitrogen gas for approximately the same peak cladding temperature.

Figures 5.7 and 5.8 show fuel rod temperatures versus axial position for the two simulations. Also shown on Figure 5.7 for information are data and the post-test prediction of the high power (13.4-kW), March 10, 1982, test run.

TABLE 5.3. HYDRA Peak Cladding Temperature Predictions for Uniform Assembly Decay Heat Generation Rates

\begin{tabular}{|c|c|c|c|}
\hline Backfill Gas & $\begin{array}{c}\text { Assembly Decay } \\
\text { Heat, } W \\
\end{array}$ & $\begin{array}{c}\text { Total Decay } \\
\text { Heat, kW }\end{array}$ & 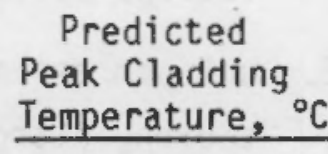 \\
\hline Helium & 844 & 13.5 & 396 \\
\hline Nitrogen & 731 & 11.7 & 401 \\
\hline
\end{tabular}




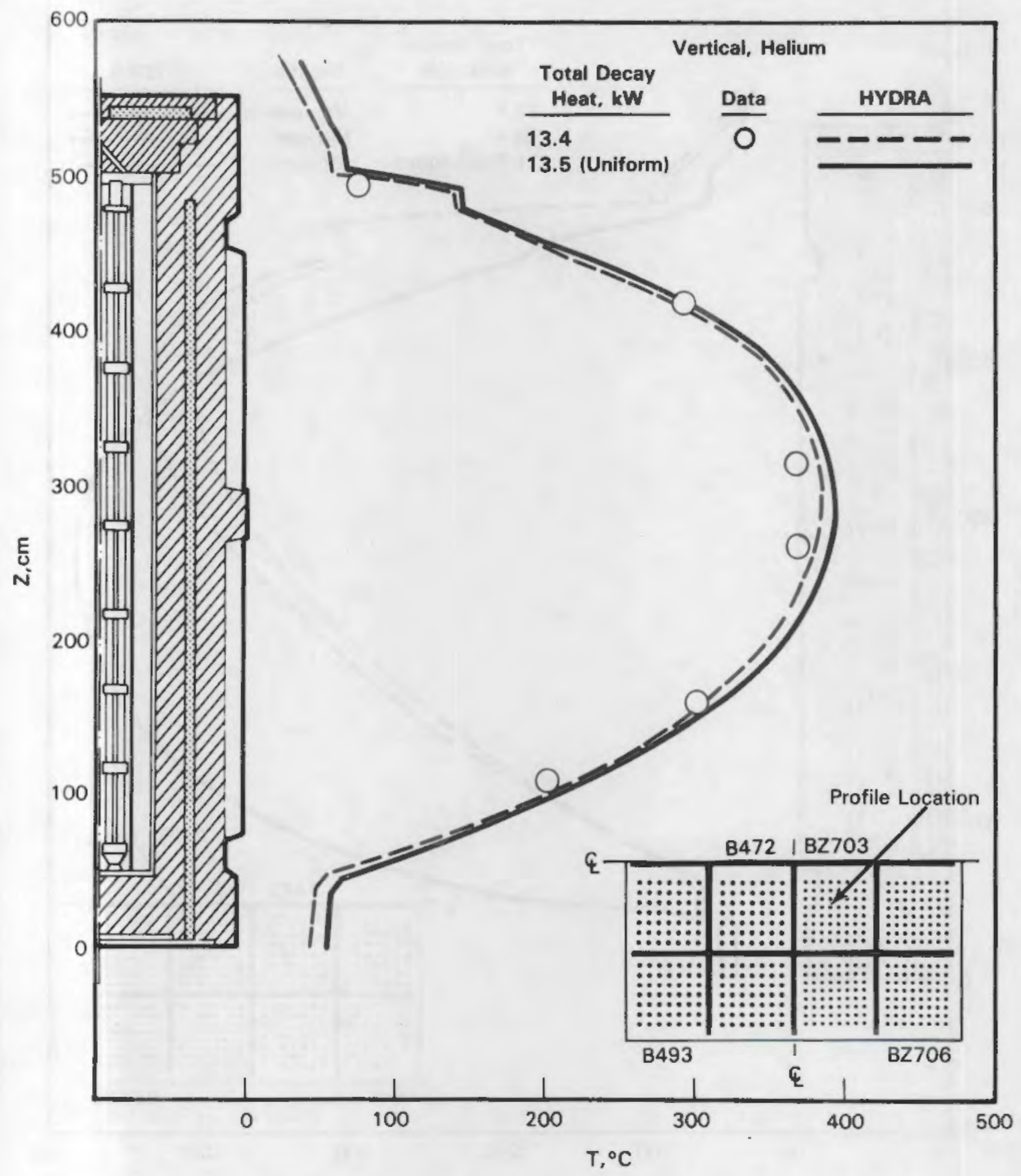

FIGURE 5.7. HYDRA Axial Temperature Profile Predictions for $13.5 \mathrm{~kW}$ Total Uniform Assembly Decay Heat Compared to Vertical, Helium Predictions and Data for 13.4 kW Total Decay Heat 


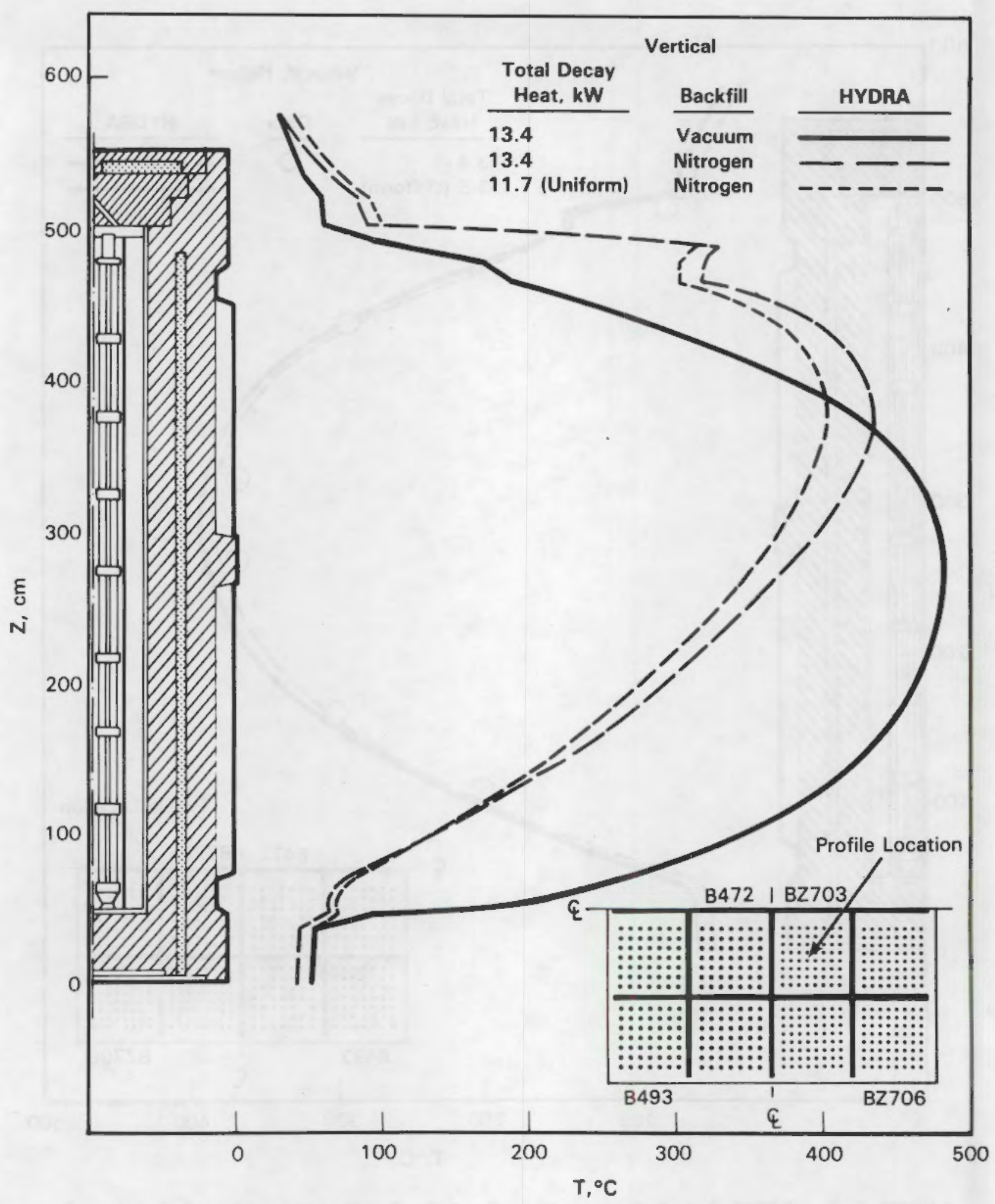

FIGURE 5.8. HYDRA Axial Temperature Profil Predictions for $11.7 \mathrm{~kW}$ Total Uniform Assembly Decay Heat in Nitrogen and for 13.4 kW Total Decay Heat in Nitrogen and Vacuum in a Vertical Orientation 
When comparing the new simulations to post-test results, note that the ambient temperatures are different and that the March 10, 1982, assembly decay heat generation rates are not uniform.

Figure 5.8 shows the results for nitrogen and vacuum backfill environments. The vacuum profile is for March 10, 1982, test conditions, and the nitrogen profile is for both March 10, 1982, test conditions and for a 11.7-kW total decay heat load and a $38^{\circ} \mathrm{C}$ ambient temperature (Part 71 licensing criteria). The predicted peak temperatures are $480^{\circ} \mathrm{C}$ in vacuum, $435^{\circ} \mathrm{C}$ in nitrogen (13.4 $\mathrm{kW}$ and March 10,1982 , test conditions), and $401^{\circ} \mathrm{C}$ for a $11.7-\mathrm{kW}$ total decay heat load and an ambient of $38^{\circ} \mathrm{C}$. The influence of convection is clearly seen by comparing the vacuum curve to the nitrogen curves. Convection is not a significant transport mechanism in the vacuum case. Another interesting feature--how the peak cladding temperature changes in response to a change in total power--is shown by comparing the two nitrogen curves. A $15 \%$ change in total decay heat $(11.7 \mathrm{~kW}$ to $13.4 \mathrm{~kW})$ resulted in a $12 \%$ change in peak cladding temperature $\left(47^{\circ} \mathrm{C}\right)$ after adjusting for the different ambient temperatures. It should be recalled that the heat generated in each fuel assembly is uniquely different in the 13.4-kW case; therefore, a comparison with the 11.7-kW case is not exact. However, the commonly observed nonlinear character of coupled conduction, convection, and radiation transport modes is indicated.

Figure 5.9 shows predicted axial temperature profiles for the cask in a horizontal orientation compared to predicted and measured profiles in a vertical orientation. Profiles in helium and nitrogen backfill gases are illustrated, along with previously shown measured and predicted profiles for the vertical, helium test runs. Axial convection is not significant in the horizontal simulations and, as Figure 5.9 suggests, axial convection is relatively unimportant in the vertical, helium backfill test run because predicted peak cladding temperatures are essentially equal and their locations are only slightly displaced. Predicted temperatures with nitrogen in a horizontal orientation are significantly hotter $\left(50^{\circ} \mathrm{C}\right)$ than those in helium cases. The profile is symmetrical about the axial midplane of the fuel assemblies, indicating a lack of convection. 


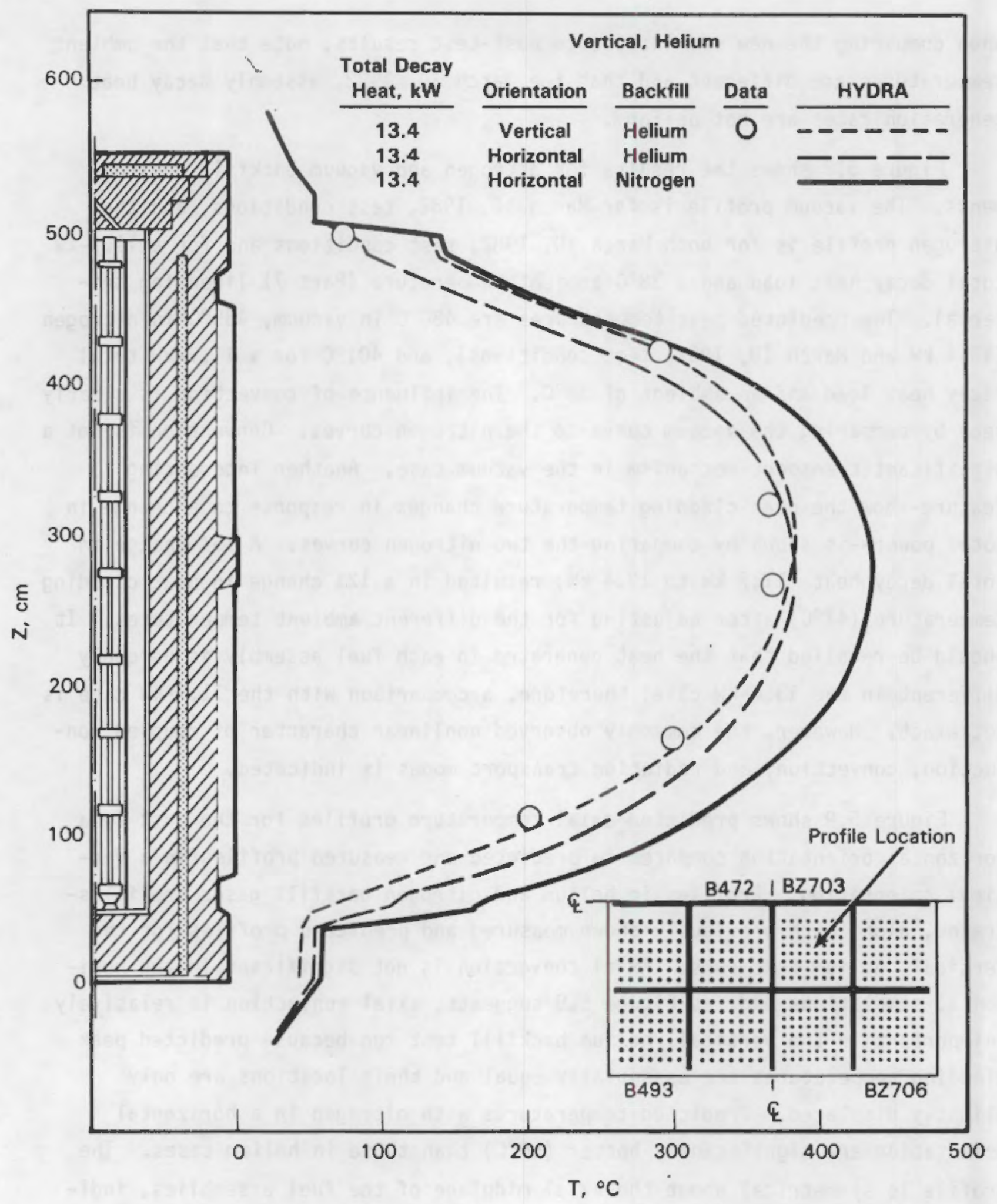

FIGURE 5.9. HYDRA Axial Temperature Profile Predictions for a Horizontal Orientation with Helium and Nitrogen Backfills Compared to Verticai Helium Predictions and Test Data 
The observations made and conclusions drawn from these simulations apply specifically to the CASTOR-1C cask. They may not be valid in all respects to casks of different configurations. The relationship of peak cladding temperature to decay heat and the relative importance of conduction, convection, and radiation transport are especially dependent on cask and basket designs. 



\subsection{SHIELDING ANALYSES}

This section includes discussions of the QAD and DOT codes used to perform the pre-look shielding analyses. The codes, the models and input, and the comparisons of predictions with experimental data are included in the discussions. The pre-look predictions were in satisfactory agreement with data, so no posttest analyses were performed.

\subsection{QAD COMPUTER CODE}

The QAD code was used to predict gamma-ray dose rates on the CASTOR-1C BWR cask outer surface. QAD and the models and input used to describe the cask are discussed in the following sections.

\subsubsection{QAD Description}

The QAD code (Malenfant 1967; ORNL 1977) was used to predict gamma-ray radiation dose rates on the outer surface of the cask. The code calculates the fast-neutron and gamma-ray penetrations through various shielding configurations using the point-kernel method. The point-kernel method involves representing the source volume by a number of point isotropic sources and computing the line-of-sight distances from each of these source points to the points of interest on the cask exterior surface. From the distances through the shielding regions and the attenuating characteristics of the shielding materials, geometric attenuation and material attenuation are determined.

The QAD code has evolved through several stages to the version used for this analysis, QAD-CG (ORNL 1977). It contains the MORSE combinatorial geometry subroutines (Straker et al. 1970) which permit accurate descriptions of physical systems.

\subsubsection{QAD Model and Input}

The CASTOR-1C cask has one-eighth symmetry; therefore, it was not necessary to model the complete cask in detail. Figure 6.1 shows an elevation view of the cask model with the origin of the coordinate system at the bottom center 


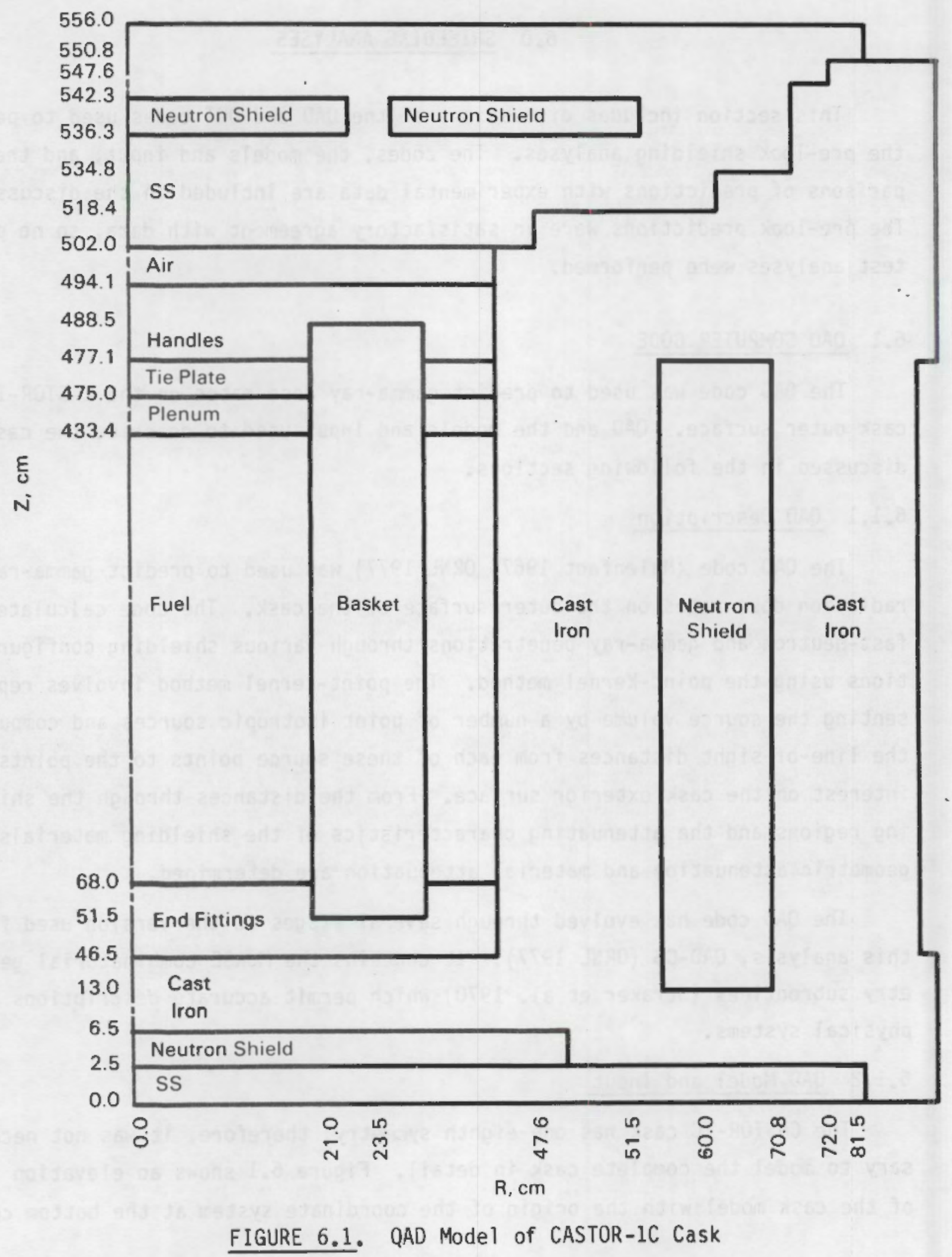


of the cask. Relative axial positions are shown, and, for illustration, the basket is separated from the end fittings, fuel, plenum, tie plate, and handles. The feet of the basket are not shown in Figure 6.1. Gaps between portions of the lids and between the lids and cask body are omitted; thus, the height of the cask model in Figure 6.1 is slightly less than that given in design drawings. Dimensions for cylindrical components are shown, and the various lids are shown as one region.

The cross section of the cask between elevations $46.5 \mathrm{~cm}$ and $477.1 \mathrm{~cm}$ is shown in Figure 6.2. Only one-fourth of the cask was modeled in detail, and the cooling fins were omitted because the dose rate measurements were taken between the fins at their base. The radial locations of the polyethylene moderator cylinders that provide radial neutron shielding are shown in Figure 6.3 . A total of 80 moderator cylinders are contained in the cast-iron body of the cask. A top view of the cask (upper right corner) is shown in Figure 6.4. The smaller circle at $R=81.5 \mathrm{~cm}$ is the top lid, which sits on the cast-iron cask body. A bottom view of the cask is shown in Figure 6.5. The full circle at $R=81.5 \mathrm{~cm}$ is the bottom plate covering the neutron shield.

The basket and fuel assemblies are shown in Figure 6.6. The fuel assemblies were modeled as homogeneous mixtures of fuel, cladding, and helium. Likewise, the end fittings, plenums, tie plates, and handles were assumed to be homogeneous mixtures. Their cross-sectional areas were the same as the fuel cross sectional area.

It was assumed that the stainless steel in the end fittings contained $200 \mathrm{ppm}$ of cobalt while the stainless steel in the plenum, tie plate, and handles contained $2000 \mathrm{ppm}$ of cobalt. It was assumed that the $7 \times 7$ assemblies contained $195 \mathrm{~kg}$ of uranium, while the $8 \times 8$ assemblies contained $185 \mathrm{~kg}$ of uranium. The elemental and basic material densities used in the QAD model are given in Table 6.1 . 


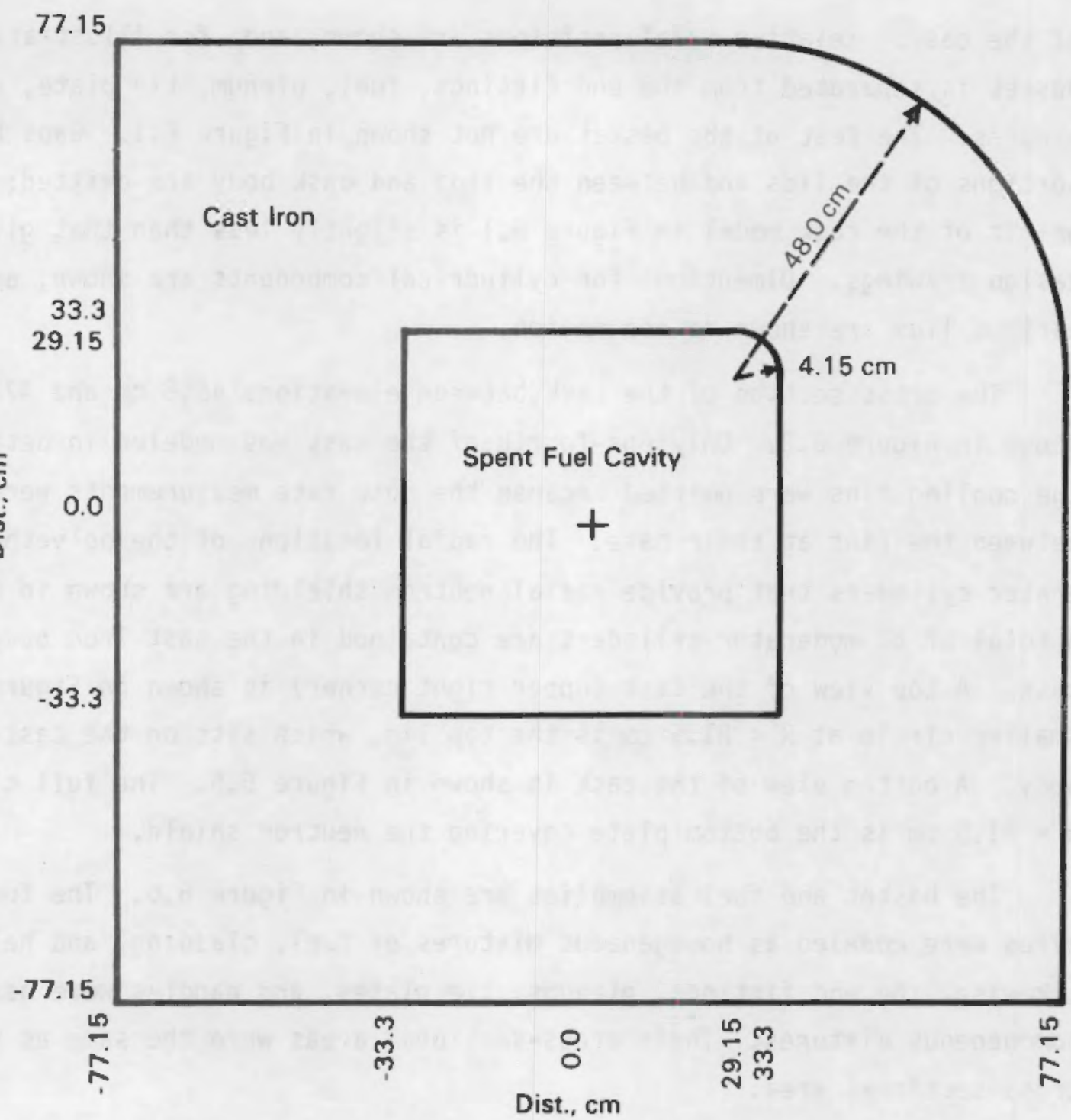

FIGURE 6.2. CASTOR-1C Cask Cross Section

Neutron and photon source terms for the fuel were based on the ORIGEN2 calculations described in Section 3.2.2. The average exposure of the fuel assemblies loaded into the cask was 27,850 MWd/MTU. The range of exposures was 27,200 to $28,500 \mathrm{MWd} / \mathrm{MTU}$. The neutron source term was $8.409 \times 10^{8} \mathrm{n} / \mathrm{sec}$. The average values of the most important photon groups are given in Table 6.2. Because the variance in exposure was very small, it was assumed that the $X-Y$ shape was flat. The shape of the photon source in the $Z$ direction was based on 


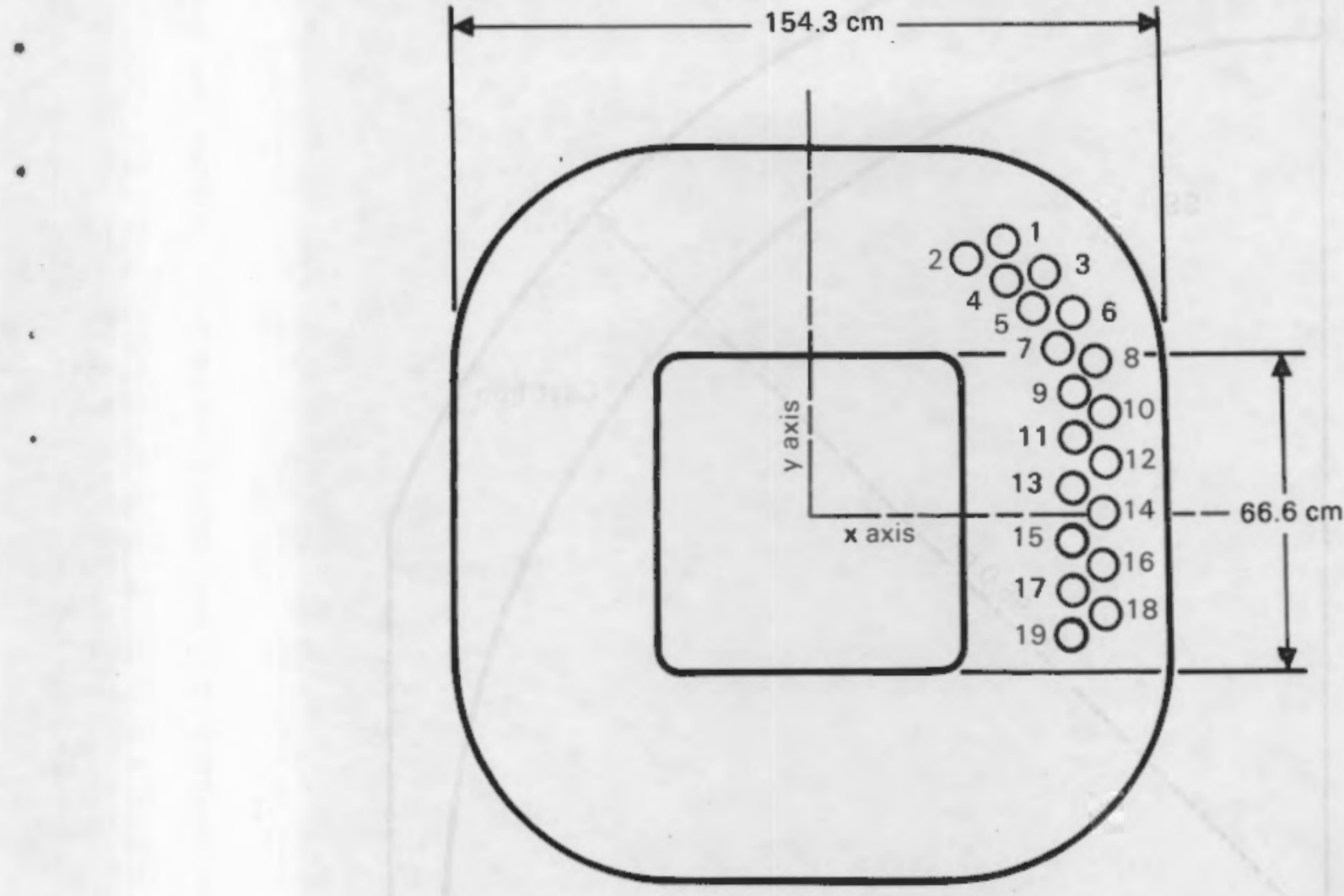

Moderator Tube Centerline Coordinates

\begin{tabular}{|c|c|c|c|}
\hline ID No. & $\mathrm{X}, \mathrm{cm}$ & $\mathrm{Y}, \mathrm{cm}$ & $\mathrm{A}, \mathrm{cm}$ \\
\hline 1 & 41.68 & 57.07 & 70.67 \\
\hline 2 & 34.16 & 53.67 & 63.62 \\
\hline 3 & 50.32 & 50.32 & 71.16 \\
\hline 4 & 42.20 & 48.84 & 64.55 \\
\hline 5 & 48.84 & 42.20 & 64.55 \\
\hline 6 & 57.07 & 41.68 & 70.67 \\
\hline 7 & 53.67 & 34.16 & 63.62 \\
\hline 8 & 61.53 & 31.66 & 69.20 \\
\hline 9 & 56.42 & 25.19 & 61.79 \\
\hline 10 & 63.44 & 20.86 & 66.78 \\
\hline 11 & 57.0 & 16.05 & 59.22 \\
\hline 12 & 63.5 & 10.7 & 64.40 \\
\hline 13 & 57.0 & 5.35 & 57.25 \\
\hline 14 & 63.5 & 0 & 63.50 \\
\hline 15 & 57.0 & -5.35 & 57.25 \\
\hline 16 & 63.5 & -10.7 & 64.40 \\
\hline 17 & 57.0 & -16.05 & 59.22 \\
\hline 18 & 63.44 & -20.86 & 66.78 \\
\hline 19 & 56.42 & -25.19 & 61.79 \\
\hline
\end{tabular}

FIGURE 6.3. Radial Locations of Polyethylene Moderator Rods 


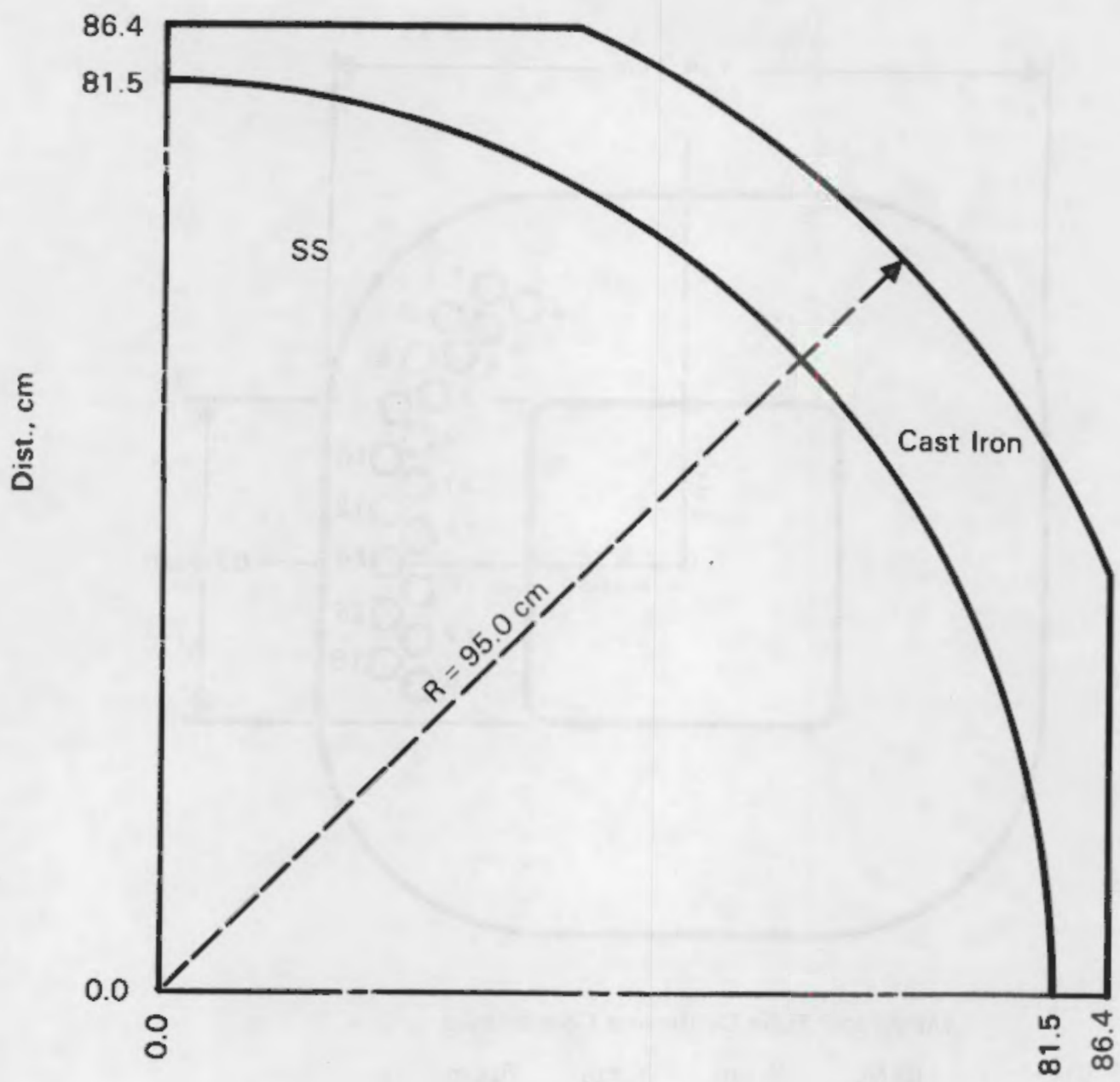

Dist., $\mathrm{cm}$

FIGURE 6.4. Top View of Cask

the relative burnup curve shown in figure 6.7. The implication is that the photon source strength is nearly proportional to burnup. Values were read from Figure 6.7 for input to $Q A D$. The relative values are given in Table 6.3 .

In addition to the gamma-rays from the fuel, other gamma-rays are produced in the stainless steel structural materials because of the presence of the cobalt impurity. During irradiation, neutron captures by ${ }^{59} \mathrm{Co}$ produce ${ }^{60} \mathrm{Co}$, which has a half-life of 5.272 years. Each ${ }^{60}$ Co decay results in two photons, one with an energy of $1.332 \mathrm{MeV}$ and the other with an energy of $1.173 \mathrm{MeV}$. 


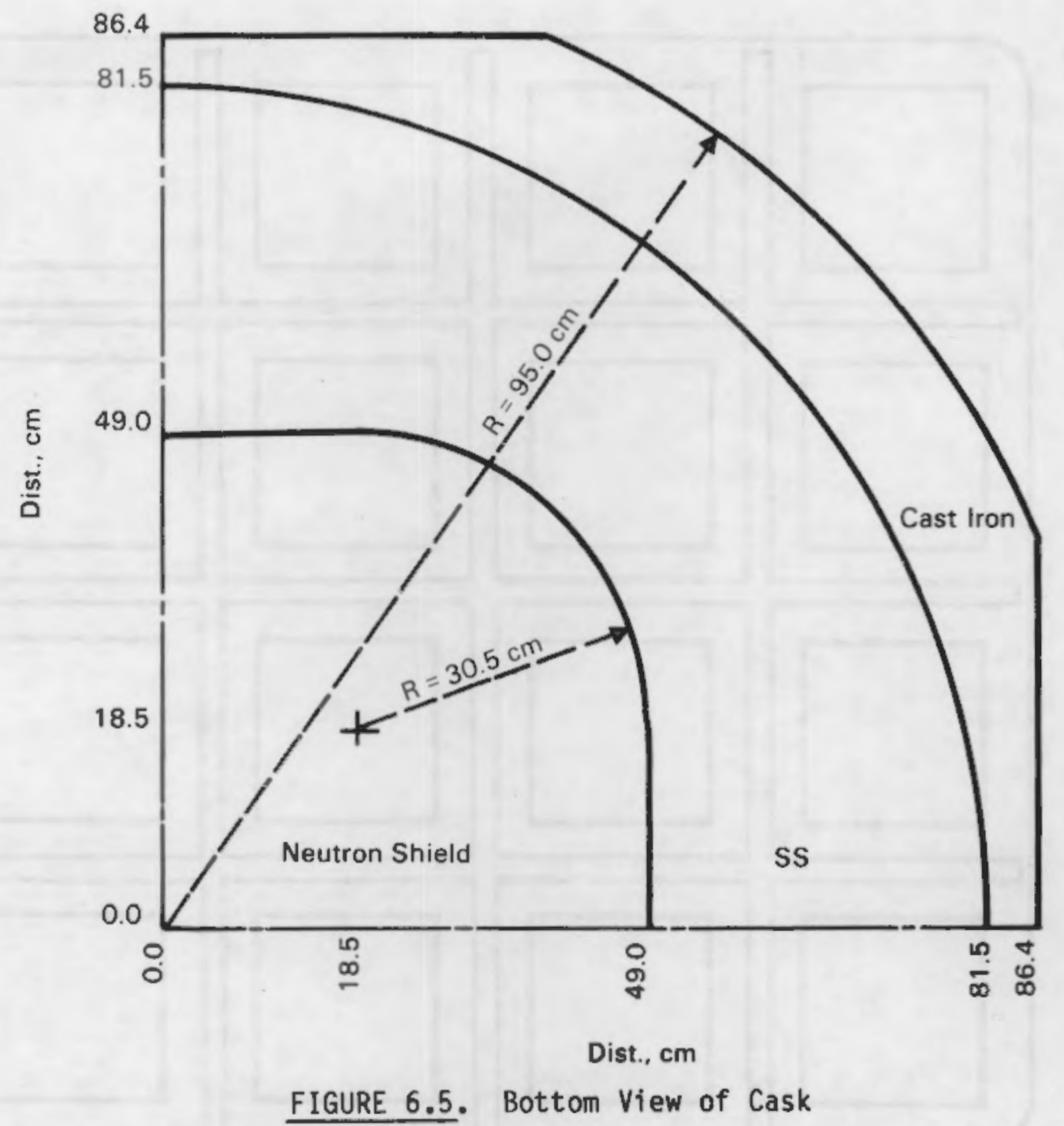

The ${ }^{60}$ Co activity was calculated using the XSORN code (ORNL 1969). The fuel and the regions above and below the fuel were modeled as slab regions. Above the fuel, the exit void fraction is assumed to be 0.742 . The ${ }^{60} \mathrm{Co}_{0}$ activations in each region are given in Table 6.4 for an exposure of $27,850 \mathrm{MWd} / \mathrm{MTU}$. A composite correction factor of 0.608 was applied to each number to account for in-reactor decay and post-irradiation decay. The decay factor assumes a measurement date of March 10, 1982. 


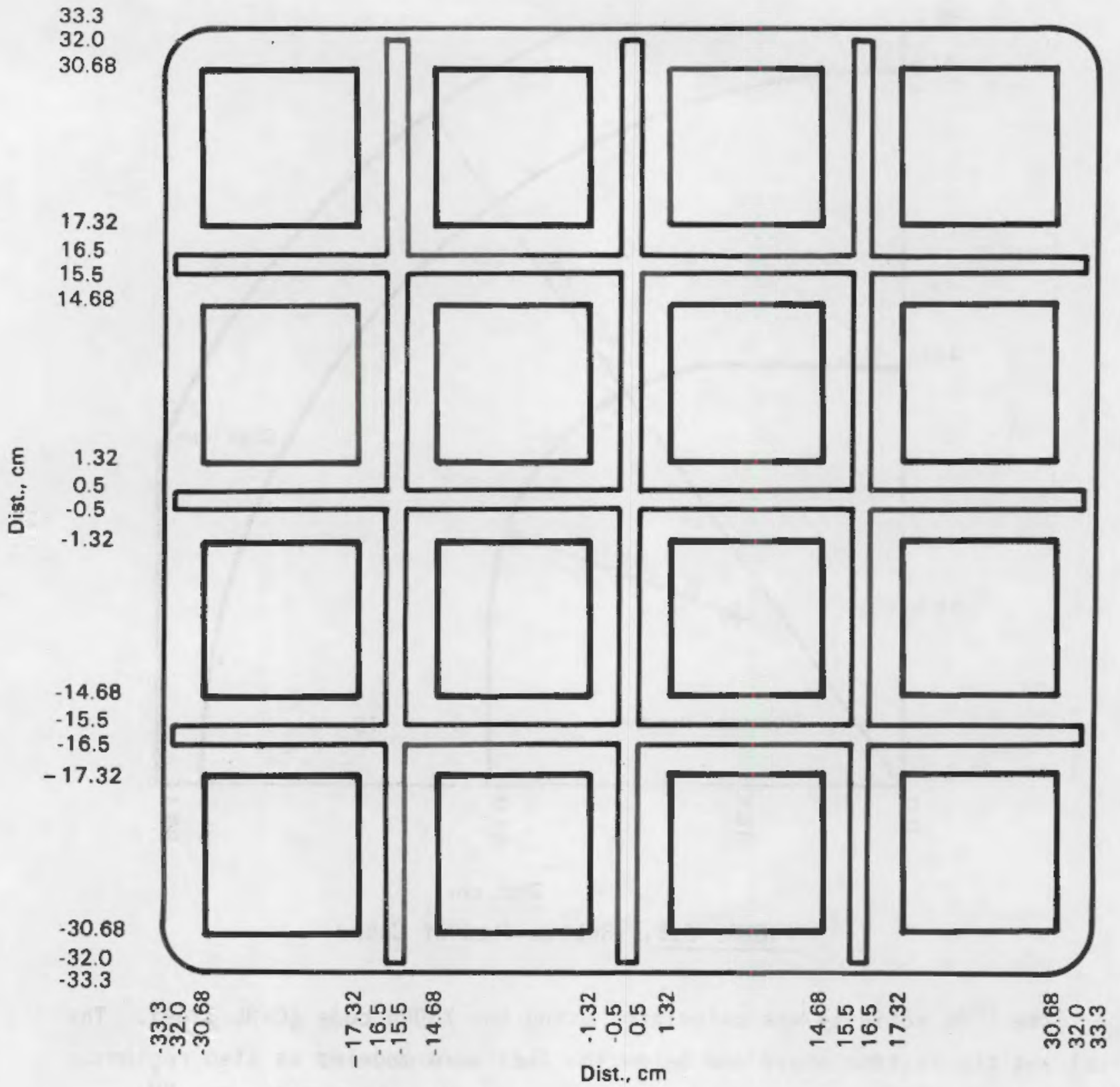

FIGURE 6.6. Cask Basket and Fuel Assemblies

The activation rate as a function of position within each region was also calculated with XSDRN. The values used in QAD are given in Table 6.5. Again, a flat source distribution was used in the $X-Y$ plane. 
TABLE 6.1. Material 0ensities for QAO Input

\begin{tabular}{|c|c|c|c|c|c|c|c|c|c|}
\hline \multirow[b]{2}{*}{ Material } & \multicolumn{9}{|c|}{ Density, $\mathrm{g} / \mathrm{cm}^{3}$} \\
\hline & $\mathrm{H}$ & C & 0 & $\mathrm{Cr}$ & $\mathrm{Mn}$ & $\mathrm{Fe}$ & $\mathbf{N i}$ & $\mathrm{Zr}$ & Ut \\
\hline Neutron shield & 0.065 & 0.692 & 0.163 & - & -- & -- & -- & - & -- \\
\hline Stainless steel & -- & -- & -- & 1.426 & 0.158 & 5.702 & 0.634 & -- & - \\
\hline End fittings & -- & -- & -- & 0.271 & 0.030 & 1.085 & 0.121 & - & -- \\
\hline Fuel & -- & -- & 0.402 & -- & - & -- & -- & 0.565 & 2.990 \\
\hline Plenum & -- & -- & -- & 0.043 & 0.005 & 0.173 & 0.019 & 1.128 & -- \\
\hline Tie plate & -- & -- & -- & 0.797 & 0.089 & 3.188 & 0.354 & -- & -- \\
\hline \multirow[t]{7}{*}{ Handles } & -- & -- & -- & 0.032 & 0.004 & 0.126 & 0.014 & - & -- \\
\hline & \multicolumn{6}{|c|}{ Basic Material Oensities } & & & \\
\hline & \multicolumn{3}{|c|}{ Material } & \multicolumn{3}{|c|}{ Density, $\mathrm{g} / \mathrm{cm}^{3}$} & & & \\
\hline & \multicolumn{3}{|c|}{ Iron } & \multicolumn{3}{|c|}{7.25} & & & \\
\hline & \multicolumn{3}{|c|}{ Stainless steel } & \multicolumn{3}{|c|}{7.92} & & & \\
\hline & \multicolumn{3}{|c|}{ Polyethylene } & \multicolumn{3}{|c|}{0.92} & & & \\
\hline & \multicolumn{3}{|c|}{ Zirconium } & & 6.4 & & & 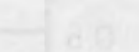 & \\
\hline
\end{tabular}

TABLE 6.2. Photon Source Strengths for QAO Input

\begin{tabular}{|c|c|}
\hline $\mathrm{E}, \mathrm{MeV}$ & Photons/sec \\
\hline 1.25 & $1.376+15$ \\
\hline 1.75 & $1.020+14$ \\
\hline 2.25 & $1.457+14$ \\
\hline 2.75 & $2.943+12$ \\
\hline
\end{tabular}




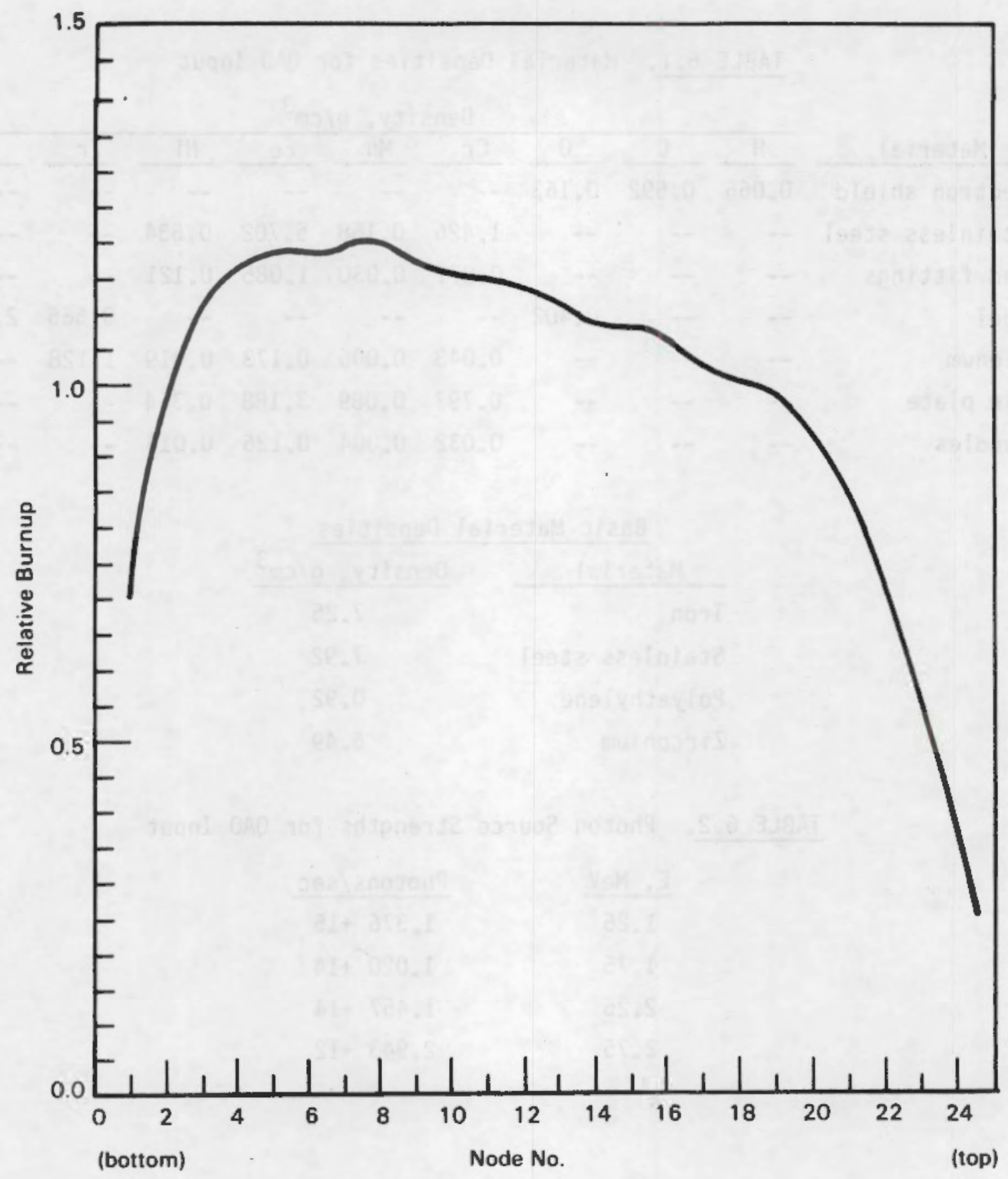

FIGURE 6.7. Axial Burnup Shape for Wurgassen Fuel Assemblies 
TABLE 6.3. Axial Gamma-Ray Source Shape for QAD Input

\begin{tabular}{rc}
$Z, \mathrm{~cm}$ & Relative Value \\
\cline { 2 - 2 } 78.0 & 0.50 \\
75.0 & 0.70 \\
90.0 & 0.97 \\
110.0 & 1.13 \\
130.0 & 1.18 \\
150.0 & 1.18 \\
170.0 & 1.19 \\
190.0 & 1.18 \\
210.0 & 1.16 \\
230.0 & 1.14 \\
250.0 & 1.12 \\
270.0 & 1.08 \\
290.0 & 1.07 \\
310.0 & 1.04 \\
330.0 & 1.01 \\
350.0 & 0.97 \\
370.0 & 0.87 \\
390.0 & 0.74 \\
410.0 & 0.53 \\
420.0 & 0.43 \\
425.0 & 0.37 \\
430.0 & 0.30 \\
433.4 & 0.25
\end{tabular}

TABLE 6.4. ${ }^{60}$ Co Source Strengths for QAD Input for Sixteen Assemblies

\begin{tabular}{lccc}
\multicolumn{1}{c}{ Region } & Activations, atoms & & Source, $\gamma / \mathrm{sec}$ \\
\cline { 5 - 5 } End fittings & $2.01+21$ & & $1.02+13$ \\
Plenum & $3.14+22$ & & $1.59+14$ \\
Tie plate & $1.22+22$ & & $6.18+13$ \\
Handles & $2.88+21$ & & $1.46+13$
\end{tabular}


TABLE 6.5. Axial ${ }^{60}$ Co Source Shapes for QAD Input

\begin{tabular}{|c|c|c|c|}
\hline \multicolumn{2}{|c|}{ End Fittins } & \multicolumn{2}{|c|}{ Plenum } \\
\hline Z, cm & $\begin{array}{l}\text { Relative } \\
\text { Value }\end{array}$ & $\underline{Z, \mathrm{~cm}}$ & $\begin{array}{l}\text { Relative } \\
\text { Value }\end{array}$ \\
\hline 46.5 & 0.09 & 433.4 & 1.28 \\
\hline 55.0 & 0.43 & 440.0 & 1.34 \\
\hline 60.0 & 1.03 & 450.0 & 1.16 \\
\hline 65.0 & 2.24 & 460.0 & 0.89 \\
\hline 68.0 & 2.75 & 470.0 & 0.58 \\
\hline & & 475.0 & 0.53 \\
\hline
\end{tabular}

\begin{tabular}{|c|c|}
\hline Z, $\mathrm{cm}$ & $\begin{array}{l}\text { Plate } \\
\text { Relative } \\
\text { Value }\end{array}$ \\
\hline 475.0 & 1.10 \\
\hline 476.1 & 1.00 \\
\hline 477.1 & 0.90 \\
\hline
\end{tabular}

\begin{tabular}{|c|c|}
\hline \multicolumn{2}{|c|}{ Handle } \\
\hline $\mathrm{Z}, \mathrm{cm}$ & $\begin{array}{l}\text { Relative } \\
\text { Value }\end{array}$ \\
\hline 477.1 & 1.30 \\
\hline 480.0 & 1.27 \\
\hline 485.0 & 1.03 \\
\hline 490.0 & 0.80 \\
\hline 494.1 & 0.65 \\
\hline
\end{tabular}

\subsection{DOT COMPUTER CODE}

The DOT code (Rhoades and Childs 1982) was used to predict neutron dose rates on the cask outer surface. DOT and the models and input used to describe the cask are discussed in the following sections.

\subsubsection{DOT Oescription}

The DOT code calculates neutron and photon particle fluxes in two dimensions using the method of discrete ordinates to solve the Boltzmann transport equation. Balance equations are solved for the flow of particles moving in a set of discrete directions in each cell of a space mesh and in each group of a multigroup energy structure. Discrete directions are selected by the user. The mesh spacings are also selected by the user. Anisotropic cross sections can be expressed in a Legendre expansion of arbitrary order.

The DLC-85 library (Ford et a1. 1980) was used for this analysis. It is a coupled neutron/photon library with $P_{3}$ cross sections. The neutron cross sections are represented in 22 energy groups, and the photon cross sections are represented in 21 energy groups.

\subsubsection{DOT Models and Input}

The cask was modeled using $R-Z$ geometry as shown in Figure 6.8 . The fuel and structural material were modeled as a homogeneous mixture. Likewise, the end fittings, plenum, tie plate, and handle regions are homogeneous mixtures with the structural material. 


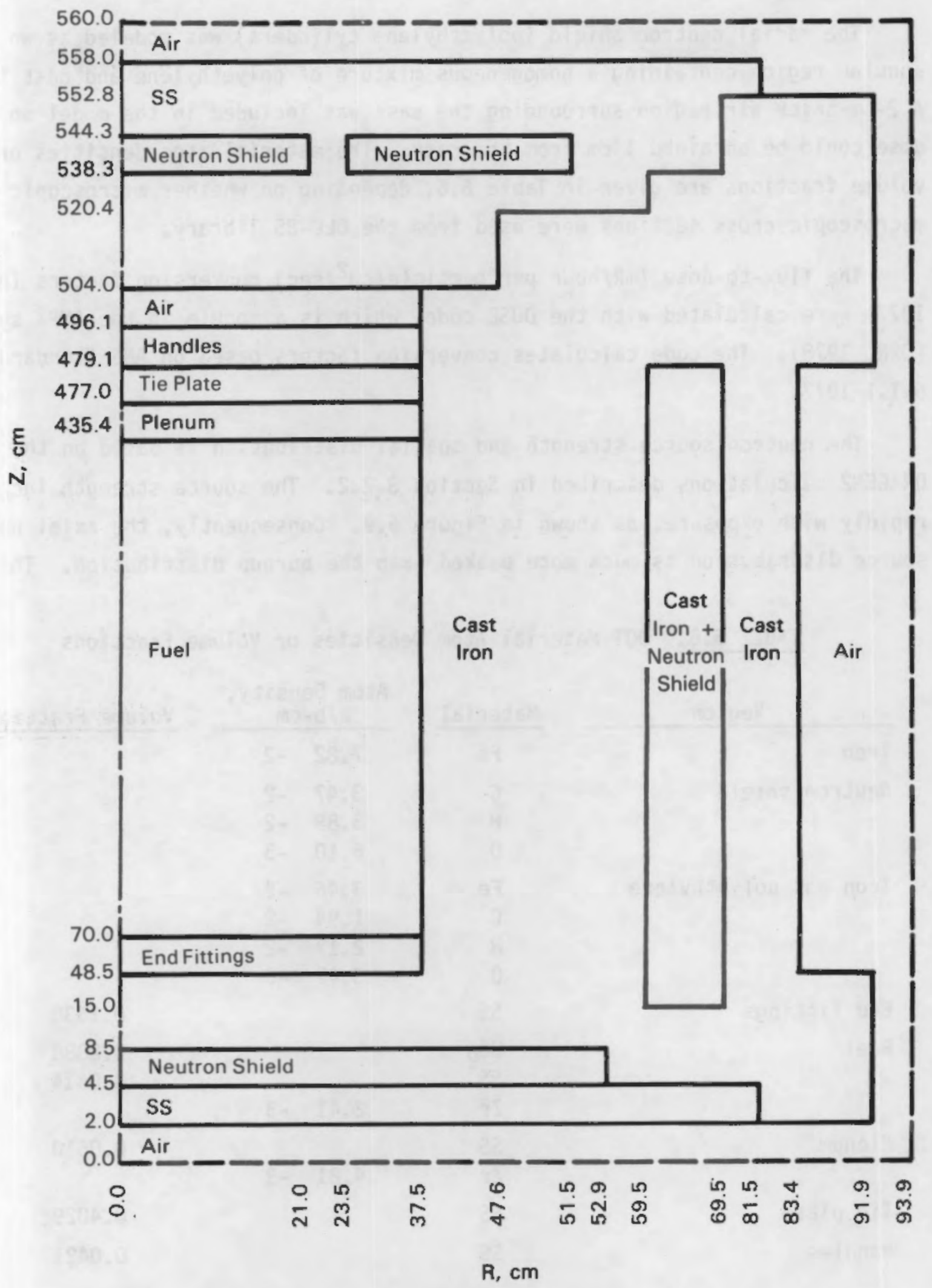

FIGURE 6.8. DOT Model of CASTOR-1C Cask 
The radial neutron shield (polyethylene cylinders) was modeled as an annular region containing a homogeneous mixture of polyethylene and cast iron. A 2-cm-thick air region surrounding the cask was included in the model so the dose could be obtained $1 \mathrm{~cm}$ from the cask. The material atom densities or volume fractions are given in Table 6.6, depending on whether microscopic or macroscopic cross sections were used from the DLC-85 library.

The flux-to-dose (mR/hour per particle/ $\mathrm{cm}^{2} / \mathrm{sec}$ ) conversion factors (ANSI 1977) were calculated with the DOSE code, which is a module in the AMPX system (ORNL 1978). The code calculates conversion factors based on ANS Standard 6.1.1-1977.

The neutron source strength and spatial distribution is based on the ORIGEN2 calculations described in Section 3.2.2. The source strength increases rapidly with exposure, as shown in Figure 6.9. Consequently, the axial neutron source distribution is much more peaked than the burnup distribution. The

TABLE 6.6. DOT Material Atom Densities or Volume Fractions

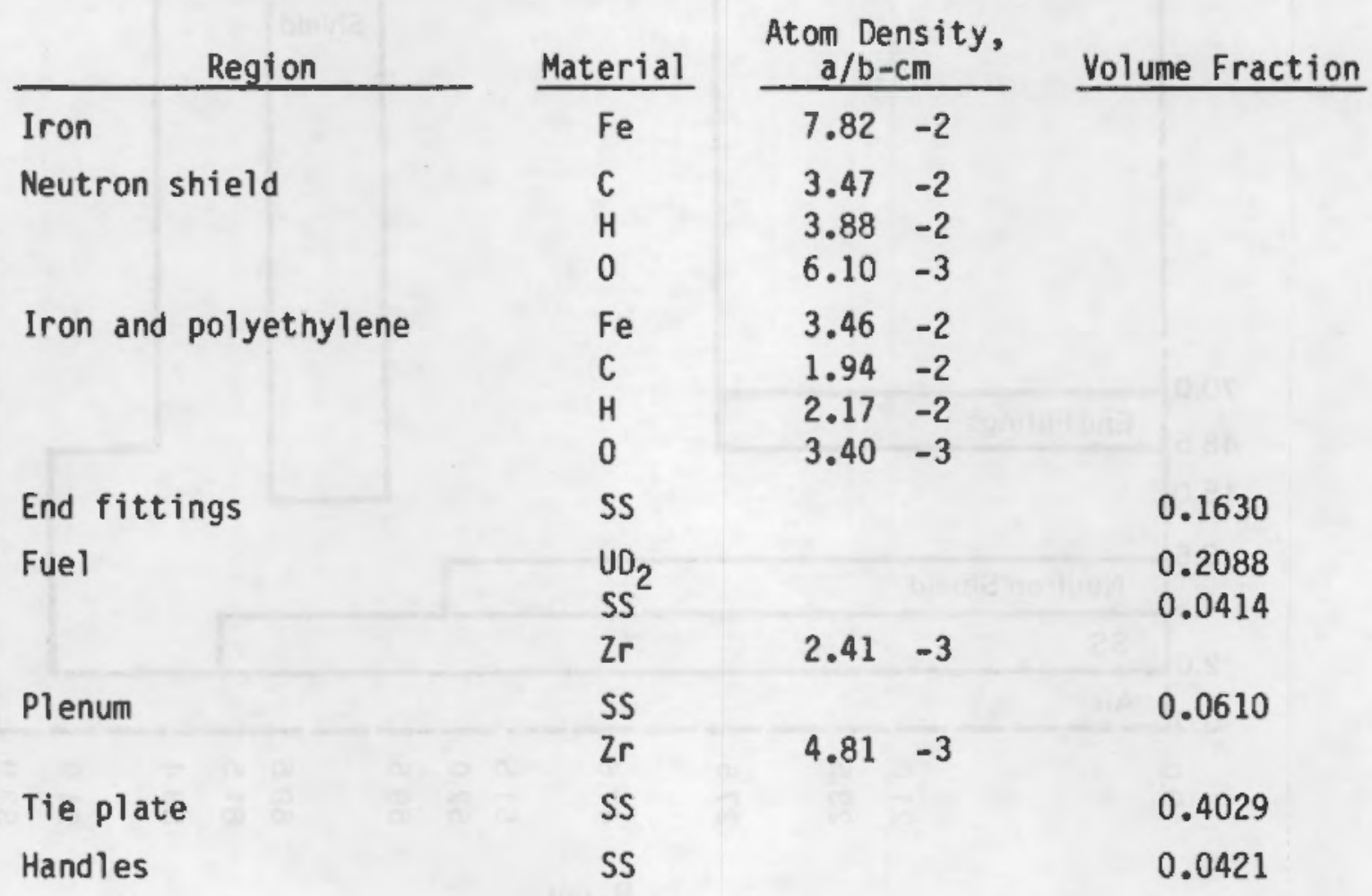




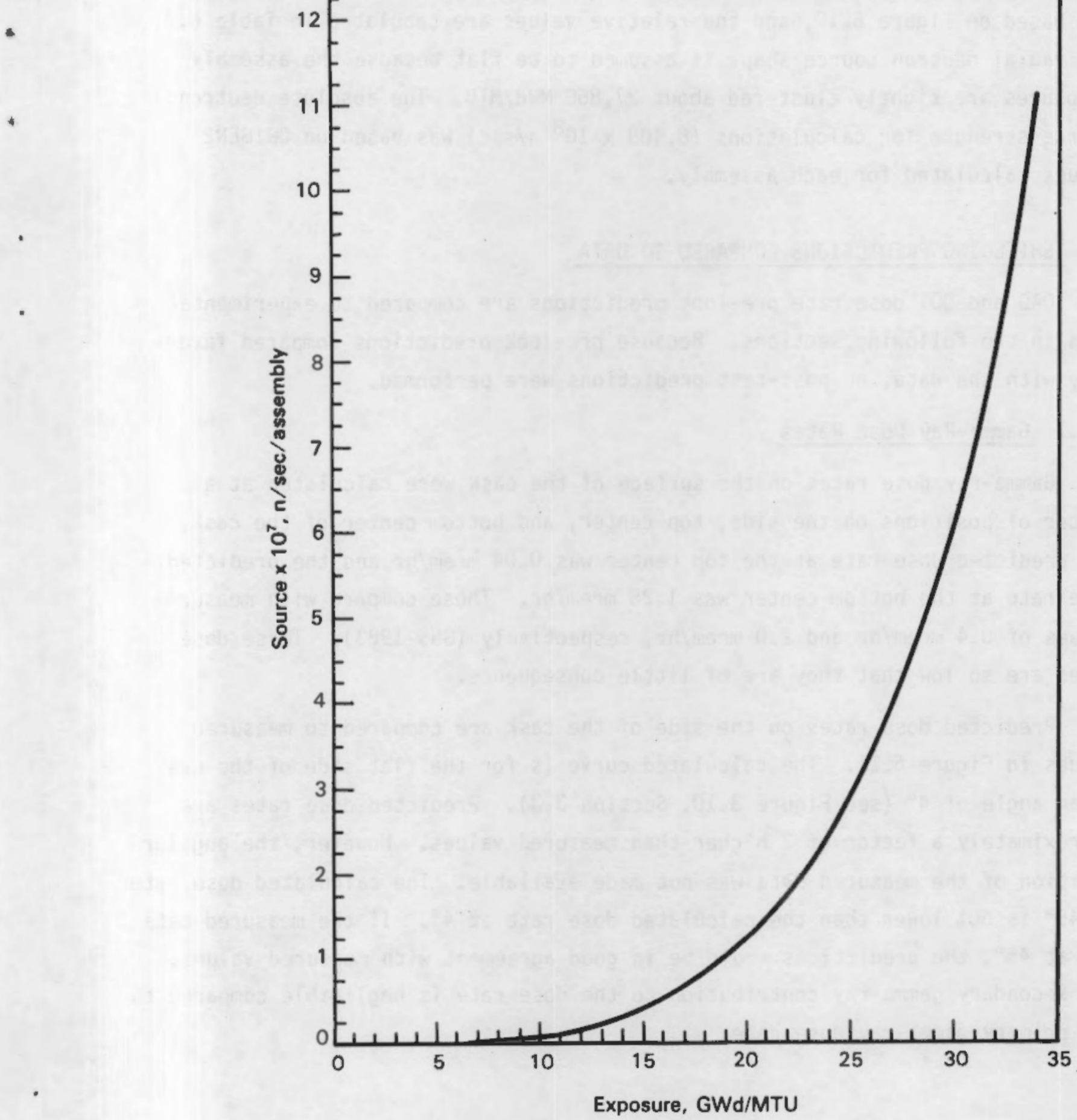

FIGURE 6.9. Neutron Source Strength as a Function of Exposure 
relative axial neutron distribution is shown in Figure 6.10. The input to D0T was based on Figure 6.10, and the relative values are tabulated in Table 6.7. The radial neutron source shape is assumed to be flat because the assembly exposures are tightly clustered about $27,850 \mathrm{MWd} / \mathrm{MTU}$. The absolute neutron source strength for calculations $\left(8.409 \times 10^{8} \mathrm{n} / \mathrm{sec}\right)$ was based on ORIGEN2 values calculated for each assembly.

\subsection{SHIELDING PREDICTIONS COMPARED TO DATA}

QAD and DOT dose rate pre-look predictions are compared to experimental data in the following sections. Because pre-look predictions compared favorably with the data, no post-test predictions were performed.

\subsubsection{Gamma-Ray Dose Rates}

Gamma-ray dose rates on the surface of the cask were calculated at a number of positions on the side, top center, and bottom center of the cask. The predicted dose rate at the top center was $0.04 \mathrm{mrem} / \mathrm{hr}$ and the predicted dose rate at the bottom center was $1.28 \mathrm{mrem} / \mathrm{hr}$. These compare with measured values of $0.4 \mathrm{mrem} / \mathrm{hr}$ and $2.0 \mathrm{mrem} / \mathrm{hr}$, respectively (GNS 1983). These dose rates are so low that they are of little consequence.

Predicted dose rates on the side of the cask are compared to measured values in Figure 6.11. The calculated curve is for the flat side of the cask at an angle of $4^{\circ}$ (see Figure 3.10 , Section 3.3 ). Predicted dose rates are approximately a factor of 2 higher than measured values. However, the angular position of the measured data was not made available. The calculated dose rate at $45^{\circ}$ is $60 \%$ lower than the calculated dose rate at $4^{\circ}$. If the measured data are at $45^{\circ}$, the predictions would be in good agreement with measured values. The secondary gamma-ray contribution to the dose rate is negligible compared to the primary gamina-ray dose rate. 


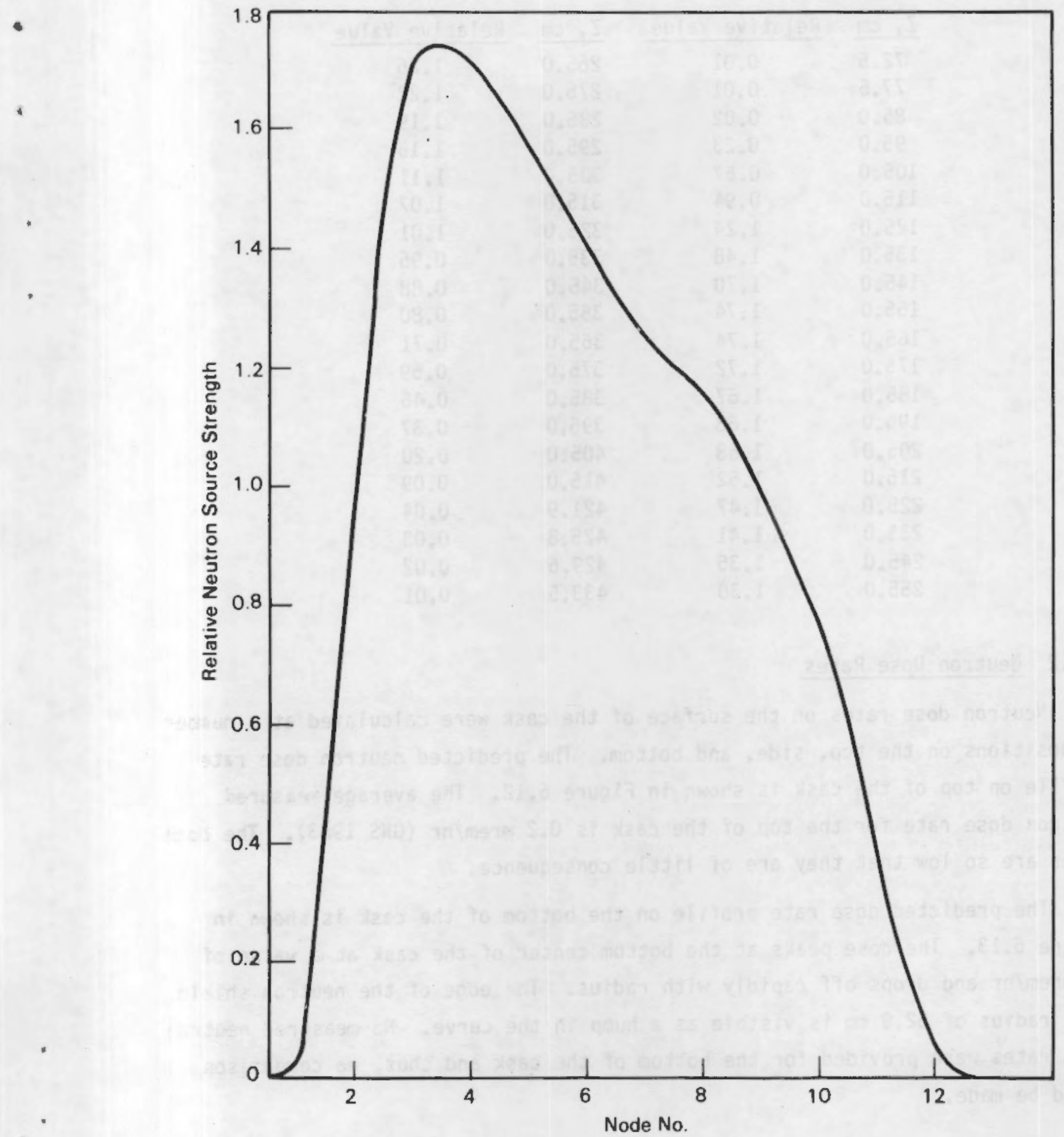

FIGURE 6.10. Fuel Assembly Relative Axial Neutron Profile 
IABLE 6.7. Axial Neutron Source Shape for DOT Input

\begin{tabular}{|c|c|c|c|}
\hline$\underline{Z, c m}$ & Relative Value & Z, cm & Relative Value \\
\hline 72.5 & 0.01 & 265.0 & 1.26 \\
\hline 77.5 & 0.01 & 275.0 & 1.22 \\
\hline 85.0 & 0.02 & 285.0 & 1.19 \\
\hline 95.0 & 0.23 & 295.0 & 1.15 \\
\hline 105.0 & 0.57 & 305.0 & 1.11 \\
\hline 115.0 & 0.94 & 315.0 & 1.07 \\
\hline 125.0 & 1.24 & 325.0 & 1.01 \\
\hline 135.0 & 1.48 & 335.0 & 0.95 \\
\hline 145.0 & 1.70 & 345.0 & 0.88 \\
\hline 155.0 & 1.74 & 355.0 & 0.80 \\
\hline 165.0 & 1.74 & 365.0 & 0.71 \\
\hline 175.0 & 1.72 & 375.0 & 0.59 \\
\hline 185.0 & 1.67 & 385.0 & 0.46 \\
\hline 195.0 & 1.63 & 395.0 & 0.37 \\
\hline 205.0 & 1.58 & 405.0 & 0.20 \\
\hline 215.0 & 1.52 & 415.0 & 0.09 \\
\hline 225.0 & 1.47 & 421.9 & 0.04 \\
\hline 235.0 & 1.41 & 425.8 & 0.03 \\
\hline 245.0 & 1.35 & 429.6 & 0.02 \\
\hline 255.0 & 1.30 & 433.5 & 0.01 \\
\hline
\end{tabular}

\subsubsection{Neutron Dose Rates}

Neutron dose rates on the surface of the cask were calculated at a number of positions on the top, side, and bottom. The predicted neutron dose rate profile on top of the cask is shown in Figure 6.12. The average measured neutron dose rate for the top of the cask is $0.2 \mathrm{mrem} / \mathrm{hr}$ (GNS 1983). The dose rates are so low that they are of little consequence.

The predicted dose rate profile on the bottom of the cask is shown in figure 6.13. The dose peaks at the bottom center of the cask at a value of $12 \mathrm{mrem} / \mathrm{hr}$ and drops off rapidly with radius. The edge of the neutron shield at a radius of $52.9 \mathrm{~cm}$ is visible as a hump in the curve. No measured neutron dose rates were provided for the bottom of the cask and thus, no comparison could be made. 


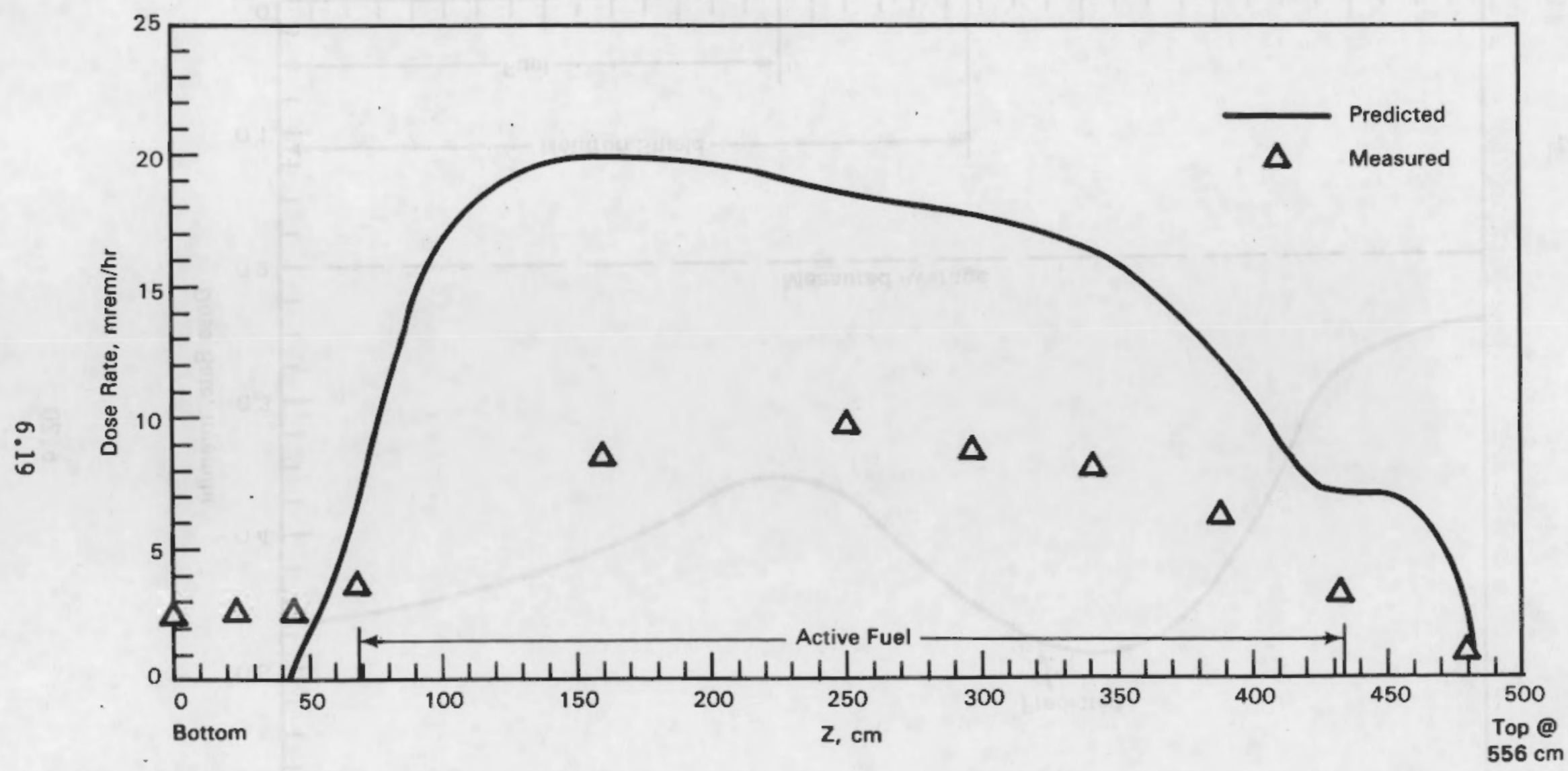

FIGURE 6.12. Predicted Neutron Dose Rate Profile on Cask Top 


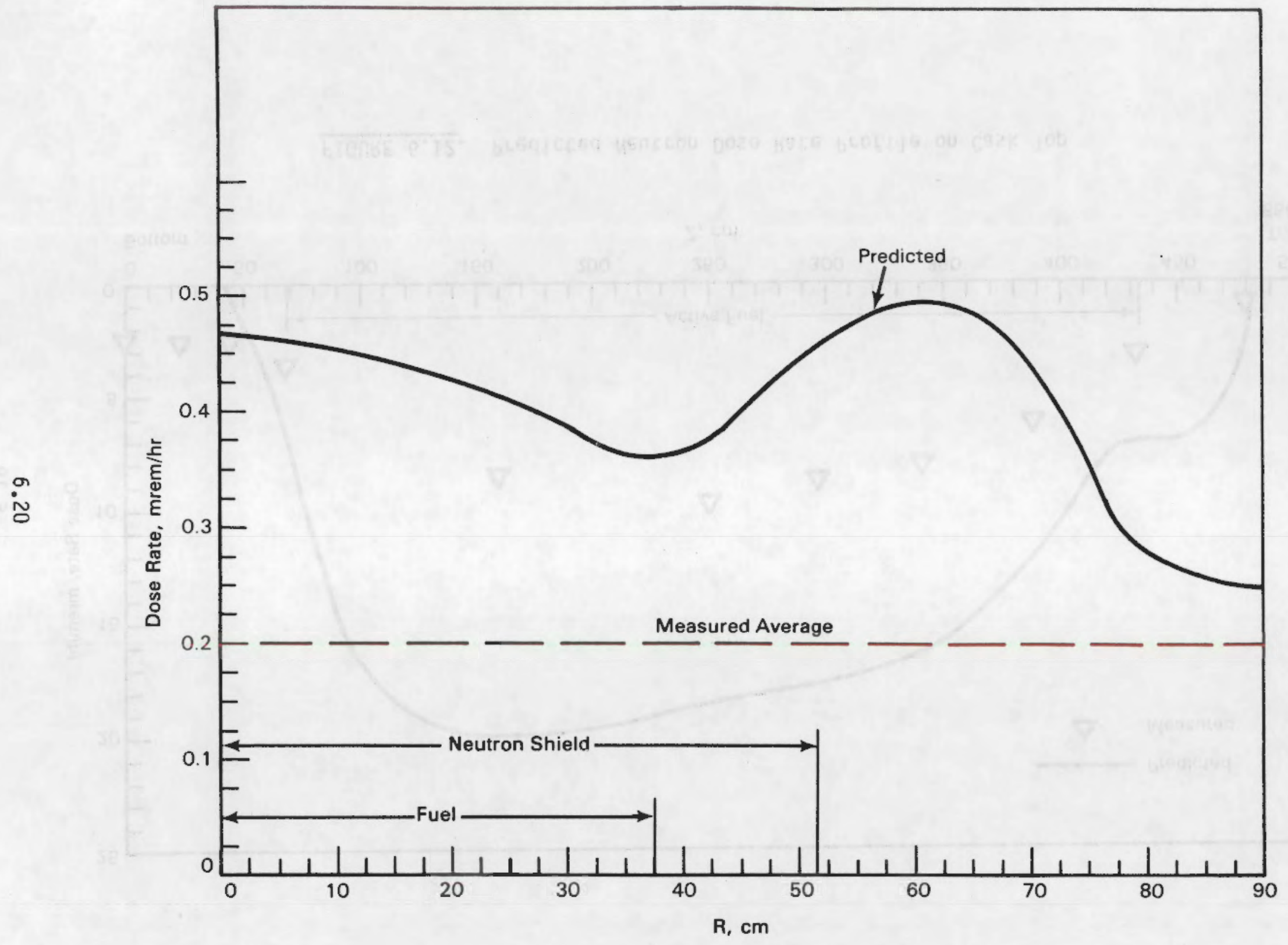

FIGURE 6.12. Predicted Neutron Dose Rate Profile on Cask Top 


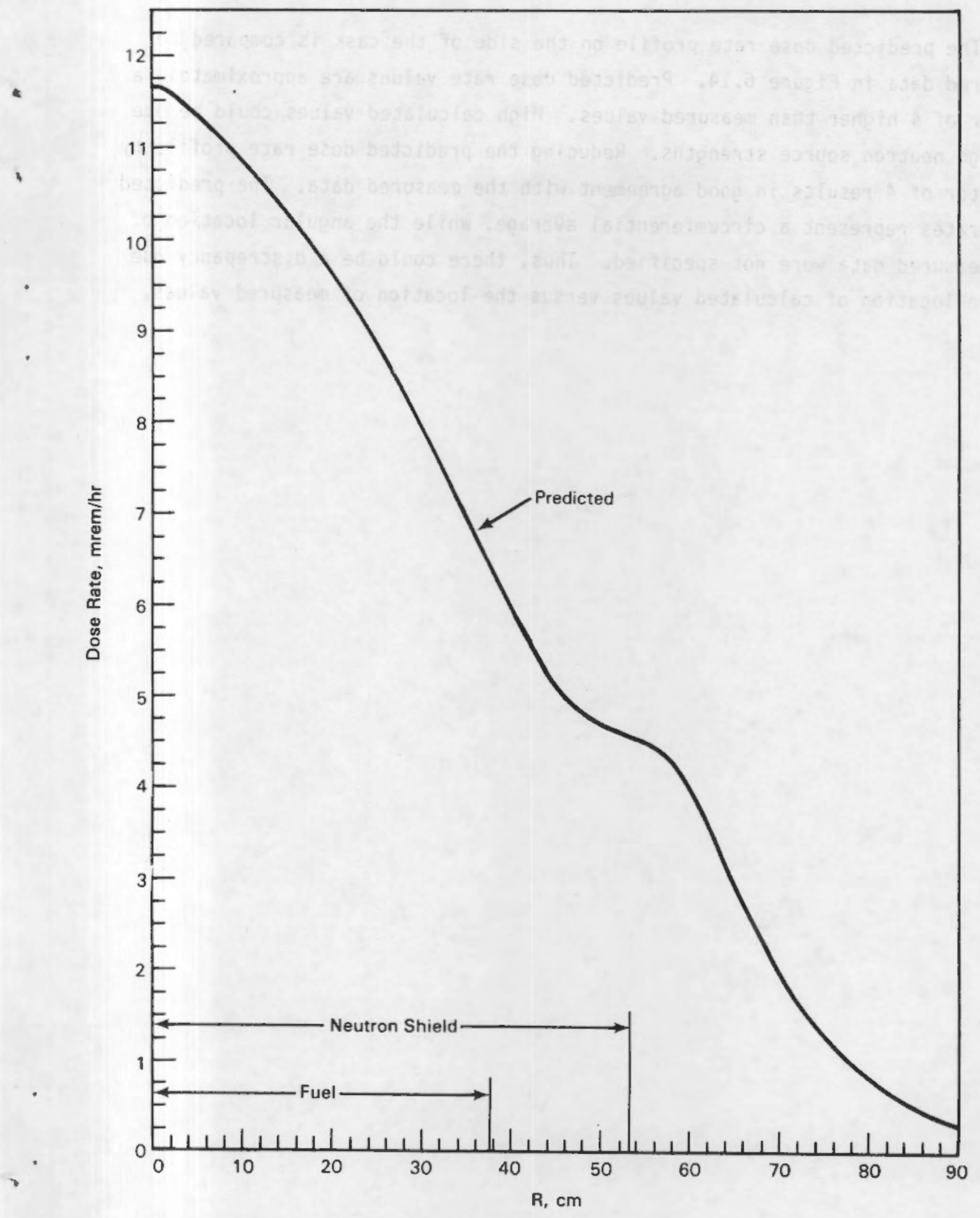

FIGURE 6.13. Predicted Neutron Dose Rate Profile on Cask Bottom 
The predicted dose rate profile on the side of the cask is compared to measured data in Figure 6.14. Predicted dose rate values are approximately a factor of 4 higher than measured values. High calculated values could be due to high neutron source strengths. Reducing the predicted dose rate profile by a factor of 4 results in good agreement with the measured data. The predicted dose rates represent a circumferential average, while the angular location of the measured data were not specified. Thus, there could be a discrepancy due to the location of calculated values versus the location of measured values. 


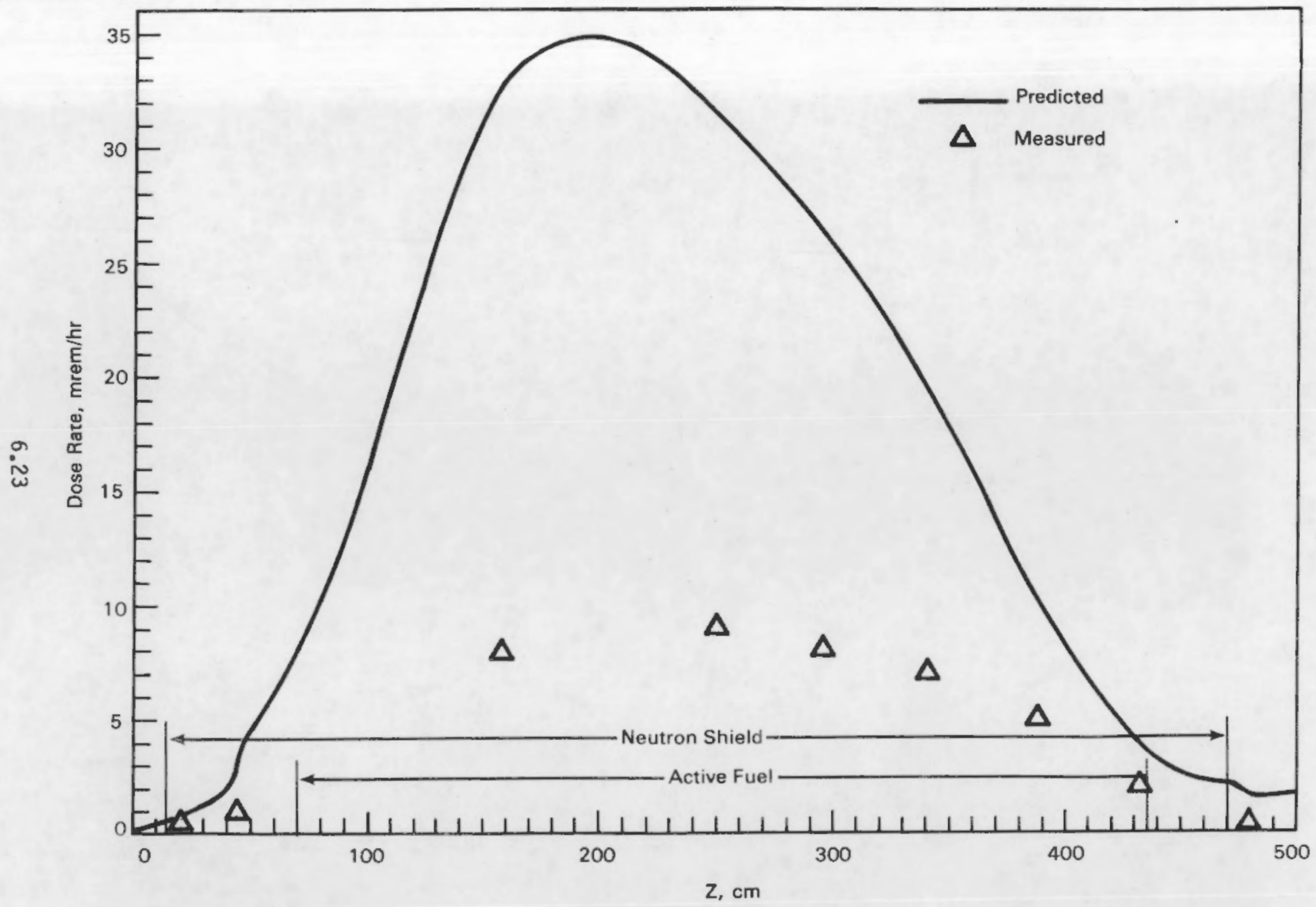

FIGURE 6.14. Comparisons of Predicted and Measured Neutron Dose Rates on Cask Side 

REFERENCES

ANS1. 1977. "Neutron and Gama-Ray Flux-to-Dose Rate Factors * ANSI/ANS6.1.1-1977, (N666), American National Standards Institute, New York, New York.

Barry, R. F. 1963. LEOPARO - A Specterum Dependent Non-Spatial Depletion Code for the IBM-7094. WCAP-3269-26, Westinghouse ETectric Corporation, Pittsburgh, Pennsylvania.

Chaddock, J. B. 1970. "Free Convection Heat Transfer from Vertical Rectangular Fin Arrays." ASHRAE tournal. August 1970:53-60.

Cox, R. L. 1977. Radiation Heat Transfer in Arrays of Parallel Cylinders. ORNL-5239, Oak Ridge National Laboratory, Oak Ridge, Tennessee.

creer, 3, M. 1984. "Decay Heat and Heat Transfer Predictions for Spent Fue: Storage Systems * In Proceedings, International Irradiated Fuel storage; Dperating Experience and Vevelopment Progrant Workshop, pp. 157-209, Ontario Hydro, Toronto, Ontario, CANADA.

Croff, A. G. 1980a. A User's hanual for the ORIGEN2 Computer Code. ORNL TM-7175, Oak Ridge National Laboratory, Oak Ridye, Tentessee.

Croff, A. G. 1980b. ORIGEN2-m Revised and Updated Version of the Oak Ridge Isotope Generation afrd Depletion Code. ORIL-5621, Dak Ridge National Laboratory, Oak Ridge, Tennessee.

Croff, A. G*, M. A. Pierke, J. W. Morrison and L. M. Petria. 1978. A Revised Uranium-Plutonium cycle PWR and BWh Models for the ORIGEN Computer Code. DEN/TM-6051, dak Ridge National Laboratory, Oak Ridge, Tennessee.

Cuta, J. M, D. R. Rector and J. M. Creer. 19ga, Thermal-Hydraulic Analysis of Consolidated Spent PhiR Fuel Rods. NP-3764, Electric Power Research Institute, Palo Alto, California.

DOE, 1985. Spent Fuel Storage Requirements. DOE/RL-85-2, U.\$. Department of Energy, Richland Operations office, Richland, washington.

Douglas, J.. and J. Gunn. 1954. "A General Formulation of Alternating Direction Methods." 1. Numer. Math. $6: 428$.

Fleisch, J., K. Einfeld and A. Luhrmann. 198z. "Long-Term Dry Storage Demonstrations with Spent LWR Fuel." In Proceedings, Dry Storage of Spent Fuel Elements Workshop, pp. 16-27. Organization for Economic Cooperation and Development, Madrid, Spain. 
Ford, W. E., III, C. C. Webster, B. R. Diggs, R. E. Pevey and A. G. Croff. 1980. FCXSEC: Multigroup Cross-Section Lipraries for Nuclear Fuel cycle Shielding Calculations. ORNL/TM-7033, Gak Ridge Nationa! Laboratorys Gak Ridge, Tennessee.

George, T. L., K. L. Basehore, C. L. Wheeler, W. A. Prather and R. E. Masterson. 1980. COBRA-WC: A Version of COERA for Single-Phase Multiassembly Thermal-Hydrautic Translent Analysis. PNL-3259, Pacific Worthwest Laboratory, Richland, Washington.

GNS. 1983. Topical Safety Analys is Report for the CASTOR-1C Cask Independent Spent Fuel Storage Installation Dry Storagel Rev. 2. 0.3. NRC Project Docket M-34. Geselischaft fur Nuklear Service mbH, Essen, West Germany.

GNS. 1985. Toptcal Safety Analysis Report for the CASTOR-1C Cask Independent Spent Fuel Storage Installation (Dry Storage) Rev. 3. 0.S. NRC Project. Docket M-34. Geselischaft fur Mukear Service mbH, Essen, West Germany.

Kays, M. M., and M. E. Crawford, 1980. Convective Heat and Mass Transfer. McGraw-Hill, inc., New York, New York.

Khan, E. U., H. A. Prather, T. L. George and J, M. Bates. 1981. A Validation Study of the COBRA-WC computer Program for LMFBR Thermal-Hydraulic Analysis, PNL-4128, Pacific Northwest Laboratory, Richland, Washington.

Lindeburge, M. R, 1981. Mechanical Engineering Revjew Manual. 6th ed. The Professlonal Engineering Program, San Carlos, Californta.

Lombardo, N. J., T. E. Michener, C. L. Wheeler and D, R. Rector. 1986. COBRA-SFS Predictions of Single Assenbly Spent Fuel Heat Transfer Data. PNL-5781: Pacific Northwest Laboratory, Richland, Washington.

Malenfant. R. E. 1967. QAD: A Series of Point-Kernel General Purpose Shielding Programs. LA-3572, Los Alamos National Laboratory, Los Alamos, New Mexico.

MCKinnon, M. A., C. M. Heeb, and J. M. Creer. 1986. Decay Heat Measurements and Predictions of BWR spent Fuel. EPRI NP-4619, Electric Power Research Institute, Palo Alto, Californta.

Mckinnon, M. A., J. W. Doman, C. M. Heeb, and J. M. Creer. 1986. Monticello BuR Spent Fuel Assembly Decay Heat Predictions and Measurements. PNL-5799, Pacific Northwest Laboratory, Richland, Washington.

ORAL. 1969. XSDRN: A Discrete Ordinates Spectral Averaging Code. A CCC-123, Radiation Shielding Information Center, Uak Ridge National Laboratory, Oak Ridge, Tennessee.

ORNL. 1977. QAD-CG: A Combinatorial Geometry Version of QADmPSA, a Point kernel Code for Nentron and Gama-Ray Shielding Calculations. CCC-307. Dak Ridge, Tennesseo. 
ORNL. 1978. AMPX-II: Modular Code System for Generating Coupled Multigroup Neutron-Gamma-Ray Cross-Section Libraries from Data in ENDF Format. PSR-63, Radiation Shielding Information Center, Oak Ridge National Laboratory, Oak Ridge, Tennessee.

Patankar, S. V. 1980. Numerical Heat Transfer and Fluid Flow. Hemisphere, Washington, D.C.

Raithby, G. D., and G. E. Schneider. 1979. "Numerical Solution of Problems in Incompressible Fluid Flow; Treatment of Velocity-Pressure Coupling." Numer. Heat Transfer. 2:417-440.

Raithby, G. 0., and G. E. Schneider. 1980. "Erratum." Numer. Heat Transfer. $3: 513$.

Rector, D. R., J. M. Cuta and J. M. Creer. 1986. "Cask Consolidation Spent Fuel Thermal Analyses Using the COBRA-SFS Code." In Proceedings, Third International Spent Fuel Storage Technology Symposium/Workshop, Vol. 1, pp. S378-S397. CoNF-860417, National Technical Information Service, Springfield, Virginia.

Rhoades, W. A., and R.L. Childs. 1982. An Updated Version of the DOT-4 Oneand Two-Dimensional Neutron/Phot on Transport Code. ORNL-5851, Oak Ridge National Laboratory, Oak Ridge, Tennessee.

Rowe, D. S. 1973. COBRA-IIIC: A Digital Computer Program for Steady-State and Transient Thermal-Hydraulic Analysis of Rod Bundle Nuc lear Fuel ETements. BNWL-1695, Pacific Northwest Laboratory, Richland, Washington.

Schmittroth, F. 1984, ORIGEN2 Calculations of PWR Spent Fuel Decay Heat Compared with Calorimeter Data. HEDL-TME 83-32, Hanford Engineering Development Laboratory, Richland, Washington.

Sissom, L. E., and D. R. Pitts. 1972. Elements of Transport Phenomena. McGraw-Hill, New York, New York.

Sparrow, E. M., and A. L. Loeffler, Jr. 1959. "Longitudinal Laminar Flow Between Cylinders Arranged in Regular Array." AIChE Journal. 5(3):325-330.

Stewart, C. W., C. L. Wheeler, R. J. Cena, C. A. McMonagle, J. M. Cuta and D. S. Trent. 1977. COBRA-IV: The Model and the Method. BNWL-2214, Pacific Northwest Laboratory, Richland, Washington.

Straker, E. A., P. N. Stevens, D. C. Irving and V. R. Cain. 1970. The Morse Code - A Multigroup Neutron and Gamma-Ray Monte Carlo Transport Code. ORNL-4585, Oak Ridge National Laboratory, Oak Ridge, Tennessee.

Touloukian, Y. S., and C. Y. Ho. 1970. Thermophysical Properties of Matter. Thermophysical Properties Research Center (TPRL), Purdue University, Lafayette, Indiana. 
Wheeler, C. L., R. A. McCanr, N. J. Lombardo, D. R. Rector and T. E, Michener. 1986. "HYDRA and COBRA-SFS Temperature Calculations for CASTOR-1C, REA-2023, CASTOR-V/21, and TN-24F Cask." In Proceedings, Third International Spent

Fuel storage Technology Sympostum/Workshop, Vol. i, pp. S77-s9o.

CONF-860417, Nationat Technical Information Service, springfiela, Virginia.

Wiles, L. E., N. J. Lombardo, C. M, Heeb, U. P. Jenquin, J, M. Creer, C. L. Wheeler and R. A. McCann. 1986. BwR Spent Fuel Storage Cask Performance Test: Volume $11-$ Pre- and Post-Test Decay Heat, Heat Transfer, and Shielding Analyses. PNL-5777 Vol. II, Paclfic Northwest Laboratory, Richlond, kashington. 


\section{APPENDI $X$}

ORIGEN2 INPUT FOR ASSEMBLY B467 
TABLE A.1. ORIGEN2 Input for Assembly B467

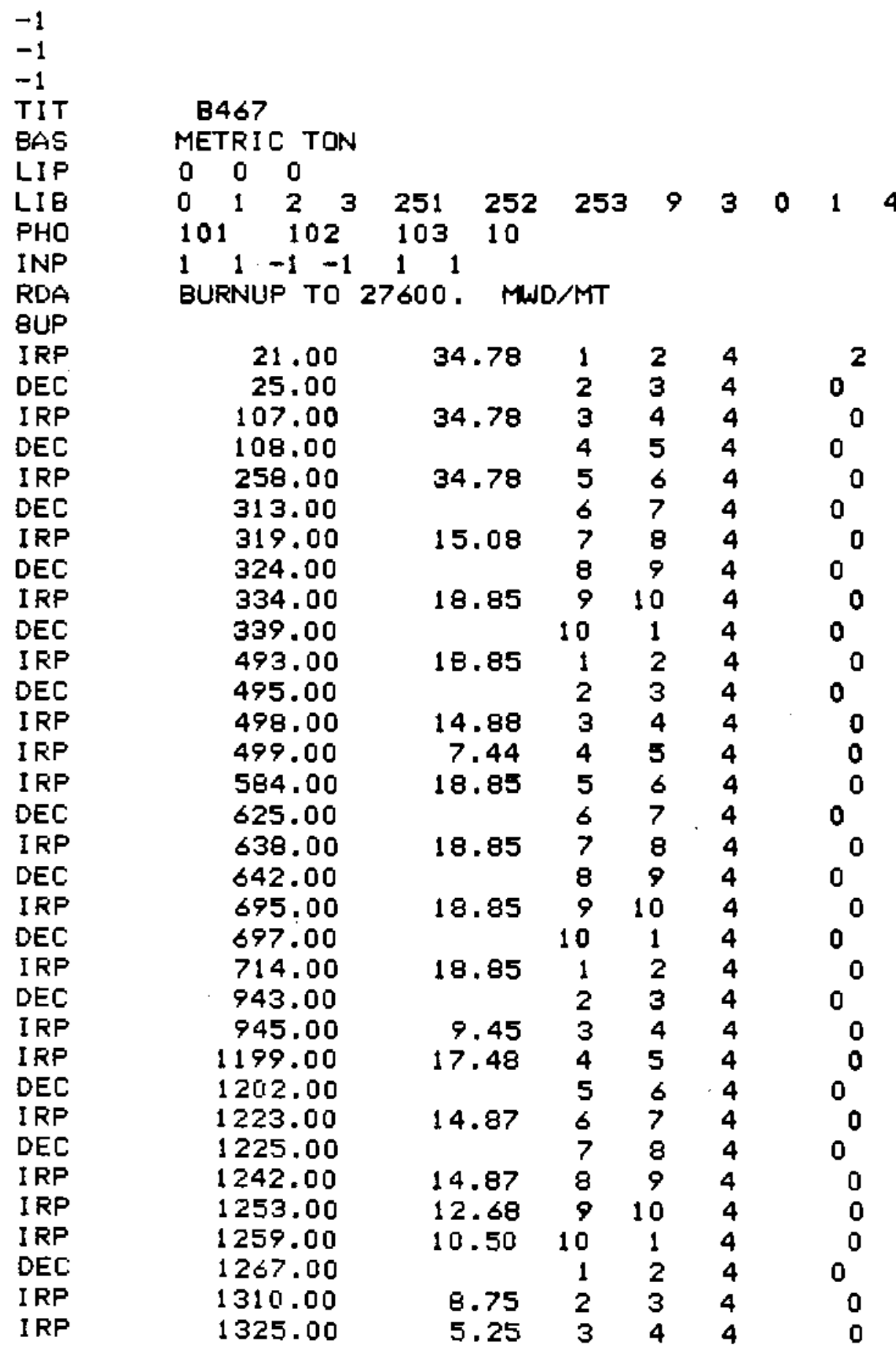


IABLE A.1. (contd)

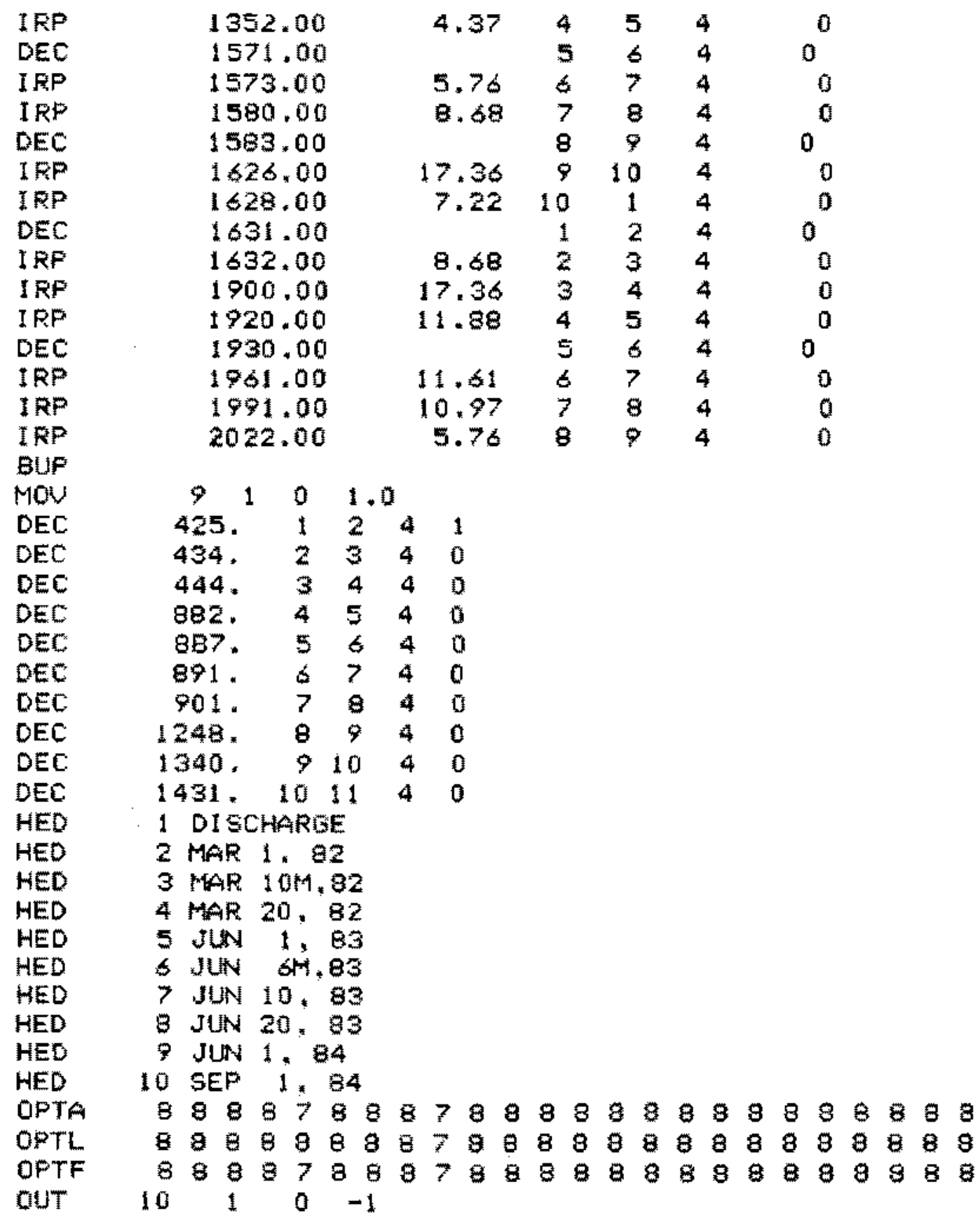


TABLE A.1. (contd)

$\begin{array}{llccc}\text { STP } & 4 & & & \\ 4 & 1000 & 3.0 & 50000 \quad 00 \\ 4 & 80000 & 224.1 & 9000000.0 \\ 4 & 130000 & 5.66 & 14000000.0 \\ 4 & 170000 & 0.0 & 1300000.0 \\ 4 & 240000 & 294.5 & 250000 & 4.72 \\ 4 & 280000 & 4.72 & 290000 & 4.72 \\ 4 & 470000 & 0.0 & 4800000.06 \\ 4 & 72000 & 18.4 & 7400005.4 \\ 2 & 922350 & 25000 . & 922380974000 . \\ 0 & & & & \end{array}$

\begin{tabular}{|c|c|}
\hline $\begin{array}{r}60000 \\
110000\end{array}$ & $\begin{array}{r}28.3 \\
000.0\end{array}$ \\
\hline $\begin{array}{l}150000 \\
220000\end{array}$ & $\begin{array}{l}00.0 \\
4.72\end{array}$ \\
\hline $\begin{array}{r}260000 \\
400000 \\
490000\end{array}$ & $\begin{array}{l}530.8 \\
230969.0 \\
0.0\end{array}$ \\
\hline $0 \quad 0.0$ & \\
\hline 0 & 0.0 \\
\hline
\end{tabular}

7000018.9 $120000 \quad 0,0$ $160000 \quad 8.26$ $230000 \quad 4.7$ $270000 \quad 33.0$ $420000 \quad 00.0$ $500000 \quad 3774.4$

Ervo 
. 


\section{DISTRIBUTION}

No. of

Copies

OFFSITE

110 DoE Technical Information Center

R. Bown

U.S. Department of Energy

offlce of Civilian Radioactive

Waste Management

RW-30

Washington, oc 20545

J. Epstein

1.s. Department of Energy

office of Civilian Radioactive Waste Management

$\mathrm{RW}-30$

Washington, DC 20545

J. R. Hilley

U.S. Department of Energy

office of Storage and

Transportation systems

Washington, $0 \mathrm{C} 20545$

D. E. Shelor

U.S. Department of Energy

office of Civilian Radioactive

Waste Management

$\mathrm{RH}-32$

Washington, of 20545

H. Steinburg

U.S. Department of Energy

office of Storage and

Transportation Systems

$\mathrm{RW}=33$

1000 Independence Ave.

Washington, DC 20585
No. of

Copies

\author{
W. Stringfield \\ U.S. Department of Energy \\ Of icice of Civilian Radiaactive \\ Waste Management \\ Washington, DC 20545 \\ C. B. Gertz \\ 1.S. Department of Energy \\ Idaho Operations office \\ 550 2nd street \\ Idaho Falls, 1083401 \\ K. G. Golliher \\ U.S. Department of Energy \\ Albuquerque Operations Dffice \\ P.0. Box 5400 \\ Albuquerçue, NM 67115 \\ L. Lanni \\ 4.5. Department of Eneray \\ Magnetic Fusion and Nuclear \\ Division \\ San Francisco Operations Office \\ 1333 Broadway \\ Gakland, ch 94612 \\ C. Mathews \\ U.S. Department of Energy \\ Oak Ridge National Laboratory \\ P.0. Box E \\ Oak Ridge, TN 37830 \\ 0. Weith \\ U.5. Department of Energy \\ Nevada Operations office \\ P.0. Box 14100 \\ Las Vegas, NV 89114
}


No. of

Copies

N. H. Davison

1.5. Nuclear Regulatory Commission

office of Nuclear Materials Safety and Safeguards

Washington, DC 20555

C. Felduan

U.S. Nuclear Regulatory Comistission

Office of Nuclear Regulatory Research

MS $5650 \mathrm{NL}$

Washington, DC 20555

W. Laxe

U.S. Nuclear Regulatory Commission

Office of Nuclear Materials Safety and Safeguards

Washington, DC 20555

C. $\mathrm{H}_{*}$ Peterson

U.S. Nuclear Regulatory Commission

Dffice of Nuclear Material

Safety and Safeguards

MS 52355

Washington, DC 20555

J. A. Carr

Battelle Menorial Institute

office of Nuclear Waste

Isolation

505 King Avenue

Columbus, on 43201

B. A. Rowles

Battelle Menorial Institute

office of Nuclear Waste Isolation

$505 \mathrm{king}$ Avenue

Columbus, OH 43201

$W, R$, Juergens

Brooks \& Perkins

12633 Inkster Road

Livonia, MI 48150
倩: of

Copies

R. Kunita

Carolina Power bighe Co.

P.0. Box 1551

Raleigh, NC 27602

C. K. Anderson

Combustion Englneering, Inc.

1000 Prospect HIII Road

Kindsor, CT 06095

Ebasco Services Incorporated

Two World Trade Center

New York, NY 10048

D. H. Schoonen

EG

P.0. Box 1625

Idaho Falls, ID 83415

P. E. Eggers

Eggers Ridihalgh Partners, Inc.

1445 Summit street

Colurnbus, on 43201

FLUOR Engineers, Inc.

Advanced Technology division

P. O. Box C-11944

Santa hnna, CA 92711-1944

J. W. Doman

Marris Operation

General Electric Company

$7555 \mathrm{E}$. Collins Road

Mormis, It 60450

E. E. Voil and

General Electric Company

Nuclear Fuel \& Services

division

$7555 \mathrm{E}$. Collins Road

Morris, IL 60450

R. Anderson

General Nuclear Services, Inc. 135 Darling Drive

Avon, CT 06001 
No. of

Copies

V. J. Barnhart

General Nuclear Services, Inc. 135 Darling Drive

Avon, CT 06001

L. B. Ballou

Lawrence Livermore National

Laboratory

P.0. Box 808

Livermore, CA 94550

M. W. Schwartz

Lawrence Livermore National

Laboratory

P.0. Box 808

Livermore, CA 94550

C. F. Smith

Lawrence Livermore National

Laboratory

P.0. Box 808

Livermore, CA 94550

G. Bosler

Los Alamos National Laboratory

Los Alamos, NM 87545

P. Rinard

Los Alamos National Laboratory

Los Alamos, NM 87545

H. Lowenberg

Lowenberg Associates

10901 Rosemont Drive

Rockville, MD 20852

3. Houston

Nuclear Assurance Corporation

5720 Peach Tree Parkway

Norcross, GA 30092

R. T. Haelsig

Nuclear Packaging Inc.

1010 S. 336th Street

Federal Way, WA 98003
No. of

Copies

L. E. Wiles

Numerical Applications, Inc.

825 Goethals Drive

Richland, WA 99352

J. V. Massey

NUTECH Engineers

145 Martinvale Lane

San Jose, CA 95116

C. V. Parks

Oak Ridge National Laboratory

P.0. Box $X$

Oak Ridge, TN 37831

D. Woods

Ralph M. Parsons Co.

100 West Walnut Street

Pasadena, CA 91124

T. L. Sanders

Sandia National Laboratory

Albuquerque, NM

M. E. Mason

Transnuclear, Inc.

1 N. Broadway

White Plains, NY 10601

8. R. Teer

Transnuclear, Inc.

1 N. Broadway

White Plains, NY 10601

TRW, Inc.

Energy Development Group

Suite 201

200 Union Blvd.

Denver, CO 80228

C. E. King

Uranium Mgt. Corp.

175 Curtner Ave. MC 620

San Jose, CA 95125 
No. of

copies

M. L. Smith

Virginia Power Co.

P. 0. Box 26666

Richmond, VA 23261

A. R. Hak 1

Westinghouse Electrit Corp.

Waste Technology Services

Division

P.0. Box 10864

Pittsburg, PA 15236

J. H. Saling

Westinghouse Electric Corp.

Waste Technology Services

Division

P.0. Box 10864

Pittsburg. PA 15236

8. A. Chin

Mechanical Engineering Dept.

247 Wilmore Labs

Auburn University, AL 36849

ONSITE

2 WoE Richland Operations Office

R. D. Izatt

J. P. Collins

2 Rockwe 11 Hanford Operations

C. L. Brown

G. T. Harper
No. of

Copies

51 Pacific Northwest Laboratory

G. H. Beeman

I. W* Brackenbush

B. M. Cole

J. M. Cuta

J. M. Creer (10)

M. D. Freshley

$E . R$, Gil ibert

R. d. Guenther

R. L. Goodman

R. J. Hall

C. M. Heeb

1. P. Jenquin

A. B. Johnson, Je.

D. K. Kreid

N. J. Lombardo

R. A, McCann

J. L. McElroy

M. A. Mckinnon

T. E. Mi chener

D. F. Newman

0. R. Oden, Ir.

D. R. Rector (10)

C. W. Stewart

R. A. Stokes

J. E. Tarner

C. L. Wheeler

Technical library (5)

Publishing Coordination (2) 